\title{
INTERIM STRESS DESIGN CRITERIA FOR LMFBR VESSEL AND CORE STRUCTURES
}

NOTICE

This report was prepared as an account of work sponsored by the United States Government. Neither the United States nor the United States Atomic Energy Commission, nor any of their employees, nor any of their contractors, subcontractors, or their employees, makes any warranty, express or implied, or assumes any legal liability or responsibility for the accuracy, completeness or usefulness of any information, apparatus, product or process disclosed, or represents that its use would not infringe privately owned rights.

E. Y.W. Tsui

J. V. Marron

A. T. Brown
Approved:

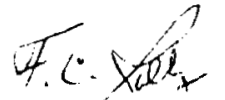

F. C. Rally, Manager

Vessels \& Internals
Approved:

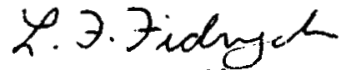

L. F. Fidrych, Manager Design Engineering

Prepared for the Union Carbide Corporation, Nuclear Division under Subcontract 3446

to

USAEC Contract W-7405-eng-26 


\section{DISCLAIMER}

This report was prepared as an account of work sponsored by an agency of the United States Government. Neither the United States Government nor any agency Thereof, nor any of their employees, makes any warranty, express or implied, or assumes any legal liability or responsibility for the accuracy, completeness, or usefulness of any information, apparatus, product, or process disclosed, or represents that its use would not infringe privately owned rights. Reference herein to any specific commercial product, process, or service by trade name, trademark, manufacturer, or otherwise does not necessarily constitute or imply its endorsement, recommendation, or favoring by the United States Government or any agency thereof. The views and opinions of authors expressed herein do not necessarily state or reflect those of the United States Government or any agency thereof. 


\section{DISCLAIMER}

Portions of this document may be illegible in electronic image products. Images are produced from the best available original document. 


\section{NOTICE}

This report was prepared as an account of work sponsored by the United States Government. Neither the United States nor the United States Atomic Energy Commission, nor any of their employees, nor any of their contractors, subcontractors, or their employees, makes any warranty, express or implied, or assumes any legal liability or responsibility for the accuracy, completeness or usefulness of any information, apparatus, product or process disclosed, or represents that its use would not infringe privately owned rights. 


\section{FOREWORD}

The interim stress criteria have been prepared by personnel of the General Electric Company's Breeder Reactor Department, in cooperation with Oak Ridge National Laboratory.

General Electric's principal investigator was Dr. E. Y. W. Tsui, who is responsible for Sections 1, 2, and 4, including Appendices A through $\mathrm{H}$. Section 3 was written by Messrs. J. V. Marron and A. T. Brown.

Acknowledgment is made to: Messrs. F. C. Rally and W. G. Meinhardt, for their helpful advice in reviewing this document; Mr. J. W. Bennett of AEC-RDT, who wrote Appendix I while on assignment as an intern; Dr. C. N. Spalaris, for his valuable suggestions; and Dr. L. F. Coffin, Jr., who supplied additional material data for this document.

Acknowledgment is also made to Drs. W. L. Greenstreet and J. M. Corum of ORNL, for their helpful discussions. 


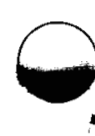
$i^{1}$

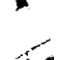

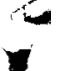
(2) 


\section{TABLE OF CONTENTS}

FOREWORD

INTRODUCTION AND SUMMARY

1. INTRODUCTION AND SUMMARY . . . . . . . . . . . . . . . . . . . . . . . . . . . . 1.1

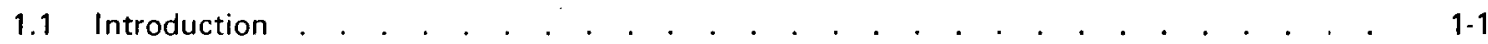

1.2 Summary . . . . . . . . . . . . . . . . . . . . . . . . . . . . . . . . . . 1.1

2. STRUCTURAL EVALUATION OF LONG-LIFE COMPONENTS . . . . . . . . . . . . . . 2.1

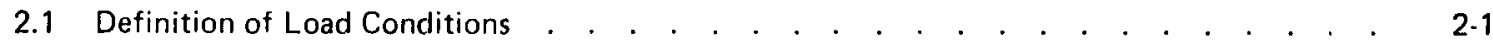

2.2 Assumptions . . . . . . . . . . . . . . . . . . . . . . . . . . . 21

2.3 General Considerations and Discussion . . . . . . . . . . . . . . . . . . . . $\quad 2-2$

2.4 Stress Criteria . . . . . . . . . . . . . . . . . . . . . . . . . . . . . 2

3. STRUCTURAL EVALUATION OF CORE COMPONENTS . . . . . . . . . . . . . . . . . 3.1

3.1 Definition of Load Conditions . . . . . . . . . . . . . . . . . . . . . . . . . . . . . 3.1

3.2 Basis for the Allowable Stress Intensity $\left(S_{m}\right) \quad$. . . . . . . . . . . . . . . . . . . . . . $\quad 3-1$

3.3 Strain Limits . . . . . . . . . . . . . . . . . . . . . . . . . . . . . 3.4

3.4 Fatigue and Fatigue-Creep Interaction . . . . . . . . . . . . . . . . . . . . . $\quad 37$

3.5 Thermal Ratchet . . . . . . . . . . . . . . . . . . . . . . . . . . . 37

4. RECOMMENDATIONS FOR FURTHER RESEARCH AND DEVELOPMENT . . . . . . . . 4-1

5. BIBLIOGRAPHY . . . . . . . . . . . . . . . . . . . . . . . . . . . 5-1

\section{APPENDIX}

A. ANALYSIS OF CONICAL SHELLS. . . . . . . . . . . . . . . . . . . . . . . . A-1

A.1 Nomenclature and Sign Convention .. . . . . . . . . . . . . . . . . . . . A-1

A.2 Principal Stresses and Stress Intensities Due to Internal Pressure . . . . . . . . . . A-3

A.3 Bending Analysis for Uniformly Distributed Edge Loads . . . . . . . . . . . . . A-4

B. CONICAL SHELLS UNDER EXTERNAL PRESSURE . . . . . . . . . . . . . . . . . B-1

B.1 Nomenclature. . . . . . . . . . . . . . . . . . . . . . . . . . . B-1

B.2 Procedure for the Stress Determination . . . . . . . . . . . . . . . . . . B-1

c. ANALYSIS OF ELLIPSOIDAL SHELLS . . . . . . . . . . . . . . . . . . . . . . . . . . . . .

C.1 Nomenclature and Sign Convention . . . . . . . . . . . . . . . . . . . . C-1

C.2 Principal Stresses and Stress Intensities Due to Internal Pressure . . . . . . . . . . . . C-3

C.3 Bending Analysis for Uniformly Distributed Edge Loads and Uniform Internal Pressure . . C-3

D. A SURVEY OF INELASTIC BEHAVIOR OF ISOTROPIC SHELLS . . . . . . . . . . . . D-1

D.1 Introduction . . . . . . . . . . . . . . . . . . . . . . . . . . . D-1

D.2 Constitutive Equations . . . . . . . . . . . . . . . . . . . . . . . . D-1

D.3 Creep and Plastic Potentials . . . . . . . . . . . . . . . . . . . . . . . . . . . . . D

D.4 Field Equations for Thin Shells . . . . . . . . . . . . . . . . . . . . . D-6

D.5 Criteria for Initial and Subsequent Yielding . . . . . . . . . . . . . . . . . . . D

D.6 Bibliography. . . . . . . . . . . . . . . . . . . . . . . . . . D-10

E. SHAKEDOWN FACTORS FOR SPHERICAL VESSE LS WITH RADIAL NOZZLES . . . . . E-1 
TABLE OF CONTENTS (Continued)

Page

F. CREEP AND FATIGUE INTERACTION OF METALS AT ELEVATED TEMPERATURES . . - F-1

F.1 Introduction . . . . . . . . . . . . . . . . . . . . . . . . . . . . . F-1

F.2 Factors Influencing Material Behavior . . . . . . . . . . . . . . . . . . . . F-1

F.3 Prediction of Fatigue and Creep Interaction . . . . . . . . . . . . . . . . . . . . . F-4

F.4 References. . . . . . . . . . . . . . . . . . . . . . . . . . . F-15

G. A BRIEF NOTE ON CREEP BUCKLING OF COLUMNS AND CIRCULAR

CYLINDRICAL SHELLS . . . . . . . . . . . . . . . . . . . . . . . . . G.1

G.1 Buckling of Columns . . . . . . . . . . . . . . . . . . . . . . . . . . . . G-1

G.2 Buckling of Cylindrical Shells . . . . . . . . . . . . . . . . . . . . . . . . . G G-1

G.3 References . . . . . . . . . . . . . . . . . . . . . . . . . G-2

H. MATERIAL DATA . . . . . . . . . . . . . . . . . . . . . . . . . H-1

I. BASIS FOR ESTABLISHMENT AND USE OF A STRAIN CRITERIA FOR

LMFBR CORE COMPONENTS . . . . . . . . . . . . . . . . . . . . . . . $\quad 1$. 1

1.1 Introduction . . . . . . . . . . . . . . . . . . . . . . . . . . . . . . . . . . . . . . 1 . 1

1.2 Prediction of Core-Environment-Produced Embrittlement of Fuel Assembly

Component Structural Materials . . . . . . . . . . . . . . . . . . . . . $1-1$

1.3 Method for Using Recommended Relationships to Account for the Reduction in the

Strain Capability of Type-321 Stainless Steel Fuel Assembly Components . . . . . . . . 1-10

I.4 Bibliography for Appendix I . . . . . . . . . . . . . . . . . . . . . . . . . . . . $\quad$. 1 .19 


\section{LIST OF ILLUSTRATIONS}

2-1A Design System Fatigue Curves for Type-304 Stainless Steel at $800^{\circ} \mathrm{F}$

Effects of Temperature and Loading Frequency on Low-Cycle Fatigue Strength of

Type-316 Stainless Steel (Frequency Range $\nu=10^{3}$ to $10^{-6} \mathrm{cpm}$ ) 


\section{LIST OF ILLUSTRATIONS (Continued)}

Figure

A.3A

A.3B

B-1

C-1

E-1

E-2

E-3

$E-4$

E-5

E-6

E-7

E-8

E.9

E-10

E.11

E-12

F-1

F-2

F-3

F.4

F. 5

F-6

F-7
Title

Page

Influence Coefficients for Long Uniform Cones-Lower Edge

A-11

A-11

Buck ling Pressure Coefficients for Circular Cones Subjected to External Radial

and Axial Pressure . . . . . . . . . . . . . . . . . . . . . . . . . . . . . B B

Sign Convention for Ellipsoidal Shells . . . . . . . . . . . . . . . . . . . . C-12

Maximum Stress in Sphere for Internal Pressure (Flush Nozzles) . . . . . . . . . . . . . E-2

Maximum Stress in Sphere for Internal Pressure (Protruding Nozzles) . . . . . . . . . . E-2

Shakedown Values for Pressure Loading (Flush Nozzle) . . . . . . . . . . . . . . E-3

Shakedown Values for Pressure Loading (Protruding Nozzle) . . . . . . . . . . . . E-3

Maximum Stress in Sphere for Thrust Loading (Flush Nozzles) . . . . . . . . . . . . . . $\quad$ E-4

Maximum Stress in Sphere for Thrust Loading (Protruding Nozzles) . . . . . . . . . . . E-4

Shakedown Values for Thrust and Moment Loadings (Flush Nozzle) . . . . . . . . . . E-5

Shakedown Values for Thrust and Moment Loadings (Flush Nozzle) . . . . . . . . . . E-5

Shakedown Values for Thrust and Moment Loadings (Protruding Nozzle) . . . . . . . . E-6

Shakedown Values for Thrust and Moment Loadings (Protruding Nozzles) . . . . . . . . E-6

Maximum Stress in Sphere for Moment Loading (Flush Nozzles) . . . . . . . . . . . E-7

Maximum Stress in Sphere for Moment Loading (Protruding Nozzles) . . . . . . . . . E-7

Creep and Fatigue Interaction . . . . . . . . . . . . . . . . . . . . . . . . . . F-2

Effect of Strain Rate on Low-Cycle Fatigue Life of AISI 304 Stainless Steel at $650^{\circ} \mathrm{C}$. . . . F-3

Effect of Notches on Cycles to Failure for $1-\mathrm{cpm}$ Continuous Cycling Tests on

Forged $1 \mathrm{Cr}-\mathrm{Mo}-\mathrm{V}$ Al Steel at $565^{\circ} \mathrm{C}$.

Plastic Strain Range versus $\mathrm{N}_{\mathrm{f}} / \mathrm{f}$ for Irradiated and Unirradiated Type-316 Stainless Steel

Tested at $1200^{\circ} \mathrm{F}$ and a Strain Rate of $4 \times 10^{-5} \mathrm{sec}$. . . . . . . . . . . . . . . . .

Plastic Strain Fatigue Curve and Variation of Creep Ductility with Time for Inconel at $1500^{\circ} \mathrm{F}$.

Cyclic Stress Definitions

Stress Range Diagram for Dynamic Creep and Fatigue-Chromium Steel in Nondimensional Expression 


\section{LIST OF ILLUSTRATIONS (Continued)}

Figure

F-8

F-10

F-11

\section{Title}

Page

Stress Range Diagram for Dynamic Creep and Fatigue-Stainless Steel in Nondimensional Expression . . . . . . . . . . . . . . . . . . . . . . . F-8

Comparison of Results for Low-Cycle Fatigue Behavior of Type-304 Stainless Steel at $1200^{\circ} \mathrm{F} \quad$ F-10 Representation of Fracture for Mixed Cyclic and Monotonic Straining . . . . . . . . . F-11

Approximate Bounds for Equation (F-25) . . . . . . . . . . . . . . . . . . . . . F-11

Combinations of Alternating Stress and Static Stress for 100 hours Life at Different

Temperatures for S-816 Alloy $(\mathrm{Co}-\mathrm{Cr}-\mathrm{Ni}) \cdot$. . . . . . . . . . . . . . . . . . . . . $\quad \mathrm{F}-12$

Application of Linear Cumulative Damage Rule to Macrocrack Initiation in Creep . . . . . F-13

Goodman-Type Diagrams for Failure of Inconel under Square and Sine Wave Fatigue Stresses $\quad$ F-14

Normalized Swindeman Interaction Curve for Inconel $\quad . \quad$. . . . . . . . . . . . . . . . . F-14

Creep Buckling of Long Cylinders under Uniform Pressure . . . . . . . . . . . . . . G-3

Load Deflection Curves for a Cylinder with $R / h=100, L / R=1$ and $E=5000$,

Subjected to Radial Pressure.

Stress-Rupture Scatterband for Grade TP347H Austenitic Seamless Pipe

Biaxial Stress-Rupture Properties of Stainless Steel in High-Purity Sodium

Creep Curves for AISI-316 Stainless Steel at $1300^{\circ} \mathrm{F}\left(704^{\circ} \mathrm{C}\right)$ under Constant Stresses . . .

Tensile Uniform Elongation for Types-304 and -316 Stainless Steels versus Fluence at Irradiation Temperatures of 371 to $400^{\circ} \mathrm{C}\left(700\right.$ to $\left.752^{\circ} \mathrm{F}\right)$

Tensile Uniform Elongation for Types-304 and -316 Stainless Steels versus Fluence at Irradiation Temperatures of 400 to $450^{\circ} \mathrm{C}\left(752\right.$ to $\left.842^{\circ} \mathrm{F}\right)$

Tensile Uniform Elongation for Types-304 and -316 Stainless Steels versus Fluence at Irradiation Temperatures of 450 to $500^{\circ} \mathrm{C}$ (842 to $932^{\circ} \mathrm{F}$ )

Tensile Uniform Elongation for Types-304 and -316 Stainless Steels versus Fluence at Irradiation Temperatures of 500 to $550^{\circ} \mathrm{C}\left(932\right.$ to $\left.1022^{\circ} \mathrm{F}\right)$

Tensile Uniform Elongation for Types-304 and -316 Stainless Steels versus Fluence at Irradiation Temperatures of 550 to $600^{\circ} \mathrm{C}\left(1022\right.$ to $\left.1112^{\circ} \mathrm{F}\right)$. . . . . . . . . . . . . . .

Tensile Unfirom Elongation for Types-304 and -316 Stainless Steels versus Fluence at Irradiation Temperatures of 600 to $750^{\circ} \mathrm{C}\left(1112\right.$ to $1382^{\circ} \mathrm{F}$

Estimated Mean Uniform Strain versus Temperature

Estimated Lower Limit versus Temperature 
$\bullet$

$a$

$\checkmark$

。

1 


\section{LIST OF TABLES}

Table

Title

Page

2-1 Stress Intensity Limits for Long Life Components . . . . . . . . . . . . . . . . . $\quad 2-3$

2-2 Values of Temperature-Dependent Constants for Types-304 and -316 Stainless Steel in Air . . 2-5

3-1 Determination of Allowable Stress Intensity . . . . . . . . . . . . . . . . . . . . . 3-3

3-2 Summary of Core Structural Design Criteria . . . . . . . . . . . . . . . . . . . 3-4

A-1 Influence Functions for Uniform Cone: $B_{11}, B_{12}, B_{21}$, and $B_{22}$. . . . . . . . . . . . . . A-6

A-2 Influence Functions for Uniform Cone: $B_{33}, B_{34}, B_{43}$, and $B_{44}$. . . . . . . . . . . A-7

C-1 Influence Coefficients of Ellipsoidal Shells . . . . . . . . . . . . . . . . . . . . . . . . . C-5

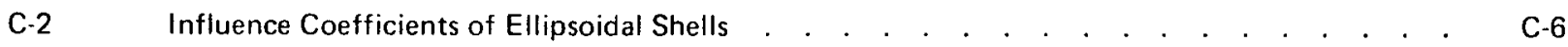

C-3 Influence Coefficients of Ellipsoidal Shells . . . . . . . . . . . . . . . . . . . . . . . C-7

C-4 Influence Coefficients of Ellipsoidal Shells . . . . . . . . . . . . . . . . . . . . . . . . . . . C-8

C-5 Influence Coefficients of Ellipsoidal Shells . . . . . . . . . . . . . . . . . . . . . . . . . . . .

C.6 Influence Coefficients of Ellipsoidal Shells . . . . . . . . . . . . . . . . . . . . . C-10

C-7 Influence Functions for Ellipsoidal Shells $(a / t=100)$. . . . . . . . . . . . . . . . . . . . . . . C-11

F-1 Numerical Values of Equation $(F-9) \quad$. . . . . . . . . . . . . . . . . . . . . . . . . . . . F-5

H-1 Values of Constants . . . . . . . . . . . . . . . . . . . . . . . . . . . . H-1

I-1 Uniform Strains in Austenitic Stainless Steels after Irradiation in EBR-II at 371 to $400^{\circ} \mathrm{C}\left(700\right.$ to $\left.752^{\circ} \mathrm{F}\right)$. . . . . . . . . . . . . . . . . . . . . . . . . . . . . . . $1-3$

1-2 Uniform Strains in Austenitic Stainless Steels after Irradiation in EBR-II at 400 to $450^{\circ} \mathrm{C}\left(752\right.$ to $\left.842^{\circ} \mathrm{F}\right)$

1-3 Uniform Strains in Austenitic Stainless Steels after Irradiation in EBR-II at 450 to $500^{\circ} \mathrm{C}\left(842\right.$ to $\left.932^{\circ} \mathrm{F}\right)$.

1.4 Uniform Strains in Austenitic Stainless Steels after Irradiation in EBR-II at 500 to $550^{\circ} \mathrm{C}\left(932\right.$ to $\left.1022^{\circ} \mathrm{F}\right)$. . . . . . . . . . . . . . . . . . . . . . . . . 1.5

I-5 Uniform Strains in Austenitic Stainless Steels after Irradiation in EBR-II at 550 to $600^{\circ} \mathrm{C}\left(1022\right.$ to $\left.1112^{\circ} \mathrm{F}\right)$.

1-6 Uniform Strains in Austenitic Stainless Steels after Irradiation in EBR-II at Greater than $600^{\circ} \mathrm{C}\left(1112^{\circ} \mathrm{F}\right)$. 
$\ominus$

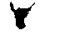




\section{INTRODUCTION AND SUMMARY}

\subsection{INTRODUCTION}

This is the final report for the Subcontract No. 3446 of the Principal Contract No. W-7405-eng-26, made by and between Union Carbide Corporation and General Electric Company for the USAEC. The objective is to develop interim stress criteria for LMFBR vessel and core structural design in general, and the General Electric Demonstration Plant in particular, utilizing the present state of the art.

The components to which the criteria of this report apply are classified into two groups: (1) long-life components, and (2) core components. This separation is made since each grouping has some distinct problerns and the criteria for each will be modified independently in subsequent revisions as more information from development programs becomes available.

The long-life components are those permanent and semi-permanent components that are shielded from the intense neutron flux of the core to permit them to be operated for the design life of the plant. A basic requirement on these components is that they be shielded so that the fluence they receive does not embrittle them to the point that they can no longer be considered ductile. Also within this grouping will be certain replaceable items which are partially shielded and designed for less than the full life of the plant but which also have fluence limited such that they can be considered ductile throughout their design life and are not subjected to significant swelling or irradiation-induced creep due to high fluence.

The core components include those that are subject to sufficient fluence that they may not be considered ductile throughout their life, are subject to significant swelling due to fast flux accumulation, and will be subjected to potential irradiation-induced creep effects.

Examples of long-life components are: the reactor container, primary coolant piping, reactor closure assembly, core clamping mechanisms, etc.

Examples of short-life components are: fuel assembly hexagonal channels* and internals, blanket assemblies, and control assembly channels. (Only the fuel and blanket channels are considered in the criteria contained here.) As a tentative criterion, a material is considered ductile if its uniform uniaxial elongation in a conventional tensile test is greater than $10 \%$. This corresponds to a fluence of approximately $10^{22}$ nvt total or slightly less, depending upon flux spectrum and temperature.

For the long-life components, the emphasis of the criteria is to provide interim rules for evaluation of components subjected to stresses at temperatures where creep effects, fatigue, and creep-fatigue interactions are incompletely covered in the existing code.** The scope involves the establishment of basic stress limits and recommends appropriate accumulative damage criteria considering the effects of hold time (frequency) and mean strain on low-cycle fatigue at temperatures in the creep range.

In the present work, it is assumed that there are no significant deleterious environmental effects from coolants and gases, and that weld metal and the heat-affected base material have essentially the same mechanical properties as the base material, except as otherwise noted.

In performance of the work, General Electric has utilized, as appropriate, the resources of other General Electric components such as the Research and Development Center and the Materials and Processes Laboratory.

\subsection{SUMMARY}

Based on the philosophy of design by analysis, the intended interim stress criteria have been developed for the design of LMFBR vessel and core structures. Although these criteria are general in nature, they are primarily established for the General Electric Demonstration Plant.

Basic stress limits have been categorized as to load duration, interaction of different stresses such as creep strain and low cycle fatigue, and the ductility of the base material. Due to the complexities involved in the highly nonlinear stress-strain-temperature relationship of the present structures that are also subjected to a variety of time dependent effects, no distinction has been made in the established categories of the basic stress limits as to whether they are load or strain controlled. Neither has an explicit cumulative damage rule been given; it is felt that the linear damage rule can be used as a basis for the time being. Considerations have been given to the elevated temperature effects, strain cycling, and other parameters which apply solely to the General Electric LMFBR Demonstration Plant. Because of a lack of sufficient test data on the sensitivity studies and embrittlement effects of irradiation, only a limited amiount of information related to the latter subject has been incorporated. To fulfill the need of the criteria, an outline of a recommended research and development program has been provided. The supplementary and supporting materials that are directly concerned with the present criteria are reported in Appendices A to I, inclusive.

\footnotetext{
* Channel is GE parlance for the thin-walled hexagonal cylinder surrounding the fuel pins.
}

** See Section 5., Bibliography, Item 2. 


\section{STRUCTURAL EVALUATION OF LONG-LIFE COMPONENTS}

\subsection{DEFINITION OF LOAD CONDITIONS}

According to the ASME Nuclear Code, each condition to which the structures under consideration may be subjected shall be categorized in accordance with the following definitions, and described in the design specification in such detail as will provide a complete basis for design, construction, and inspection in accordance with the Code rules.

\subsubsection{Design Conditions}

The design conditions (temperature, pressure, mechanical loads, life, etc.) must be at least as severe as those specified for the normal operating conditions.

\subsubsection{Operating Conditions}

The Operating Condition categories are defined as follows.

a. Normal Conditions-Any condition in the course of system startup, operation in the design power range, and system shutdown, in the absence of upset, emergency, or faulted conditions.

b. Upset Conditions-Any deviations from normal conditions anticipated to occur often enough that design should include a capability to withstand the conditions without operational impairment. The upset conditions include those transients which result from any single operator error or control malfunction, transients caused by a fault in a system component requiring its isolation from the system, transients due to loss of load or power, and any system upset not resulting in a forced outage. The estimated duration of an upset condition shall be included in the design specifications. Upset conditions include the effect of the specified earthquake for which the system must remain operational or must regain its operational status.

c. Emergency Conditions-Any deviations from normal conditions that require shutdown for correction of the conditions or repair of damage in the system. The conditions. have a low probability of occurrence but are included to provide assurance that no gross loss of structural integrity will result as a concomitant effect of any damage developed in the system. The total number of postulated occurrences for such events shall not exceed 25.

d. Faulted Conditions-Those combinations of conditions associated with extremely low probability postulated events whose consequences are such that the integrity and operability of the nuclear energy system may be impaired to the extent where considerations of public health and safety are involved. Such considerations require compliance with safety criteria as may be specified by jurisdictional authorities. Among the faulted conditions may be a specified earthquake for which safe shutdown is required.

\subsection{ASSUMPTIONS}

The present criteria are predicated on the following assumptions and limitations.

a. The requirements of this document are generally intended for the use of austenitic stainless steels, especially for Types $304(304 \mathrm{~L})$ and $316(316 \mathrm{~L})$ at normal condition temperatures up to $1100^{\circ} \mathrm{F}$.

b. For temperatures up to $800^{\circ} \mathrm{F}$, methods of analysis conforming to the current ASME Code* requirements are applicable.

c. For temperatures between 800 and $900^{\circ} \mathrm{F}$, elastic and limit analyses may be used for the determination of primary stresses. However, these methods of analysis will not account for plastic or creep strains, and may not be adequate for the evaluation of creep-fatigue effects.

d. For temperatures greater than $900^{\circ} \mathrm{F}$, only inelastic analysis, which takes the elastic, plastic, and creep effects into account, should be used for cyclic loadings. For non-cyclic loads, the stationary creep analysis may be substituted for the rigorous time-dependent analysis.

e. Pending a better understanding of the creep-fatigue interaction behavior for the materials under consideration, the linear damage rule is being considered herein as a basis for both individual and cumulative loadings.

f. This document is of interim nature. It is subject to change as improved methods and criteria are developed from current research.

" Hereafter, reference to "the Code," "Code requirements," etc., mentioned in this document shall mean Section III, including addenda through Summer 1970 and all upi-to-date applicable Code Cases except as otherwise noted. 


\subsection{GENERAL CONSIDERATIONS AND DISCUSSION}

Described in this subsection are the results of a brief survey of the state of the art for the pertinent parameters related to both low- and high-temperature structural technology, including some discussions. The following topics have been considered in the present survey:

- Methods of Elastic Analysis of Some Classical Shells

- Inelastic Behavior of Isotropic Shells

- Shakedown Factors for Spherical Shells and Nozzles

- Creep and Fatigue Interaction of Metals at Elevated Temperatures

- A Note on Creep Buckling of Columns and Cylinders

- Material Data

\subsubsection{Methods of Elastic Analysis of Some Classical Shells}

To satisfy the requirements of the philosophy of design by analysis, it is desirable that methods of analysis be provided for the designers, especially methods for analysis of thin-walled elastic axisymmetric shells, which have been developed during the last decade. In view of the limitations of methods for analyzing some classical vessels under both internal and external pressures and edge loads as well as limitations in current standards, it is felt that at least the following available methods of analysis could be incorporated:

- Analysis of Conical Shells

- Conical Shells under External Pressure

- Analysis of Ellipsoidal Shells

Detailed description of each of the above methods of analysis is reported in Appendices A, B, and C, respectively. It is noted that the analysis of uniform conical shells given in Appendix $A$ is exact for thin elastic shells, whereas the results contained in the Appendix $\mathrm{C}$ were obtained by solving the field equations of classical shells under consideration numerically, using the finite difference technique and appropriate elliptic integrals.

\subsubsection{Inelastic Behavior of Isotropic Shells}

The phenomenological theory that describes the inelastic behavior of isotropic thin-walled shells has been reviewed. Results are given in Appendix D. If the present formulation is properly translated, it will yield the corresponding physical components which may serve as the basic expressions for the inelastic analysis of the structures under consideration.

\subsubsection{Shakedown Factors for Spherical Vessels with Radial Nozzles}

To facilitate a rapid design of spherical vessels with both flush and protruding nozzles, the valuable contributions of Leckie and Penny have been compiled, as reported in Appendix E. Although this information is provided for low-temperature applications, it is believed that it can be used also for temperatures within the sub-creep range with appropriate modifications as shown in Table 2-1.

\subsubsection{Creep and Fatigue Interaction of Metals at Elevated Temperatures}

The state of the art of the behavior and the interaction of creep and fatigue of metals at elevated temperatures has been studied to some extent. Results are reported in Appendix F. It should be noted that due to the intrinsic complexities involved, the progress on the understanding of the behavior of creep and fatigue and their interaction in metal in general, and stainless steels in particular, is rather slow; at the present time, no simple but accurate rules have been established for the prediction of the creep and fatigue interaction for any metal, including, of course, the candidate materials under consideration.

When a structural component is under cyclic load in the absence of mean stress or strain, the fatigue life of the component can be predicted by one of the available empirical equations derived by various investigators; namely, Manson-Halford, Conway-Berling, Coffin, and others. Other things being equal, results generated by either one of these equations are approximately the same (see Figure F-9 of Appendix F). However, only Coffin's equation automatically takes care of the strain rate of loading frequency effects. For this main reason, the following so-called Generalized Equation is chosen for the generation of design curves in the present criteria:

$$
\Delta \epsilon_{t}=\frac{A}{E} C_{2}{ }^{n} N_{f}-\beta n{ }_{\nu} k_{1}+(1-k) \beta n+C_{2} N_{f}-\beta(1-k) \beta
$$


Table 2-1

STRESS INTENSITY LIMITS FOR LONG LIFE COMPONENTS

( $t=210,000 \mathrm{~h}$, Total Fluence $<10^{22} \mathrm{nvt}$ and Ductility $>10 \%$ )

\begin{tabular}{|c|c|c|c|c|c|c|}
\hline \multirow[b]{2}{*}{ Condition } & \multirow[b]{2}{*}{$\begin{array}{c}\text { Temperature } \\
\left.\text { ( }{ }^{\circ} \mathrm{F}\right) \\
\end{array}$} & \multicolumn{4}{|c|}{ Stress Category } & \multirow[b]{2}{*}{$\begin{array}{l}\text { Recommended } \\
\text { Method of } \\
\text { Analysis } \\
\end{array}$} \\
\hline & & $\begin{array}{l}\text { General }{ }^{\dagger} \\
\text { Primary } \\
\text { Membrane } \\
\end{array}$ & $\begin{array}{l}\text { Local } \\
\text { Primary } \\
\text { Membrane } \\
\end{array}$ & $\begin{array}{c}\text { Primary Membrane }{ }^{\dagger} \\
\text { Plus } \\
\text { Primary Bending } \\
\end{array}$ & $\begin{array}{c}\text { Primary Membrane } \\
\text { Plus } \\
\text { Secondary } \\
\end{array}$ & \\
\hline \multirow{2}{*}{$\begin{array}{l}\text { Specified } \\
\text { Design }\end{array}$} & $\mathrm{T}<900$ & $P_{m} \leqslant S_{m}$ & $\mathrm{P}_{\mathrm{L}} \leqslant 1.5 \mathrm{~S}_{\mathrm{m}}$ & $P_{L}+P_{B} \leqslant 1.5 S_{m}$ & & Elastic \\
\hline & $T \geqslant 900$ & $P_{m} \leqslant S_{m}$ & $P_{\mathrm{L}} \leqslant 1.1 \mathrm{~S}_{\mathrm{m}}$ & $P_{L}+P_{B} \leqslant 1.1 S_{m}$ & & Inelastic \\
\hline \multirow{3}{*}{$\begin{array}{l}\text { Normal } \\
\text { and } \\
\text { Upset }\end{array}$} & \multirow{2}{*}{$\mathbf{T}<\mathbf{9 0 0}$} & $P_{m} \leqslant S_{m}$ & $P_{L} \leqslant 1.5 S_{m}$ & $P_{L}+P_{B} \leqslant 1.5 S_{m}$ & $P_{L}+P_{B}+Q \leqslant K S_{m}^{* * *}$ & Elastic \\
\hline & & $2 \mathrm{C}_{\mathrm{L}} / 3$ & $2 \mathrm{C}_{\mathrm{L}} / 3$ & $2 \mathrm{C}_{\mathrm{L}} / 3$ & & Limit \\
\hline & $T \geqslant 900$ & $P_{m} \leqslant 1.1 S_{m}$ & $\mathrm{P}_{\mathrm{L}} \leqslant 1.1 \mathrm{~S}_{\mathrm{m}}$ & $P_{L}+P_{B} \leqslant 1.1 S_{m}$ & $P_{L}+P_{B}+Q \leqslant \sigma_{y}^{* *}$ & Inelastic \\
\hline \multirow[t]{2}{*}{ Emergency ${ }^{\dagger}$} & $\mathrm{T}<\mathbf{9 0 0}$ & $P_{m} \leqslant 1.2 S_{m}$ & $\mathrm{P}_{\mathrm{L}} \leqslant 1.8 \mathrm{~S}_{\mathrm{m}}$ & $P_{L}+P_{B} \leqslant 1.8 S_{m}$ & & Elastic \\
\hline & $T \geqslant 900$ & $P_{m} \leqslant 1.2 S_{m}$ & $P_{L} \leqslant 1.3 S_{m}$ & $P_{L}+P_{B} \leqslant 1.3 S_{m}$ & & Inelastic \\
\hline \multirow{2}{*}{ Faulted } & $\mathrm{T}<\mathbf{9 0 0}$ & \multirow{2}{*}{$\mathrm{c}_{\mathrm{L}} \bullet$} & \multirow{2}{*}{$\mathrm{C}_{\mathrm{L}}$} & \multirow{2}{*}{$c_{L}$} & & \multirow{2}{*}{ Limit } \\
\hline & $T \geqslant 900$ & & & & & \\
\hline
\end{tabular}

Notes:

* $\mathrm{C}_{\mathrm{L}}=$ lower bound collapse load

* * Values of $\sigma_{y}$ are shown in Figure 2-6

*** A. For spherical vessels with radial nozzles

1. $\mathrm{T}<800^{\circ} \mathrm{F}$ :

$K=1.5 k_{i}$, where $k_{j}$ are shakedown factors given in Appendix $E$

2. $800 \leqslant T<900^{\circ} \mathrm{F}$ :

$K=1.5 k_{i}-\left(k_{i}-1\right)(T-800) / 100$

B. For all other structures

1. $\mathrm{T}<800^{\circ} \mathrm{F}$ :

$$
K=\mathbf{3 . 0}
$$

2. $800 \leqslant T<900^{\circ} \mathrm{F}$ : $K=3.0 \cdot(T-800) / 100$

$\dagger$ Life fraction rule $\sum_{j}\left(\frac{t}{T_{M, L B}}\right)_{j} \leqslant 1$ 
where

$$
\begin{aligned}
\Delta \epsilon_{\mathrm{t}} & =\text { total strain range, } \\
N_{\mathrm{f}} & =\text { cycles to failure, } \\
\nu & =\text { loading frequency, }=\dot{\epsilon} / 2 \Delta \epsilon_{\mathrm{t}} \\
\dot{\epsilon} & =\text { strain rate, }
\end{aligned}
$$

and $A, \beta, C_{2} E, k, k_{1}$ and $n$ are the temperature-dependent material constants.

Based on the test results conducted previously by the Nuclear System Program of General Electric and some additional information supplied by the Research and Development Center of GE for the present subcontract, numerical values of these temperature-dependent constants have been evaluated by regression analysis for temperatures at 806 , 1200 , and $1500^{\circ} \mathrm{F}$. Detailed results and interpolated values for other temperatures are listed in Table $2 \cdot 2$. With these known values of material constants and appropriate factors of safety assigned for the strains and cycles to failure as input quantities, Equation $(2-1)$ is solved for temperatures at $800,1000,1200$, and $1500^{\circ} \mathrm{F}$ for both Types-304 and -316 stainless steels; the design fatigue curves are obtained as shown in Figures $2-1$ and $2-2$. Figures $2-3$ and $2-4$ show, respectively, the effects of temperature and loading frequency on the fatigue strength of Types-304 and -316 stainless steels for the frequency range between 1000 and 0.000001 cycles per minute. It is apparent that the frequency or strain rate effects are significant at higher temperature range where the fatigue life is directly proportional to the loading frequency, except that for the low-temperature range a reverse tendency is shown in the long-life portion of these limiting frequency surfaces; i.e., the fatigue life increases with decrease in strain rate.

In the case when a structural component is subjected to cyclic load in the presence of mean stress or strain, then the design fatigue curves such as those shown in Figures 2.1 and 2-2 are insufficient to estimate the life of the structure, and a creep and fatigue interaction relation is needed to solve the problem completely. Generally, the creep-fatigue interaction relation for most metallic materials is nonlinear. This statement is supported by the evidence as shown in Figures $F-9, F-10, F-12, F-13$, and F-14 of Appendix $F$ and the normalized Taira Interaction curve for 18-8 stainless steel as shown in Figure 2-5. However, due to a lack of test data for the candidate materials under consideration, it is difficult to select the most probable values for the exponents for each term of the nonlinear interaction relation. For the time being, therefore, the linear damage rule is considered as a basis in the present criteria for both individual and cumulative loadings.

\subsubsection{A Note on Creep Buckling of Columns and Cylinders}

Presented in Appendix $G$ is a brief survey of the creep-buckling analysis of columns and circular cylindrical shells under simple loadings. Some analytic expressions for the prediction of the life of these structures are included. It is believed that additional work on this difficult subject should be carried out in order to establish the fundamental creep-buckling criteria so that a reliable estimate of the lifetime of the structures under consideration can be achieved.

\subsubsection{Material Data}

A limited compilation of the data on the stress-rupture and creep behavior of the candidate and other similar materials is reported in Appendix $H$.

\subsection{STRESS CRITERIA}

\subsubsection{Basis for the Allowable Stress Intensity $\left(\mathrm{S}_{\mathrm{m}}\right)$}

The following limits are established for operating temperature above $400^{\circ} \mathrm{F}$. Unless otherwise specified, the limits for the allowable stresses are based on the unirradiated material properties. The values defined herein are based on the lowest factor for each category of the components given as follows.

- One-third of the minimum specified tensile strength at room temperature

- One-third of the tensile strength at metal temperature

- Two-thirds of the minimum specified yield strength at room temperature

- Two-thirds of the minimum stress to cause rupture at time " $t$ "

- Ninety percent of the yield strength of the materials at metal temperature

- Eighty percent of the average stress to produce one percent total strain at time " $\mathrm{t}$ " for a constant stress type of loading

- Eighty percent of the minimum stress to cause initiation of tertiary creep at time " $t$ "

Figure 2-6 shows the minimum yield strength of Types-304 and -316 stainless steels. 
Table 2-2

VALUES OF TEMPERATURE-DEPENDENT CONSTANTS FOR TYPES-304 AND -316 STAINLESS STEEL IN AIR

\begin{tabular}{|c|c|c|c|c|c|c|c|c|}
\hline \multicolumn{9}{|c|}{ Stainless } \\
\hline $\begin{array}{c}\text { Temperature } \\
\left({ }^{\circ} \mathrm{F}\right)\end{array}$ & $\begin{array}{c}\text { Stainless } \\
\text { Steel } \\
\text { Material }\end{array}$ & $\begin{array}{c}A \\
\left(10^{3}\right)\end{array}$ & B & $\mathrm{C}_{2}$ & $\begin{array}{c}E \\
\left(10^{6}\right)\end{array}$ & $k$ & $k_{1}$ & $n$ \\
\hline \multirow{2}{*}{806} & 304 & 944.373 & 0.407654 & 0.295013 & 23.4 & 0.928102 & -0.3505 & 0.485605 \\
\hline & 316 & 340.279 & 0.480136 & 0.452621 & 24.0 & 0.926391 & -0.02477 & 0.205252 \\
\hline \multirow{2}{*}{900} & 304 & 685.0 & 0.485 & 0.500 & 23.1 & 0.890 & 0.015 & 0.415 \\
\hline & 316 & 330.0 & 0.477 & 0.355 & 23.9 & 0.900 & -0.03 & 0.250 \\
\hline \multirow{2}{*}{1000} & 304 & 480.0 & 0.560 & 0.700 & 22.6 & 0.857 & 0.035 & 0.360 \\
\hline & 316 & 315.0 & 0.500 & 0.320 & 23.5 & 0.880 & 0.018 & 0.260 \\
\hline \multirow{2}{*}{1100} & 304 & 325.0 & 0.630 & 0.900 & 22.0 & 0.830 & 0.046 & 0.305 \\
\hline & 316 & 295.0 & 0.530 & 0.320 & 23.0 & 0.860 & 0.037 & 0.250 \\
\hline \multirow{2}{*}{1200} & 304 & 214.138 & 0.706759 & 1.108190 & 21.6 & 0.810691 & 0.05309 & 0.258626 \\
\hline & 316 & 265.758 & 0.568755 & 0.354196 & 22.0 & 0.857607 & 0.05162 & 0.239849 \\
\hline \multirow{2}{*}{1300} & 304 & 130.0 & 0.770 & 1.300 & 20.2 & 0.802 & 0.056 & 0.203 \\
\hline & 316 & 230.0 & 0.625 & 0.425 & 20.6 & 0.855 & 0.063 & 0.215 \\
\hline \multirow{2}{*}{1400} & 304 & 98.2 & 0.820 & 1.500 & 19.2 & 0.803 & 0.056 & 0.155 \\
\hline & 316 & 170.0 & 0.685 & 0.560 & 19.2 & 0.870 & 0.073 & 0.185 \\
\hline \multirow{2}{*}{1500} & 304 & 63.256 & 0.869543 & 1.717250 & 18.8 & 0.812116 & 0.05338 & 0.105791 \\
\hline & 316 & 94.249 & 0.742406 & 1.388860 & 18.4 & 0.904949 & 0.07900 & 0.150867 \\
\hline
\end{tabular}

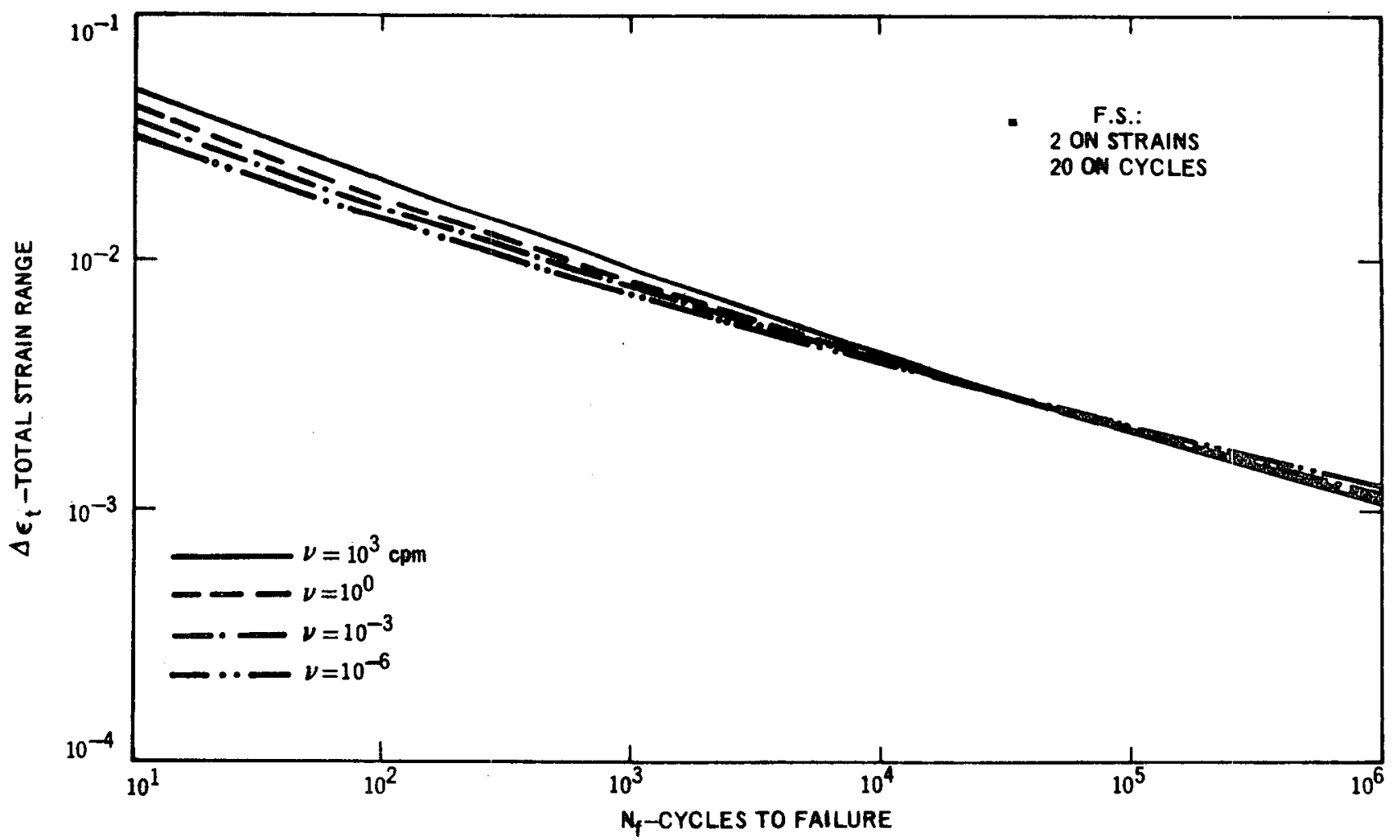

Figure 2-1A. Design System Fatigue Curves for Type-304 Stainless Steel at $800^{\circ} \mathrm{F}$ 


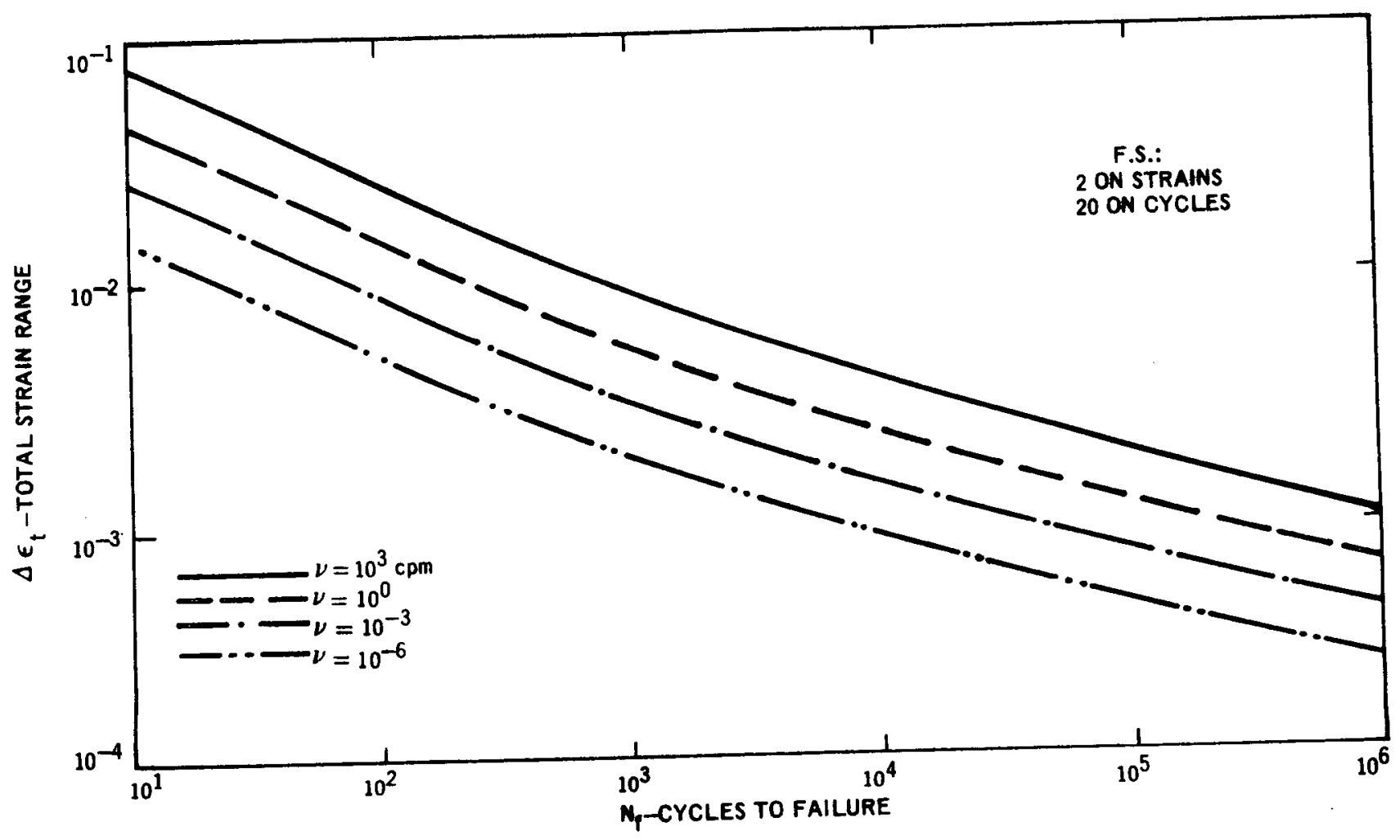

Figure 2-1B. Design System Fatigue Curves for Type-304 Stainless Steel at $1000^{\circ} \mathrm{F}$

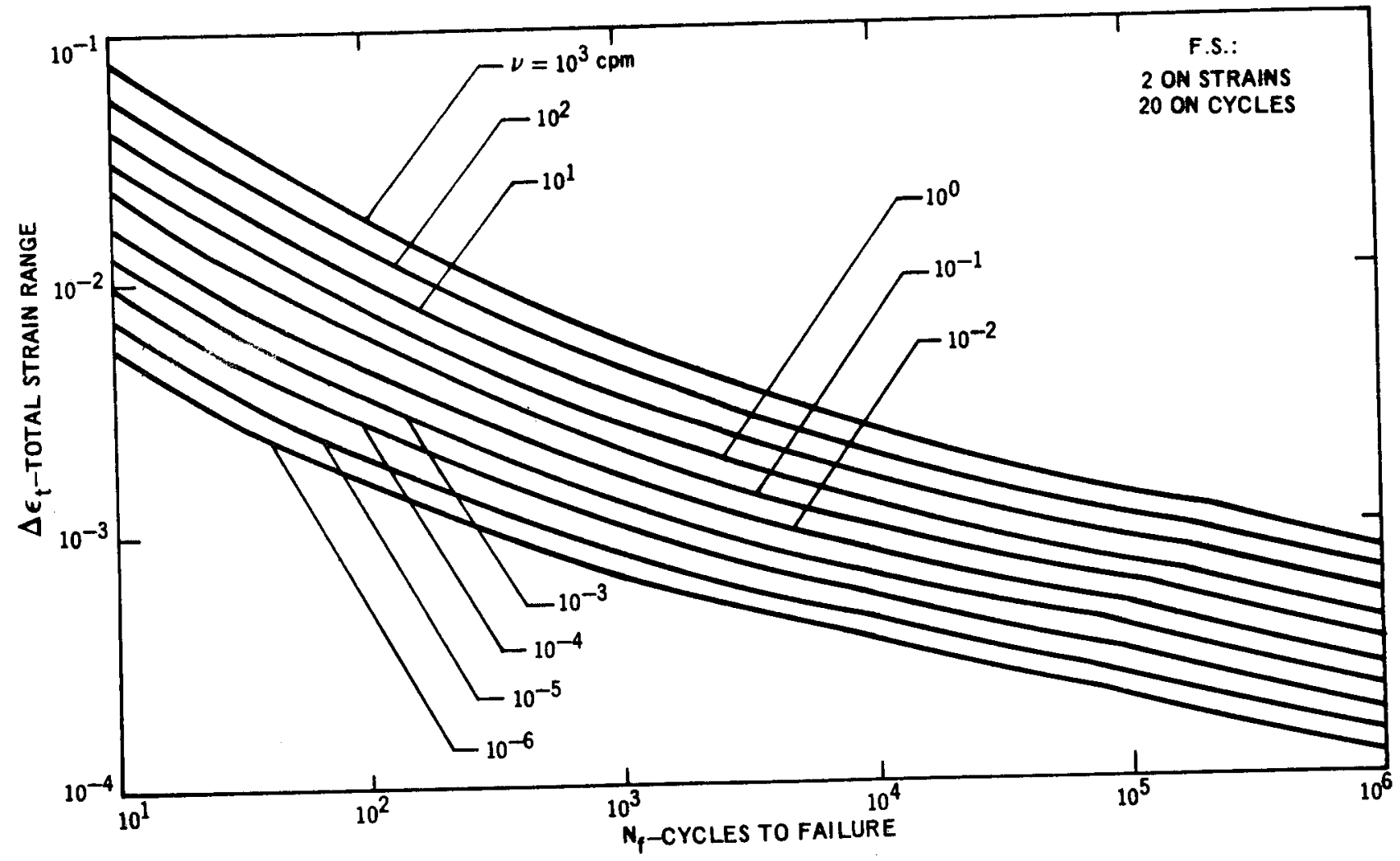

Figure 2-1C. Design System Fatigue Curves for Type-304 Stainless Steel at $1200^{\circ} \mathrm{F}$ 


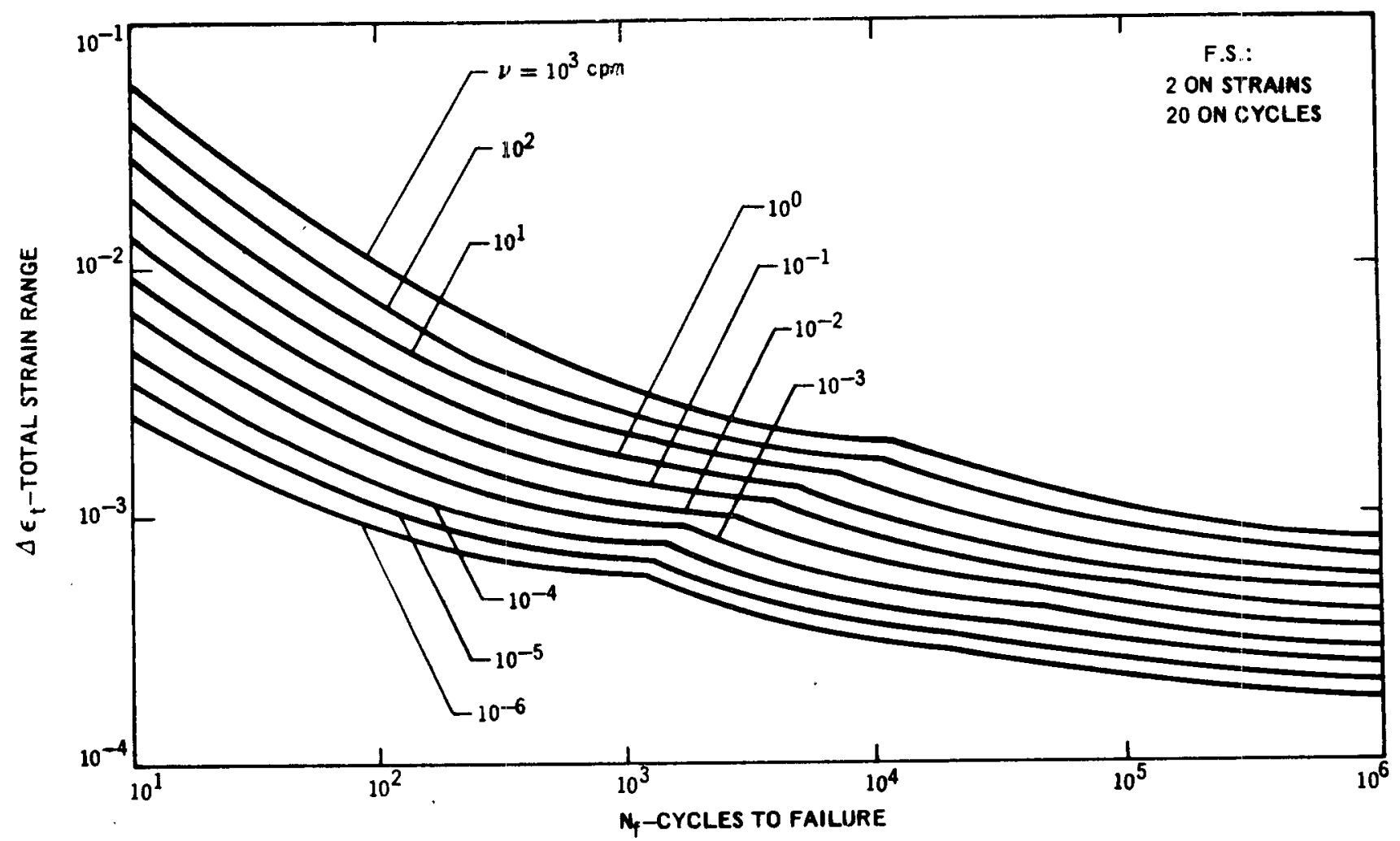

Figure 2-10. Design System Fatigue Curves for Type-304 Stainless Steel at $1500^{\circ} \mathrm{F}$

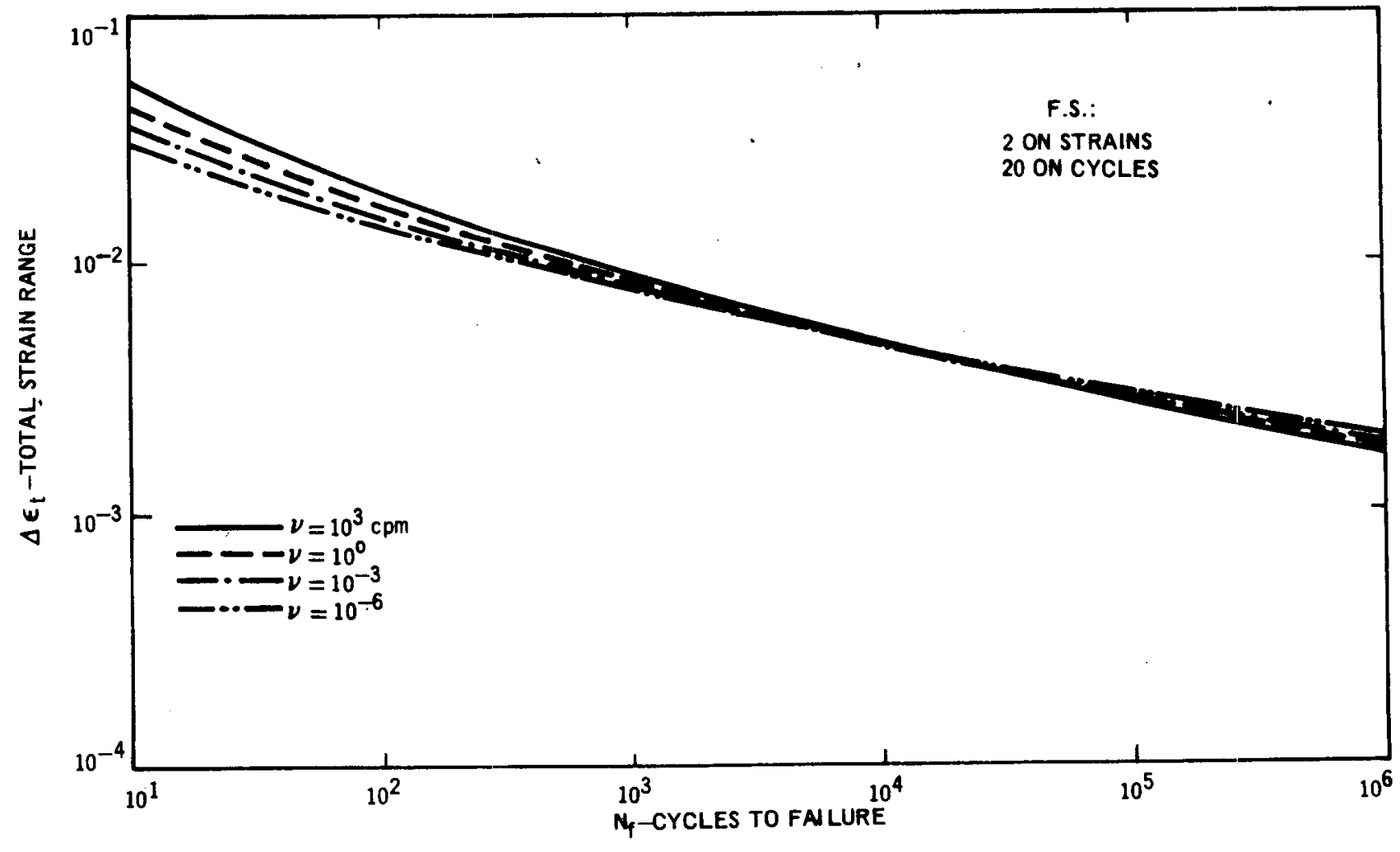

Figure 2-2A. Design System Fatigue Curves for Type-316 Stainless Steel at $800^{\circ} \mathrm{F}$ 


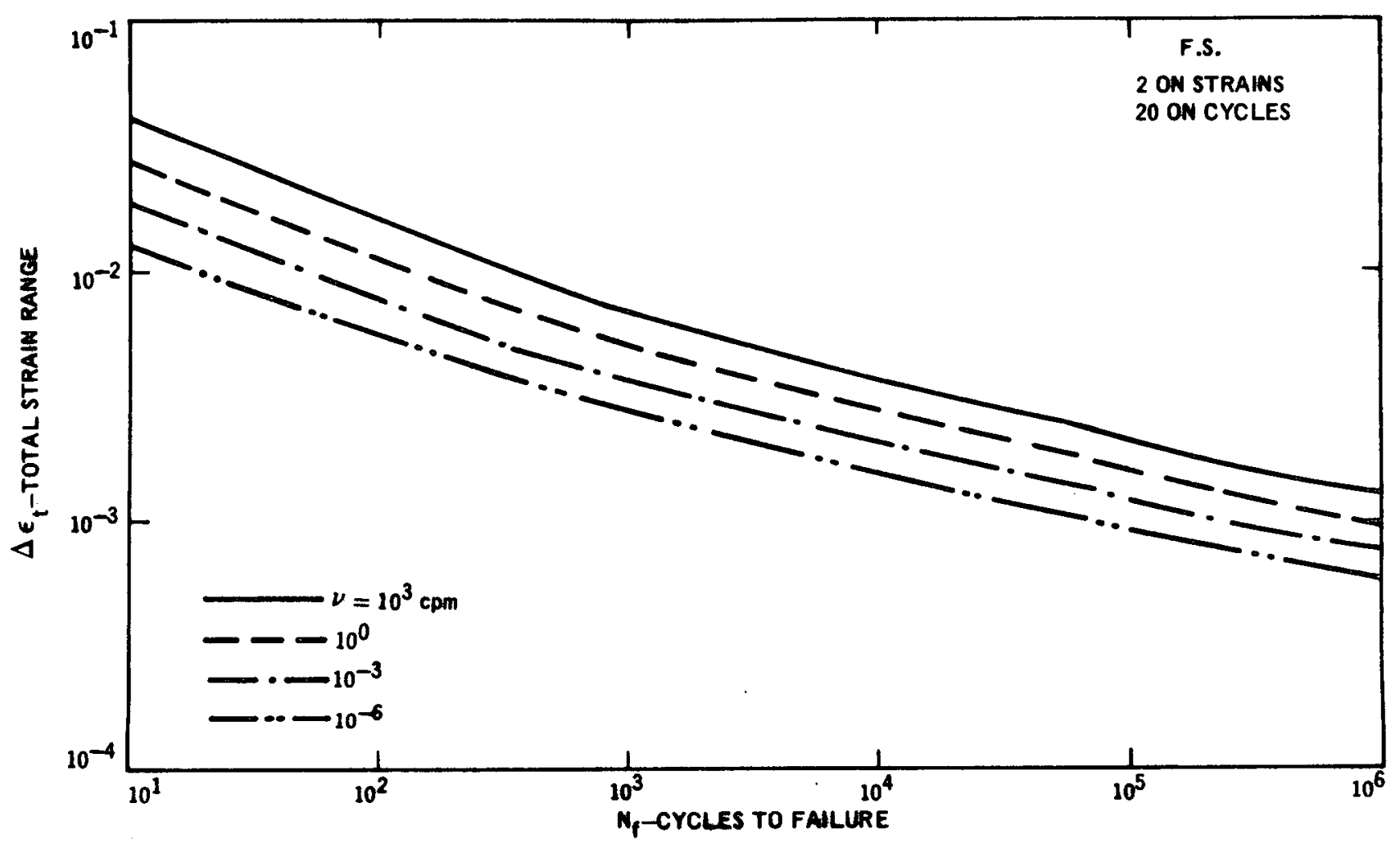

Figure 2-2B. Design System Fatigue Curves for Type-316 Stainless Steel at $1000^{\circ} \mathrm{F}$

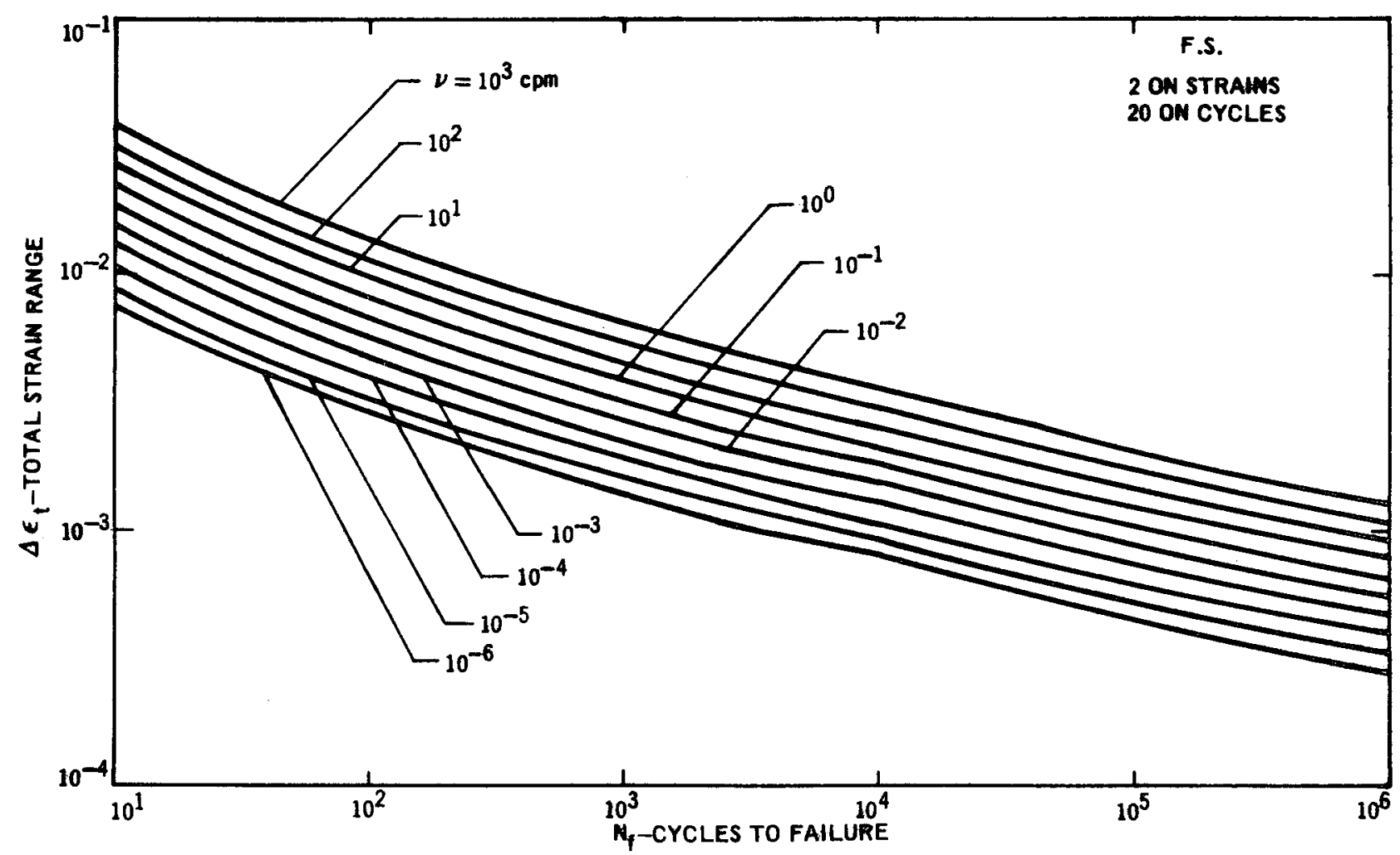

Figure 2-2C. Design System Fatigue Curves for Type-316 Stainless Steel at $1200^{\circ} \mathrm{F}$ 


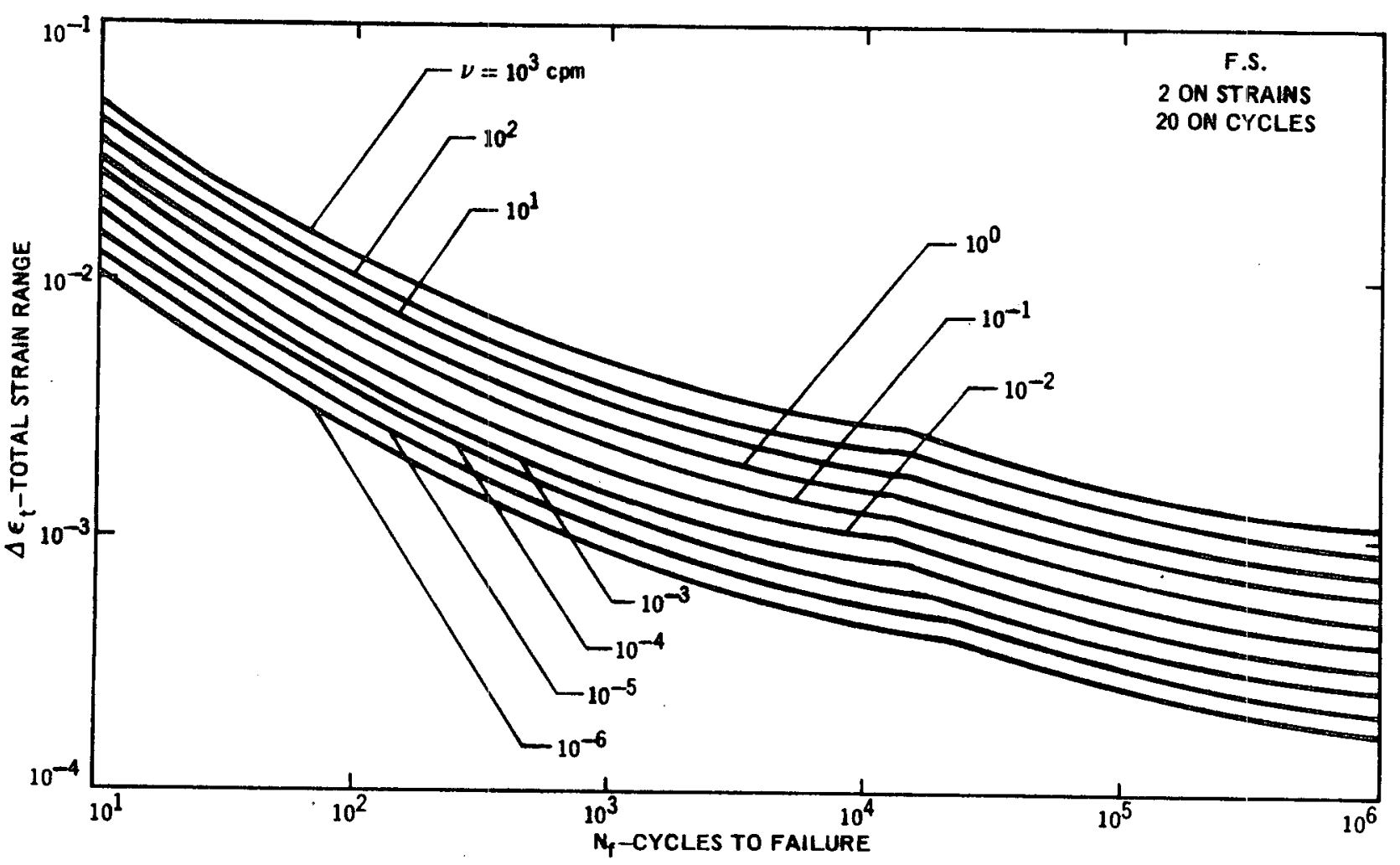

Figure 2-2D. Design System Fatigue Curves for Type-316 Stainless Steel at $1500^{\circ} \mathrm{F}$ 


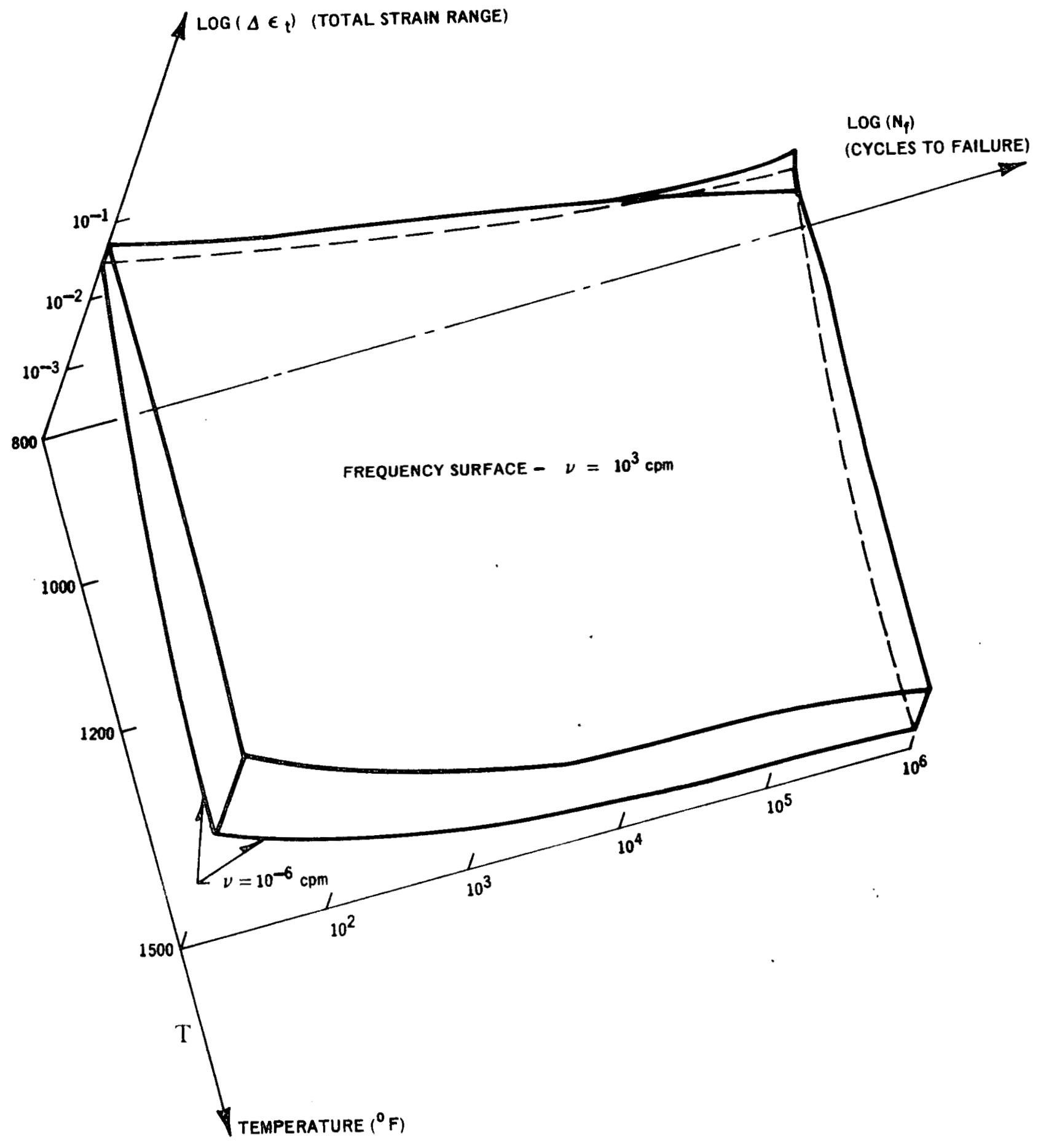

Figure 2-3. Effects of Temperature and Loading Frequency on Low-Cycle Fatigue Strength of Type-304 Stainless Steel (Frequency Range $\nu=10^{3}$ to $10^{-6} \mathrm{cpm}$ ) 


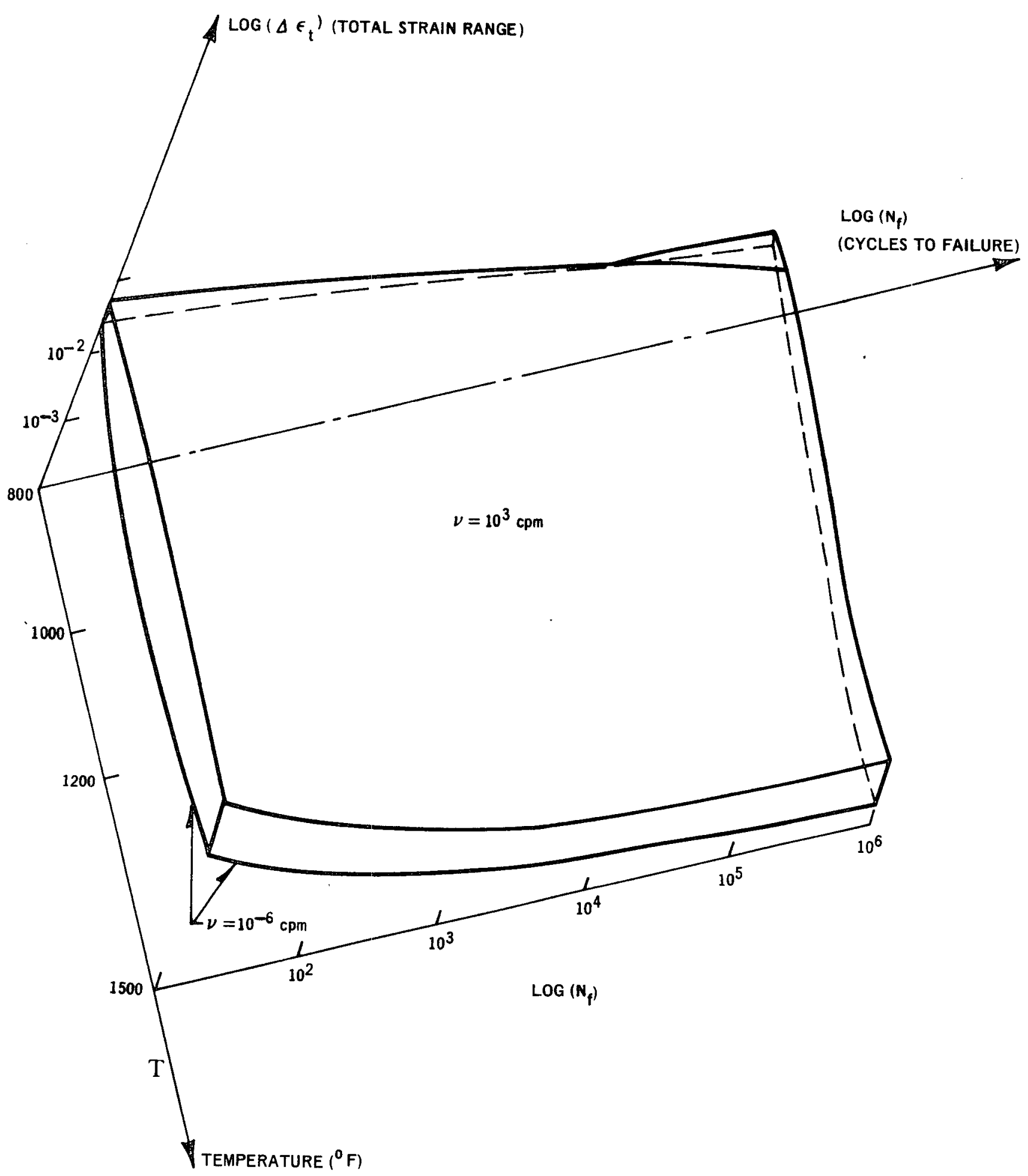

Figure 2-4. Effects of Temperature and Loading Frequency on Low-Cycle Fatigue Strength of Type-316 Stainless Steel (Frequency Range $\nu=10^{3}$ to $10^{-6} \mathrm{cpm}$ ) 


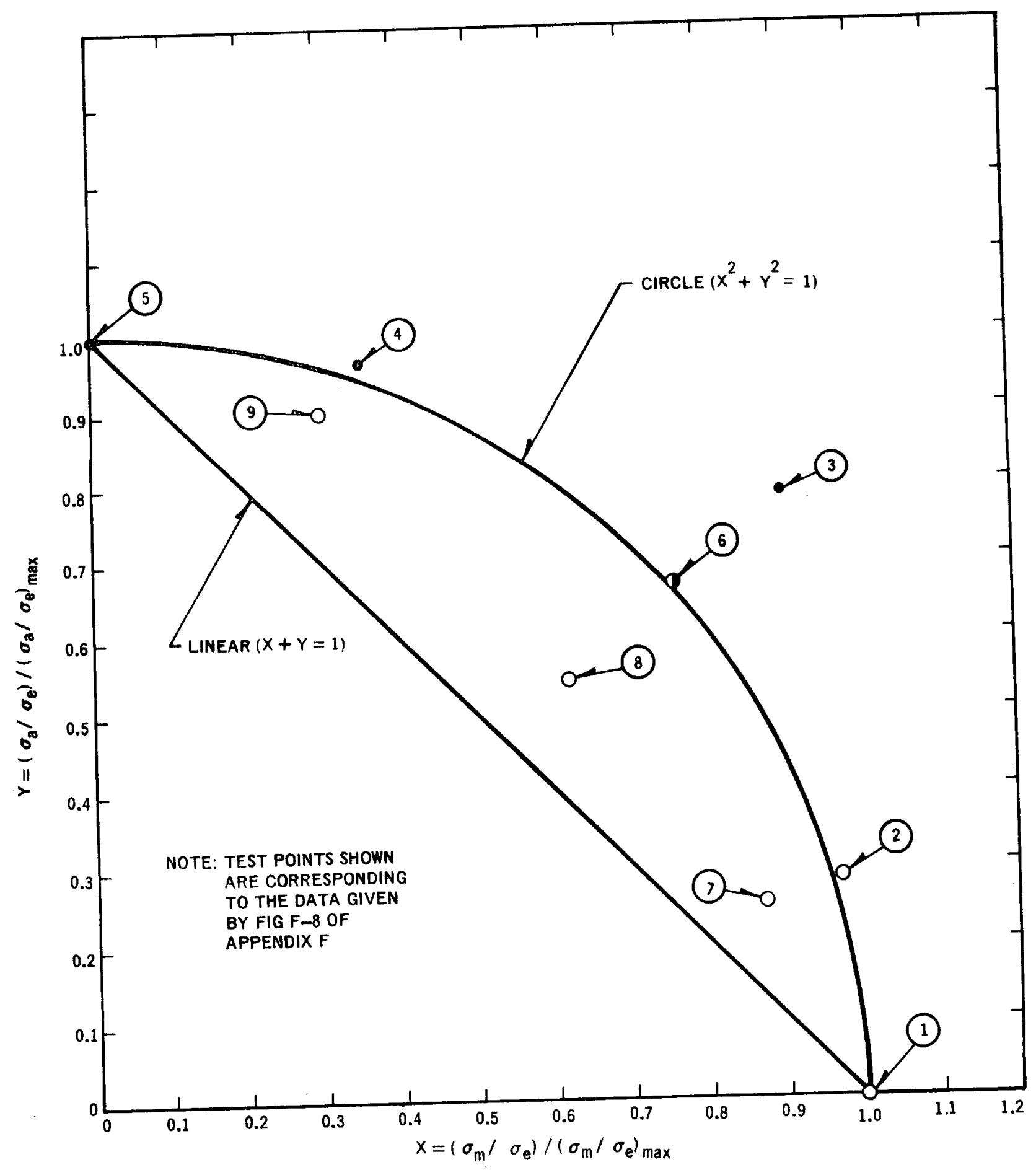

Figure 2-5. Normalized Taira Interaction Curve for $18-8$ Stainless Steel at $650^{\circ} \mathrm{C}$ 


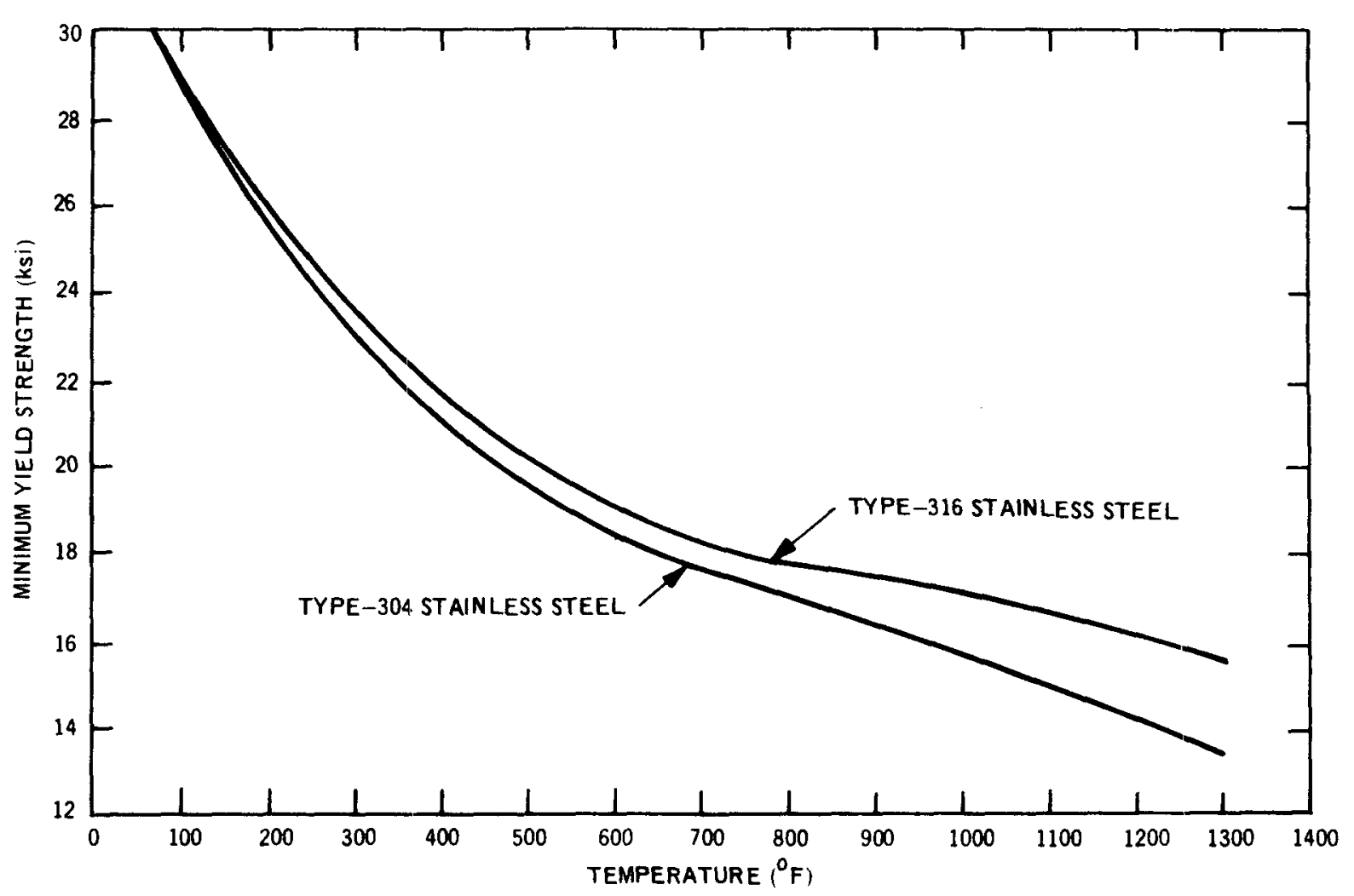

Figure 2-6. Minimum Yield Strength of Types-304 and -316 Stainless Stee/s

From Figure 2.7 it can be seen that for temperatures up to about $900^{\circ} \mathrm{F}$, numerical values of $\mathrm{S}_{\mathrm{m}}$ are quite stable. However, for $\mathrm{T}>900^{\circ} \mathrm{F}$, they decrease rather rapidly because they are essentially governed by the creep rupture strength of the materials. The temperature range below $900^{\circ} \mathrm{F}$ can be considered as the sub-creep range for the candidate materials, and the value $\mathrm{T}=900^{\circ} \mathrm{F}$ is assumed then as the limiting temperature for the elastic and limit analyses as well as the creep range.

\subsubsection{Stress Intensity Limits}

According to the categories of stresses and their combinations, " and the specified design and various operating conditions, the stress intensity limits are defined in the following manner.

\subsubsection{Specified Design Condition}

The primary membrane stress intensity $P_{m}$ shall not exceed the value $S_{m}$, shown in Figure 2-7, for components having a design life of full plant life $(210,000 \mathrm{~h})$.

If inelastic analysis is used, the limiting values of the primary membrane stress, $P_{L}$, or the combination of local primary membrane stress plus bending stress, $P_{L}+P_{B}$ may be increased by a factor of 1.1. When limit analysis is chosen, the allowable design load shall not exceed two-thirds of the lower-bound value of the collapse load.

Table 2-1 summarizes the limiting values for the general primary membrane, the local membrane, and the primary membrane, plus the bending stresses for all temperature ranges.

\subsubsection{Operating Conditions}

According to the ASME Nuclear Code, the operating conditions include normal, upset, emergency and faulted conditions. The limiting stress intensities for each of these conditions are listed for different combinations of stress categories as follows.

\section{a. General Primary Membrane and Local Membrane Stress Intensity}

The limits for both normal and upset conditions are identical to the corresponding values for the specified design condition; the limits for the emergency and faulted conditions, together with the methods of analysis for different temperature ranges, are listed in Table 2-1.

*For definition of stress categories, see subsection 3.2 . 


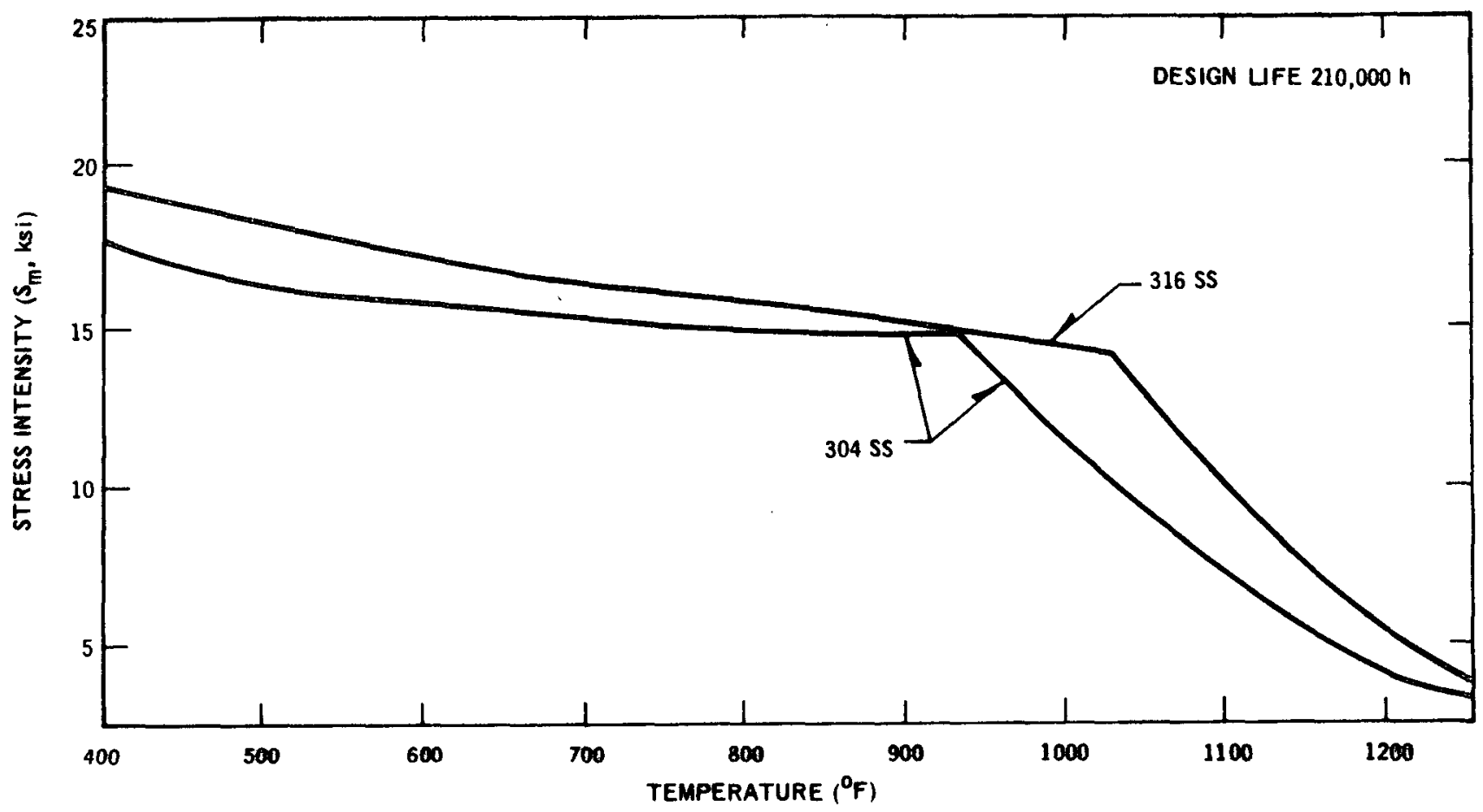

Figure 2-7. Design Stress Intensity Value, $S_{m}$, for Types-304 and -316 Stainless Steels

\section{b. Primary Membrane plus Bending Stress Intensity}

The stress intensity limits for the present case are essentially the same as the corresponding values defined for the general primary and local membrane stresses, except that the limit for the emergency condition at higher temperature range for this case is slightly smaller, as depicted in Table 2-1.

c. Primary Membrane plus Secondary Stress Intensity

The allowable primary plus secondary stress intensity, $P_{L}+P_{B}+Q$, for different operating conditions shall not exceed the multiples of $S_{m}$ as defined in Table 2-1.

For each of the foregoing combinations, it is required that appropriate seismic analysis shall be performed for the Upset and Faulted Condition, using suitable recorded ground motions for the OBE (Operating Basis Earthquake) and DBE (Design Basis Earthquake), respectively.

To prevent rupture of components at various stress levels in the creep range (i.e., for temperatures above $900^{\circ} \mathrm{F}$ ), the life fraction sum associated with the general primary membrane stress intensities $\left(P_{m}\right)$ alone and the combined primary membrane plus bending stress intensities $\left(P_{L}+P_{B}\right)$ for all increments of loadings during Normal, Upset, and Emergency Conditions shall satisfy the following requirements:

$$
\sum_{j}\left(\frac{t}{T_{M, L B}}\right)_{j} \leqslant 1
$$

where

$$
\begin{aligned}
t & =\text { total duration of stress intensity } P_{m} \text { or } P_{L}+P_{B} \text { for the temperature and loading } j \\
T_{M, L B} & =\quad \begin{array}{l}
\text { maximum allowed time under the stress intensity } P_{m} \text { or } P_{L}+P_{B} \text { for temperature and } \\
\text { loading } j, \text { as determined from the stress-rupture time curves as shown in Figure } 2-8 .
\end{array}
\end{aligned}
$$

Equation (2-2) is also applicable to the Faulted Condition for the corresponding cases of stress intensities. 


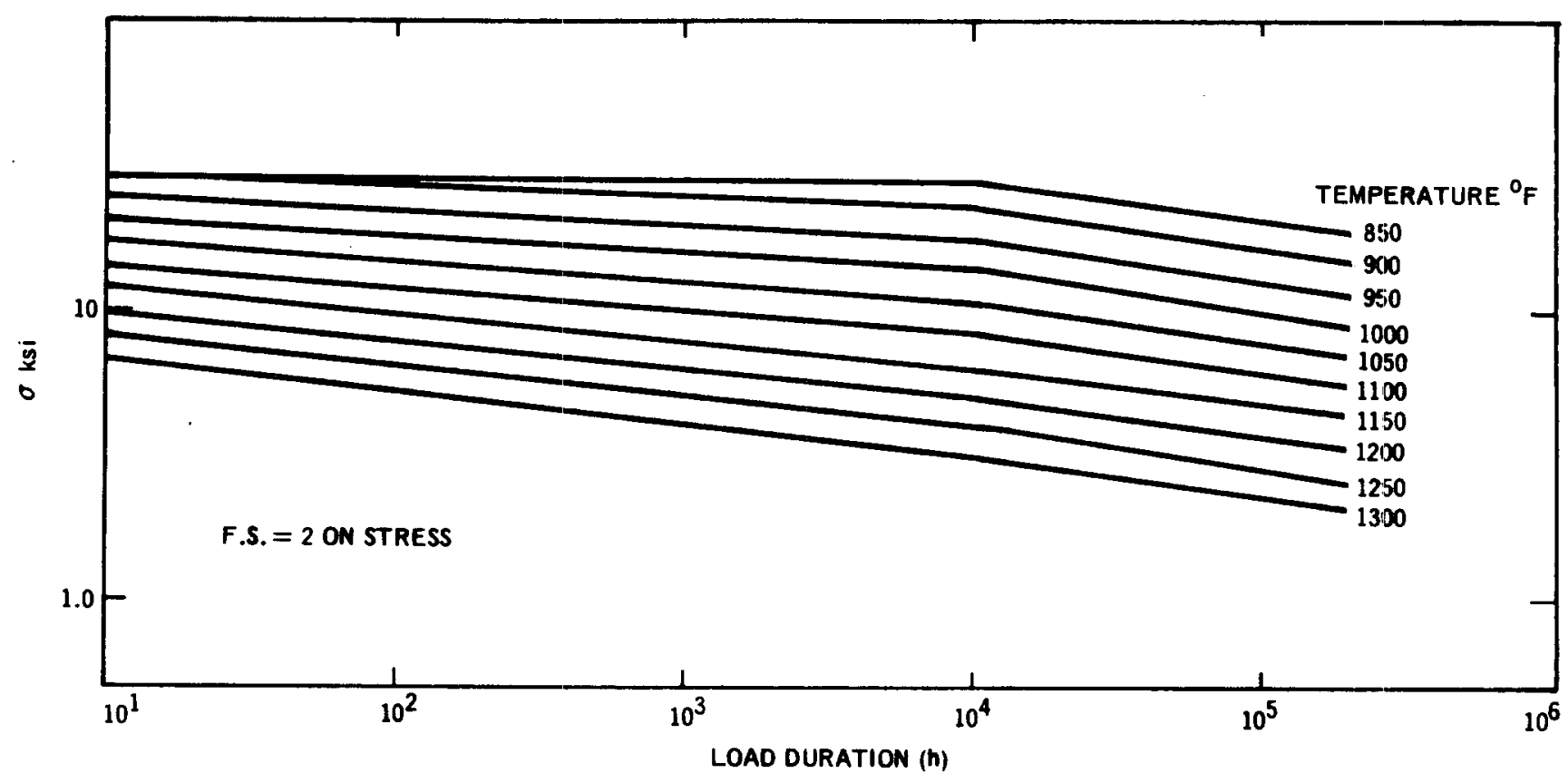

Figure 2-8A. Design Stress Rupture Curves for Type-304 Austenitic Stainless Steel

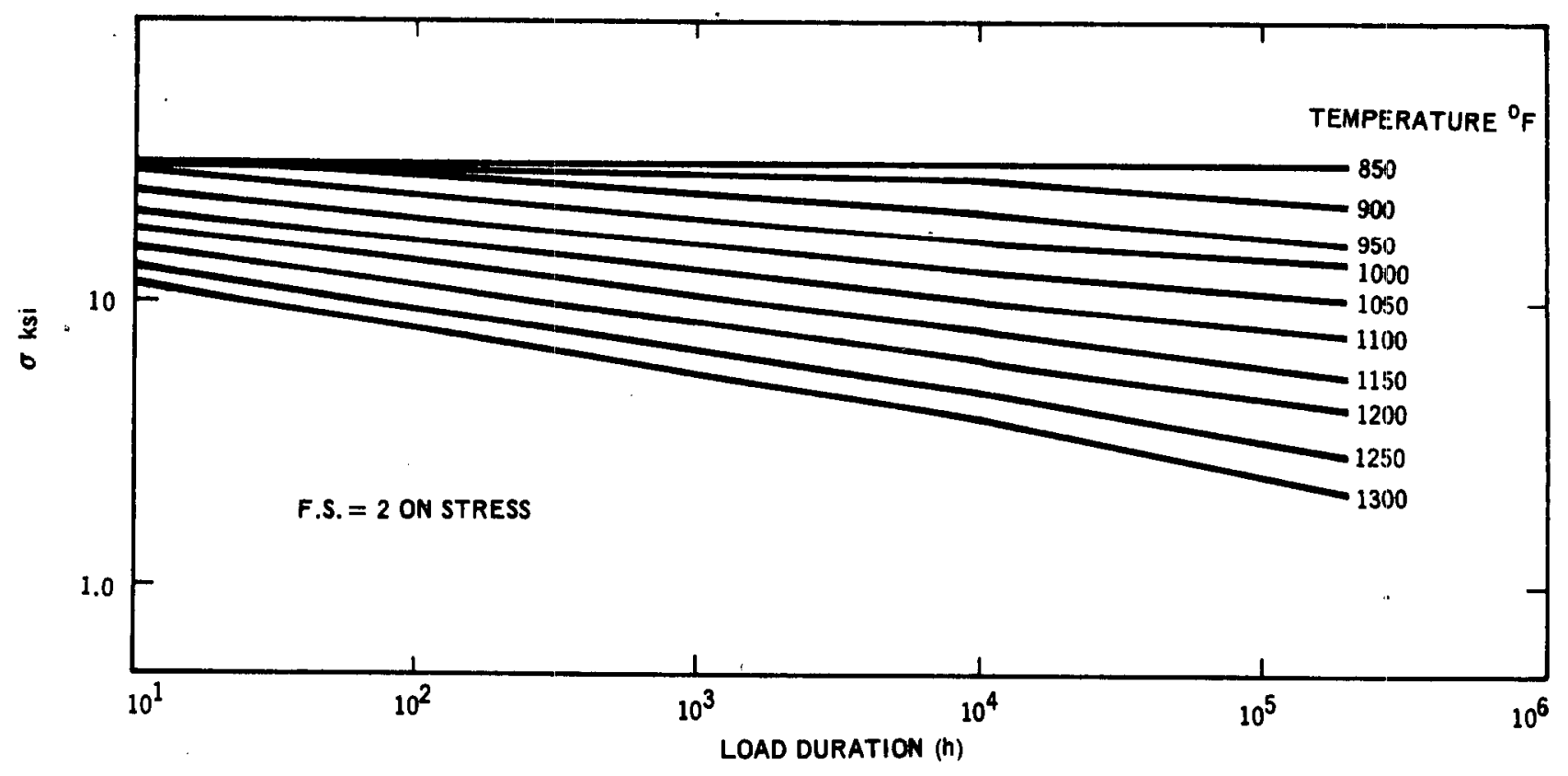

Figure 2-8B. Design Stress Rupture Curves for Type-316 Austenitic Stainless Steel 
It should be pointed out here that an attempt has been made to incorporate some useful published information into the present criteria; namely, shakedown factors for radial nozzles in spherical pressure vessels. Although these factors are intended for low-temperature stress field, their applicability has been extended to the relatively higher temperature range after appropriate modifications were made.

The values of $K$, which define the stress intensity limits for the combination of primary membrane plus secondary stresses for temperatures below $900^{\circ} \mathrm{F}$ as shown in Table 2-1, merit some explanation. Although $90 \%$ of the yield strength of the candidate materials has been used as the basis for $S_{m}$, loads in excess of the limit load are permitted because these materials have no well-defined yield point but have strong, strain-hardening capabilities, and consequently, the $S_{m}$ value in the present situation can be considered as being no less than two-thirds of the "design yield strength." Since the maximum shakedown stress is two times the yield stress, the maximum value of $K$ then becomes $2 \times 2 / 3=3$. This maximum value is considered valid in these criteria for temperatures up to $800^{\circ} \mathrm{F}$. For a temperature range between 800 to $900^{\circ} \mathrm{F}$, linearly decreasing values have been assigned for $\mathrm{K}$. The reason for the provision of this transition is primarily due to the uncertainty of the shakedown phenomena for the creep range.

It should be noted here that the stress intensity limits for the stress categories, including bending or secondary stress at temperatures above $900^{\circ} \mathrm{F}$ as listed in Table 2-1, are relatively conservative as compared with the corresponding limits for the low-temperature range. The reason for this is not only to prevent rupture failure but also to guard against ratcheting due to thermal and mechanical transients.

\subsubsection{Deformation Limits}

The maximum accumulated inelastic strain $(\epsilon)$ at any time and at any location, caused by the combined effects of plasticity, creep, and stress relaxation under the cumulative result of all Normal and Upset Operation Conditions, is limited to the following values:

a. For parent materials:

$\epsilon \leqslant 0.01$ for membrane stresses $\left(\mathrm{P}_{\mathrm{m}}\right)$

$\epsilon \leqslant 0.02$ for combined membrane plus bending stresses $\left(P_{L}+P_{B}\right)$

$\epsilon \leqslant 0.04$ for combined membrane plus secondary stresses $\left(P_{L}+P_{B}+Q\right)$

b. For weld and heat-affected zone:

$$
\epsilon \leqslant 0.005
$$

\subsubsection{Creep-Fatigue Limitations}

For structural components under cyclic loadings without mean stress or strain, the fatigue life shall be predicted by the design curves as in Figures 2-1, and 2.2 for Types-304 and -316 stainless steels, respectively. These curves are based on a safety factor (F.S.) of 2 on strains and $\mathbf{2 0}$ on cycles. It may seem that using $\mathbf{2 0}$ for the factor of safety is too conservative. However, since the unirradiated material properties were used to obtain the present results, it is expected that the corresponding fatigue life for the components subject to high fluence will be considerably lower, and the use of such a large factor of safety is justified because it happens that the short-life portion of the established design curves is governed by such a factor.

If a structural component is subjected to a cyclic loading which yields a mean strain $(\epsilon$ ) (this mean strain may be caused by creep, thermal or mechanical effects, or inertia loads due to earthquakes), then the following linear law for creep-fatigue interaction shall be used for the determination of the combined effects due to individual or multiple loadings:

$$
\sum_{j}\left(\frac{\epsilon}{\epsilon_{f}}\right)_{j}+\sum_{k}\left(\frac{n}{N_{f}}\right)_{k} \leqslant 1,
$$

where

\footnotetext{
$\epsilon=$ mean strain due to loadings j,

$\epsilon_{\mathrm{f}}=$ allowable ductility at stress intensity of loadings $j$,

$\mathbf{n}=$ number of applied cycles of loadings $k$,

$\mathrm{N}_{\mathrm{f}}=$ number of design allowable cycles of loadings $\mathrm{k}$.
} 
To obtain a meaningful fatigue life estimate of components, it is suggested that an inelastic analysis be used as a basis for the evaluation of the strains, and the life shall be determined at least at one location where the mean and alternating strains are maximum.

Alternatively, the following expression may be used for the approximate prediction of lifetime of components using the design stress rupture curves shown in Figure 2-8:

$$
\sum_{j}\left(\frac{t}{T_{f}}\right)_{j}+\sum_{k}\left(\frac{n}{N_{f}}\right)_{k} \leqslant 1,
$$

where

$$
\begin{aligned}
t & =\text { time duration of loadings } j, \\
T_{f} & =\text { allowable time at a given stress intensity from loadings } j .
\end{aligned}
$$

The definitions for $n$ and $N_{f}$ are the same as those for Equation (2-3), and the summation sign $(\Sigma)$ is for the multiple loading condition.

\subsubsection{Instability under Compressive Loadings--Buckling}

The utilization of charts of Article 1-11 of the Code and Appendix B of the present document shall be restricted to temperature conditions no greater than $800^{\circ} \mathrm{F}$. For temperatures higher than $800^{\circ} \mathrm{F}$, appropriate elastic, plastic, or creep buckling analysis or experimental evaluation shall be performed for the evaluation of structural stability, using the following factors of safety against buckling for both cases:

$$
\begin{aligned}
& \text { Load Factor of Safety }=\frac{\text { Load at Instability }}{\text { Applied Load }} \geqslant 2.0 . \\
& \text { Time Factor of Safety }=\frac{\text { Time to Instability }}{\text { Applied Load Duration }} \geqslant 2.0 \text {. }
\end{aligned}
$$

For columns and cylindrical shells of constant thickness, approximate lifetime for simple loadings may be estimated from the information given in Appendices $G$ and $H$. 
$\odot$ 


\section{STRUCTURAL EVALUATION OF CORE COMPONENTS}

Criteria for evaluation of core components have been established as a design guide. There are much less data available on the material properties and material behavior of highly irradiated stainless steel compared with unirradiated stainless steel, and the rate at which material data can be developed is slow due to the time involved in accumulating fluence in existing reactor facilities. The criteria are the best judgment of the design rules to apply with the data available. As more information on material behavior becomes available, revisions to the criteria will undoubtedly be required. In their present form, the criteria are used as a guide to judge the possible integrity of core components and to select and evaluate space requirements and design alternatives in layout, sizing, and support of core components. Three factors complicate the structural design of core components in addition to the factors common to unirradiated and moderately irradiated components at high temperature:

a. Swelling

In a fast-flux environment, stainless steel swells because of metallurgical structural changes under neutron bombardment. For a neutron fluence corresponding to a few months operation, parts of the reactor are subjected to swelling that is much larger than the expansion associated with operating at elevated temperature. Since this is a temperature-dependent phenomenon and since there are flux and temperature gradients in the core region, this phenomenon has the potential for inducing significant stresses in reactor components. It is considered analagous to thermal expansion for stress analysis.

b. Embrittlement

As a function of neutron fluence and temperature, stainless steels lose ductility so that after a few weeks of operation, parts of the core would have a ductility (tensile elongation) less than $10 \%$, and limited data indicate this continues to decrease with fluence to very low values. Further development is needed to characterize this more precisely; however, the review presented in Appendix $I$ indicates the range of ductility that may be available. The criteria attempt to recognize this characteristic of material behavior. Figure 3-1 is included for perspective. It shows the rate at which ductility reduces to $10 \%$ in the reference design of the G.E. Demonstration Plant. Fuel assemblies are planned to experience two or three operative cycles, and peripheral assemblies three to six cycles.

c. Irradiation-Induced Creep

Under stress and high irradiation at temperatures below the thermal creep range, deformation has been observed, which has been designated irradiation-induced creep. This is generally believed to be nondamaging in the sense of using up available strain to failure and in this criteria, is not added to thermal creep, elastic, and cyclic strains in determining accumulated damage. It must be considered in determining gross deflection and distortion of components.

\subsection{DEFINITION OF LOAD CONDITIONS}

Load conditions are defined in the same categories as in subsection 2.1, which is based upon Reference 1 ; i.e., Normal, Upset, Emergency, and Faulted.

\subsection{BASIS FOR THE ALLOWABLE STRESS INTENSITY $\left(\mathbf{S}_{\mathbf{m}}\right)$}

Since core components pass from the ductile condition to an embrittled condition, two sets of bases are established, with the dividing line between them set at the condition at which the uniform elongation in a tensile test drops to $10 \%$. The two regions are referred to as the ductile region and quasi-brittle region.

a. Ductile Region $-\mathbf{S}_{\mathbf{m}}$ is the smallest of:

- Ninety percent of yield strength of the material at metal temperature when unirradiated, with a linear transition to two-thirds the irradiated yield strength at the quasi-brittle point.

- Fifty percent of the unirradiated ultimate strength of the material at the metal temperature.

- Eighty percent ${ }^{*}$ of the minimum stress to cause rupture at the metal temperature and fluence.

b. Quasi-Brittle Region $-S_{m}$ is the smallest of:

- Two-thirds of the irradiated material vield strength at the metal temperature and fluence.

- One-third of the irradiated ultimate strength at the metal temperature and fluence.

- Eighty percent ${ }^{*}$ of the minimum stress to cause rupture at metal temperature and fluence in the design life of the component.

\footnotetext{
* The life fraction rule discussed in subsection 3.2.1 shall apply to varying primary stresses and/or varying temperatures.
} 


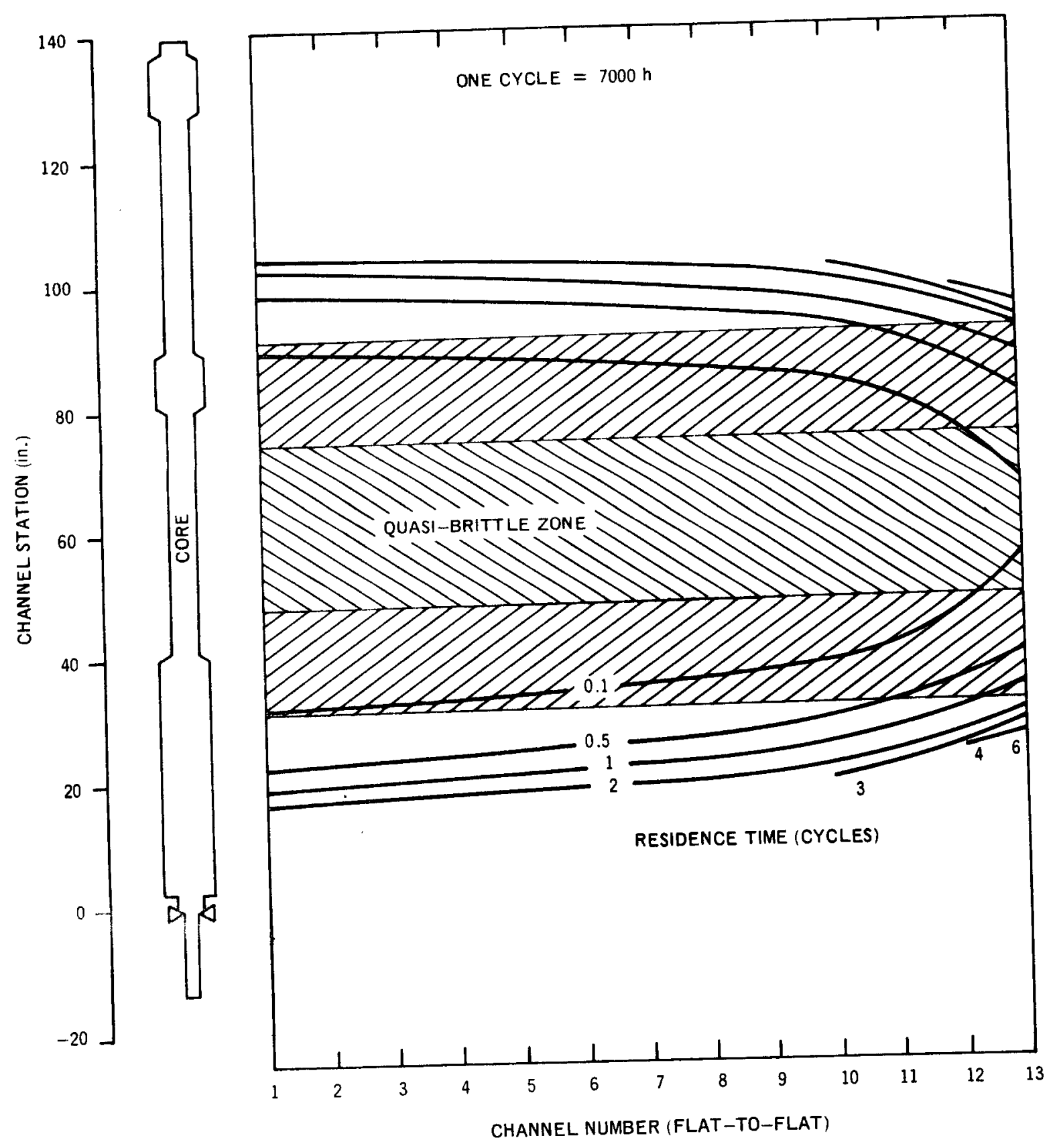

Figure 3-1. Boundaries for Quasi-Brittle Material for Various Residence Times 
The quantity " $\mathrm{S} m$ " is the design stress intensity value, which has different " $R$ " coefficients for the four types of loading conditions. The definition of " $R$ " and its values are shown in Table 3-1.

All stresses that are not time dependent are calculated on an elastic basis for comparison with limits in these criteria, but in time-dependent stress situations such as caused by swelling, stress relaxation by creep is permitted. Advantage should be taken of the fact that yield and ultimate strength increase with irradiation. The fact that ductility. as expressed in uniform elongation data, decreases with irradiation is also accounted for (see Figure 3-2). These data were recently developed, as reported in Appendix $\mathrm{I}$.

Primary stress intensities, $P_{m}, P_{L}$, and $P_{B}$, are those which are not self-limiting and are required to balance external forces and satisfy laws of equilibrium. They are induced by mechanical loads which are not relieved as a result of deformation under the load, and those thermal or swelling-induced loads for which relief would induce excessive deformation due to elastic followup.

Secondary stresses, $\mathrm{O}$, are those which are self-limiting and which are necessary to satisfy continuity of the structure. They may be caused by mechanical loads, thermal growth restraint, and irradiation swelling restraints.

Peak stresses are highly localized additions to the primary and secondary stresses, which account for local stress concentrations or nonlinear thermal gradients. Peak stresses do not cause noticeable structural distortion, and are employed only in a fatigue analysis.

Thermal ratchet stress is a sustained membrane stress which, when combined with a cyclic thermal stress, will produce a cyclic growth.

Stress intensity is defined as the difference between the algebraically largest principal stress and the algebraically smallest principal stress at a given location. The stress intensity is numerically equal to twice the maximum shear stress and is directionless.

Table 3-1

\section{DETERMINATION OF ALLOWABLE STRESS INTENSITY}

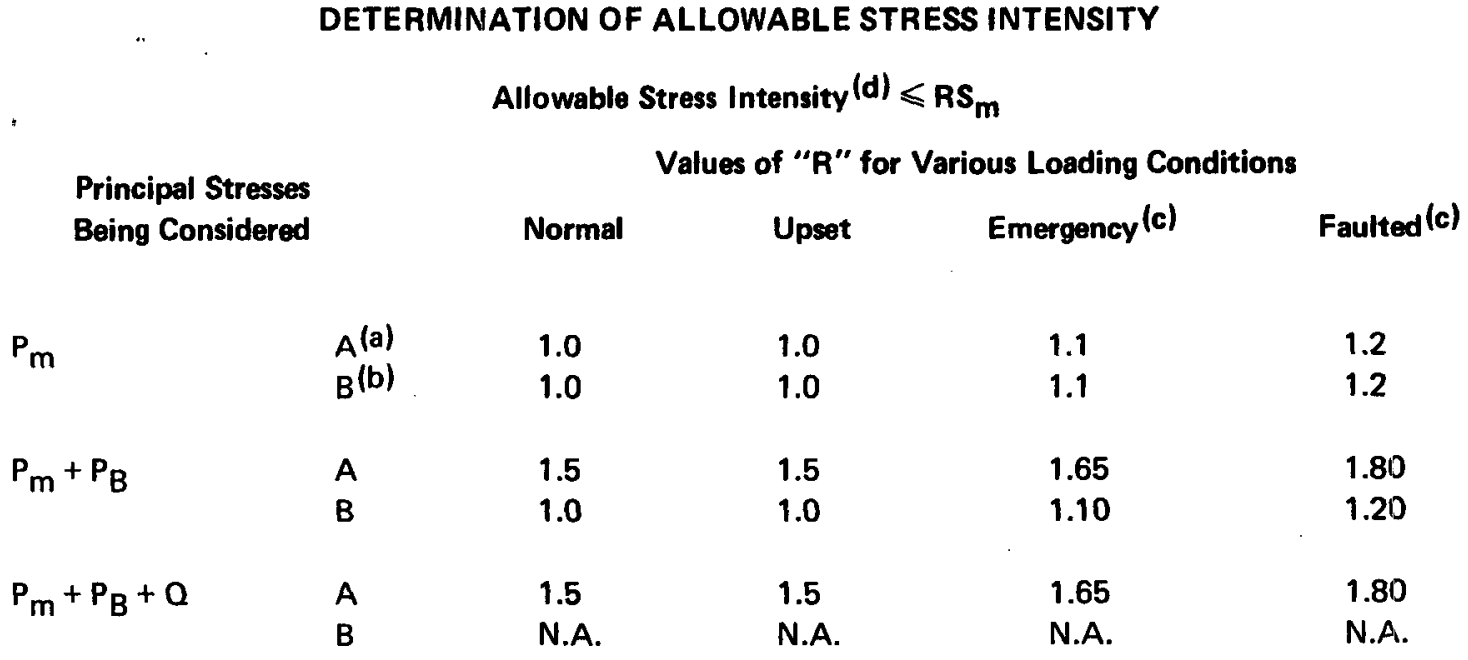

Notes:

(a) "A" signifies $\sigma_{\text {yield }}$ and $\sigma_{\text {ultimate }}$ criterion

(b) "B" signifies minimum stress to cause rupture criterion

(c) $10 \%$ and $20 \%$ increases are tentative selections for emergency and faulted conditions

(d) See Table 3-2 for delineation of $S_{m}$ and the various criterion definitions 
GEAP-13719

Table 3-2

\section{SUMMARY OF CORE STRUCTURAL DESIGN CRITERIA}

\section{Mode of Loading \\ Design Stress \\ Intensity \\ $\mathrm{S}_{\mathrm{m}}$}

Fatigue

Strain

Buckling (Elastic, Elastic-Plastic, or Creep)
Stress or Strain Criteria

\begin{tabular}{|c|c|c|c|}
\hline (Less & $\begin{array}{l}\text { Quasi-Brittle } \\
\text { than } 10 \% \text { Elongation) }\end{array}$ & & Ductile \\
\hline 0.67 & $\sigma_{\text {yield }}$ & 0.90 & $\begin{array}{l}\sigma_{\text {yield }} \text { (when } \\
\text { unirradiated and linear } \\
\text { transition to brittle point) }\end{array}$ \\
\hline 0.33 & $\sigma_{\text {ultimate }}$ & 0.50 & $\sigma_{\text {ultimate }}$ \\
\hline 0.80 & $\begin{array}{l}\text { of minimum stress } \\
\text { to cause rupture }\end{array}$ & 0.80 & $\begin{array}{l}\text { of minimum stress to } \\
\text { cause rupture }\end{array}$ \\
\hline
\end{tabular}

See subsection 3.4

Obtain percent allowable uniaxial strain from Figure 3-2 for a given fluence and temperature. Multiply this value by the fraction obtained in Figure 3-3 for the biaxiality ratio at the point of interest. This is allowable combined plastic strain and thermal creep strain. Elastic strain from irradiation-induced creep and uniform swelling strain are considered to be nondamaging.

\section{$\leqslant 800^{\circ} \mathrm{F}$ Use Article $1-11$ of the ASME Boiler and Pressure Vessel Code \\ $>800^{\circ} \mathrm{F}$ Apply the code charts and formulas or use a suitable method of analysis or model testing but use a factor of safety of $\mathbf{2 . 0}$ minimum for loads and duration of load}

See Table 3-1 for application of $S_{m}$.

\subsubsection{Time-Varying Primary Stresses}

When primary stresses that are subject to stress-rupture criteria vary with time, a summation of time rațios is calculated:

$$
\text { allowable } \Sigma \frac{t_{s}}{t_{a}} \leqslant 1.00
$$

where

$t_{s}=$ the time spent at a particular stress intensity and temperature level, and

$t_{a}=$ the allowable time spent at the particular stress intensity and temperature level based on $X \%$ of the stress to cause rupture, where the percent is obtained from Tables 3-1 and 3-2.

\subsection{STRAIN LIMITS}

Due to the variation in ductility with neutron fluence, a single total accumulated strain from plastic deformation, thermal creep, and irradiation-induced creep is not appropriate. As reported in Appendix I, a review has been made of the limited data available on the strain at failure under varying conditions of strain rate, fluence, and stress-biaxiality, 


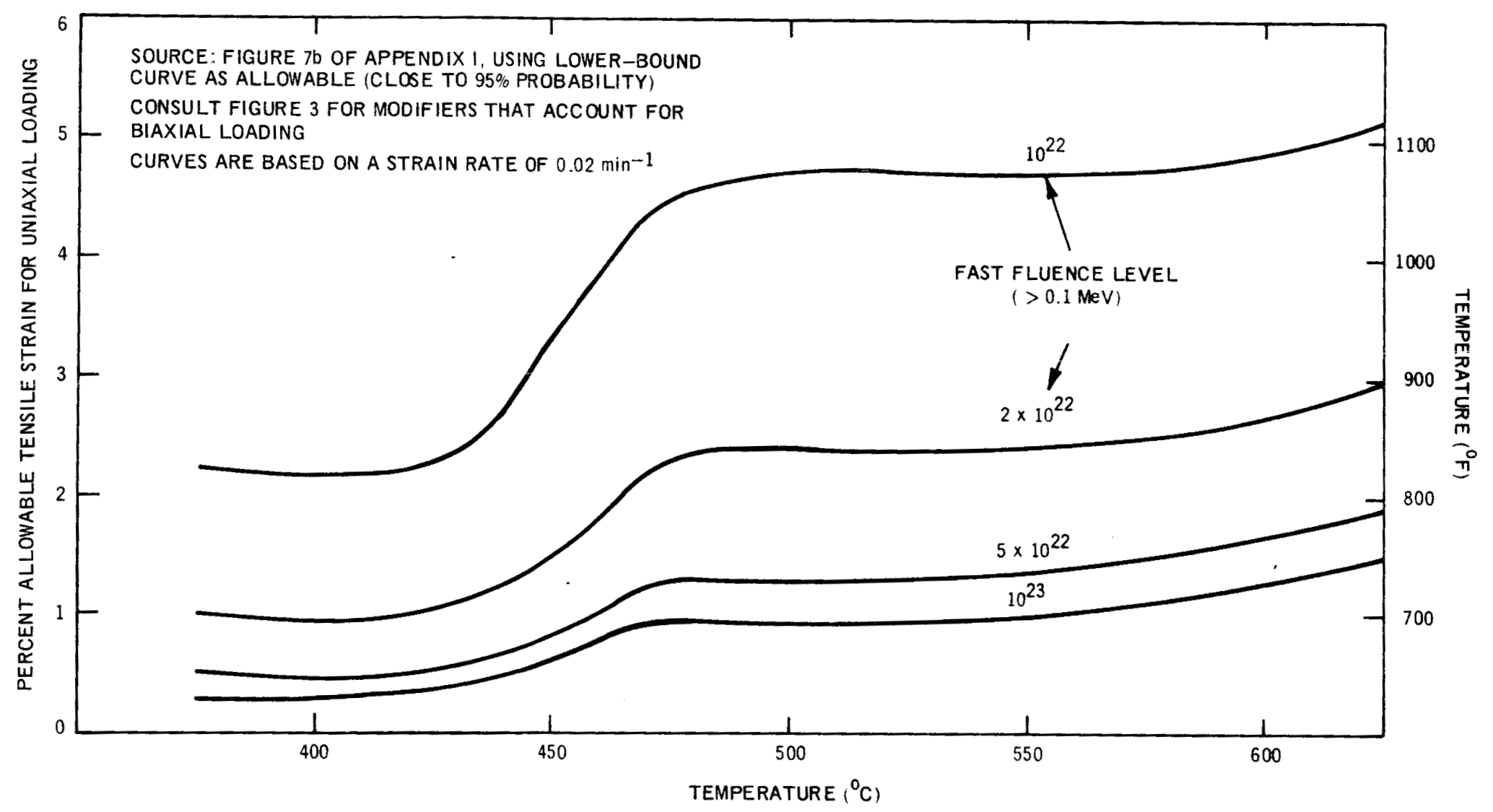




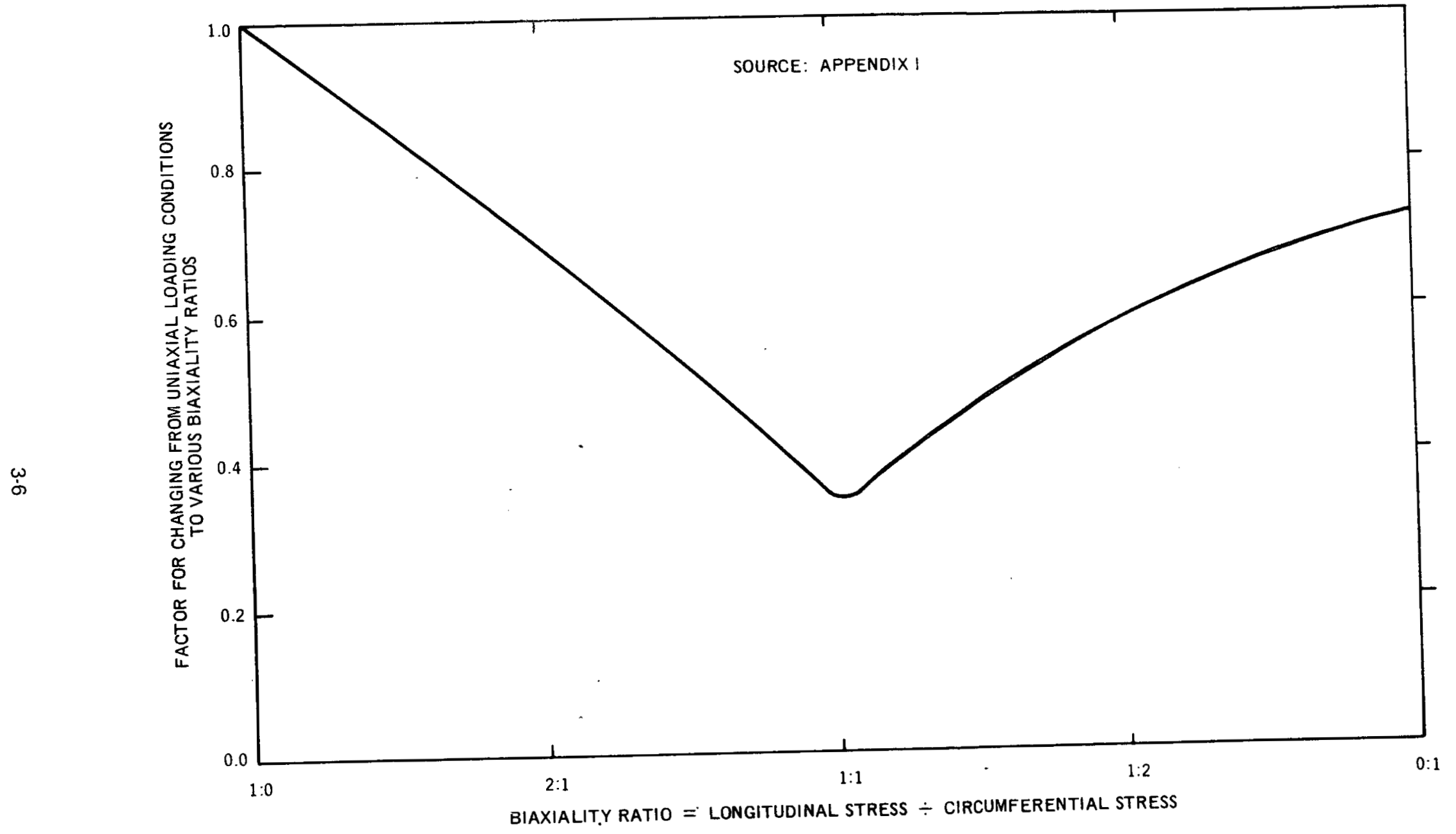

Figure 3-3. Correction Factors for Various Biaxiality Ratios

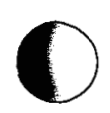


and from this, Figure 3-2 was developed. The dependence on strain rate was eliminated by assuming, for application, that a failure strain at a strain rate of 0.02 per minute applies for all strain rates. This appears to be conservative for strain rates lower and higher than $0.02 \mathrm{per} \mathrm{min}$. The basic stress limits are established to minimize the probability of failure from excessive strain due to creep, however, combined with primary and secondary stresses. The criteria are based upon yield strength so an accounting of accumulated strain is required to verify that, at high temperature, time-dependent effects do not override the short-time effects.

The recommended method for considering strains at various times in the life of the section of interest utilizes a strain damage index. Each strain limit that is calculated for the section of interest at each fluence value should be used as a normalizing value for the amount of strain calculated to occur during the time period associated with the fluence value. Rejection will be assumed to occur when the sum of these fractions totals one or greater. For example, consider an imaginary component that receives step increment strains of $1 \%$ at fluences of $10^{21}, 10^{22}$, and $10^{23}(\mathrm{E}>0.1 \mathrm{MeV}$ ), and that the allowable strains determined for the component from Figures $3-2$ and $3-3$ are $10 \%, 5 \%$ and $1.5 \%$. The fraction of available strain used at each fluence value, and the total life fraction used as determined by this damage index, are as follows:

$$
\begin{array}{cccc}
10^{21} \mathrm{n} / \mathrm{cm}^{2} & 10^{22} \mathrm{n} / \mathrm{cm}^{2} & 10^{23} \mathrm{n} / \mathrm{cm}^{2} & \text { Total } \\
\frac{1 \%}{10 \%}+\frac{1 \%}{5 \%}+\frac{1 \%}{1.5 \%}=0.9667
\end{array}
$$

\subsection{FATIGUE AND FATIGUE-CREEP INTERACTION}

The degree to which fatigue and fatigue-creep interaction will be significant in the evaluation of short-life core components has not been fully explored for the actual transients to be expected in an operating reactor. The same principles and formulations as discussed in Section 2 apply; however, test data on highly irradiated material are not currently available to select the appropriate material constants for the generalized fatigue equation. Due to irradiation embrittlement, the amount of cyclic plastic strain that can be tolerated is expected to be much lower than for unirradiated material. The stress limits established in subsection 3.2, coupled with an avoidance to the extent possible of stress risers in the components, should minimize the potential for fatigue failures. Further data are required on which to establish criteria, as formulated in Section 2.

\subsection{THERMAL RATCHET}

The potential for thermal ratcheting is a result of the combination of a steady primary membrane stress with a cyclic secondary stress. The limits on $P_{m}+P_{B}+Q$ in Table 3-1 are established to preclude this. 
$\bullet$

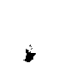




\section{RECOMMENDATIONS FOR FURTHER RESEARCH AND DEVELOPMENT}

Although the present version of the stress criteria is of an interim nature, it would serve as a reasonably suitable supplement to the current code for the design of long-life components at elevated temperatures, provided that methods of inelastic and creep-fatigue interaction analyses are established and basic material data are available. To fulfill the needs of the present design criteria, therefore, it is recommended that the following further research and development efforts be conducted.

Because the development need is so immediate and some of the tests are extremely difficult and time consuming to conduct, a priority system is established. The number in parentheses indicates the priority, with 1 being the highest and 3 the lowest. It is recommended that tests with priority 1 be conducted first because it is this information that wilt be the most immediate benefit for use in the G.E. Demonstration Plant. (Note that several parameters may be outlined for each R\&D effort. For example, three parameters may be outlined, such as temperature, fluence, and stress. The highest priority would be one in which a 1 is listed after each parameter.)

a. Material Data

The applicable austenitic stainless steel materials for evaluation are listed as follows: Type 304 (1), $321(1)$, 316 Cold Worked 20\% (2), 316 Annealed (1), 347 (3), PE 16 (British Alloy) (2).

All the foregoing materials will be immersed in sodium, ranging from stagnation to flow velocities of $25 \mathrm{ft} / \mathrm{sec}$. Sodium purity requirements are per RDT Std. M13-1T Reactor Grade Sodium (cold-trapped at $275^{\circ} \mathrm{F}+25^{\circ} \mathrm{F}$ ). An evaluation should be made relative to the trade-offs between the cost of obtaining the various information required in sodium environments versus the usefulness of the information obtained in inert gases on air environment for the following items.

- Creep curves-total strain versus time for unirradiated staintess steels listed above at the following stress levels:

$\begin{array}{cc}\begin{array}{c}\text { Temperature } \\ \left({ }^{\circ} \mathrm{F}\right)\end{array} & \begin{array}{c}\text { Stress Levels } \\ \text { (ksi) }\end{array} \\ 800(3) & 25(3), 35(2), 45(1), 55(1) \\ 900(2) & 20(3), 30(2), 40(1), 50(1) \\ 1000(1) & 15(2), 25(1), 35(1), 45(1) \\ 1100(1) & 10(2), 20(1), 30(1), 40(1)\end{array}$

- Uniform and total elongations as functions of temperature, fluence, strain rates, and mode of loading for the following conditions:

\begin{tabular}{clcl}
$\begin{array}{c}\text { Temperature } \\
\left({ }^{\circ} \mathrm{F}\right)\end{array}$ & \multicolumn{1}{c}{$\begin{array}{c}\text { Total } \\
\text { Fluence }\end{array}$} & $\begin{array}{c}\text { Strain } \\
\text { Rate } \\
\text { in./in./sec }\end{array}$ & $\begin{array}{l}\text { Mode of } \\
\text { Loading }\end{array}$ \\
$800(1)$ & $0 \mathrm{nvt}(1)$ & $100(1)$ & Monotonic \\
$900(3)$ & $10^{21} \mathrm{nvt}(1)$ & $10(3)$ & Monotonic \\
$1000(1)$ & $20 \times 10^{22} \mathrm{nvt}(1)$ & $1(3)$ & Monotonic \\
$1100(1)$ & & $0.1(3)$ & Monotonic \\
& & $0.01(1)$ & Monotonic
\end{tabular}

- Low-cycle fatigue properties (less than 10,000 cycles) for the following conditions:

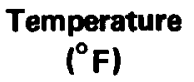

$900(2)$

$1000(1)$

$1100(1)$

\section{Total Strain Range (\%)}

$0.5(1)$

$1.0(1)$

$2.0(1)$

$3.0(1)$

\section{Strain Rate}

$\left(\sec ^{-1}\right)$

$4.5 \times 10^{-3}$ (1)

$4.5 \times 10^{-4}$ (1)

$4.5 \times 10^{-5}$ (1) 
- Uniaxial and biaxial stress rupture properties for the following conditions:

$\begin{array}{ll}\begin{array}{c}\text { Temperature } \\ \left({ }^{\circ} \mathrm{F}\right)\end{array} & \text { Fluence Total } \\ 800(3) & 0 \text { nvt (1) } \\ 900(2) & 10^{21} \text { nvt (1) } \\ 1000(1) & 20 \times 10^{22} \text { nvt (1) } \\ 1100(1) & 20 \times 10^{22} \text { nvt (1) }\end{array}$

- General effect of hold time on the effect of Creep Fatigue Interaction. (1)

- General evaluation of the Fatigue Creep Interaction problem at $1000^{\circ} \mathrm{F}$, considering Types-304, -316 , and -321 stainless steels. (1)

- Determine which of the following strains contribute to failure and the relative effect of each (Types-321 and $-31620 \%$ cold worked steels only): (1)

- Volumetric metal swelling

- Irradiation-induced creep

- Thermal creep

- Plastic effects

b. Weld Tests

Although the criteria were not specifically written for welds, it is known that the welds are less ductile than the parent metal and may be more limiting in establishing deformation limits. It is highly recommended that welds of 304,321 , and 316 material be examined relative to establishing deformation limits and the fatigue creep interaction problem. Deformation limits shall be classified into three categories: membrane, bending (linear gradient through thickness), and peak. (1)

c. Model Tests

- Verification of shakedown loads and their corresponding ratcheting phenomena for nozzle attachment to pressure vessels at elevated temperatures (nozzle connection to cylindrical shell) using small-scale models and representative thermal and mechanical loads. (1)

- Determination of critical load and lifetimes of columns and cylinders under compression and external pressures at elevated temperatures $\left(1100^{\circ} \mathrm{F}\right) .(3)$

d. Development of New Analytical Tools

- Based on the available information and results obtained in a., Material Data, evaluation and derivation of a suitable set of empirical equations for creep (and relaxation) curves for the Types-304 and -316 austenitic stainless steels.

- Derivation of a system of constitutive equations for the candidate materials and associated field equations for the elastic-plastic-creep analysis of both thin-and thick-walled shells, using the Gaussian general curvilinear coordinate system.

- Development of a digital computer program for the inelastic and fatigue analyses, for sensitivity studies, for the prediction of shakedown, and for thermal and mechanical ratcheting phenomena for the structures under consideration. Although finite element digital programs are being developed, it is felt that the development of a similar program, using the two-dimensional finite difference numerical method and the degenerated three-dimensional theory of elasticity should also be carried out simultaneously as a back-up tool, and correlations should be made between the results obtained by this method and those obtained from model tests and finite element techniques. (1)

- A computer code for the analysis of hollow beams subjected to lateral loads and variable internal pressure, which incorporate both creep and plasticity effects. The code should have the capacity to introduce discrete average temperature, delta temperature, average flux, and delta flux at each axial node point. It should accept equations for irradiation-induced creep, thermal creep, and swelling of stainless steel in separate routines. (1) 
- A computer code for the analysis of interacting body force on loading pads for fuel channels in Demonstration Plant size core to determine load redistributions. The program should accept body forces that vary with times, gaps between pads, and the load pad stiffness, and produce the detailed loads at the contacting surface. Note that the modification of the current operational code, SPACES, may be an alternative approach to developing a new digital program (see item e.). (1)

e. Updating and Modification of Existing Computer Codes

- Modification of the two-dimensional finite difference and finite element digital program, TOSS, for the analysis of perforated circular plates and cylinders, which will incorporate both creep and plasticity effects. (1)

- Updating the operational program, RMONIC, for the creep buckling analysis of cylinders under axial load and external pressure. (2)

- Modification of the operational digital program, SPACES, for the analysis of redundant structures composed of irregular core supporting components and subjected to time-dependent surface tractions and thermal loads. (1)

f. Extension Effort for G.E. Stress Criteria

- Comparison of the G.E. interim criteria with those for FFTF and Code Case 1331-5 as applied to the G.E. Demonstration Plant. (1)

- Updating and improvement of the present version of the design criteria, particularly in the establishment of suitable methods for the prediction of creep and fatigue interaction of stainless steels at elevated temperatures. (1) 
-

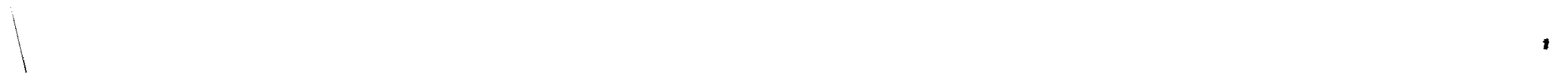

○ 


\section{BIBLIOGRAPHY}

1. Criteria of the ASME Boiler and Pressure Vessel Code for Design bV Analysis in Sections III and VIII, Division 2 , ASME, 1968.

2. Boiler and Pressure Vessel Code, Section VIII, Division 1 and Sections III and VIII, Division 2 ASME, 1971.

3. Snow, A. L., Interim Supplementary Structural Design Criteria for Elevated Temperatures, FRA-152, Rev. 3, 1970.

4. Smith, G. V., An Evaluation of the Yield, Tensile, Creep, and Rupture Strengths of Wrought 304, 316, 321 and 347 Stainless Stee/s at Elevated Temperatures, ASTM Data Series DS 5S2, 1969.

5. Creep Rate vs. Total Creep as a Basis for Design, ASM Publication No. P9-101, 1969.

6. Coffin, L. F., Jr., A Generalized Equation for Predicting High-Temperature, Low-Cycle Fatigue, Including Hold Times, Report No. 69-C-401, General Electric, 1969.

7. Comprelli, F. A., et al., Materials Mechanical Property Limits for Demonstration Plant, Memo No. 69-6, BRDO, General Electric, Sunnyvale, Ca., 1969.

8. Baker, E. H., et al., Shell Analysis Manual, N68-24802, North American Aviation, Downey, Ca., 1968.

9. Samuelson, L. A., Creep Buckling of Imperfect Circular Cylindrical Shells under Non-Uniform External Loads, Report HF-1327:4, The Aeronautical Research institute of Sweden, Stockholm, 1970.

10. Rabatnov, Y. N., Creep Problems in Structural Members, John Wiley \& Sons, New York, 1969.

11. Leckie, F. A. and Penny, R. K., "Shakedown Loads for the Radial Nozzles in Spherical Pressure Vessels" International Journal of Solids and Structures, Vol. 3, 1967.

12. Tsui, E. Y. W., Stresses in Shells of Revolution, Pacific Coast Publishers, Menlo Park, 1968.

13. Okszak, W. and Sawczuk, A., Inelastic Behavior in Shel/s, P. Noordhoff, Ltd., Groningen, the Netherlands, 1967.

14. Hult, Jan, Creep in Engineering Structures, Blaisdell Publishing Co., Waltham, Mass., 1966.

15. Berling, J. T. and Slot, T., Effect of Temperature and Strain Rate on Low-Cycle Fatigue Resistance of A/S/ 304 , 316 and 348 Stainless Steels, GEMP-642, General Electric, 1968.

16. Conway, J., Stress-Rupture Parameters: Origin, Calculation and Use, Gordon \& Breach, Science Publishers, New York, 1969.

17. Tsui, E. Y. W. and Burns, A. B., "Optimum Thickness Transitions for Cylindrical Pressure Vessels with Hemispherical Heads," J. Spacecraft AlAA, June 1967.

18. Tsui, E. Y. W., et al., Element Stiffness Matrices of Thick-Walled Orthotropic Shells with Applications, Proceedings of the First Symposiom of Applications of Finite Element Methods in Civil Engineering, Vanderbilt University, Tennessee, 1968.

19. Timo, D. P., Typical Fatigue Problems and Fixes in Large Steam Turbines, Report No. DF70-LS-42, General Electric, 1970.

20. Coffin, L. F., Jr., and Goldhoff, R. M., Predictive Testing in Elevated Temperature Fatigue and Creep: Status and Problems, Report No. 71-C-114, General Electric, 1971.

21. Proposed Code Case 1331-5 (ASME B\&PV Code, Section (II) for Nuclear System Components at Elevated Temperatures, March 1971 Revisior.

22. Miller, D. R., "Thermal Stress Ratchet Mechanism in Pressure Vessels," Journal of Basic Engineering, ASME, 1959.

23. Slember, R., Developments in High-Temperature Design Criteria, United Nuclear Corporation, Research and Engineering Center, Elmsford, N. Y., 1971.

24. Wei, B. C., "Improved High Temperature Design Methods and Criteria Required by LMFBR's," presented at ASME Pressure Vessel and Piping Meeting, September 1970. 
- 


\section{APPENDIX A. ANALYSIS OF CONICAL SHELLS}

In this appendix, formulas are given for stresses and deformations in conical shells subjected to internal pressure. These formulas are provided for low-temperature applications wherein creep effects have not been considered. Formulas are also given for bending analysis of conical shells under the action of uniformly distributed edge forces and moments.

\section{A.1 NOMENCLATURE AND SIGN CONVENTION}

The symbols and sign convention adopted in this article are defined as follows:

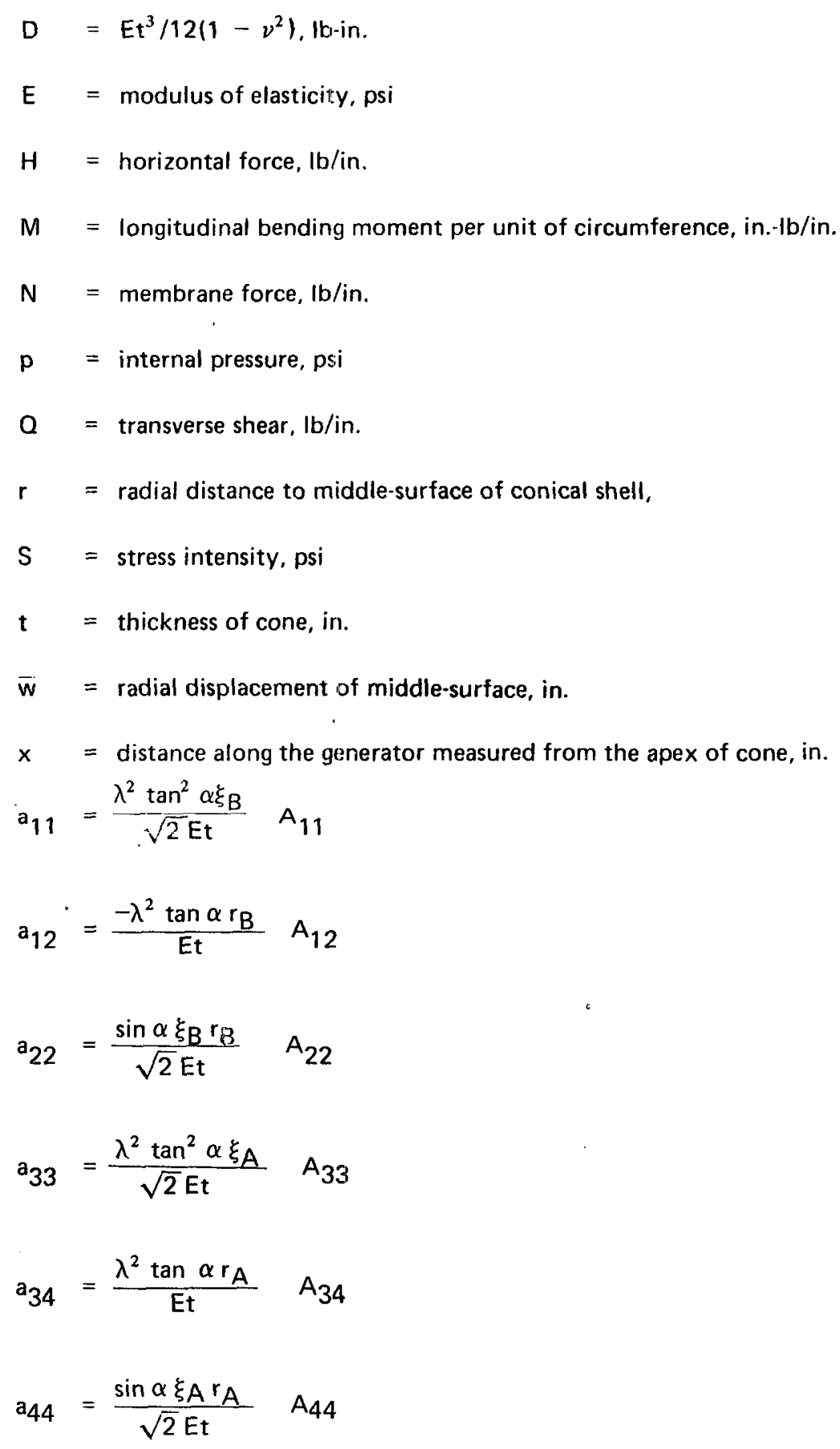




$$
\begin{aligned}
& a_{13}=\frac{\lambda^{2} \tan ^{2} \alpha \xi_{A}}{\sqrt{2} E t} A_{13} \\
& a_{23}=\frac{-\lambda^{2} \tan \alpha r_{A}}{E t} A_{23} \\
& a_{14}=\frac{\lambda^{2} \tan ^{2} \alpha r_{A}}{E t} A_{14} \\
& a_{24}=\frac{-\sin \alpha \xi_{B} r_{A}}{\sqrt{2} E t} A_{24} \\
& a_{31}=r_{B} a_{13} / r_{A} \\
& a_{32}=r_{B} a_{23} / r_{A} \\
& a_{41}=r_{B} a_{14} / r_{A} \\
& a_{42}=r_{B} a_{24} / r_{A} \\
& b_{11}=B_{11} \\
& \mathrm{~b}_{12}=\frac{\cos \alpha}{2 \lambda^{2}} \mathrm{~B}_{12} \\
& b_{21}=\frac{\lambda^{2} \tan \alpha}{E t} \quad r_{B} B_{21} \\
& b_{22}=\frac{\sin \alpha \xi_{B} r_{B}}{\sqrt{2} E t} B_{22} \\
& \mathrm{~b}_{33}=\mathrm{B}_{33} \\
& b_{34}=\frac{\cos \alpha}{2 \lambda^{2}} \quad B_{34} \\
& b_{43}=\frac{-\lambda^{2} \tan \alpha}{E t} r_{A} B_{43} \\
& b_{44}=\frac{\sin \alpha}{\sqrt{2} E t} \xi_{A} r_{A} B_{r r} \\
& \alpha=\text { semi-apex angle of cone }
\end{aligned}
$$




$$
\begin{aligned}
& \lambda^{4}=E_{t} \cot ^{2} \alpha / D \\
& \theta \quad=\text { rotation of middle-surface, radian } \\
& \xi \quad=2 \lambda \sqrt{x} \\
& \chi \quad=\xi_{A} / \xi_{B} \\
& \nu \quad=\text { Poisson's ratio } \\
& \sigma_{t} \quad=\text { tangential (circurnferential) stress component, psi } \\
& \sigma_{\ell} \quad=\text { longitudinal (meridional) stress component, psi } \\
& \sigma_{r} \quad=\text { radial stress component, psi }
\end{aligned}
$$

The sign convention arbitrarily chosen for the analysis of conical shells in this appendix is as indicated in Figure A-1.

\section{A.2 PRINCIPAL STRESSES AND STRESS INTENSITIES DUE TO INTERNAL PRESSURE}

The formulas for principal stresses and stress intensities presented in this subsection include the loading effects of internal pressure only, and exclude the effects of all structural discontinuities.

\section{A.2.1 Principal Stresses}

According to the thin-shell theory, the principal stresses developed at any point in the wall of a conical shell at any location along the generator, $x$, due to internal pressure are given by the following formulas:

$$
\begin{aligned}
& \sigma_{1}=\sigma_{\mathrm{t}}=\mathrm{p} \times \tan \alpha / \mathrm{t} \\
& \sigma_{2}=\sigma_{\mathrm{s}}=\mathrm{p} \times \tan \alpha / 2 \mathrm{t} \\
& \sigma_{3}=\sigma_{\mathrm{r}}=0 .
\end{aligned}
$$

\section{A.2.2 Stress Intensity}

The general primary membrane stress intensity developed across the thickness of a conical shell due to internal pressure is given by

$$
\mathrm{S}=\mathrm{px} \tan \alpha / \mathrm{t} \text {. }
$$




\section{A.3 BENDING ANALYSIS FOR UNIFORMLY DISTRIBUTED EDGE LOADS}

The formulas in this paragraph describe the behavior of a conical shell when subjected to the action of bending moments, $M$ inch-pounds per inch of circumference, and forces, $H$ pounds per inch of circumference, uniformly distributed at the edges and acting at the mean radius of the shell. The behavior of the shell due to all other loadings must be evaluated independently and combined by superposition.

\section{A.3.1 Edge Rotations and Displacements in Terms of Edge Loads}

a. The rotations $\theta_{B}$ and $\theta_{A}$, and radial displacements $\bar{w}_{B}$ and $\bar{w}_{A}$, developed at the edges of a conical shell as shown in Figure $A-1$, and sustaining the action of edge loads $M_{B}, M_{A}, H_{B}$ and $H_{A}$ are given by the following formulas:

$$
\begin{aligned}
& \theta_{B}=a_{11} M_{B}+a_{12} H_{B}+a_{13} M_{A}+a_{14} H_{A} . \\
& \bar{w}_{B}=a_{21} M_{B}+a_{22} H_{B}+a_{23} M_{A}+a_{24} H_{A} . \\
& \theta_{A}=a_{31} M_{B}+a_{32} H_{B}+a_{33} M_{A}+a_{34} H_{A} . \\
& \bar{w}_{A}=a_{41} M_{B}+a_{42} H_{B}+a_{43} M_{A}+a_{44} H_{A} .
\end{aligned}
$$

In these formulas, $a_{11}, a_{12}$, etc., are expressed in terms of $A_{11}, A_{12}$, etc. The nondimensional values of these influence coefficients are shown in Figure A-2.

b. For conical shells of sufficient length, the loading conditions prescribed at one edge do not influence the displacements at the other edge; i.e., $a_{13}=a_{31}=a_{14}=a_{41}=a_{23}=a_{32}=a_{24}=a_{42}=0$.

Consequently, the foregoing formulas reduce to

$$
\begin{aligned}
& \theta_{B}=a_{11} M_{B}+a_{12} H_{B^{\prime}} \\
& \bar{w}_{B}=a_{21} M_{B}+a_{22} H_{B^{\prime}} \\
& \theta_{A}=a_{33} M_{A}+a_{34} H_{A}, \\
& \bar{w}_{A}=a_{43} M_{A}+a_{44} H_{A} .
\end{aligned}
$$

Figure A-3 shows the corresponding influence coefficients for this decoupled case.

\section{A.3.2 Moment and Radial Displacement in Terms of Loading Conditions at the Edges}

a. For a full or sufficiently long truncated conical shell, the variations of moment $M(\xi)$ and radial translation $\bar{w}(\xi)$ due to edge loads $M_{B}$ and $H_{B}$ are given by the following formulas:

$$
M(\xi)=b_{11} M_{B}+b_{12} H_{B} \text {. }
$$




$$
\bar{w}(\xi)=b_{21} M_{B}+b_{22} H_{B}
$$

where $b_{11}, b_{12}$, etc., are expressed in terms of $B_{11}, B_{12}$, etc. Values of these nondimensional influence functions are given in Table A-1.

b. For a sufficiently long truncated conical shell, the meridional moment $M(\xi)$ and radial displacement $\bar{w}(\xi)$ can be expressed in terms of edge loads $M_{A}$ and $H_{A}$, as follows:

$$
\begin{aligned}
& M(\xi)=b_{33} M_{A}+b_{34} H_{A^{\prime}} \\
& \bar{w}(\xi)=b_{43} M_{A}+b_{44} H_{A^{\prime}}
\end{aligned}
$$

where $b_{33}, b_{34}$, etc., contain the nondimensional influence functions whose numerical values are tabulated in Table A.2.

\section{A.3.3 Principal Stresses in a Conical Shell Due to Edge Loads}

The principal stresses in a conical shell due to edge loads at the outside and inside surfaces of shell at any meridional location, are given by the formulas:

$$
\begin{aligned}
& \sigma_{1}=\sigma_{t}(\xi)=E \bar{w}(\xi) / r \pm 6 \nu M(\xi) / t^{2}, \\
& \sigma_{2}=\sigma_{\ell}(\xi)= \pm 6 M(\xi) / t^{2}, \\
& \sigma_{3}=\sigma_{r}=0
\end{aligned}
$$

In these formulas where terms are preceded by a double sign, \pm , the upper sign refers to the outside surface of the cone and the lower sign refers to the inside surface. 
Table A-1

INFLUENCE FUNCTIONS FOR UNIFORM CONE: $B_{11}, B_{12}, B_{21}$, AND $B_{22}$

\begin{tabular}{rrrrrrrrrrrrr}
\multicolumn{3}{c}{$\xi_{\mathrm{B}}=10$} & \multicolumn{3}{c}{$\xi_{\mathrm{B}}=20$} & \multicolumn{3}{c}{$\xi_{\mathrm{B}}=30$} & \multicolumn{3}{c}{$\xi_{\mathrm{B}}=40$} \\
$\xi$ & \multicolumn{1}{c}{$\mathrm{B}_{11}$} & $\mathrm{~B}_{12}$ & $\xi$ & $\mathrm{B}_{11}$ & \multicolumn{1}{c}{$\mathrm{B}_{12}$} & $\xi$ & $\mathrm{B}_{11}$ & $\mathrm{~B}_{12}$ & $\xi$ & $\mathrm{B}_{11}$ & $\mathrm{~B}_{12}$ \\
0 & & & 10 & 0.0032 & -0.0425 & 20 & 0.0022 & -0.0450 & 30 & 0.0018 & -0.0513 \\
1 & 0.0131 & 0.1416 & 11 & 0.0041 & -0.0040 & 21 & 0.0031 & -0.0078 & 31 & 0.0027 & -0.0102 \\
2 & -0.0014 & 0.2758 & 12 & 0.0013 & 0.1249 & 22 & 0.0011 & 0.1386 & 32 & 0.0011 & 0.1621 \\
3 & -0.0276 & 0.4496 & 13 & -0.0099 & 0.3599 & 23 & -0.0077 & 0.4300 & 33 & -0.0069 & 0.5166 \\
4 & -0.0625 & 0.5383 & 14 & -0.0320 & 0.5918 & 24 & -0.0266 & 0.7464 & 34 & -0.0245 & 0.9162 \\
5 & -0.0894 & 0.3000 & 15 & -0.0567 & 0.4529 & 25 & -0.0494 & 0.6056 & 35 & -0.0462 & 0.7608 \\
6 & -0.0678 & -0.5945 & 16 & -0.0513 & -0.7360 & 26 & -0.0465 & -0.9671 & 36 & -0.0442 & -1.2132 \\
7 & 0.0660 & -2.3445 & 17 & 0.0497 & -3.6509 & 27 & 0.0458 & -5.0556 & 37 & 0.0440 & -6.4815 \\
8 & 0.3660 & -4.4844 & 18 & 0.3203 & -7.8529 & 28 & 0.3057 & -11.2363 & 38 & 0.2986 & -14.6255 \\
9 & $\mathbf{0 . 7 8 2 7}$ & -5.0568 & 19 & 0.7424 & -9.6699 & 29 & 0.7273 & -14.2247 & 39 & 0.7195 & -18.7665 \\
10 & 1.0000 & 0.0000 & 20 & 1.0000 & 0.0000 & 30 & 1.0000 & 0.0000 & 40 & 1.0000 & 0.0000
\end{tabular}

\begin{tabular}{|c|c|c|c|c|c|c|c|c|c|c|c|}
\hline \multicolumn{3}{|c|}{$\xi_{B}=50$} & \multicolumn{3}{|c|}{$\xi_{B}=55$} & \multicolumn{3}{|c|}{$\xi_{B}=10$} & \multicolumn{3}{|c|}{$\xi_{B}=20$} \\
\hline$\xi$ & $B_{11}$ & $B_{12}$ & $\xi$ & $B_{11}$ & $\mathrm{~B}_{12}$ & $\xi$ & $\mathrm{B}_{21}$ & $\mathrm{~B}_{22}$ & $\xi$ & $B_{21}$ & $B_{22}$ \\
\hline 40 & 0.0017 & -0.0587 & 45 & 0.0016 & -0.0626 & 0 & & & 10 & 0.0001 & 0.0004 \\
\hline 41 & 0.0025 & -0.0123 & 46 & 0.0024 & -0.0133 & 1 & 0.0002 & 0.0001 & 11 & 0.0012 & 0.0011 \\
\hline 42 & 0.0010 & 0.1882 & 47 & 0.0010 & 0.2018 & 2 & 0.0008 & 0.0003 & 12 & 0.0034 & 0.0018 \\
\hline 43 & -0.0065 & 0.6082 & 48 & -0.0064 & 0.6549 & 3 & 0.0017 & -0.0003 & 13 & 0.0058 & 0.0007 \\
\hline 4 & -0.023 & 1.0911 & 49 . & -0.0229 & 1.1795 & 4 & 0.0000 & -0.0041 & 14 & 0.0036 & -0.0058 \\
\hline 15 & -0.0444 & 0.9171 & 50 & -0.0438 & 0.9955 & 5 & -0.0123 & -0.0146 & 15 & -0.0146 & -0.0221 \\
\hline 16 & -0.0429 & -1.4643 & 51 & -0.0424 & -1.5908 & 6 & -0.0478 & -0.0305 & 16 & -0.0634 & -0.0455 \\
\hline 17 & 0.0430 & -7.9153 & 52 & 0.0427 & -8.6338 & 7 & -0.1070 & -0.0303 & 17 & -0.1398 & -0.0486 \\
\hline שט & 0.2944 & -18.0174 & 53 & 0.2929 & -19.7139 & 8 & -0.1287 & 0.0537 & 18 & -0.1684 & 0.0457 \\
\hline נד & 0.7147 & -23.3033 & 54 & 0.7130 & -25.5708 & 9 & 0.0934 & 0.3396 & 19 & 0.0763 & 0.3606 \\
\hline 50 & 1.0000 & 0.0000 & 55 & 1.0000 & 0.0000 & 10 & 0.9474 & 0.8951 & 20 & 0.9834 & 0.9527 \\
\hline
\end{tabular}

\begin{tabular}{rrrrrrrrrrrrrr}
\multicolumn{3}{c}{$\xi_{\mathrm{B}}=30$} & \multicolumn{3}{c}{$\xi_{\mathrm{B}}=40$} \\
$\xi$ & \multicolumn{1}{c}{$\mathrm{B}_{21}$} & \multicolumn{1}{c}{$\mathrm{B}_{22}$} & $\xi$ & \multicolumn{1}{c}{$\mathrm{B}_{21}$} & \multicolumn{1}{c}{$\mathrm{B}_{22}$} & $\xi$ & \multicolumn{1}{c}{$\mathrm{B}_{21}$} & $\mathrm{~B}_{22}$ & $\xi$ & $\mathrm{B}_{21}$ & \multicolumn{1}{c}{$\mathrm{B}_{22}$} \\
& & & & & & & & & & \\
20 & 0.0001 & 0.0005 & 30 & 0.0000 & 0.0005 & 40 & 0.0000 & 0.0005 & 45 & 0.0000 & 0.0005 \\
21 & 0.0013 & 0.0014 & 31 & 0.0014 & 0.0015 & 41 & 0.0014 & 0.0015 & 46 & 0.0014 & 0.0015 \\
22 & 0.0040 & 0.0022 & 32 & 0.0042 & 0.0024 & 42 & 0.0044 & 0.0025 & 47 & 0.0044 & 0.0025 \\
23 & 0.0069 & 0.0011 & 33 & 0.0074 & 0.0013 & 43 & 0.0076 & 0.0014 & 48 & 0.0077 & 0.0014 \\
24 & 0.0047 & -0.0060 & 34 & 0.0051 & -0.0062 & 44 & 0.0054 & -0.0062 & 49 & 0.0055 & -0.0063 \\
25 & -0.0150 & -0.0239 & 35 & -0.0151 & -0.0247 & 45 & -0.0153 & -0.0252 & 50 & -0.0153 & -0.0254 \\
26 & -0.0675 & -0.0495 & 36 & -0.0694 & -0.0514 & 46 & -0.0704 & -0.0524 & 51 & -0.0708 & -0.0528 \\
27 & -0.1490 & -0.0538 & 37 & -0.1532 & -0.0562 & 47 & -0.1557 & -0.0576 & 52 & -0.1566 & -0.0581 \\
28 & -0.1804 & -0.0429 & 38 & -0.1862 & 0.0406 & 48 & -0.1895 & 0.0408 & 53 & -0.1907 & 0.0405 \\
29 & 0.0694 & 0.3660 & 39 & 0.0658 & 0.3684 & 49 & 0.0636 & 0.3698 & 54 & 0.0628 & 0.3703 \\
30 & 0.9911 & 0.9696 & 40 & 0.9941 & 0.9776 & 50 & 0.9957 & 0.9823 & 55 & 0.9962 & 0.9839
\end{tabular}


Table A-2

INFLUENCE FUNCTIONS FOR UNIFORM CONE: $B_{33}, B_{34}, B_{43}$, AND $B_{44}$

\begin{tabular}{|c|c|c|c|c|c|c|c|c|c|c|c|}
\hline \multicolumn{3}{|c|}{$\xi_{A}=1$} & \multicolumn{3}{|c|}{$\xi_{A}=10$} & \multicolumn{3}{|c|}{$\xi_{A}=10$} & \multicolumn{3}{|c|}{$\xi_{A}=30$} \\
\hline$\xi$ & $B_{33}$ & $B_{34}$ & $\xi$ & $B_{33}$ & $B_{34}$ & $\xi$ & $\mathrm{B}_{33}$ & $\mathrm{~B}_{34}$ & $\xi$ & $\mathbf{B}_{33}$ & $\mathrm{~B}_{34}$ \\
\hline 0 & & & 10 & -1.0000 & 0.0000 & 20 & -1.0000 & 0.0000 & 30 & -1.0000 & 0.0000 \\
\hline 1 & -1.0000 & 0.0000 & 11 & -0.5894 & 3.7615 & 21 & -0.6434 & 8.3274 & 31 & -0.6610 & 12.8731 \\
\hline 2 & -0.0764 & 0.0247 & 12 & -0.2069 & 2.4787 & 22 & -0.2403 & 5.8225 & 32 & -0.2524 & 9.2018 \\
\hline 3 & -0.0143 & 0.0152 & 13 & -0.0279 & 0.9492 & 23 & -0.0327 & 2.3260 & 33 & -0.0347 & 3.7443 \\
\hline 4 & -0.0024 & 0.0066 & 14 & 0.0206 & 0.1655 & 24 & 0.0280 & 0.3992 & 34 & 0.0310 & 0.6460 \\
\hline 5 & 0.0001 & 0.0022 & 15 & 0.0194 & -0.0721 & 25 & 0.0268 & -0.2154 & 35 & 0.0300 & -0.3680 \\
\hline 6 & 0.0003 & 0.0005 & 16 & 0.0091 & -0.0817 & 26 & 0.0129 & -0.2380 & 36 & 0.0146 & -0.4083 \\
\hline 7 & 0.0002 & 0.0000 & 17 & 0.0024 & -0.0415 & 27 & 0.0034 & -0.1221 & 37 & 0.0038 & -0.2116 \\
\hline 8 & 0.0001 & -0.0001 & 18 & -0.0002 & -0.0121 & 28 & -0.0004 & -0.0351 & 38 & -0.0005 & -0.0611 \\
\hline 9 & 0.0000 & 0.0000 & 19 & -0.0006 & 0.0001 & 29 & -0.0010 & 0.0016 & 39 & $-0.00^{\prime} 12$ & 0.0034 \\
\hline 10 & 0.0000 & 0.0000 & 20 & -0.0004 & 0.0026 & 30 & -0.0006 & 0.0088 & 40 & -0.0008 & 0.016 \\
\hline
\end{tabular}

$$
\xi_{\mathrm{A}}=40
$$

$\xi \quad B_{33}$

$41-0.6697$

$42-0.2586$

$43-0.0358$

$44 \quad 0.0327$

$45 \quad 0.0318$

$46 \quad 0.0156$

$47 \quad 0.0041$

$48-0.0006$

$49-0.0014$

$50-0.0009$

$$
\xi_{A}=50
$$

$\beta_{34}$

0.0000

17.4117

12.5896

5.1750

0.8974

$-0.5233$

$-0.5834$

$-0.3044$

$-0.0882$

0.0053

0.0240 $\xi \quad \mathrm{B}_{33}$

$50-1.0000$

$51-0.6749$

$52-0.2624$

$53-0.0364$

$54 \quad 0.0337$

55

56

57

58

59

60

0.0163

0.0043

$-0.0006$

$-0.0014$

$-0.0009$

\subsection{9}

$$
\xi_{A}=1
$$

$B_{34}$

0.0000

21.9470

15.9808

6.6111

1.1510

$-0.6797$

$-0.7607$

$-0.3988$

$-0.1160$

0.0073

0.0321
$B_{43}$

$\xi$

$\xi$

0

$1 \quad 0.2605$

$2-0.0643$

$3-0.1064$

$4-0.0809$

$5-0.0426$

$6-0.0145$

$\begin{array}{rr}7 & -0.0008 \\ 8 & 0.0031\end{array}$

$9 \quad 0.0027$

10

0.001

$$
\xi_{A}=30
$$

$\xi \quad \mathrm{B}_{43}$

$20 \quad 0.9980$

$21 \quad 0.0308$

$22-0.2285$

$23-0.1829$

$24-0.0824$

25

26

27

28

29

30
$-0.0170$

0.0077

0.0101

0.0058

0.0018

$-0.0000$
$B_{44}$

$\begin{array}{lll}1.0880 & 30 & 1.0006\end{array}$

$$
\begin{array}{lll}
0.3846 & 31 & 0.0387
\end{array}
$$

0.0328

$-0.0719$

$-0.0633$

$-0.0303$

$-0.0072$

0.0020

0.0034

0.0020

0.0007

31

32

33

34

35

36

37

38

39

40
$-0.2206$

$-0.1776$

$-0.0800$

$-0.0165$

0.0073

0.0097

0.0055

0.0017

$-0.0000$

$$
\xi_{A}=40
$$

$\mathrm{B}_{44}$

10

0.4638

0.1351

0.0150

$-0.0209$

$-0.0212$

$-0.0118$

$-0.0040$

$-0.000$

0.0009

$$
\xi_{A_{1}}=10
$$

$\mathrm{B}_{43}$

$B_{44}$

$\begin{array}{rr}0.9793 & 1.0688 \\ 0.0072 & 0.3919 \\ -0.2469 & 0.0313 \\ -0.1945 & -0.0763 \\ -0.0880 & -0.0674 \\ -0.0185 & -0.0328 \\ 0.0081 & -0.0081 \\ 0.0110 & 0.0020 \\ 0.0064 & 0.0036 \\ 0.0021 & 0.0022 \\ 0.0000 & 0.0008\end{array}$


a) GEOMETRY AND FORCES (DEFORMATIONS)

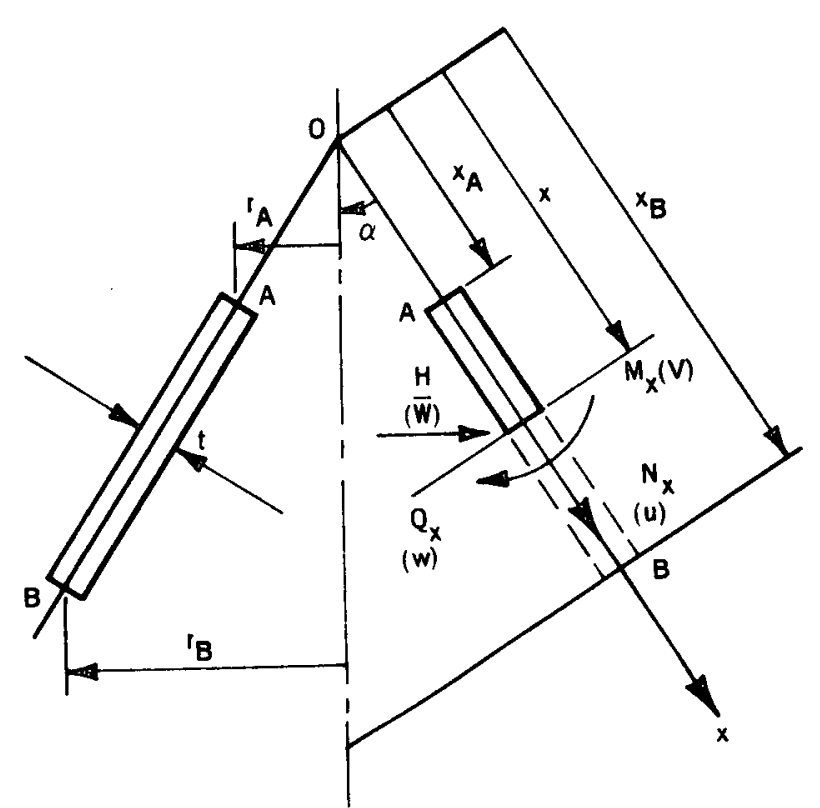

b) EDGE LOADED SHELL

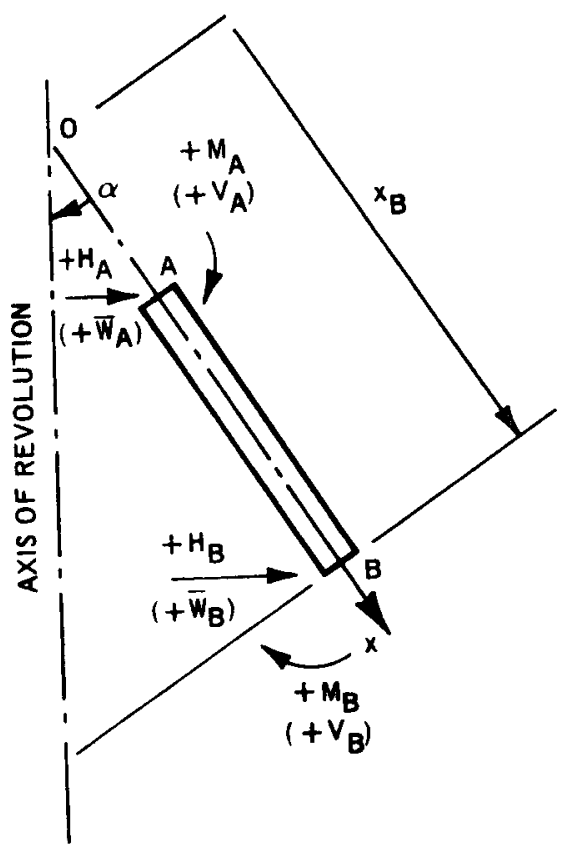

Figure A-1. Sign Convention for Conical Shells
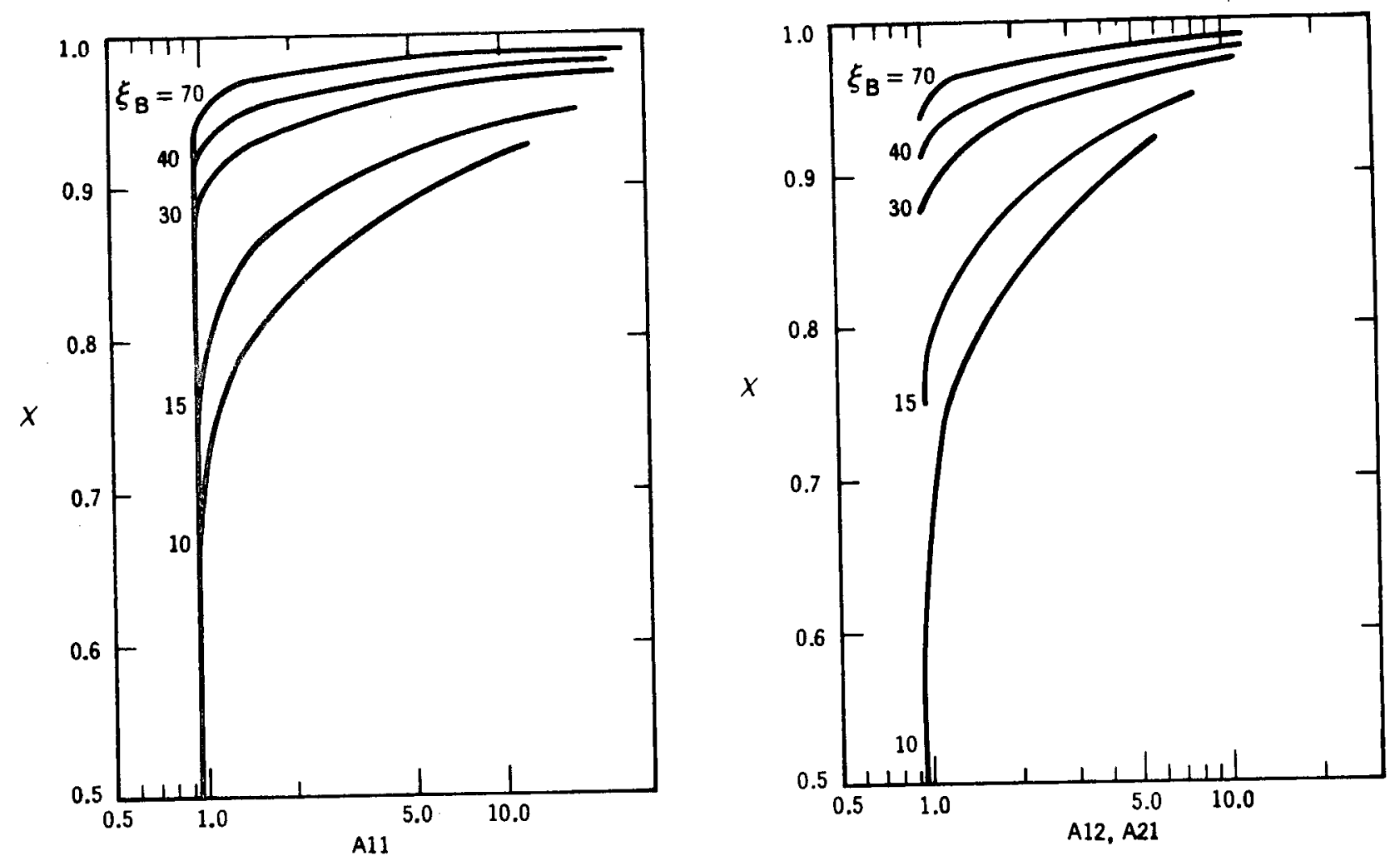

Figure A-2A. Influence Coefficients for Uniform Cones 

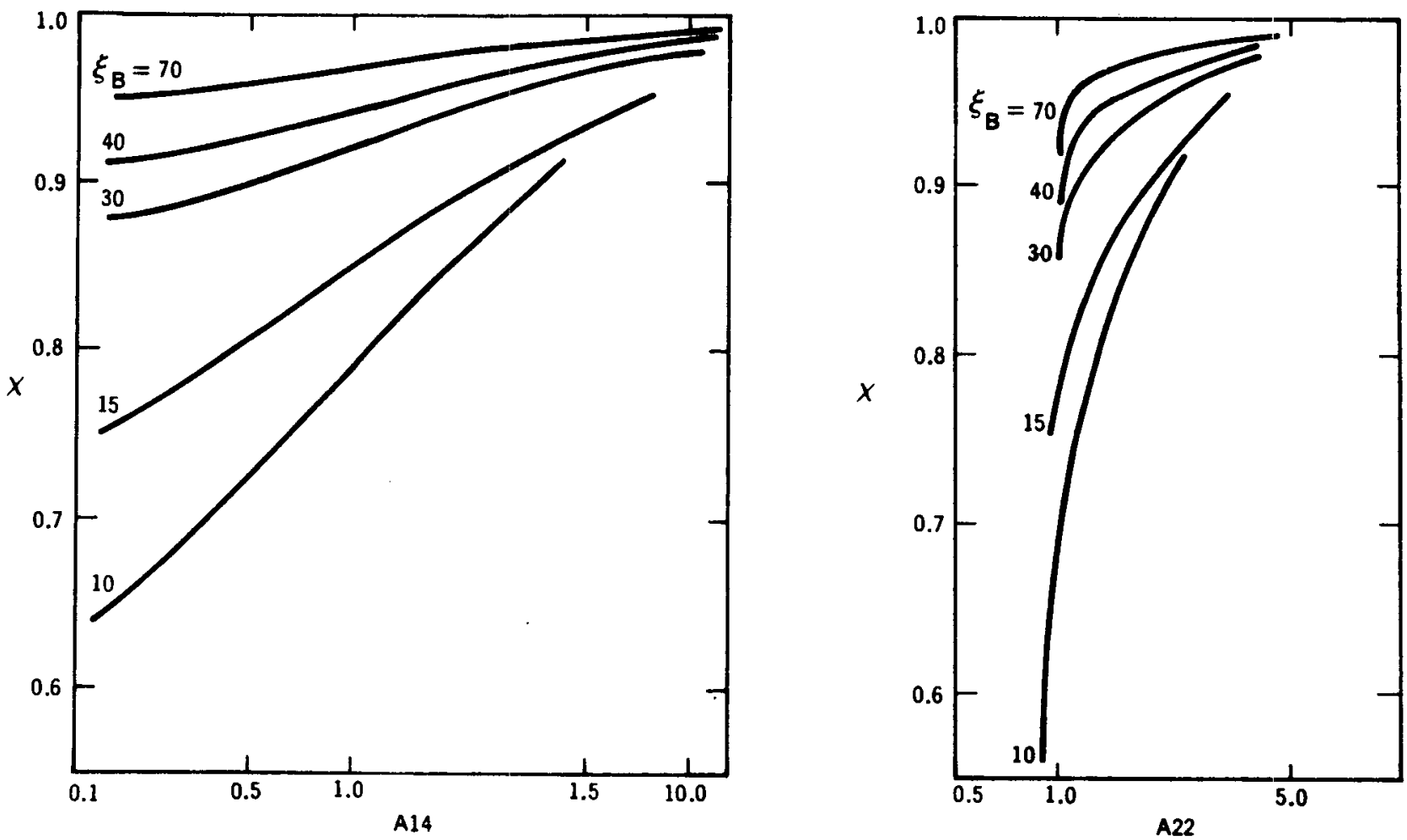

Figure A-2B. Influence Coefficients for Uniform Cones (Cont'd)
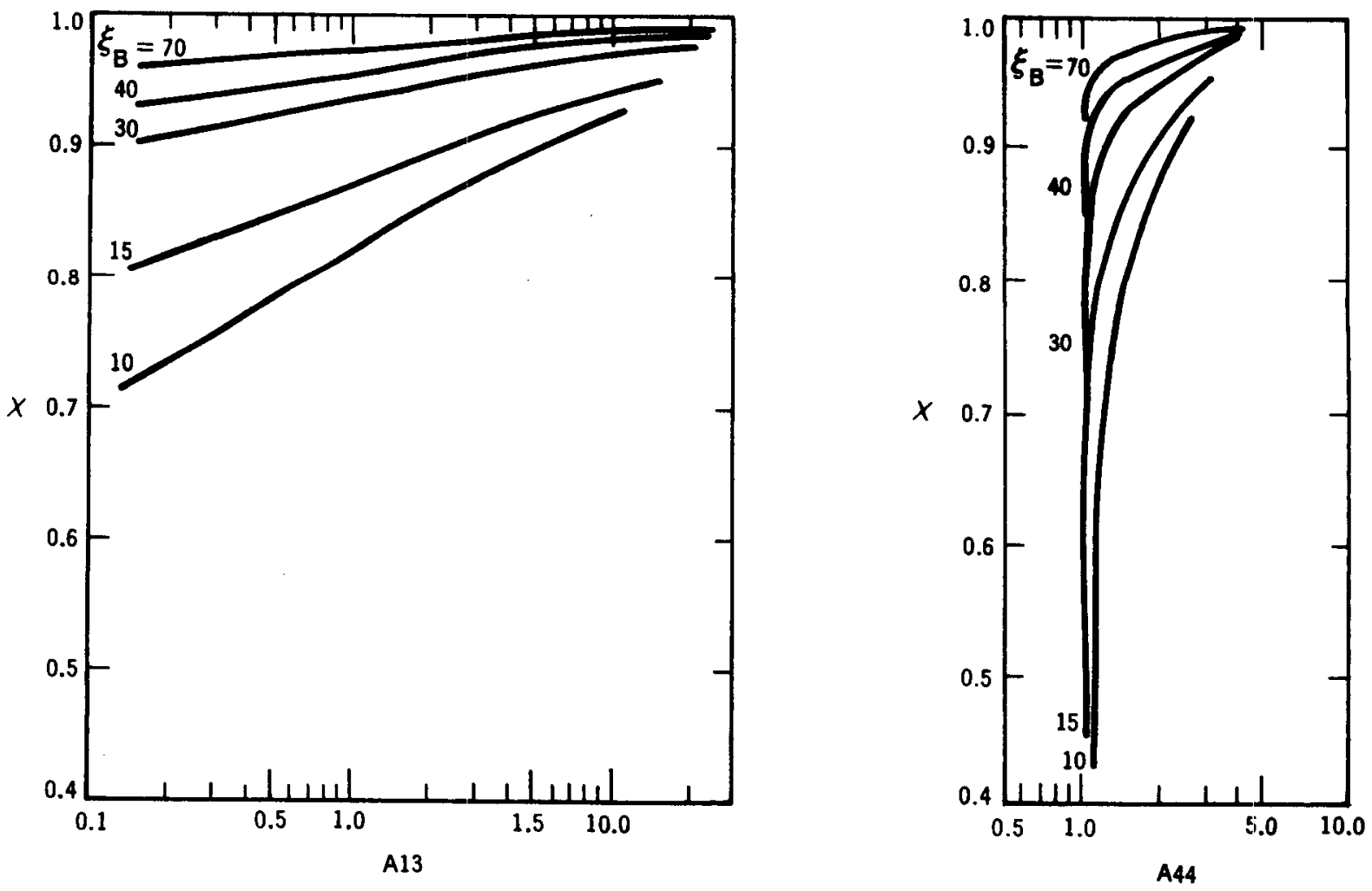

Figure A-2C. Influence Coefficients for Uniform Cones (Cont'd) 

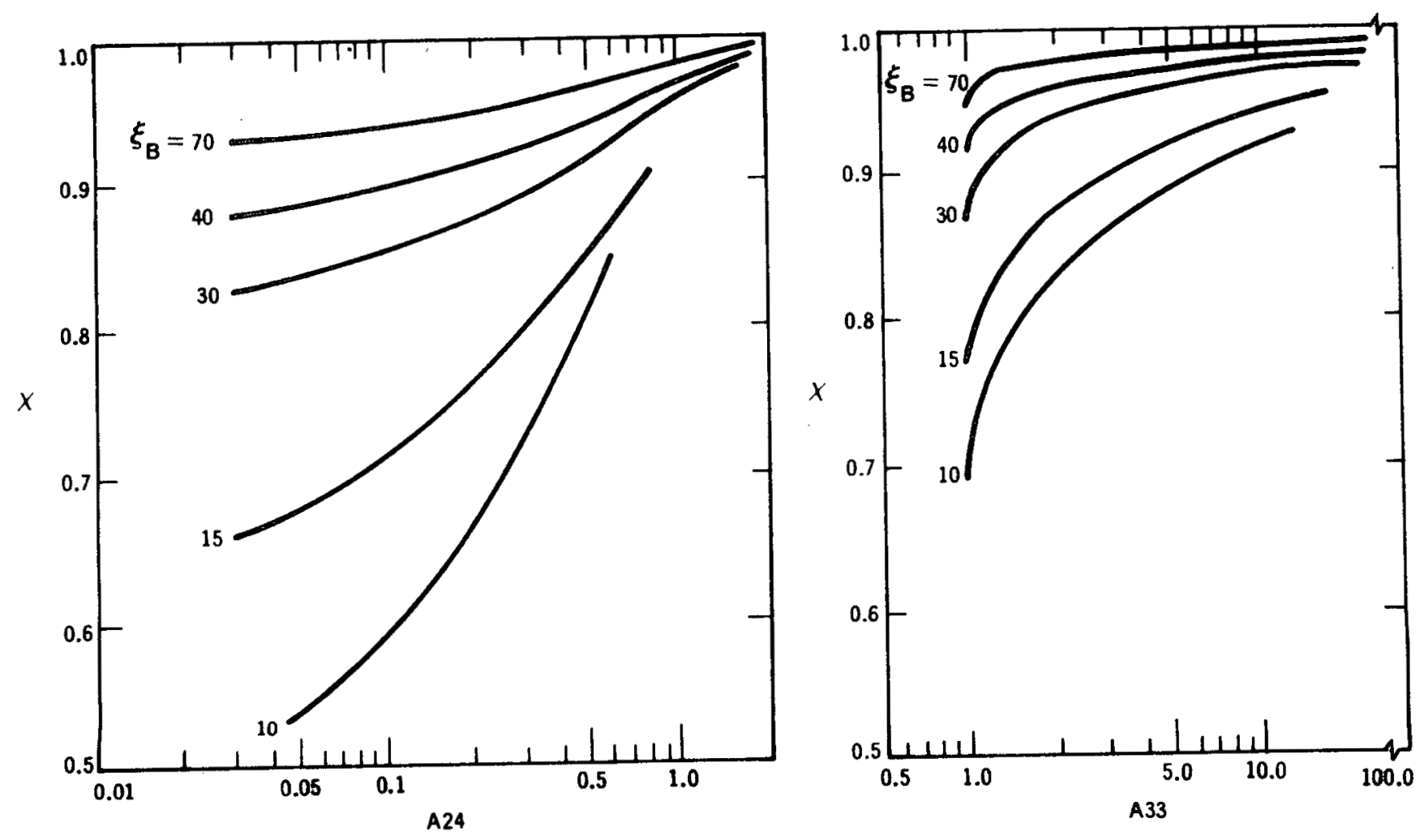

Figure A-2D. Influence Coefficients for Uniform Cones (Cont'd)
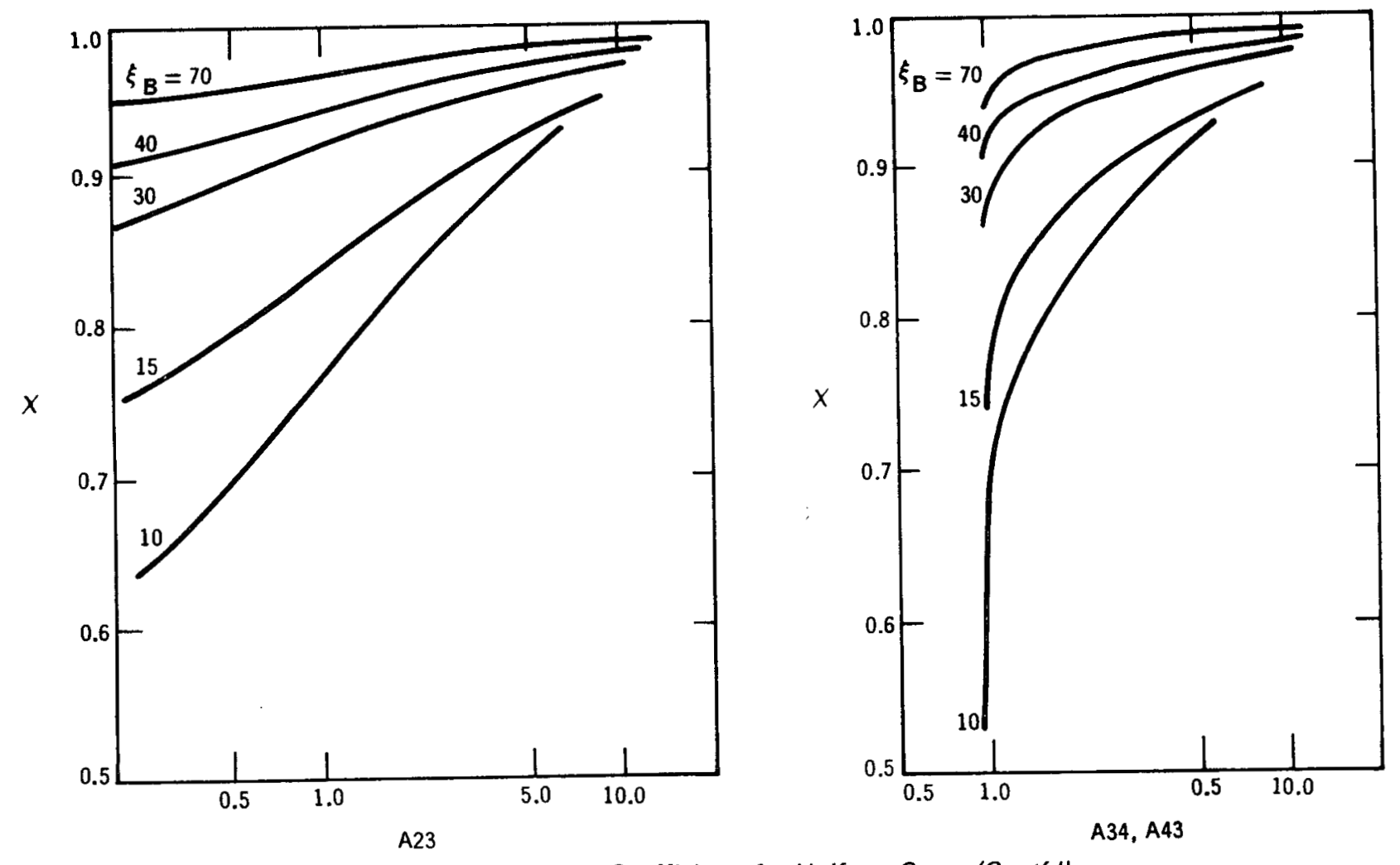

Figure A-2E. Influence Coefficients for Uniform Cones (Cont'd) 


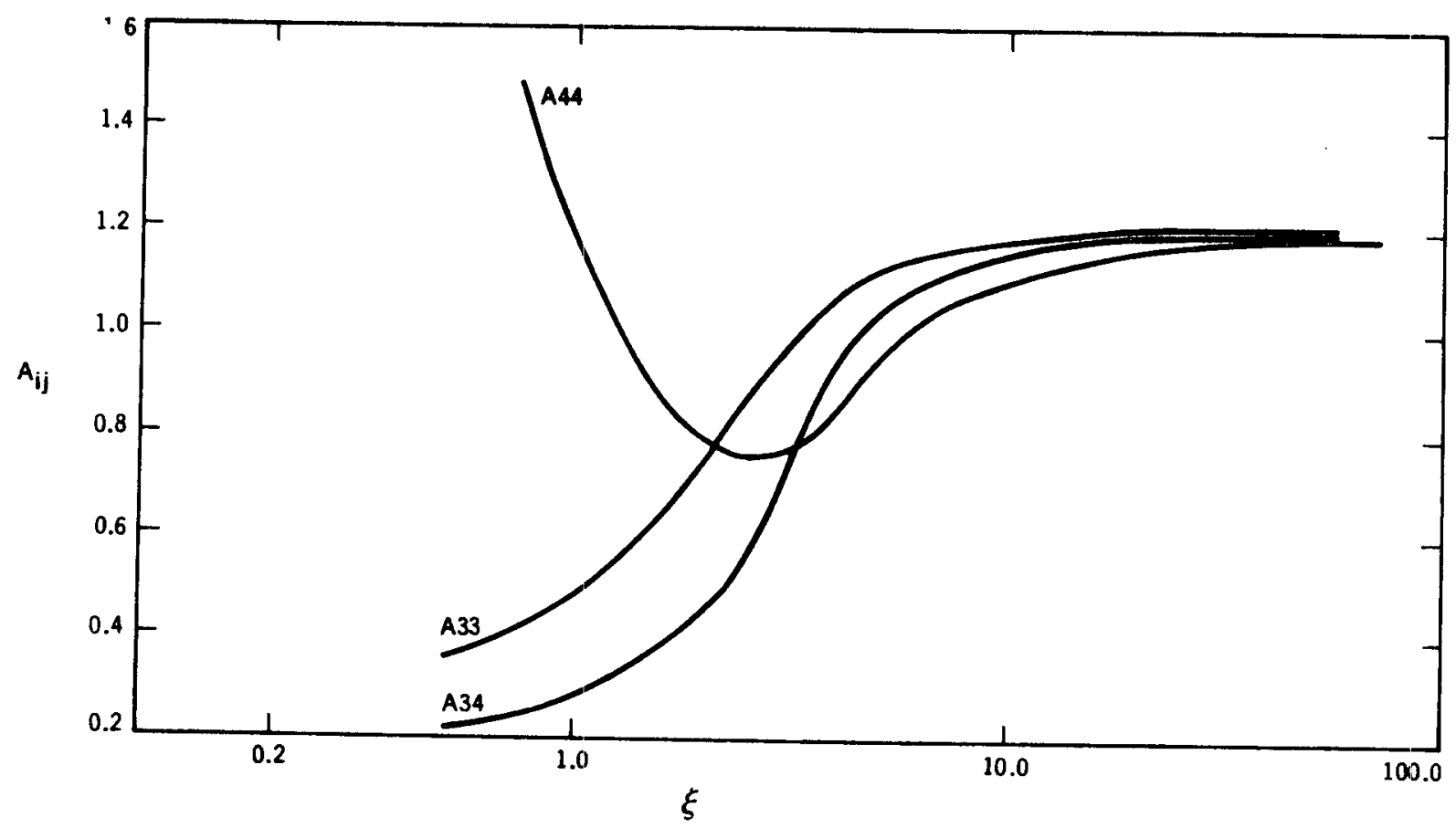

Figure A-3A. Influence Coefficients for Long Uniform Cones-Lower Edge

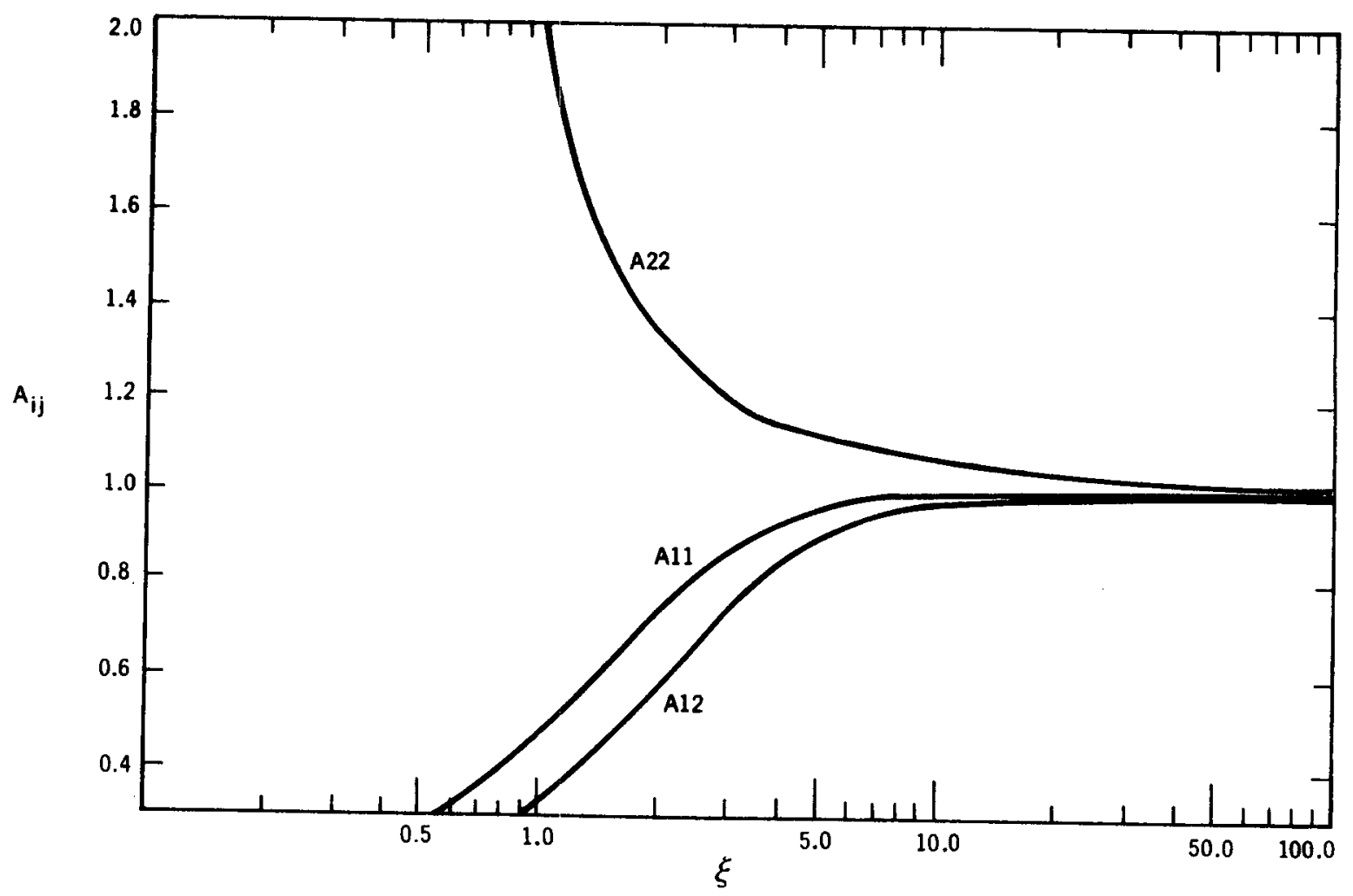

Figure A-3B. Influence Coefficients for Long Uniform Cones-Upper Edge 
-

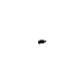

-

0 


\section{APPENDIX B. CONICAL SHELLS UNDER EXTERNAL PRESSURE}

Rules are given in this appendix for determining the stresses under external pressure loading in conical shells. A chart for determining the stresses in this specific type of shells is given in Figure B-1. This chart is provided for low temperature applications wherein creep effects are neglected.

\section{B.1 NOMENCLATURE}

The symbols used in this appendix are defined as follows:

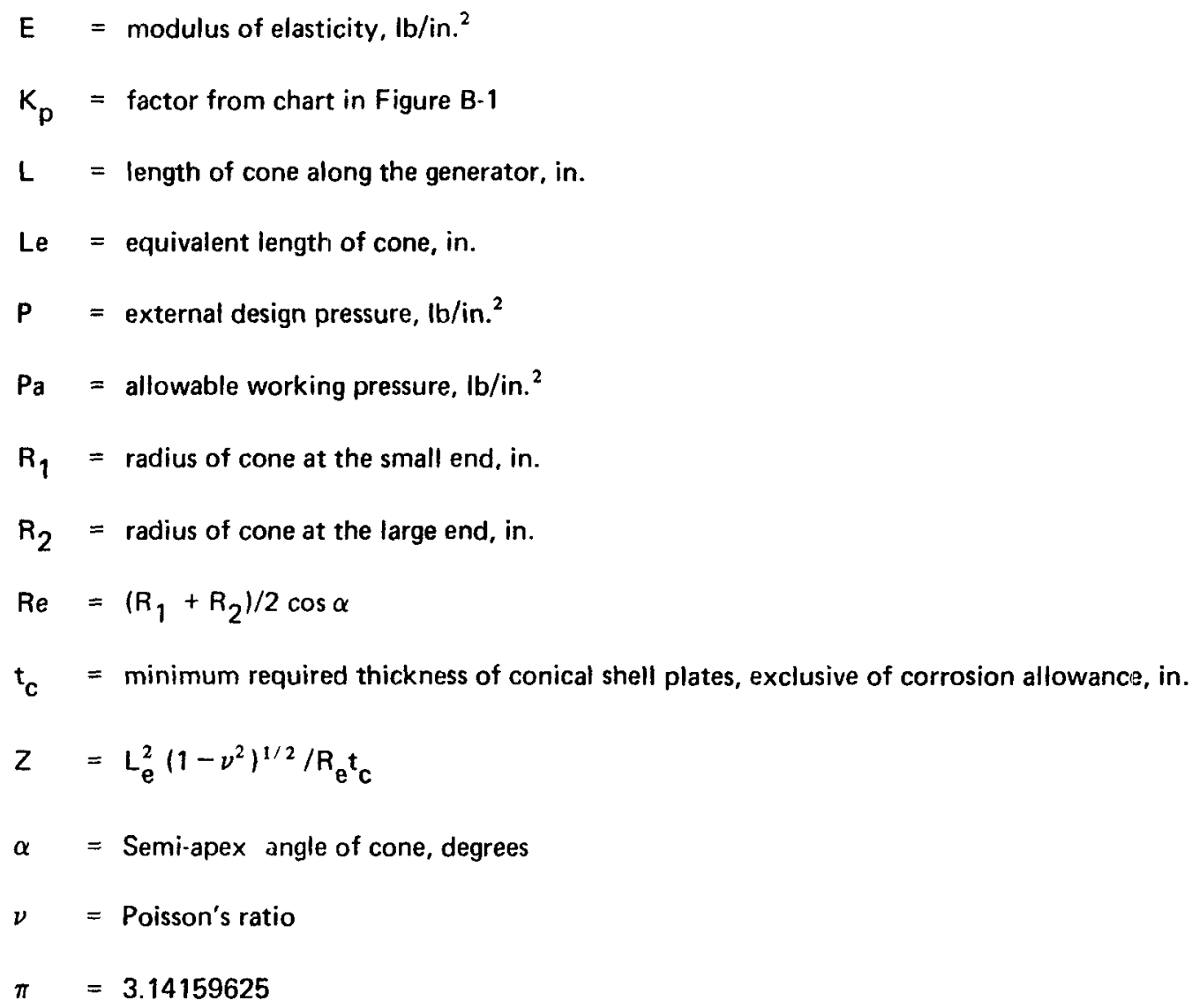

\section{B.2 PROCEDURE FOR THE STRESS DETERMINATION}

The stress in a conical shell under external pressure shall be determined by the following procedure:

Step 1. Assume a value for $t_{c}$. Determine the factor $Z$ according to the following formula:

$$
Z=\frac{L_{c}^{2}}{R_{e} t_{c}}\left(1-\nu^{2}\right)^{1 / 2}
$$

Step 2. Enter the bottom of Figure B-1 at the value of $Z$ determined in Step 1.

Step 3. Move vertically to inclined line. 
Step 4. From this intersection, move horizontally to the left and read the value $K_{p}$.

Step 5. Compute the allowable working pressure $P_{a}$ for the value of $t_{c}$ which was assumed by the following formula:

$$
P_{a}=\frac{\pi^{2} E t_{c}^{3}}{12\left(1-\nu^{2}\right) L_{e}^{2} R_{e}} .
$$

Step 6. Compare $P_{a}$ with $P$. If $P_{a}$ is smaller than $P$, a greater value for $t_{c}$ must be selected and the design procedure repeated until a value for $P_{a}$ is obtained that is equal to or greater than $P$, and the corresponding value of stress is safe against elastic buckling. 


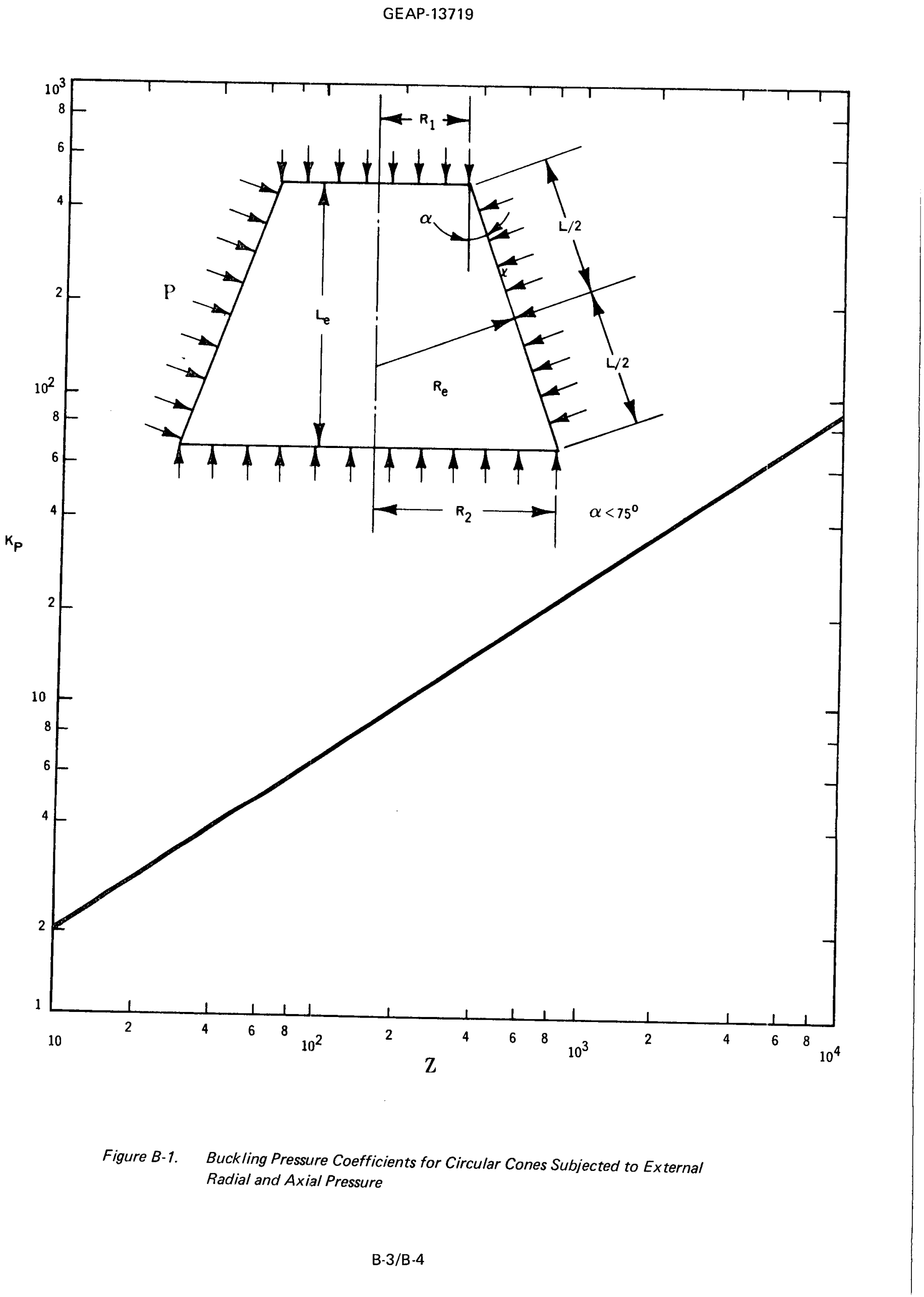


$-$

$\ominus$ 


\section{APPENDIX C. ANALYSIS OF ELLIPSOIDAL SHELLS}

In this appendix, formulas are given for stresses and deformations in ellipsoidal shells subjected to internal pressure. These formulas are provided for low-temperature applications wherein creep effects have not been considered.

Formulas are also given for bending analysis of ellipsoidal shells under the action of uniformly distributed edge forces and moments.

\section{C.1 NOMENCLATURE AND SIGN CONVENTION}

The symbols and sign convention adopted in this article are defined as follows:

a $\quad=$ semi-major axis of shell

b = semi-minor axis of shell

$E \quad=$ modulus of elasticity, psi

$H=$ horizontal force, $\mathrm{lb} / \mathrm{in}$.

$M=$ longitudinal bending moment per unit length of circumference, in. $-1 b /$ in.

$\mathrm{N}=$ membrane force, $\mathrm{Ib} / \mathrm{in}$.

$p \quad=$ internal pressure, psi

$r_{1}=$ principal radius of curvature in the longitudinal direction

$=a^{2} b^{2} /\left(a^{2} \sin ^{2} \phi+b^{2} \cos ^{2} \phi\right)^{3 / 2}$

$r_{2}=$ principal radius of curvature in the circumferential direction

$=a^{2} /\left(a^{2} \sin ^{2} \phi+b^{2} \cos ^{2} \phi\right)^{1 / 2}$

$S \quad=$ stress intensity, psi

$\mathbf{s}=$ nondimensional variable distance of shell.

$=$ distance of shell along the meridional direction divided by the total length of shell

$t=$ thickness of shell, in.

$\bar{W}=$ radial displacement of the middle surface of shell, in.

$\theta=$ rotation of the middle surface of shell, radians

$\lambda=a / b$

$\phi \quad=$ meridional angle

$\nu=$ Poisson's ratio 


$$
\begin{aligned}
& \sigma_{t}=\text { circumferential stress component, psi } \\
& \sigma_{\ell}=\text { meridional stress component, psi } \\
& \sigma_{r}=\text { radial stress component, psi } \\
& a_{11}=A_{11} / E^{2} \\
& a_{12}=A_{12} / E t \\
& a_{13}=A_{13} / E t^{2} \\
& a_{14}=A_{14} / E t \\
& a_{21}=a_{12} \\
& a_{22}=A_{22} / E \\
& a_{23}=A_{23} / E t \\
& a_{24}=A_{24} / E \\
& a_{31}=A_{31} / E^{2} \\
& a_{32}=A_{32} / E t \\
& a_{33}=A_{33} / E^{2} \\
& a_{34}=A_{34} / E t \\
& a_{41}=A_{41} / E t \\
& a_{42}=A_{42} / E \\
& a_{43}=a_{34} \\
& a_{44}=A_{44} / E \\
& b_{1}=B_{1} / E^{2} \\
& b_{2}=B_{2} / E t \\
& b_{3}=B_{3} / E t^{2} \\
& b_{4}=B_{4} / E t \\
& b_{11}=B_{11} \\
& b_{12}=B_{12} / t \\
& \mathrm{~b}_{21}=\mathrm{B}_{21} / \mathrm{Et} \\
& b_{22}=B_{22} / E
\end{aligned}
$$


The sign convention arbitrarily chosen for the analysis of ellipsoidal shells in this article is as indicated in Figure C-1.

\section{C.2 PRINCIPAL STRESSES AND STRESS INTENSITIES DUE TO INTERNAL PRESSURE}

According to the thin-shell theory, the principal stresses developed at any point in the wall of an ellipsoidal shell at any location at an angle $\phi$ due to internal pressure are given by the formulas:

$$
\begin{aligned}
& \sigma_{1}=\sigma_{t}=\operatorname{pr}_{2}\left(1-r_{2} / 2 r_{1}\right) / t, \\
& \sigma_{2}=\sigma_{\ell}=p r_{2} / 2 t \\
& \sigma_{3}=\sigma_{r}=0 .
\end{aligned}
$$

\section{C.2.1 Stress Intensity}

The general primary membrane stress intensity developed across the thickness of an ellipsoidal shell due to internal pressure may be computed either by

$$
S=\sigma_{1}
$$

or

$$
\mathrm{S}=\sigma_{2}
$$

whichever yields a maximum value.

\section{C.3 BENDING ANALYSIS FOR UNIFORMLY DISTRIBUTED EDGE LOADS AND UNIFORM INTERNAL PRESSURE}

The formulas in this subsection describe the behavior of an ellipsoidal shell when subjected to the action of bending moments ( $M$ inch-pounds per inch of circumference), the forces $(H$ pounds per inch of circumference, uniformly distributed at the edges and acting at the mean radius of the shell), and uniform internal pressure, (p pounds per square inch with the equilibrating membrane edge stress resultants $N_{A}$ and $N_{B}$, as shown in Figure $\mathrm{C}-1$ ). The behavior of the shell due to all other loadings must be evaluated independently and combined by superposition.

\section{C.3.1 Edge Rotations and Displacements in Terms of Edge Loads and Internal Pressure}

The rotations $\theta_{B}$ and $\theta_{A}$, and radial displacements $\bar{W}_{B}$ and $\bar{W}_{A^{\prime}}$, developed at the edges of an ellipsoidal shell, as shown in Figure $C-1$, and sustaining the action of edge loads $M_{B}, M_{A}, H_{B}, H_{A}$ and internal pressure $p$, are given by the following formulas:

$$
\begin{aligned}
& \theta_{B}=a_{11} M_{B}+a_{12} H_{B}+a_{13} M_{A}+a_{14} H_{A}+b_{1}\left(p t^{2} / 2\right), \\
& \bar{W}_{B}=a_{21} M_{B}+a_{22} H_{B}+a_{23} M_{A}+a_{24} H_{A}+b_{2}\left(p t^{2} / 2\right), \\
& \theta_{A}=a_{31} M_{B}+a_{32} H_{B}+a_{33} M_{A}+a_{34} H_{A}+b_{3}\left(p t^{2} / 2\right),
\end{aligned}
$$




$$
\bar{w}_{A}=a_{41} M_{B}+a_{42} H_{B}+a_{43} M_{A}+a_{44} H_{A}+b_{4}\left(p t^{2} / 2\right)
$$

In these formulas, $a_{11}, a_{12}$, etc., are expressed in terms of $A_{11}, A_{12}$, etc. Values of these constants for different combinations of $\lambda, \phi_{A}, \phi_{B}$, and $a / t$ are shown in Tables $C-1$ through $\mathrm{C}-6$.

\section{C.3.2 Moment and Radial Displacement in Terms of Loading Conditions at the Edges}

For a closed crown $\left(\phi_{A}=0, \phi_{B}=90^{\circ}\right)$ ellipsoidal shell, the variations of moment $M(\phi)$ and radial translation $\bar{W}(\phi)$ due to edge loads $M_{B}$ and $H_{B}$ acting at the equator are given by the following formulas:

$$
\begin{aligned}
& M(\phi)=b_{11} M_{B}+b_{12} H_{B} \\
& \bar{W}(\phi)=b_{21} M_{B}+b_{22} H_{B} .
\end{aligned}
$$

where $b_{11}, b_{12}$, etc., are expressed in terms of $B_{11}, B_{12}$, etc. Values of these coefficients for $a / t=100, \lambda=2,3$, and 4 are listed in Table $\mathrm{C}-7$ according to the nondimensional distance, s.

\section{C.3.3 Principal Stresses in an Ellipsoidal Shell Due to Edge Loads}

The principal stresses in an ellipsoidal shell due to edge loads at the outside and inside surfaces of shell at any meridional location with a meridional angle, $\phi$, are given by the formulas:

$$
\begin{aligned}
& \sigma_{1}=\sigma_{\mathrm{t}}(\phi)=\mathrm{E} \overline{\mathrm{W}}(\phi) / \mathrm{r}_{2} \cos \phi \pm 6 \nu \mathrm{M}(\phi) / \mathrm{t}^{2} \\
& \sigma_{2}=\sigma_{\ell}(\phi)= \pm 6 \mathrm{M}(\phi) / \mathrm{t}^{2} \\
& \sigma_{3}=\sigma_{r}(\phi)=0 .
\end{aligned}
$$

In these formulas, where terms are preceded by a double sign \pm , the upper sign refers to the outside surface of the ellipse and the lower sign refers to the inside surface. 
Table C-1

INFLUENCE COEFFICIENTS OF ELLIPSOIDAL SHELLS

\begin{tabular}{|c|c|c|c|c|c|}
\hline$\lambda$ & $\begin{array}{l}\phi_{A}, \\
\phi_{B}\end{array}$ & ${ }_{{ }_{k}^{A}}^{B_{k}}$, & $a / t=20$ & $a / t=100$ & $a / t=200$ \\
\hline 2 & $\begin{array}{l}\hat{D} \\
\ddot{D} \\
0 \\
" 1 \\
a^{\varangle}\end{array}$ & $\begin{array}{l}A_{11} \\
A_{12} \\
A_{13} \\
A_{14}^{13} \\
A_{22}^{22} \\
A_{23} \\
A_{24} A_{31} \\
A_{32} \\
A_{33}^{3} \\
A_{34}^{34} \\
A_{41}^{41} \\
A_{44}^{44} \\
B_{1} \\
B_{2}^{2} \\
B_{4}^{3}\end{array}$ & $\begin{array}{l}0.3896+02 \\
-0.6958+02 \\
0 . \\
0 . \\
0.2326+03 \\
0 . \\
0 . \\
0 . \\
0 . \\
0 . \\
0 . \\
0 . \\
0 . \\
0 . \\
0.8449+02 \\
-0.5270+03 \\
0 . \\
0 .\end{array}$ & $\begin{array}{l}0.8531+02 \\
-0.3342+03 \\
0 . \\
0 . \\
0.2580+04 \\
0 . \\
0 . \\
0 . \\
0 . \\
0 . \\
0 . \\
0 . \\
0 . \\
0 . \\
0.2895+03 \\
-0.1237+05 \\
0 . \\
0 .\end{array}$ & $\begin{array}{l}0.1203+03 \\
-0.6645+03 \\
0 . \\
0 . \\
0.7288+04 \\
0 . \\
0 . \\
0 . \\
0 . \\
0 . \\
0 . \\
0 . \\
0 . \\
0 . \\
0.4399+03 \\
-0.4809+05 \\
0 . \\
0 .\end{array}$ \\
\hline
\end{tabular}

$$
\lambda \begin{array}{ll}
\varnothing_{A}, & { }_{j k},
\end{array} \quad a / t=20 \quad a / t=100 \quad a / t=200
$$

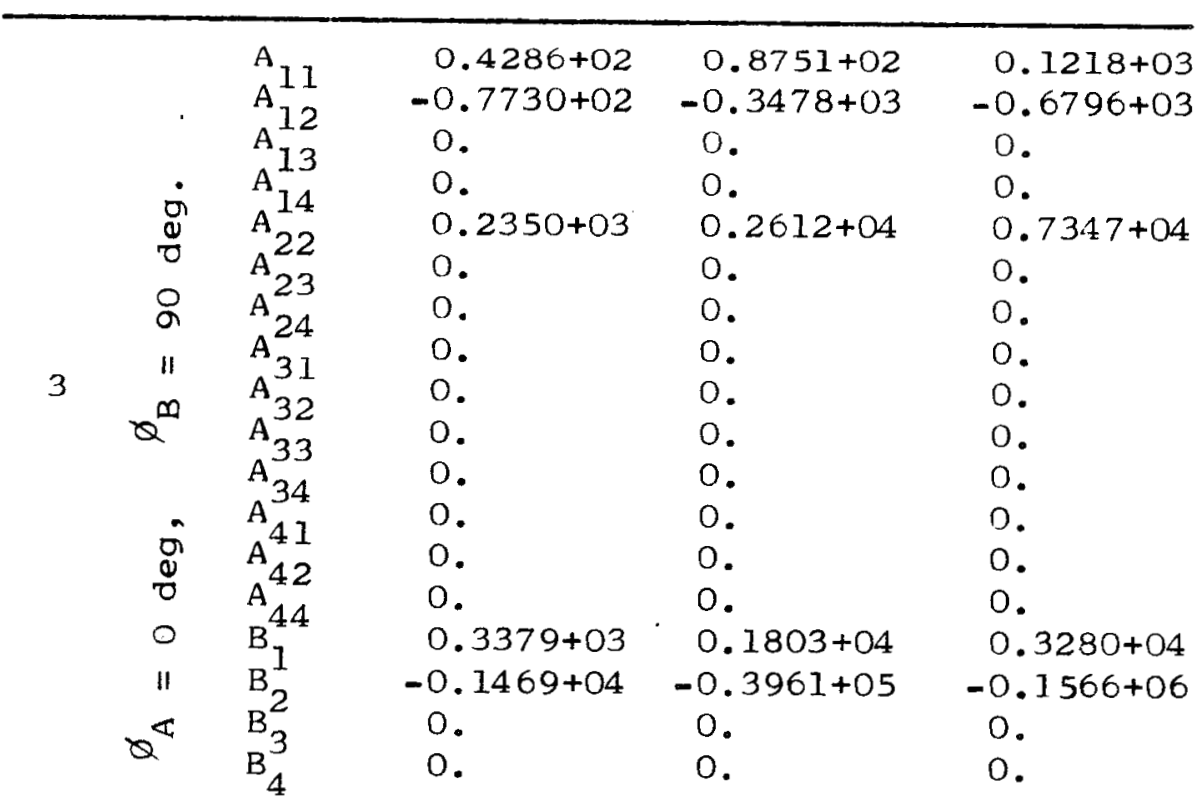


Table C-2

INFLUENCE COEFFICIENTS OF ELLIPSOIDAL SHELLS

\begin{tabular}{|c|c|c|c|c|c|}
\hline$\lambda$ & $\begin{array}{l}\varnothing_{\mathrm{A}}, \\
\varnothing_{\mathrm{B}}\end{array}$ & ${ }_{j k}^{B_{k}}$ & $a / t=20$ & $a / t=100$ & $a / t=200$ \\
\hline 4 & $\begin{array}{l}\dot{0} \\
0 \\
0 \\
8 \\
\sigma \\
" 1 \\
Q^{\infty} \\
\dot{0} \\
0 \\
0 \\
11 \\
Q^{<}\end{array}$ & $\begin{array}{l}A_{11} \\
A_{12} \\
A_{13} \\
A_{14} \\
A_{22}^{23} \\
A_{24} \\
A_{31} \\
A_{32} \\
A_{33} \\
A_{34}^{34} \\
A_{41} \\
A_{42}^{4} \\
B_{1}^{1} \\
B_{2}^{2} \\
B_{3}^{3} \\
B_{4}\end{array}$ & $\begin{array}{l}0.4891+02 \\
-0.8578+02 \\
0 . \\
0 . \\
0.2314+03 \\
0 . \\
0 . \\
0 . \\
0 . \\
0 . \\
0 . \\
0 . \\
0 . \\
0 . \\
0.7206+03 \\
-0.2419+04 \\
0 . \\
0 .\end{array}$ & $\begin{array}{l}0.9247+02 \\
-0.3709+03 \\
0 . \\
0 . \\
0.2641+04 \\
0 . \\
0 . \\
0 . \\
0 . \\
0 . \\
0 . \\
0 . \\
0 . \\
0 . \\
0.4968+04 \\
-0.7424+05 \\
0 . \\
0 .\end{array}$ & $\begin{array}{l}0.1258+03 \\
-0.7100+03 \\
0 . \\
0 . \\
0.7434+04 \\
0 . \\
0 . \\
0 . \\
0 . \\
0 . \\
0 . \\
0 . \\
0 . \\
0 . \\
0.1031+05 \\
-0.3039+06 \\
0 . \\
0 .\end{array}$ \\
\hline
\end{tabular}


GEAP-13719

Table C-3

INFLUENCE COEFFICIENTS OF ELLIPSOIDAL SHELLS

\begin{tabular}{|c|c|c|c|c|c|}
\hline$\lambda$ & $\phi_{\mathrm{A}}$, & ${ }_{B_{k}}^{A_{j k}}$ & $a / t=20$ & $a / t=100$ & $a / t=200$ \\
\hline 2 & $\begin{array}{c}\dot{g} \\
\dot{0} \\
0 \\
\dot{\sigma} \\
a^{\infty}\end{array}$ & $\begin{array}{l}A_{11} \\
A_{12}^{12} \\
A_{13}^{13} \\
A_{22}^{12} \\
A_{23}^{24} \\
A_{31}^{24} \\
A_{32}^{3} \\
A_{33} \\
A_{34}^{34} \\
A_{42}^{41} \\
A_{44}^{4} \\
B_{1}^{1} \\
B_{3}^{2} \\
B_{4}^{3}\end{array}$ & $\begin{array}{l}0.3899+02 \\
-0.6962+02 \\
-0.5188 \\
-0.2859 \\
0.2327+03 \\
0.1360+01 \\
0.2476 \\
-0.1870+01 \\
0.4905+01 \\
0.4055+02 \\
0.1311+02 \\
-0.1030+01 \\
0.8928 \\
0.1579+02 \\
0.7861+02 \\
-0.5212+03 \\
0.3181+03 \\
0.3815+03\end{array}$ & $\begin{array}{r}0.8532+02 \\
-0.3342+03 \\
-0.6155-02 \\
-0.2890-02 \\
0.2580+04 \\
0.1600-01 \\
-0.1530-01 \\
-0.2219-01 \\
0.5770-01 \\
0.1065+03 \\
0.8093+02 \\
-0.1042-01 \\
-0.5517-01 \\
0.1566+03 \\
0.2893+03 \\
-0.1237+05 \\
0.8017+04 \\
0.1682+05\end{array}$ & $\begin{array}{r}0.1203+03 \\
-0.6646+03 \\
0.1262-03 \\
0.2480-03 \\
0.7286+04 \\
-0.1216-02 \\
-0.1116-02 \\
0.4551-03 \\
-0.4385-02 \\
0.1560+03 \\
0.1690+03 \\
0.8943-03 \\
-0.4065-02 \\
0.4312+03 \\
0.4401+03 \\
-0.4809+05 \\
0.3291+05 \\
0.8985+05\end{array}$ \\
\hline
\end{tabular}

\begin{tabular}{|c|c|c|c|c|c|}
\hline$\lambda$ & $\begin{array}{c}\phi_{A}, \\
\phi_{B}\end{array}$ & ${ }_{\mathrm{B}}^{\mathrm{A}}{ }_{\mathrm{k}}$ & $a / t=20$ & $a / t=100$ & $a / t=200$ \\
\hline 3 & 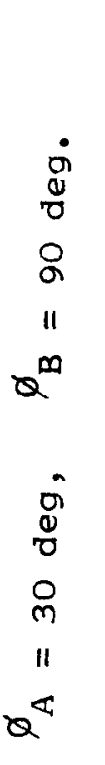 & $\begin{array}{l}A_{11} \\
A_{12}^{12} \\
A_{13}^{13} \\
A_{22}^{14} \\
A_{23}^{22} \\
A_{24}^{2} \\
A_{31}^{3} \\
A_{32}^{33} \\
A_{34}^{3} \\
A_{41}^{41} \\
A_{44}^{42} \\
B_{1}^{1} \\
B_{2}^{2} \\
B_{4}^{3}\end{array}$ & $\begin{array}{l}0.4290+02 \\
-0.7736+02 \\
-0.8073 \\
-0.4214-01 \\
0.2352+03 \\
0.9967 \\
-0.3962 \\
-0.4271+01 \\
0.5273+01 \\
0.3942+02 \\
0.6429+01 \\
-0.2230 \\
-0.2096+01 \\
0.7271+01 \\
0.3348+03 \\
-0.1479+04 \\
0.3464+03 \\
0.3071+03\end{array}$ & $\begin{array}{r}0.8751+02 \\
-0.3477+03 \\
0.1147-01 \\
0.1751-01 \\
0.2611+04 \\
-0.1378 \\
-0.8388-01 \\
0.6068-01 \\
-0.7291 \\
0.1187+03 \\
0.4821+02 \\
0.9266-01 \\
-0.4438 \\
0.6373+02 \\
0.1805+04 \\
-0.3962+05 \\
0.7637+04 \\
0.1134+05\end{array}$ & $\begin{array}{r}0.1219+03 \\
-0.6796+03 \\
-0.1892-03 \\
-0.1037-02 \\
0.7345+04 \\
0.8288-02 \\
0.9295-02 \\
-0.1000-02 \\
0.4384-01 \\
0.1799+03 \\
0.1056+03 \\
-0.5485-02 \\
0.4917-01 \\
0.1713+03 \\
0.3281+04 \\
-0.1566+06 \\
0.3208+05 \\
0.5814+05\end{array}$ \\
\hline
\end{tabular}


Table C-4

INFLUENCE COEFFICIENTS OF ELLIPSOIDAL SHELLS

\begin{tabular}{|c|c|c|c|c|c|}
\hline$\lambda$ & $\begin{array}{l}\phi_{\mathrm{A}}, \\
\phi_{\mathrm{B}}\end{array}$ & ${ }^{{ }^{A}}{ }_{k}{ }_{k}$, & $a / t=20$ & $a / t=100$ & $a / t=200$ \\
\hline 4 & 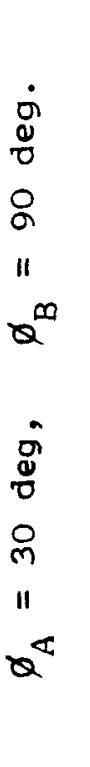 & $\begin{array}{l}A_{11} \\
A_{12}^{12} \\
A_{13} \\
A_{14}^{14} \\
A_{22}^{23} \\
A_{24} \\
A_{31}^{31} \\
A_{33}^{32} \\
A_{34}^{34} \\
A_{41}^{41} \\
A_{42}^{4} \\
B_{1}^{1} \\
B_{2}^{2} \\
B_{3}^{3}\end{array}$ & $\begin{array}{l}0.4899+02 \\
-0.8588+02 \\
-0.6444 \\
0.1323 \\
0.2318+03 \\
0.1218 \\
-0.5612 \\
-0.4509+01 \\
0.8526 \\
0.3545+02 \\
0.3401+01 \\
0.9262 \\
-0.3927+01 \\
0.4563+01 \\
0.7233+03 \\
-0.2441+04 \\
0.4037+03 \\
0.2827+03\end{array}$ & $\begin{array}{r}0.9247+02 \\
-0.3709+03 \\
0.5988-01 \\
0.1694-01 \\
0.2641+04 \\
-0.2550 \\
0.1222-01 \\
0.4190 \\
-0.1784+01 \\
0.1210+03 \\
0.3067+02 \\
0.1186 \\
0.8543-01 \\
0.3476+02 \\
0.4973+04 \\
-0.7423+05 \\
0.6927+04 \\
0.8918+04\end{array}$ & $\begin{array}{r}0.1258+03 \\
-0.7100+03 \\
-0.4721-02 \\
-0.1677-02 \\
0.7432+04 \\
0.2566-01 \\
-0.3188-02 \\
-0.3303-01 \\
0.1795 \\
0.1910+03 \\
0.7110+02 \\
-0.1174-01 \\
-0.2227-01 \\
0.9030+02 \\
0.1032+05 \\
-0.3039+06 \\
0.2970+05 \\
0.4372+05\end{array}$ \\
\hline
\end{tabular}


GEAP-13719

Table C-5

INFLUENCE COEFFICIENTS OF ELLIPSOIDAL SHELLS

\begin{tabular}{|c|c|c|c|c|c|}
\hline$\lambda$ & $\begin{array}{l}\phi_{\mathrm{A}}, \\
\phi_{\mathrm{B}}\end{array}$ & ${ }_{B_{k}}^{A_{j k}}$ & $a / t=20$ & $a / t=100$ & $a / t=200$ \\
\hline \multirow{18}{*}{2} & \multirow{5}{*}{$\underset{0}{0}$} & & $0.3914+02$ & $0.8533+02$ & $0.1203+03$ \\
\hline & & & $-0.6995+02$ & $-0.3342+03$ & $-0.6647+03$ \\
\hline & & & $-0.2341+01$ & 0.2785 & $-0.4249-02$ \\
\hline & & & $0.3232+01$ & -0.1733 & 0.1312 \\
\hline & & & $0.2363+03$ & $0.2580+04$ & $0.7285+04$ \\
\hline & o & $\mathrm{A}_{2}^{2}$ & $-0.4888+01$ & 0.2594 & -0.2474 \\
\hline & \multirow{2}{*}{11} & & $-0.1759+02$ & $0.5584+01$ & $-0.1549+01$ \\
\hline & & & $-0.3576+01$ & 0.4254 & $-0.6490-02$ \\
\hline & $Q^{\infty}$ & $A_{32}^{31}$ & $-0.7466+01$ & 0.3962 & -0.3778 \\
\hline & & & $0.4355+02$ & $0.1039+03$ & $0.1491+03$ \\
\hline & à & $A$ & $0.3813+02$ & $0.2055+03$ & $0.4178+03$ \\
\hline & $\frac{0}{0}$ & & $0.4937+01$ & -0.2647 & 0.2004 \\
\hline & & & $-0.2687+02$ & $0.8529+01$ & $-0.2366+01$ \\
\hline & 0 & & $.0 .8448+02$ & $0.8923+03$ & $0.2497+04$ \\
\hline & 11 & $\mathrm{~B}_{1}^{4}$ & $0.1314+03$ & $0.2767+03$ & $0.4600+03$ \\
\hline & 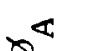 & $\mathrm{B}_{2}$ & $-0.7927+03$ & $-0.1195+05$ & $-0.4832+05$ \\
\hline & & $\mathrm{B}_{3}^{2}$ & $0.6757+03$ & $0.1601+05$ & $0.6407+05$ \\
\hline & & $\mathrm{B}_{4}$ & $0.1327+04$ & $0.6880+05$ & $0.3826+06$ \\
\hline
\end{tabular}

$\lambda \stackrel{\varnothing}{A},_{\varnothing_{B}^{A}}^{A_{B k},} \quad a / t=20 \quad a / t=100 \quad a / t=200$

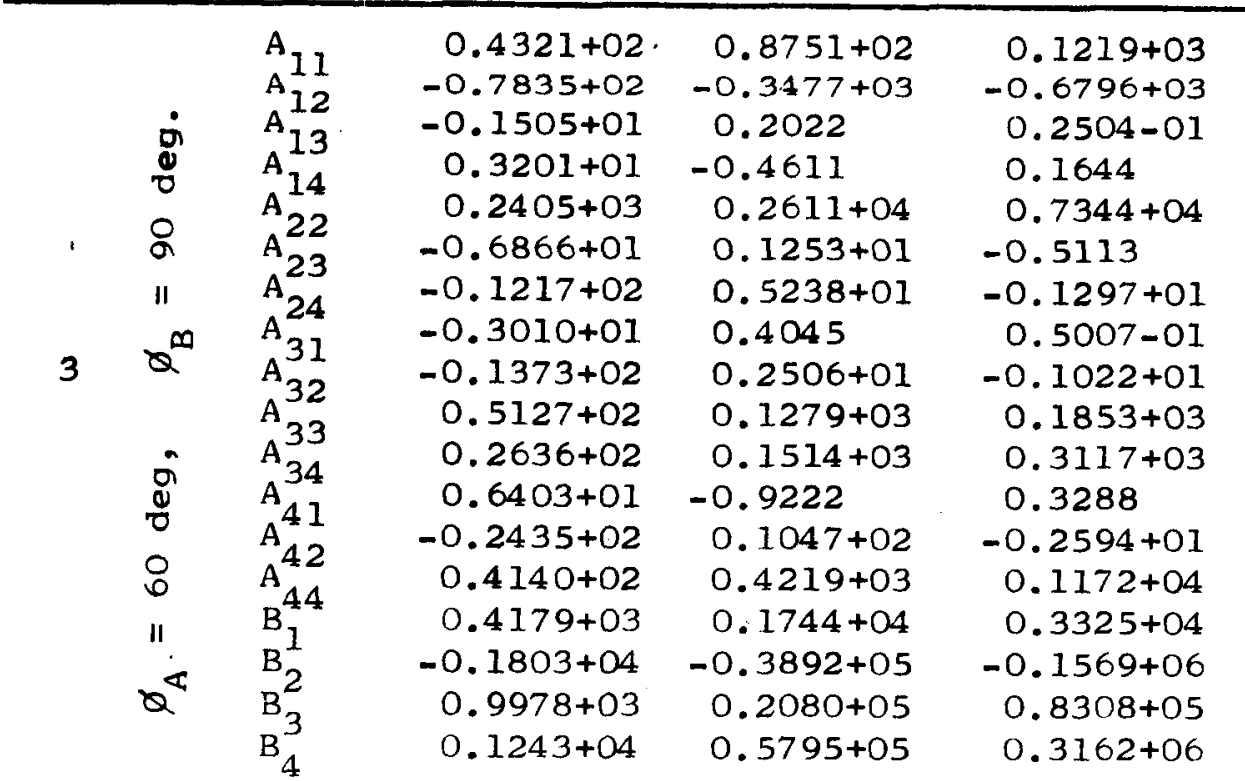


Table C-6

INFLUENCE COEFFICIENTS OF ELLIPSOIDAL SHELLS

\begin{tabular}{|c|c|c|c|c|c|}
\hline$\lambda$ & $\begin{array}{l}\phi_{A}, \\
\phi_{B}\end{array}$ & ${ }_{{ }_{k}}^{A_{j k}}$ & $a / t=20$ & $a / t=100$ & $a / t=200$ \\
\hline 4 & 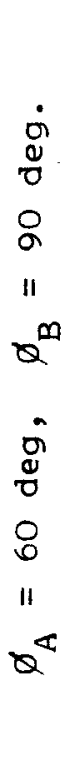 & $\begin{array}{l}A_{11} \\
A_{12} \\
A_{13} \\
A_{14} \\
A_{22} \\
A_{23} \\
A_{24} \\
A_{31} \\
A_{32}^{32} \\
A_{33} \\
A_{34} \\
A_{41} \\
A_{42} \\
A_{44} \\
B_{1}^{1} \\
B_{2} \\
B_{3}^{2} \\
B_{4}^{3}\end{array}$ & $\begin{array}{r}0.4965+02 \\
-0.8767+02 \\
-0.4503 \\
0.3047+01 \\
0.2382+03 \\
-0.8378+01 \\
-0.8707+01 \\
-0.1133+01 \\
-0.2108+02 \\
0.5566+02 \\
0.1873+02 \\
0.7669+01 \\
-0.2191+02 \\
0.2391+02 \\
0.8333+03 \\
-0.2786+04 \\
0.1279+04 \\
0.1138+04\end{array}$ & $\begin{array}{r}0.9248+02 \\
-0.3708+03 \\
0.3358-01 \\
-0.6323 \\
0.2641+04 \\
0.2497+01 \\
0.4702+01 \\
0.8456-01 \\
0.6284+01 \\
0.1460+03 \\
0.1151+03 \\
-0.1591+01 \\
0.1183+02 \\
0.2325+03 \\
0.4854+04 \\
-0.7335+05 \\
0.2292+05 \\
0.4708+05\end{array}$ & $\begin{array}{l}0.1258+03 \\
-0.7099+03 \\
0.7242-01 \\
0.1732 \\
0.7430+04 \\
-0.8001 \\
-0.9478 \\
0.1822 \\
-0.2013+01 \\
0.2141+03 \\
0.2409+03 \\
0.4360 \\
-0.2385+01 \\
0.6406+03 \\
0.1038+05 \\
-0.3042+06 \\
0.9177+05 \\
0.2516+06\end{array}$ \\
\hline
\end{tabular}


Table C-7

INFLUENCE FUNCTIONS FOR ELLIPSOIDAL SHELLS $\{a / t=100\}$

\begin{tabular}{|c|c|c|c|c|}
\hline & & & & \\
\hline$S$ & $\lambda=2$ & $\lambda=4$ & $\lambda=2$ & $\lambda=4$ \\
\hline 0.03 & $-0.3507-04$ & $0.1158-02$ & $0.4471-03$ & $-0.8128-02$ \\
\hline 0.07 & $-0.4362-04$ & $0.1252-02$ & $0.4630-03$ & $-0.8240-02$ \\
\hline 0.10 & $-0.5733-04$ & $0.1402-02$ & $0.4729-03$ & $-0.8145-02$ \\
\hline 0.13 & $-0.7409-04$ & $0.1592-02$ & $0.4536-02$ & $-0.7852-02$ \\
\hline 0.17 & $-0.9008-04$ & $0.1799-02$ & $0.368 i-0 \overline{2}$ & $-0.7200-02$ \\
\hline 0.20 & $-0.9930-04$ & $0.1989-02$ & $0.1694-02$ & $-0.5976-02$ \\
\hline 0.23 & $-0.9297-04$ & $0.2109-02$ & $0.1999-02$ & $-0.3919-02$ \\
\hline 0.27 & $-0.5925-04$ & $0.2096-02$ & $0.7971-02$ & $-0.7289-03$ \\
\hline 0.30 & $0.1658-04$ & $0.1867-02$ & $0.1667-02$ & $0.3923-02$ \\
\hline 0.33 & $0.1508-03$ & $0.1320-02$ & $0.2818-02$ & $0.1036-01$ \\
\hline 0.37 & $0.3578-03$ & $0.3360-03$ & $0.4183-03$ & $0.1887-01$ \\
\hline 0.40 & $0.6447-03$ & $-0.1220-02$ & $-0.5567-02$ & $0.2961-01$ \\
\hline 0.43 & $0.1000-02$ & $-0.3486-02$ & $-0.6582-02$ & $0.4255-01$ \\
\hline 0.47 & $0.1382-02$ & $-0.6591-02$ & $-0.6564-02$ & $0.5730-01$ \\
\hline 0.50 & $0.1692-02$ & $-0.1062-01$ & $-0.4507-02$ & $0.7292-01$ \\
\hline 0.53 & $0.1758-02$ & $-0.1559-01$ & $0.9670-03$ & $0.8769-01$ \\
\hline 0.57 & $0.1299-02$ & $-0.2135-01$ & $0.1152-01$ & $0.9878-01$ \\
\hline 0.60 & $-0.8261-04$ & $-0.2753-01$ & $0.2881-01$ & $0.1018+00$ \\
\hline 0.63 & $-0.2894-02$ & $-0.3336-01$ & $0.5377-01$ & $0.9048-01$ \\
\hline 0.67 & $-0.7670-02$ & $-0.3752-01$ & $0.8523-01$ & $0.5592-01$ \\
\hline 0.70 & $-0.1475-01$ & $-0.3789-01$ & $0.1176+00$ & $-0.1362-01$ \\
\hline 0.73 & $-0.2384-01$ & $-0.3120-01$ & $0.1368+00$ & $-0.1330+00$ \\
\hline 0.77 & $-0.3310-01$ & $-0.1263-01$ & $0.1152+00$ & $-0.3200+00$ \\
\hline 0.80 & $-0.3760-01$ & $0.2467-01$ & $0.3827-02$ & $-0.5930+00$ \\
\hline 0.83 & $-0.2679-01$ & $0.9001-01$ & $-0.2733+00$ & $-0.9662+00$ \\
\hline 0.87 & $0.1925-01$ & $0.1954+00$ & $-0.8164+00$ & $-0.1437+01$ \\
\hline 0.30 & $0.1340+00$ & $0.3543+00$ & $-0.1710+0 \hat{1}$ & $-0.1946+01$ \\
\hline 0.93 & $0.3632+00$ & $0.5758+00$ & $-0.2854+01$ & $-0.2349+01$ \\
\hline 0.97 & $0.7258+00$ & $0.8391+00$ & $-0.3367+01$ & $-0.2107+01$ \\
\hline 1.00 & $0.1000+01$ & $0.1000+01$ & $0.0000+00$ & $0.0000+00$ \\
\hline
\end{tabular}

\begin{tabular}{|c|c|}
\hline \multicolumn{2}{|c|}{$\mathrm{B}_{21}$} \\
\hline$\lambda=2$ & $\lambda=4$ \\
\hline$-0.4825-03$ & $0.5107-02$ \\
\hline$-0.8615-03$ & $0.9665-02$ \\
\hline$-0.6328-03$ & $0.9772-02$ \\
\hline $0.7766-03$ & $0.2292-02$ \\
\hline $0.4189-02$ & $-0.1667-01$ \\
\hline $0.1064-01$ & $-0.5182-01$ \\
\hline $0.2116-01$ & $-0.1086+00$ \\
\hline $0.3638-01$ & $-0.1925+00$ \\
\hline $0.5565-01$ & $-0.3083+00$ \\
\hline $0.7578-01$ & $-0.4583+00$ \\
\hline $0.8924-01$ & $-0.6400+00$ \\
\hline $0.8181-01$ & $-0.8420+00$ \\
\hline $0.3027-01$ & $-0.1039+01$ \\
\hline$-0.9914-01$ & $-0.1187+01$ \\
\hline$-0.3495+00$ & $-0.1211+01$ \\
\hline$-0.7664+00$ & $-0.9996+00$ \\
\hline$-0.1379+01$ & $-0.3921+00$ \\
\hline$-0.2163+01$ & $0.8289+00$ \\
\hline$-0.2977+01$ & $0.2941+01$ \\
\hline$-0.3452+01$ & $0.6276+01$ \\
\hline$-0.2843+01$ & $0.1118+02$ \\
\hline $0.1531+00$ & $0.1794+02$ \\
\hline $0.7555+01$ & $0.2660+02$ \\
\hline $0.2201+02$ & $0.3664+02$ \\
\hline $0.4597+02$ & $0.4629+02$ \\
\hline $0.7886+02$ & $0.5130+02$ \\
\hline $0.1091+03$ & $0.4234+02$ \\
\hline $0.9332+02$ & $-0.3369+00$ \\
\hline$-0.9409+02$ & $-0.1173+03$ \\
\hline$-0.7100+03$ & $-0.3709+03$ \\
\hline
\end{tabular}

$\begin{array}{cc} & \\ \lambda=2 & B_{22} \\ & \lambda=4 \\ & \\ 0.7460-03 & 0.1315-02 \\ -0.1125-02 & 0.1580-01 \\ -0.9606-02 & 0.5990-01 \\ -0.2857-01 & 0.1498+00 \\ -0.6136-01 & 0.3007+00 \\ -0.1094+00 & 0.5246+00 \\ -0.1695+00 & 0.8275+00 \\ -0.2290+00 & 0.1201+01 \\ -0.2604+00 & 0.1627+01 \\ -0.2138+00 & 0.2045+01 \\ -0.9979-02 & 0.2359+01 \\ 0.4627+00 & 0.2415+01 \\ 0.1342+01 & 0.1979+01 \\ 0.2764+01 & 0.7254+00 \\ 0.4805+01 & -0.1781+01 \\ 0.7361+01 & -0.6087+01 \\ 0.9949+01 & -0.1283+02 \\ 0.1141+02 & -0.2266+02 \\ 0.9498+01 & -0.3616+02 \\ 0.4331+00 & -0.5349+02 \\ -0.2142+02 & -0.7403+02 \\ -0.6323+02 & -0.9556+02 \\ -0.1318+03 & -0.1130+03 \\ -0.2276+03 & -0.1163+03 \\ -0.3313+03 & -0.8704+02 \\ -0.3728+03 & 0.7073+01 \\ 0.1696+03 & 0.2216+03 \\ 0.6914+03 & 0.6496+03 \\ 0.3001+04 & 0.1432+04 \\ 0.7434+04 & 0.2642+04\end{array}$




\section{GEAP-13719}

A. GEOMETRY

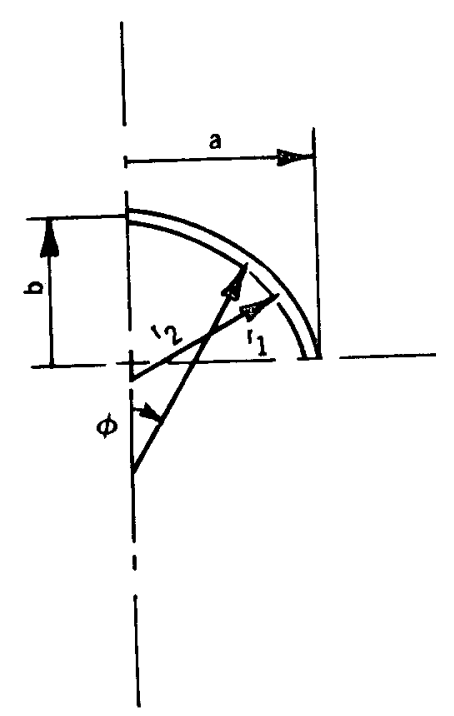

B. SHELL UNDER INTERNAL PRESSURE
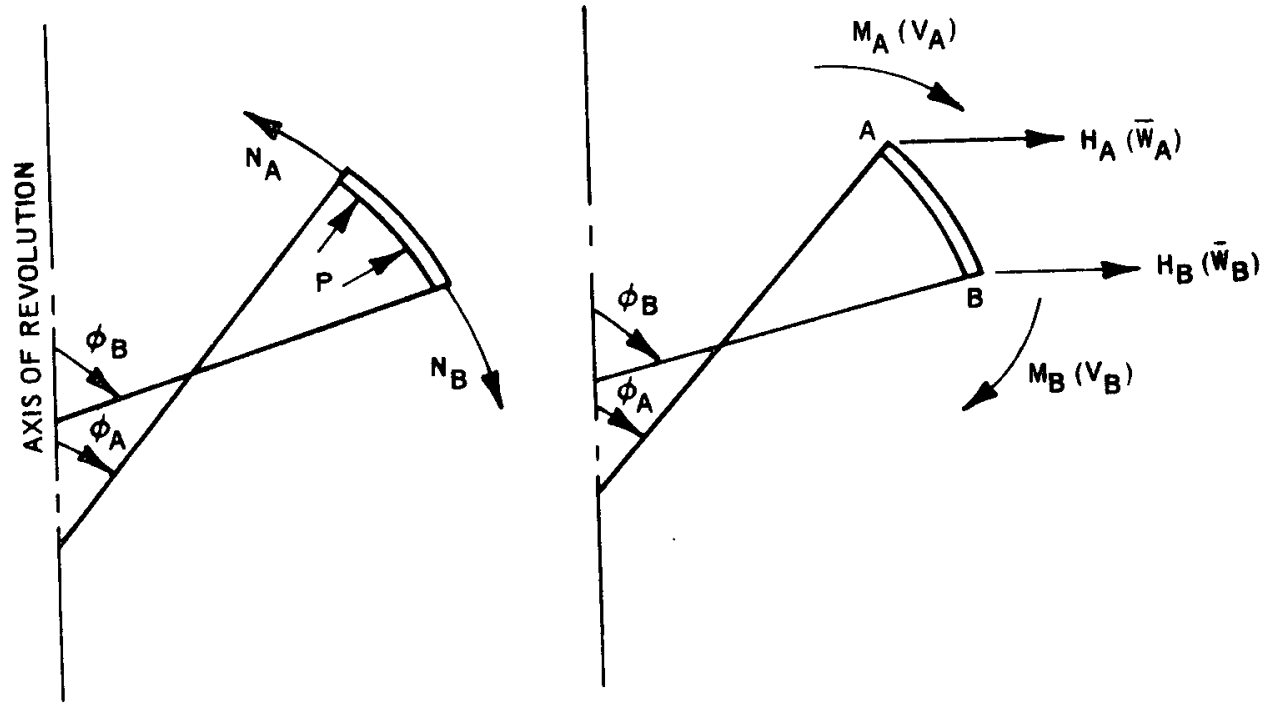

Figure C-1. Sign Convention for Ellipsoidal Shells 


\section{APPENDIX D. A SURVEY OF INELASTIC BEHAVIOR OF ISOTROPIC SHELISS}

\section{D.1 INTRODUCTION}

A survey of the methods of analyzing thin-walled isotropic inelastic shells has been conducted, and the results are summarized briefly. It is assumed that the small deformation theory is valid and strain rates are slow enough that the inertia effects are negligible. Insofar as the constitutive equations are concerned, the entire mathematical treatment is formulated from the phenomenological theory.

To make the presentation compact, tensor notation is utilized with the following conventional rules:

- Latin letter indices take the range of 1 to 3, whereas Greek indices assume the range of 1 and 2.

- Any term in which the same superscript or subscript appears twice stands for the sum of all such terms obtained by giving this index its complete range of values.

- The Kronecker deltas are defined as

$$
\begin{aligned}
& \delta_{i j}=0, i=j, \\
& \delta_{i j}=1, i=j, j \text { not summed. }
\end{aligned}
$$

\section{D.2 CONSTITUTIVE EQUATIONS}

A constitutive equation defines a relation between quantities describing the states of stress and strain as well as their various time derivatives. Symbolically, such an equation can be written as

$$
F\left(\sigma_{i j}, \dot{\sigma}_{i j}, \ldots, \epsilon_{i j}, \dot{\epsilon}_{i j}, \ldots, T, t\right)=0,
$$

where $\sigma_{\mathrm{ij}}, \epsilon_{\mathrm{ij}}, \mathrm{T}$, and $\mathrm{t}$ are stress, strain, temperature and time, respectively. Dots represent time derivatives. The tensorial character of the above equation makes it clear that material properties showing the relation between stress and strain quantities form tensors.

The response of a plastically isotropic material is elastic under load until the stress level reaches the yield surface. Such a surface can be expressed by a scalar vield function as

$$
\phi\left(\sigma_{i j}\right)=K^{n}
$$

where $K$ is the material yield constant and $n$ the order of the function. For ideally plastic materials, $\dot{\phi}=0$, whereas for solids with hardening $\dot{\phi}>0$. If infintesimal theory is prescribed, the strain tensor is defined as

$$
\epsilon_{i j}=\frac{1}{2}\left(u_{i, j}+u_{j, i}\right)
$$

where $u_{i}$ is the displacement vector and commas represent partial derivatives. The strain tensor, in turn, can be decomposed into the following components: 


$$
\epsilon_{i j}=\epsilon_{i j}^{E}+\epsilon_{i j}^{C}+\epsilon_{i j}^{P}
$$

where the superscripts $E, C$, and $P$ stand for elastic, creep, and plastic parts of the total strain, respectively. If one assumes that volume changes of the material can occur only in the elastic range, then

$$
\dot{\epsilon}^{C}+\dot{\epsilon}^{P}=0
$$

and consequently, one is concerned with only the deviatoric parts of the inelastic components of the stress and strain tensors; namely,

$$
\begin{aligned}
& s_{i j}=\sigma_{i j}-\frac{1}{3} \sigma_{k k} \delta_{i j} . \\
& e_{i j}=\epsilon_{i j}-\frac{1}{3} \epsilon_{k k} \delta_{i j} .
\end{aligned}
$$

For linear viscoelastic materials, Equation (D-1) can be expressed as

$$
P \sigma_{i j}=2 G Q \epsilon_{i j}+\frac{1}{3}(3 K P-2 G Q) \epsilon_{i j} \delta_{i j}-3 \alpha K P T \delta_{i j}
$$

where $P$ and $Q$ are linear differential operators and $G, K, T$, and $\alpha$ are shear and bulk moduli, temperature, and the coefficient of thermal expansion, respectively. It can be shown that for Kelvin solid, the operators $P$ and $Q$ take the following respective values:

$$
P=1 \text {, }
$$

and

$$
\mathrm{Q}=1+\frac{\eta}{\mathrm{G}} \frac{\partial}{\partial \mathrm{t}} \text {, }
$$

whereas for Maxwell material,

$$
P=\frac{G}{\eta}+\frac{\partial}{\partial t},
$$

and

$$
\mathrm{Q}=\frac{\partial}{\partial \mathrm{t}},
$$

in which $\eta=$ shear viscosity.

Equation (D-7) is simplified if it is expressed in terms of the deviatoric components of the stress and strain tensors; i.e.,

$$
P s_{i j}=2 G Q e_{i j} \text {. }
$$


The advantage of using the linear viscoelastic theory is that solutions are usually obtainable by the application of Laplace transforms. However, the disadvantage of such linear theory is that many materials do not fit in this category and the use of the nonlinear viscoelastic theory is advisable in this situation. If nonlinear creep is postulated, Equation (D-1) may take either the flow type,

$$
\dot{\epsilon}_{i j}=\dot{\epsilon}_{i j}+f\left(\sigma_{k k}\right) \sigma_{i j} \cdot
$$

or one which involves the explicit time.

$$
\epsilon_{i j}=\epsilon_{i j}^{E}+f\left(\sigma_{k \ell}, t\right) \sigma_{i j}
$$

Ordinarily, in structural problems involving creep, the elastic strain is neglibibly small when compared with creep strain. The functional relation between creep strain and time (and stress) can be expressed as

$$
f\left(\sigma_{i j}, t\right)=\epsilon_{i j}^{C} \underset{i j}{C}
$$

Then, the three stages of creep can be defined in the following manner:

$$
\begin{aligned}
& \ddot{f}<0 \text { primary stage, } \\
& \ddot{f}=0 \text { secondary stage, } \\
& \ddot{f}>0 \text { tertiary stage, }
\end{aligned}
$$

which are also known as unsteady, steady, and accelerated stages. If elastic deformation is neglected, the stress and strain rate relation for steady creep may be approximated by

$$
\dot{\epsilon}_{i j}^{C}=\dot{\epsilon}_{i j}=f\left(\sigma_{i j}\right) s_{i j} \text {. }
$$

where $f\left(\sigma_{i j}\right)$ is a scalar function.

Generally, solutions of the creep problems are based on various generalizations of Norton's law; i.e.,

$$
\dot{\boldsymbol{\epsilon}}=k \sigma^{n} \text {. }
$$

in which $\mathrm{k}$ and $\mathrm{n}$ are material constants. For example,

$$
\dot{\epsilon}_{i j}=\tilde{k}\left(s_{r s} s_{r s}\right)^{(n-1) / 2} s_{i j}, \dot{\epsilon}_{i i}=0 .
$$

The foregoing equation is obtained by assuming that the second invariant of the tensors involved in Equation (D-13) controls the material properties. To overcome certain difficulties encountered in obtaining a solution, it is possible to utilize the following relationship between the maximum shear stress and shear strain rate:

$$
\dot{\epsilon}_{i}-\dot{\epsilon}_{i}=f\left(\tau_{\max }\right)\left(\sigma_{i}-\sigma_{j}\right)
$$


Creep instability is due to the nonlinearity of Equation (D-15). This phenomenon can occur under tension or compression loads. In the case of compressive loading, it is called creep buckling.

Two basic types of constitutive equations have been developed for the study of primary creep; namely,

$$
\epsilon_{i j}=\epsilon_{i j}^{E}+F(t)\left(s_{i j} s_{i j}\right)^{m}, m>1 \text {. }
$$

and

$$
\dot{\epsilon}_{i j}=f(\epsilon) \sigma_{i j}^{m} .
$$

Creep behavior, represented by Equation (D-17a), is referred to as time-hardening, whereas Equation (D-17b) belongs to the category of strain-hardening.

There are two theories that deal with the plastic behavior of materials. The first one is called deformation theory. or theory of small elastic-plastic strains in which the deformations are expressed in terms of stress-strain relations. The second one is called the flow or incrementat theory. In the latter, the constitutive equations are written as stress-strain rate relations.

The constitutive equation for the deformation theory is expressed in terms of stress and strain derivators, and volume change is not permissible in the plastic range.

For loading:

$$
s_{i j}=2 G\left(1-\frac{\phi}{2 G}\right) e_{i j}, \sigma_{i i}=3 K \epsilon_{i j}, \phi>0 .
$$

For unloading

$$
s_{i j}=2 \mathrm{Ge}_{\mathrm{ij}}, \phi=0 \text {, }
$$

where $\phi$ is a scalar function. Equation (D-18b) implies that the unloading is elastic.

Since $G$ and $\phi$ are scalars, Equation (D-18a), which also is called the Hencky-llyushin relations, expresses the coaxiality of the stress and strain tensors during plastic deformation.

The corresponding equation for the flow theory is

$$
\dot{e}_{i j}=\frac{1}{2 G} \dot{\bar{s}}_{i j}+\psi s_{i j}, \sigma_{i i}=3 K \epsilon_{i i}
$$

where $\psi$ is a non-negative scalar function. It is noted that the flow theory admits redistribution of stresses in the plastic regions because the proportionality of stress and strain tensors is not required in this theory but the stress and strain rate tensors, however, must be coaxial.

\section{D.3 CREEP AND PLASTIC POTENTIALS}

Analogous to the elastic potential, the creep and plastic potentials have also been introduced in the mechanics of inelastic continua. This concept is rather associated with the application of variational principles so that approximate solutions may be made for the inelastic problems. 
According to the general relations of Equation (D-1), besides the elastic energy density given by

$$
v=\frac{1}{2} \sigma_{i j} \epsilon_{i j}^{E}
$$

one has the power and complimentary power, respectively, given by the following expressions:

$$
U=\sigma_{i j} \dot{\epsilon}_{i j} \text {, }
$$

and

$$
\tilde{U}=\dot{\sigma}_{i j} \epsilon_{i j}
$$

It is noted that the elastic part of Equation (D-21) is reversible, whereas the creep and plastic parts; namely,

$$
\mathrm{D}_{\mathrm{C}}=\sigma_{\mathrm{ij}} \dot{\epsilon}_{\mathrm{ij}}^{\mathrm{C}}
$$

and

$$
D_{p}=\sigma_{i j} \dot{\epsilon}_{i j}
$$

are dissipated. The corresponding creep and plastic potentials can be constructed as follows:

$$
\begin{aligned}
& \Phi=\int_{0}^{\epsilon_{i j}} \sigma_{i j} d \dot{\epsilon}_{i j} \text { or } \sigma_{i j}=\frac{\partial \Phi}{\partial \dot{\epsilon}_{i j}}, \\
& \Psi=\int_{0}^{\sigma_{i j}} \dot{\epsilon}_{i j} d \sigma_{i j} \text { or } \dot{\epsilon}_{i j}=\frac{\partial \Psi}{\partial \sigma_{i j}} .
\end{aligned}
$$

For incompressible creep and plastic deformations,

$$
\sigma_{i j} \dot{\epsilon}_{i j}=s_{i j} \dot{e}_{i j} \text {. }
$$

If the material is linearly viscous, Equation (D-1) may be written as

$$
s_{i j}=2 \eta \dot{\mathrm{e}}_{i j}^{c}
$$

and the creep potential must have the following form in order to satisfy Equation D-22:

$$
\Phi\left(\dot{\epsilon}_{i j}^{c}\right)=\eta \dot{\epsilon}_{i j}^{c} \dot{\epsilon}_{i j}^{c}
$$


For steady creep, Equation (D-22a) becomes

$$
D=B\left(s_{i j} s_{i j}\right)^{(n+1) / 2}
$$

and the corresponding dissipative potentials are

$$
\begin{aligned}
& \Phi=\frac{n}{n+1} B\left(s_{i j} S_{i j}\right)^{(n+1) / 2} . \\
& \Psi=\frac{1}{n+1} B\left(S_{i j} S_{i j}\right)^{(n+1) / 2} .
\end{aligned}
$$

In view of Equations (D-25) and (D-26), it is apparent that

$$
\mathrm{D}=\Phi+\Psi \text {. }
$$

It can also be shown that for a perfectly plastic material with the flow law

$$
\dot{\epsilon}_{\mathrm{ij}}=\Psi s_{\mathrm{ij}} \text {, }
$$

the associated flow law in the plastic flow theory is

$$
\dot{\epsilon}_{i j}^{P}=\Psi \frac{\partial F}{\partial \sigma_{i j}},
$$

where F represents the Huber-Mises yield condition; i.e.,

$$
F=s_{i j} s_{i j}-\text { const. }=0 .
$$

The dissipative potentials given by Equation (D-26) form the basis of the variational methods for inelastic analysis.

\section{D.4 FIELD EQUATIONS FOR THIN SHELLS}

The formulation of field equations to be discussed is for thin isotropic shells. These equations are based on the small deformation theory and the Love-Kirchhoff hypothesis that deformed normal remains straight, normal stresses and transverse shear strains are negligibly small, torsion about the normal is not considered, and the ratio of thickness of shell to the minimum principal radius of curvature is very much smaller than unity.

The stress resultants and couples are obtained by integrating the stresses and moments through the thickness, t; i.e.,

$$
N_{\alpha \beta}=\int_{\frac{-t}{2}}^{\frac{+t}{2}} \sigma_{\alpha \beta} d z
$$




$$
\begin{aligned}
& a_{\alpha}=\int_{\frac{-t}{2}}^{\frac{t t}{2}} \sigma_{\alpha 3} d z, \\
& M_{\alpha \beta}=\int_{\frac{-t}{2}}^{\frac{t t}{2}} \sigma_{\alpha \beta} z d z .
\end{aligned}
$$

The strains are expressed by

$$
\epsilon_{\alpha \beta}=\lambda_{\alpha \beta}+2 x_{\alpha \beta} \cdot \epsilon_{\alpha 3}=0
$$

in which $\lambda_{\alpha \beta}$ is the middle-surface strain tensor and $x_{\alpha \beta}$ is the curvature tensor of the deformed shell. These quantities can be expressed in terms of displacement vector, $u_{i}$, and their derivatives

The dissipation density of shell is

$$
D=\int_{\frac{-t}{2}}^{\frac{t t}{2}} \sigma_{\alpha \beta} \dot{\epsilon}_{\alpha \beta} d z=\dot{\lambda}_{\alpha \beta} N_{\alpha \beta}+\dot{x}_{\alpha \beta} M_{\alpha \beta} .
$$

The constitutive equation [Equation (D-1)] for shells can be transformed in terms of stress resultants and their time derivatives as follows:

$$
f\left(\mathbf{N}_{\alpha \beta}, \dot{\mathrm{N}}_{\alpha \beta}, \ldots, \mathrm{M}_{\alpha \beta} \ldots \ldots, \lambda_{\alpha \beta}, \ldots, \mathrm{x}_{\alpha \beta}, \ldots, \mathrm{T}, \mathrm{t}\right)=0
$$

The yield condition for plastic shells may be expressed as

$$
F\left(M_{\alpha \beta}, N_{\alpha \beta}\right)-k^{n}=0
$$

The force equations of equilibrium in the tri-orthogonal directions are

$$
\mathrm{N}_{\alpha \beta} \mid \alpha-b_{\alpha}^{\beta} \mathrm{Q}^{\alpha}+\mathrm{P}^{\beta}=0,
$$




$$
N^{\alpha \beta} b_{\alpha \beta}+\left.Q^{\alpha}\right|_{\alpha}+p^{3}=0
$$

where the tensor of transverse shears is given by

$$
Q^{\alpha}=\left.M^{\alpha \beta}\right|_{\alpha}
$$

$b_{\alpha \beta}$ is the surface tensor of the second fundamental form of shell, and vertical lines denote the surface covariant differentiations.

\section{D.5 CRITERIA FOR INITIAL AND SUBSEQUENT YIELDING}

In dealing with certain inelastic problems where the plastic effects are predominant, both initial and continued yield criteria are needed in order to obtain solutions.

Among the available theories, either the Tresca or the von Mises criterion for initial yielding may be used. However, it is believed that the latter gives close agreement with experiment for ductile materials under cyclic loading. The equation for the Tresca criterion can be expressed as

$$
f_{o}=\max \left|S_{i}-s_{j}\right|-\sigma_{0}=0
$$

where $f_{0}, S_{i}$ and $\sigma_{0}$ are the initial yield surface, the principal stress vector, and the yield stress in simple tension, respectively. The corresponding von Mises expression is

$$
f_{0}=\frac{1}{2} s_{i j} s_{i j}-\frac{1}{3} \sigma_{0}^{2}=0
$$

There are two basic hardening theories that explain the behavior of the loading surface f; namely, isotropic and kinematic hardening. For the isotropic case, successive loading surfaces are uniform expansions of the initial yield surface. If von Mises' initial yielding is prescribed, the equation for the subsequent yielding function is

$$
f=\frac{1}{2} s_{i j} s_{i j}-\frac{1}{3} \sigma_{e}^{2}=0
$$

where $\sigma_{\mathrm{e}}$ is an equivalent stress which increases with increasing strain and is equal to $\sigma_{0}$ at initial yield. The corresponding von Mises expression is

$$
f=\frac{1}{2} \widetilde{s}_{i j} \widetilde{s}_{i j}-\frac{1}{3} \sigma_{o}^{2}=0
$$

where

$$
s_{i j}=\left(\sigma_{i j}-\alpha_{i j}\right)-\frac{1}{3}\left(\sigma_{k k}-\alpha_{n n}\right) \sigma_{i j},
$$

and $\alpha_{i j}$ is the yield surface shift tensor. 


\section{D.6 BIBLIOGRAPHY}

1. Olszak, W. and Sawczuk, P., Inelastic Behavior in Shells, P. Noordhoff, Itd., the Netherlands, 1967.

2. Hult, Jan, Creep in Engineering Structures, Blaisdell Publishing Company, London, 1966.

3. Flügge, W., Viscoelasticity, Blaisdell Publishing Company, London, 1967.

4. Rabotnov, Yu. N., Creep Problems in Structural Members, John Wiley \& Sons, New York, 1969.

5. Green, A. E. and Zerner, W., Theoretical Elasticity, Oxford University Press, 1954.

6. Hill, R., The Mathematical Theory of Plasticity, Oxford University Press, 1960.

7. Odquist, F. K. G., Mathematical Theory of Creep and Creep Rupture, Oxford University Press, London, 1966.

8. Mendelson, A., Plasticity: Theory and Application, MacMillan Company, New York, 1968.

9. Mendelson, A., Hirschberg, M. H., and Manson, S. S., "A General Approach to the Practical Solution of Creep Problems", Trans. of the ASME Series D, Journal of Basic Engineering, December 1959.

10. Ziegler, H., "A Modification of Prager's Hardening Rule," Quarterly Applied Mathematics, Vol. 17, 1959, pp. 55-65. 


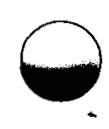

$\ominus$ 


\section{APPENDIX E. SHAKEDOWN FACTORS FOR SPHERICAL VESSELS WITH RADIAL NOZZLES}

The importance of the shakedown phenomena in the plastic or limit analysis and design of structures has been recognized for a long time. The principle involved is to introduce a set of self-equilibrated residual stresses in the redundant structure of the appropriate magnitude and sign by loading it beyond the elastic limit, and then reduce the load gradually to zero; then the structure will behave elastically under subsequent loadings of the same magnitude and sense. An excellent example of applying such a principle to obtain a highly efficient and purely elastic simple structure is in the manufacturing of spiral springs.

Using Melan's theorem and the available elastic solutions of analyzing discontinuity stresses in spherical shells with both flush and protruding radial nozzles, lower bound estimates of shakedown values for pressure and thrust and moment loadings have been found by F. A. Leckie and his co-workers. The results were obtained by using standard linear programming techniques.

Presented in this appendix is a compilation of results obtained by these investigators.

For completeness, values of the corresponding stress concentration factors are reproduced, and the shakedown values have also been expressed in terms of the yield stress.

The assumptions used in the evaluation of these results are:

- The material of the shell is elastic and perfectly plastic

- Tresca yield criterion is valid

- Maximum stresses occur in the spherical portion at the point of intersection

- Strain hardening and anisotropy of material are neglected.

Figures $E-1$ and $E \cdot 2$ show the stress concentration factors for the flush and protruding nozzles, respectively, versus the nondimensional parameter $\rho$, while Figures E-3 and E-4 depict the shakedown values for the respective nozzles. It is noted that the vertical scale at the left $\overline{\mathrm{P}}=\rho \mathrm{R} / 2 \mathrm{~T} \sigma^{*}$, and that on the right $k_{1,2}=\sigma_{\max } / \sigma^{*}$. where $\sigma^{*}$ is the yield stress in simple tension. Only two values of $t / T$ were used for the evaluation of $k_{1,2}$, namely $t / T=0.25$ and 1.0 .

Figures E-5 and E-6 show the stress concentration factors for the flush and protruding nozzles, respectively, for the thrust loading, while Figures E-7 through E-10 show the corresponding shakedown values for $\tilde{q}=Q \sqrt{R / T} / T \sigma^{*}$ and $k_{4,6}=\sigma_{\max } / \sigma^{*}$ as shown by the scale at the left. It should be noted that values for $k_{4,6}$ are computed based on the ratio of $R / T=90$. Figures $E-11$ and E-12 present the stress concentration factors for the two types of nozzles for moment loading. The corresponding lower bound estimates of the values of shakedown factor are also shown by the scale at the right of Figures $E-7$ to $E-10$, where $\bar{m}=M \sqrt{R / T} / \pi_{p}^{2} T \sigma^{*}$ and $k_{3,5}=\sigma_{\max } / \sigma^{*}$. Here again, the values of $k_{3,5}$ are based on $R / T=90$. Finally, it should be pointed out that the shakedown factors given are for the specific loading acting alone. In the case of combined loading, the original investigators recommended the use of the following approximate interaction formula:

$$
\frac{\bar{p}}{\bar{p}_{0}}+\frac{\bar{q}}{\bar{q}_{o}}+\frac{\bar{m}}{\bar{m}_{o}}=1
$$

Values of $\bar{P}_{0}, \bar{q}_{0}$ and $\bar{m}_{0}$ are given in Figures $E-3, E-4, E-7, E-8, E-9$, and $E-10$. 
GEAP-13719

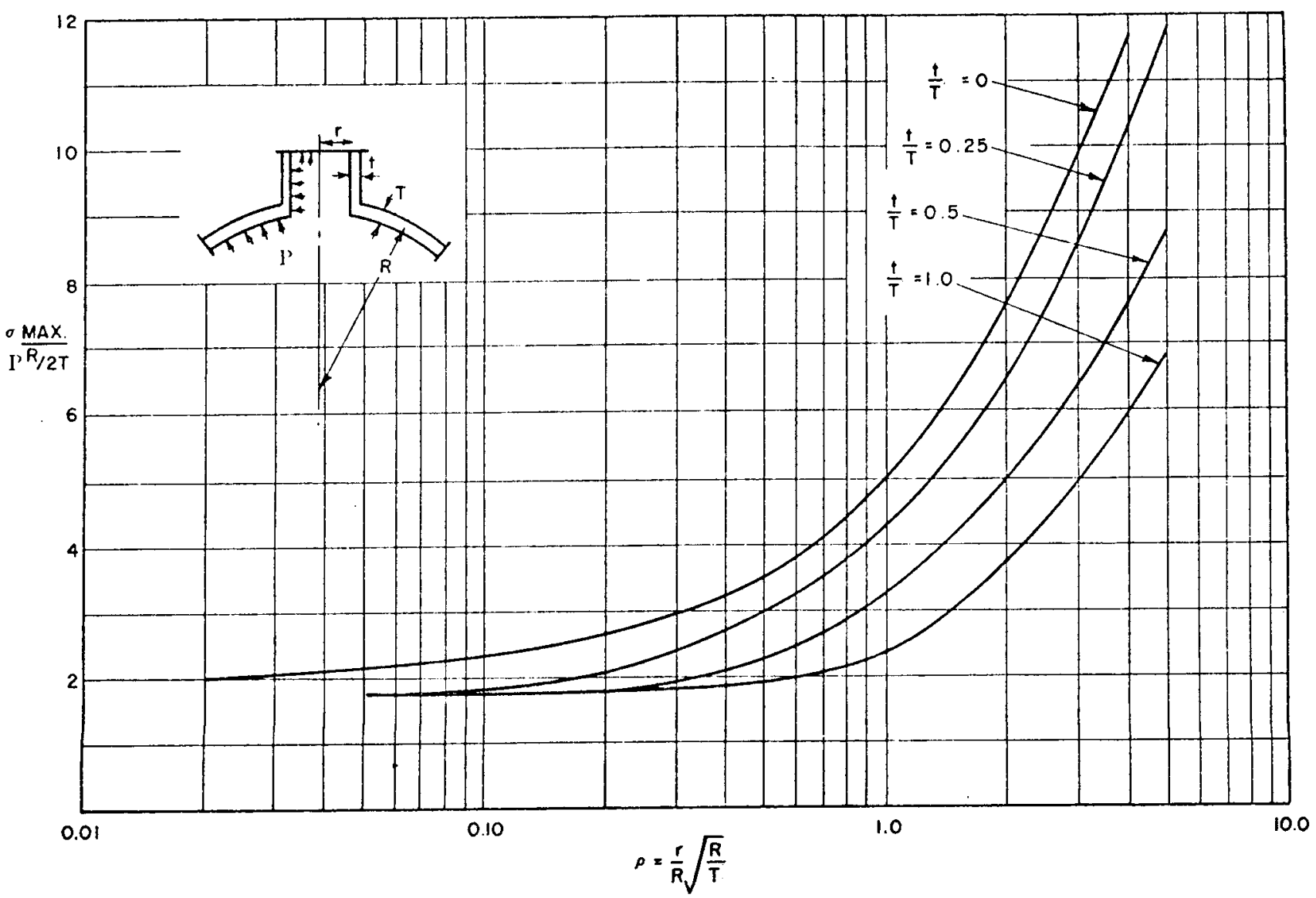

Figure E-1. Maximum Stress in Sphere for Internal Pressure (Flush Nozzles)

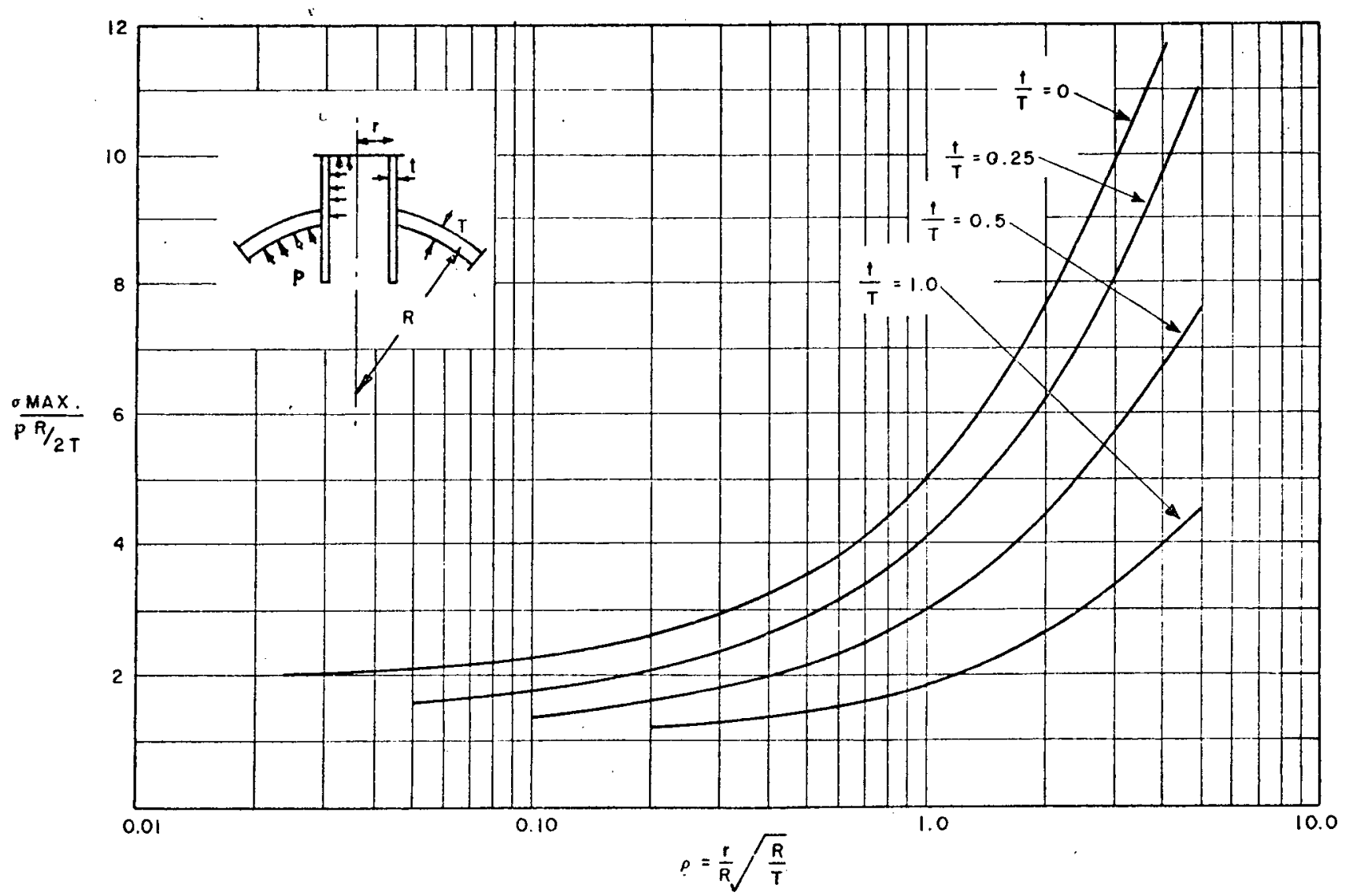

Figure E-2. Maximum Stress in Sphere for Internal Pressure (Protruding Nozzles) 


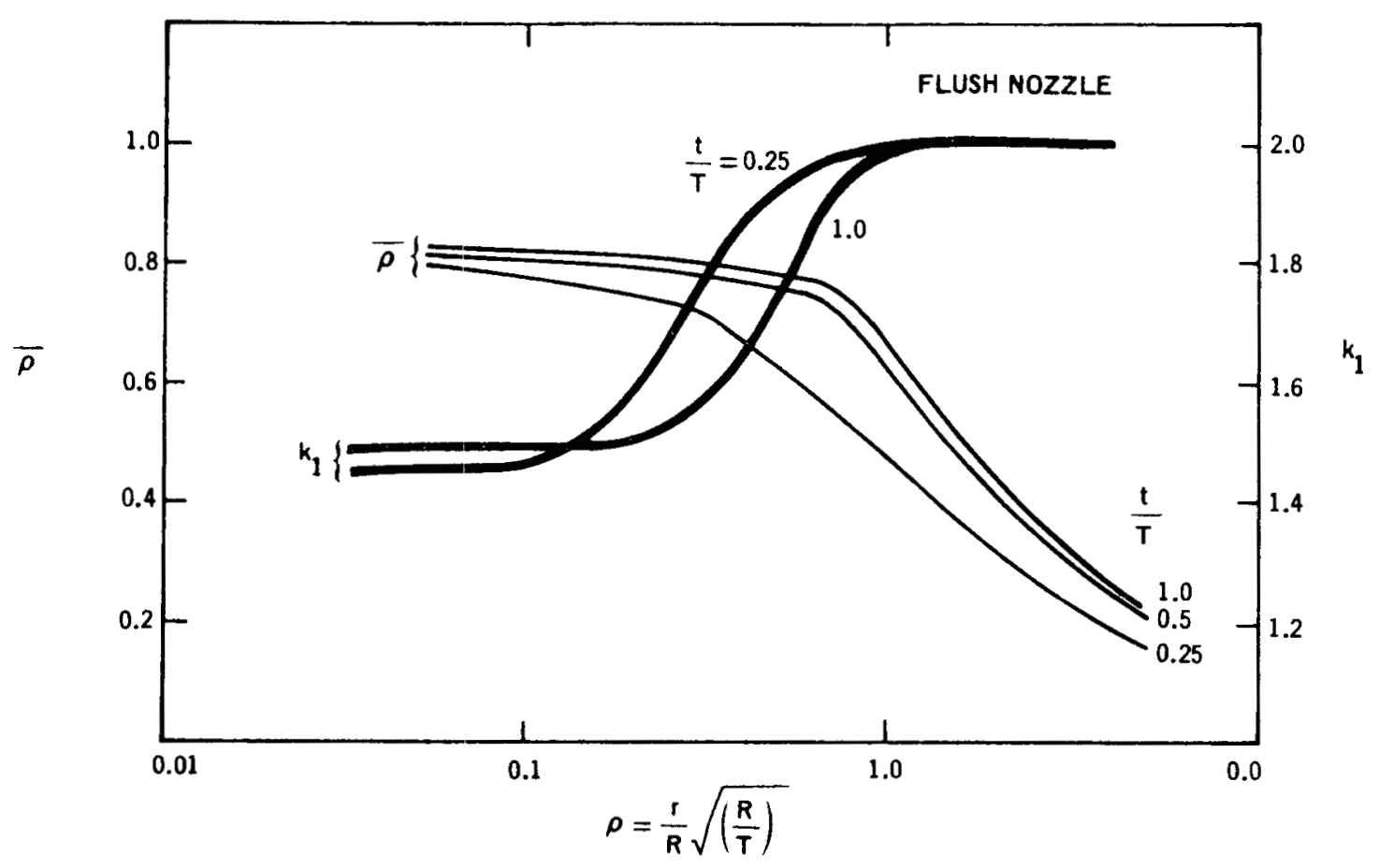

Figure E-3. Shakedou'n Values for Pressure Loading (Flush Nozzle)

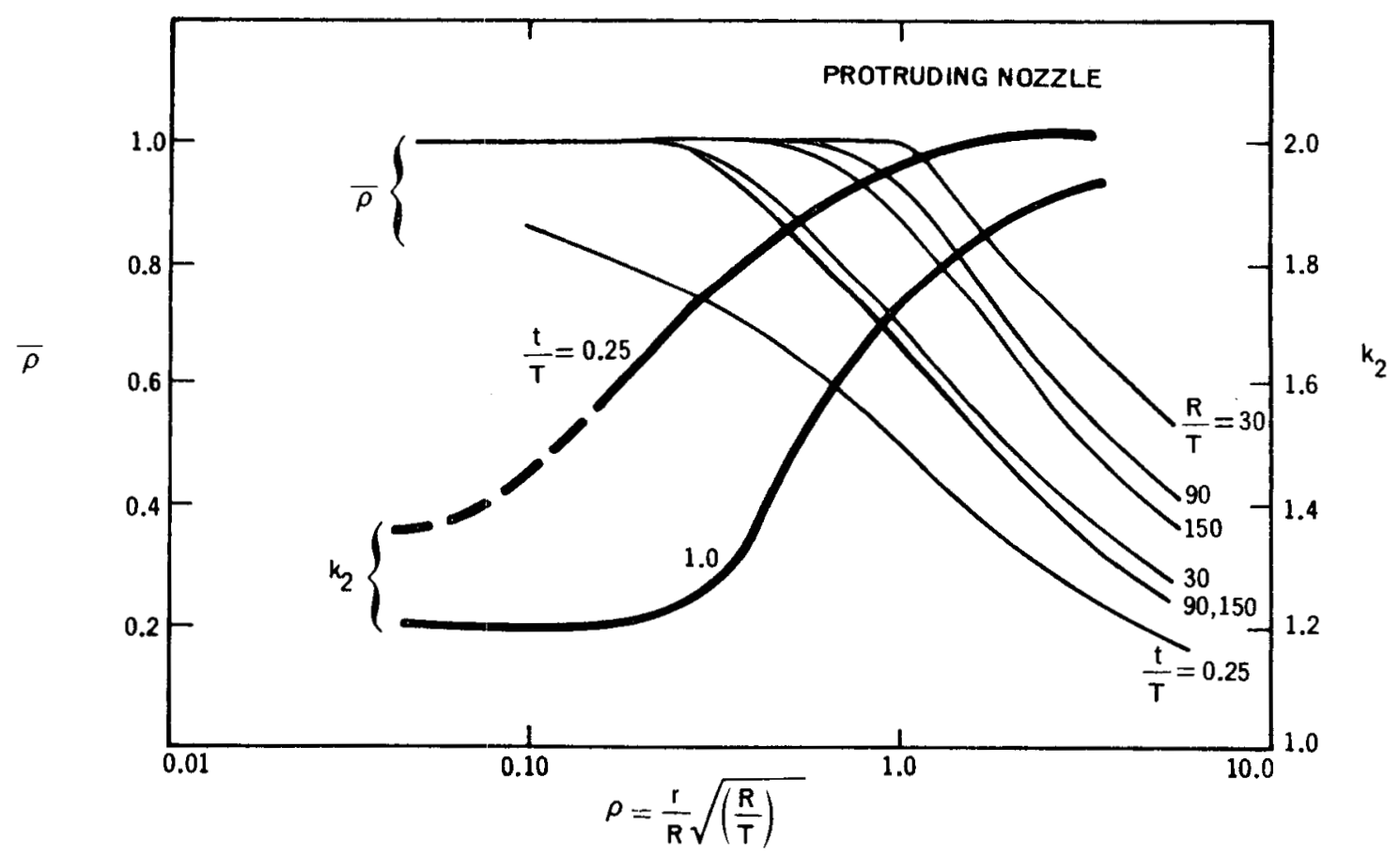

Figure E-4. Shakedown Values for Pressure Loading (Protruding Nozzle) 
GEAP-13719

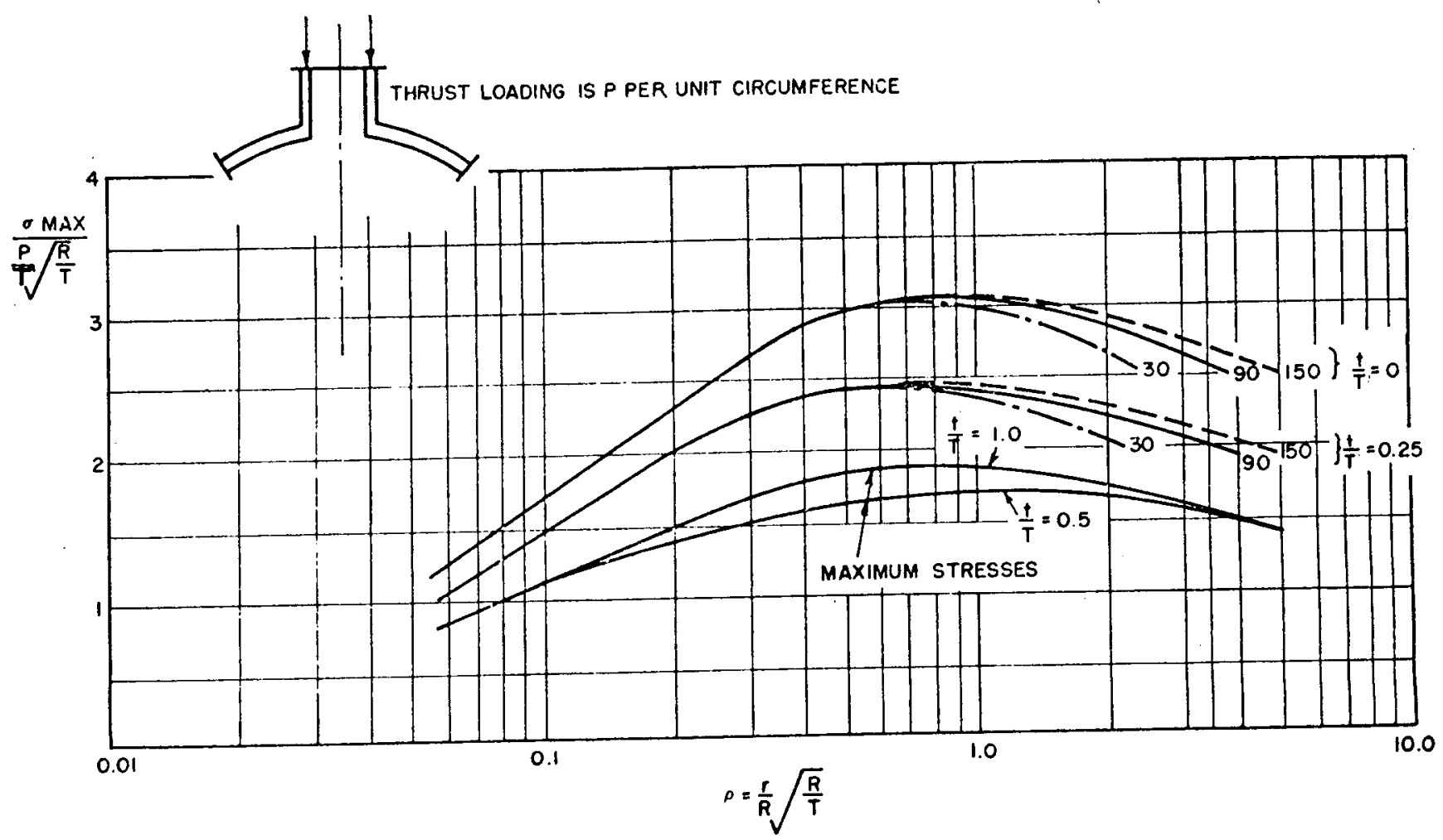

Figure E-5. Maximum Stress in Sphere for Thrust Loading (Flush Nozzles)

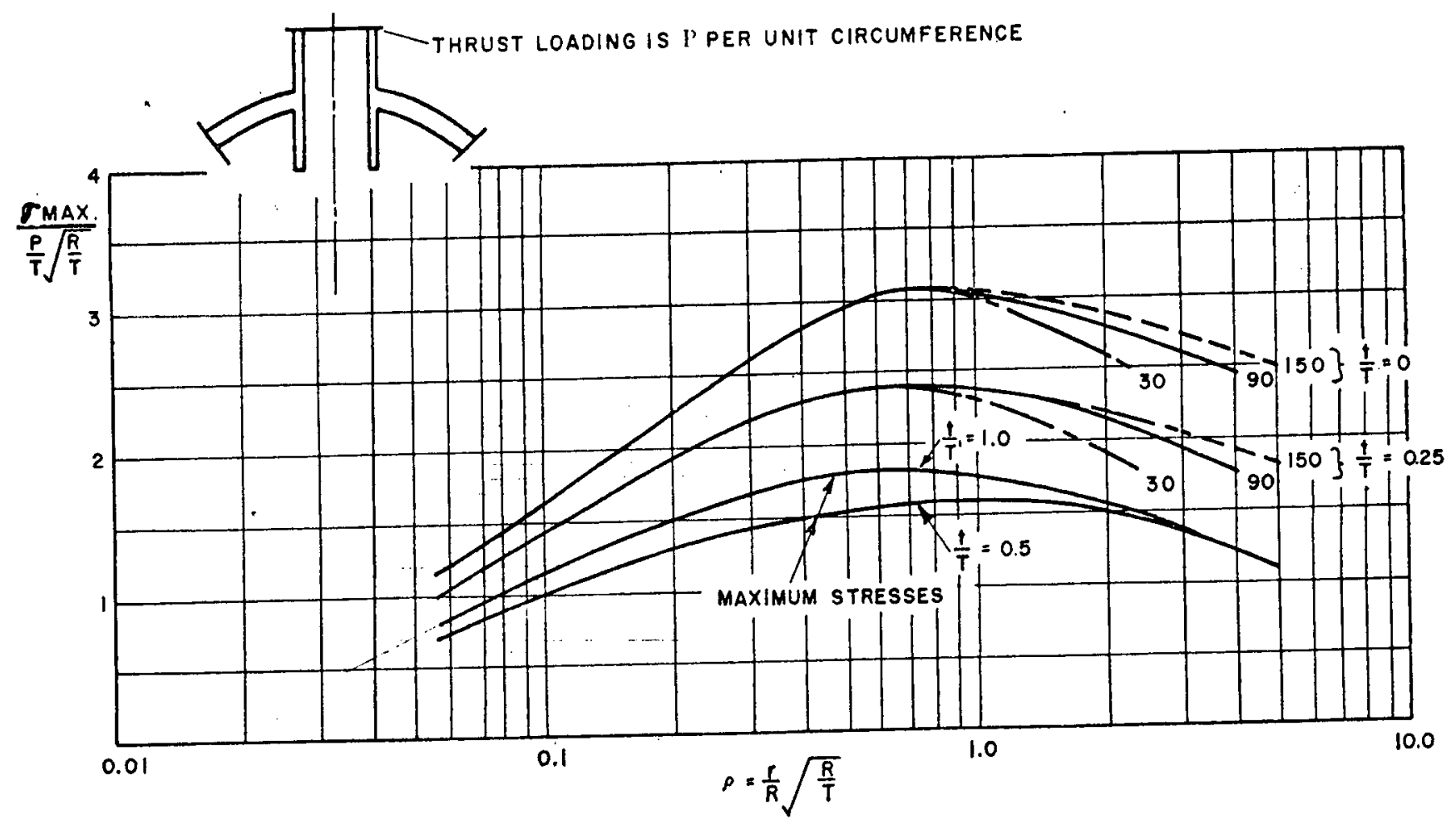

Figure E-6. Maximum Stress in Sphere for Thrust Loading (Protruding Nozzles) 


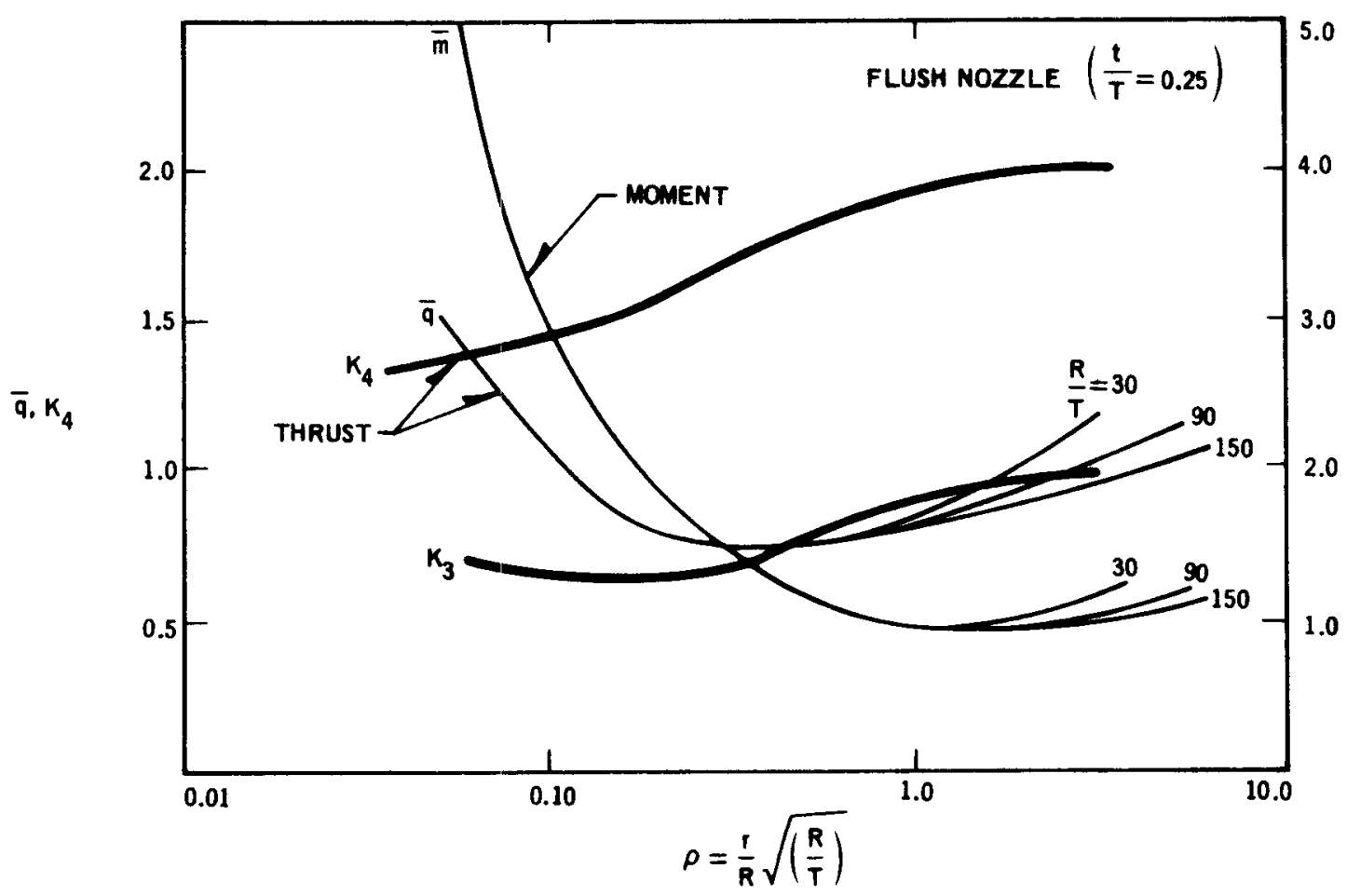

Figure E-7. Shakedown Values for Thrust and Moment Loadings (Flush Nozzle)

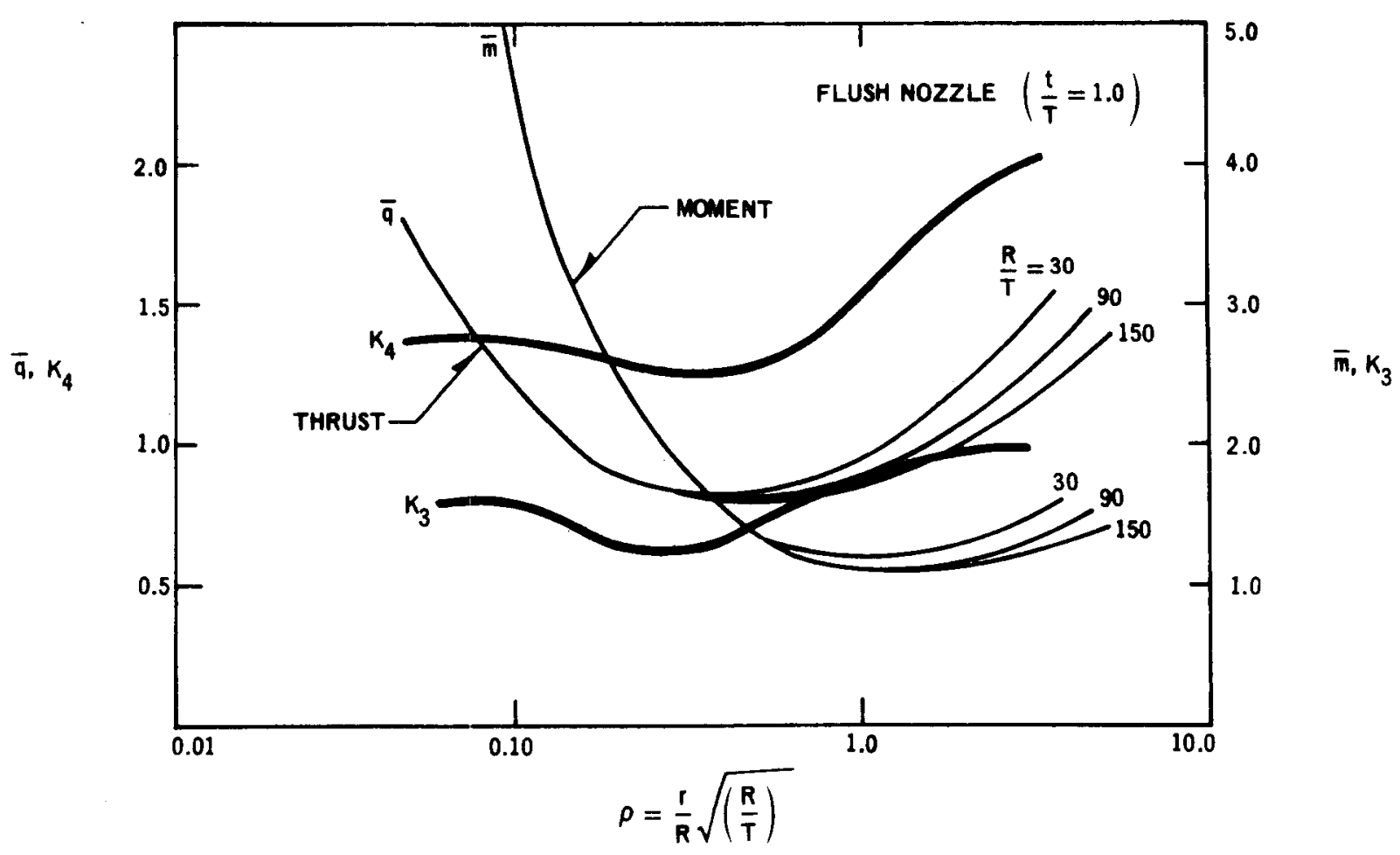

Figure E-8. Shakedown Values for Thrust and Moment Loadings (Flush Nozzle) 


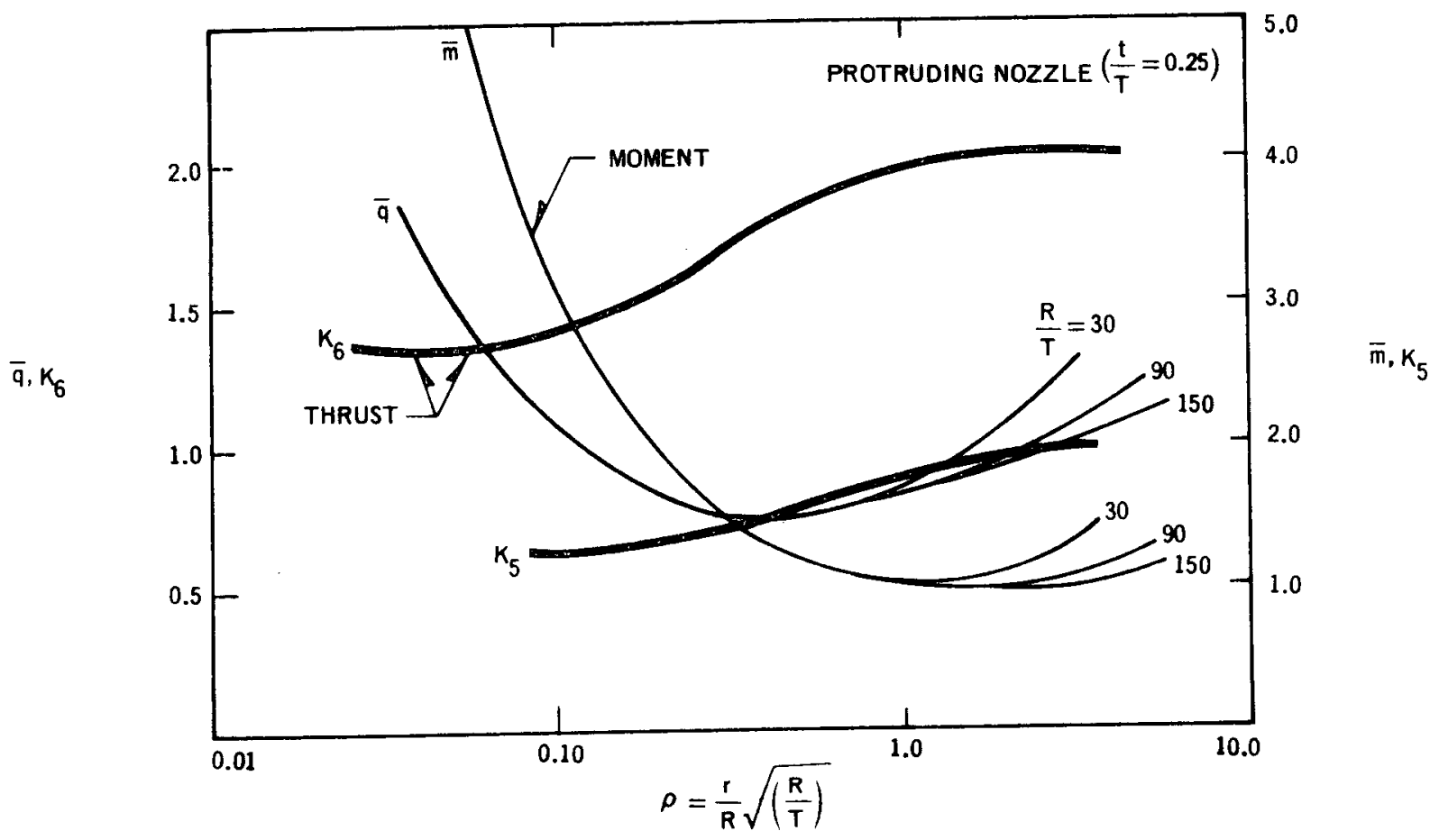

Figure E-9. Shakedown Values for Thrust and Moment Loadings (Protruding Nozzle)

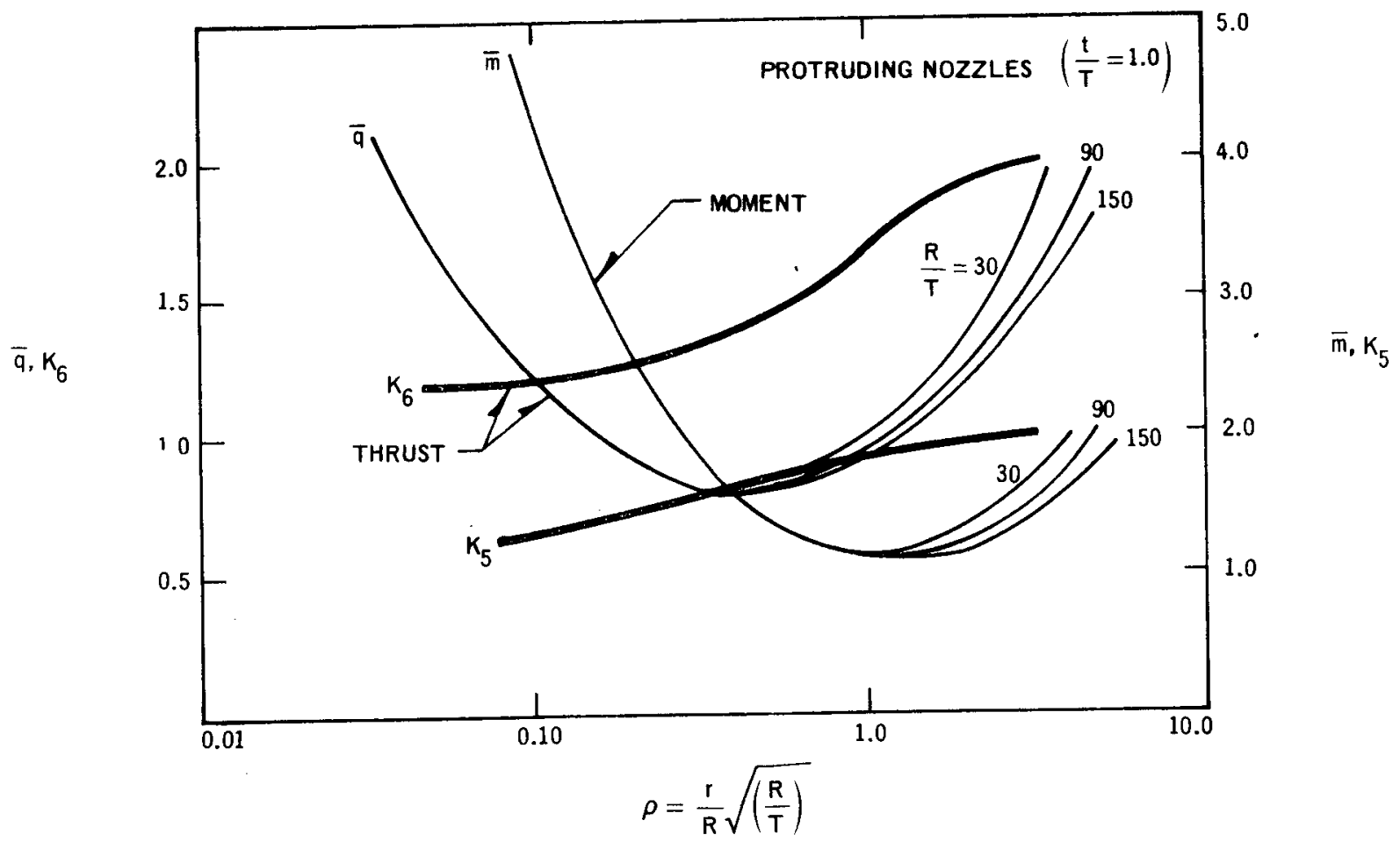

Figure E-10. Shakedown Values for Thrust and Moment Loadings (Protruding Nozzles) 


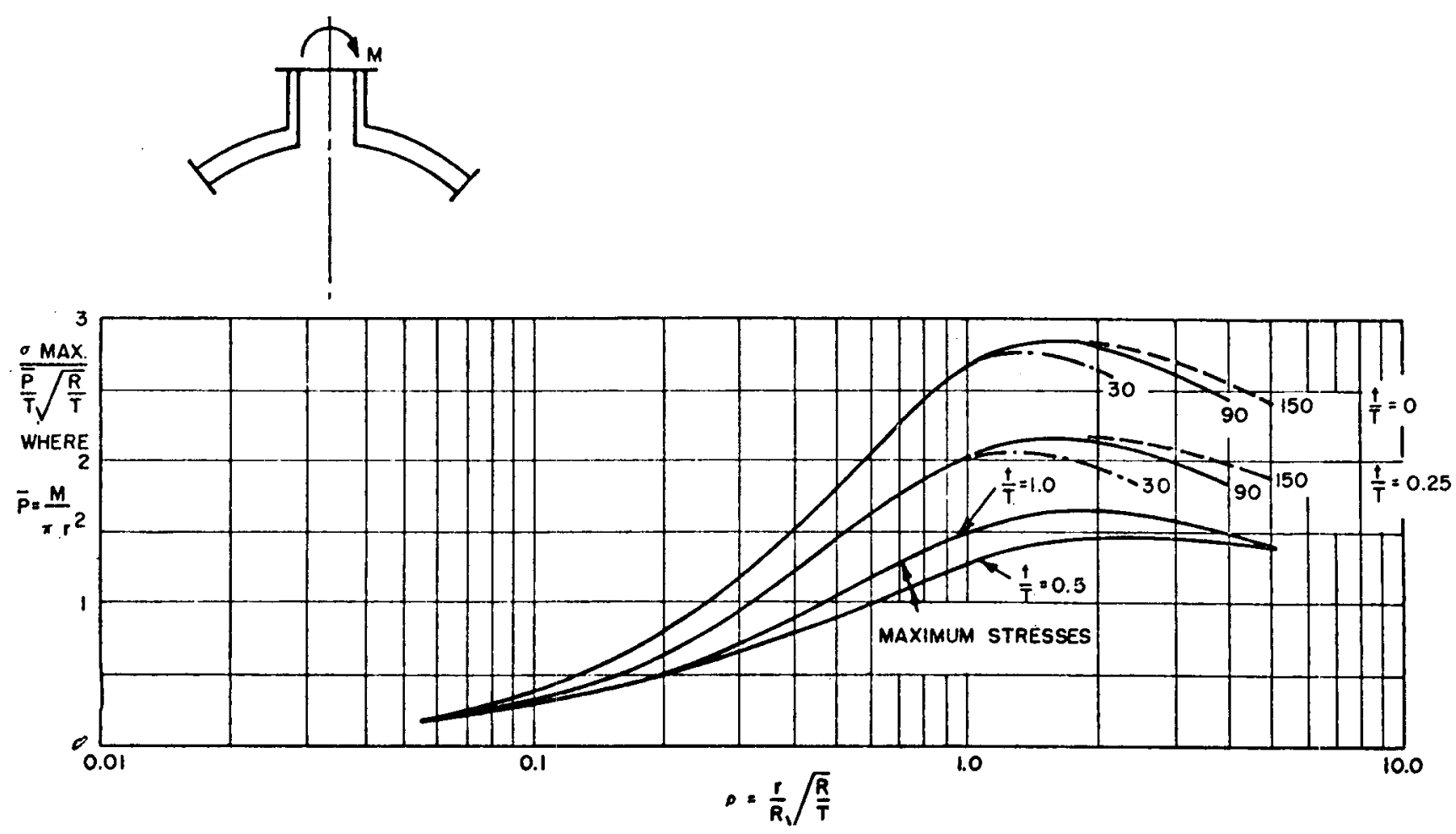

Figure E.11. Maximum Stress in Sphere for Moment Loading (Flush Nozzles)

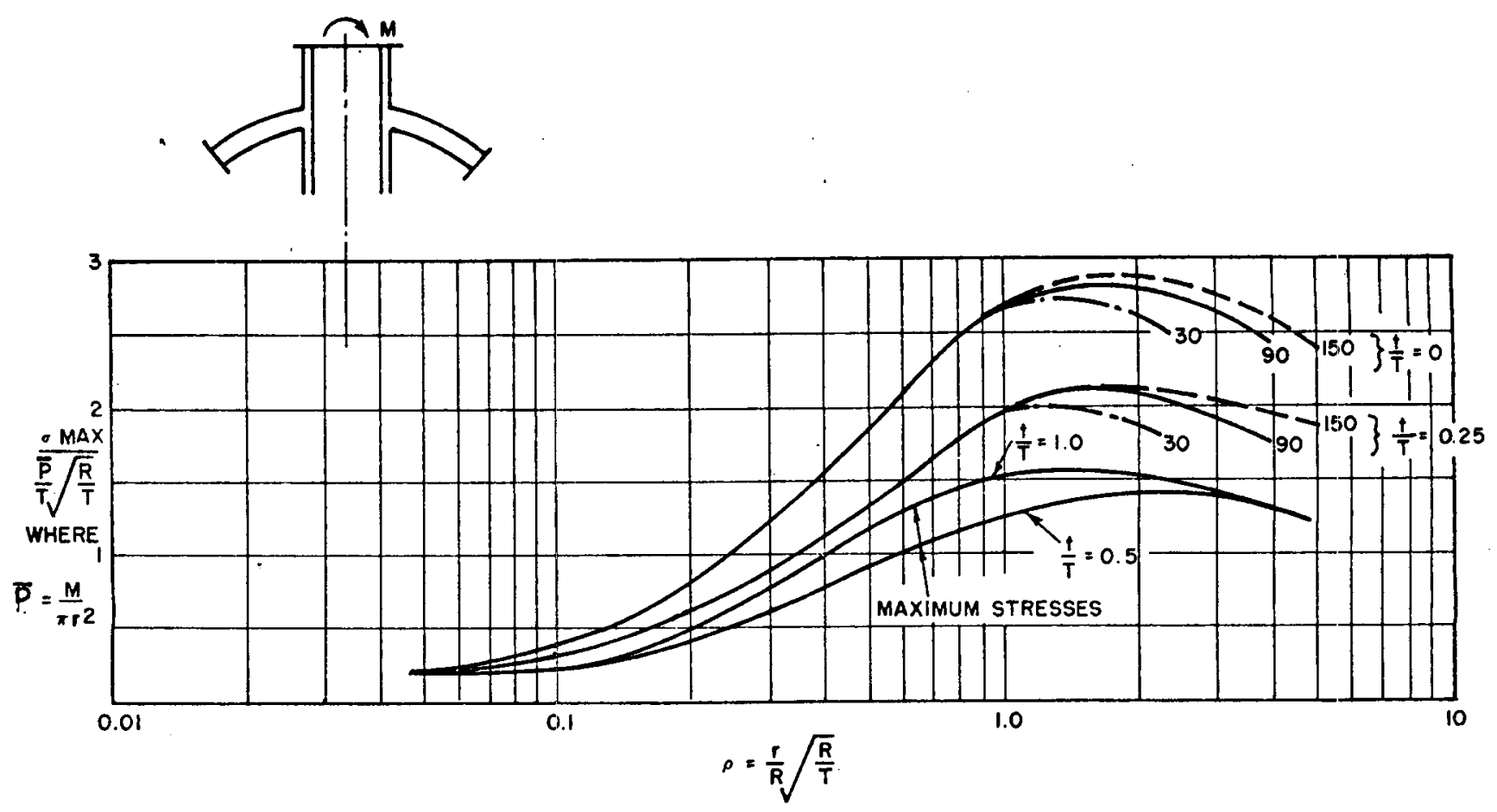

Figure E-12. Maximum Stress in Sphere for Moment Loading (Protruding Nozzles) 


\section{BIBLIOGRAPHY (APPENDIX E)}

1. Prager, W., An Introduction to Plasticity. Addison-Wesley Publishing Company, Reading, Mass., 1959.

2. Leckie, F. A. and Penny, R. K., Stress Concentration Factors for the Stresses at Nozzle Intersections in Pressure Vesse/s, Bulletin No. 90, Welding Research Council, 1963.

3. Leckie, F. A., Payne, D. J., and Penny, R. K., Use of Elastic Solutions to Obtain Lower Bounds on the Performance of Structures under Cyclic Loading and Temperature, Paper No. 1, Applied Mechanics Convention, Cambridge, England, 1966.

4. Leckie, F. A., "Shakedown Pressures for Flush Cylinder-Sphere Shell Intersections," Journal Mechanical Engineering Science, Vol. 7, No. 4, 1965.

5. Leckie, F. A. and Penny, R. K., "Shakedown Loads for the Radial Nozzles in Spherical Pressure Vessels," International Journal of Solids and Structures, Vol. 3, 1967.

6. Leckie, F. A. and Penny, R. K., "Shakedown as a Guide to the Design of Pressure Vessels," Journal of Engineering for Industry, ASME, 1969.

7. Van den Broek, J. A., The Theory of Limit Design, John Wiley \& Sons, New York, 1948. 


\section{APPENDIX F. CREEP AND FATIGUE INTERACTION OF METALS AT ELEVATED TEMPERATURES}

\section{F.1 INTRODUCTION}

For the purpose of establishing an interim stress design criterion for LMFBR pressure vessels and their core components subjected to cyclic thermal and mechanical loads under various operation conditions, a survey of low-cycle fatigue and creep behavior of metals at elevated temperatures has been conducted. The results of this work are summarized in this appendix. It contains a brief description of the parameters which affect the material behavior in general and some analytical empirical methods of predicting the interactions between creep and fatigue of pure metals and high-alloy heat-resistant materials, including stainless steels.

\section{F.2 FACTORS INFLUENCING MATERIAL BEHAVIOR}

\section{F.2.1 Dynamic Creep of Pure Metals}

Creep of a pure metal under both static and dynamic stressing was observed experimentally. ${ }^{1}$ Based on the results of tests on the dynamic creep of lead which was carried out under a vibratory stress superimposed upon a static tensile stress, it was observed that repeated static overstresses are less severe in their effect on the creep rate than repeated periods of superimposed fatigue stressing.

\section{F.2.2 Influence of Cyclic Stress or Strain on Alloys}

As previously mentioned, the creep of pure metals (and the simpler alloys) is generally accelerated by a superimposed cyclic stress. In high-strength alloys, however, at least for ratios of alternating to mean stress less than one, and depending on the material and temperature range, the effect of the dynamic stress can be to strengthen or to weaken.

The interaction between the creep mean stress $\left(\sigma_{\mathrm{m}}\right)$ and alternating fatigue stress $\left(\sigma_{\mathrm{a}}\right)$ at various temperatures is shown in Figure F-1a, which can be normalized as shown in Figure F-1b. In this figure, four different possibie correlations for data under creep-fatigue conditions are shown.

The results of a temperature-resistant allov ( $N$ i 20.6, Co 42.9, Cr 19.4, Mo 4.1\%) for unnotched and notched specimens at elevated temperatures were obtained by Lazan. ${ }^{2}$ It was found that at higher temperature range, there is an apparent strengthening for the unnotched data for stress ratios less than 0.67 approximately.

A comparison of the creep and fatigue rupture curves for the nickel-chromium alloy was carried out by Tilly. ${ }^{3}$ He observed that the sensitivity to stress direction depends on the test temperature, and the material is weaker in pushpull at the lower test temperatures, but creep is the dominating factor at $900^{\circ} \mathrm{C}$. Also, at high temperature, the repeated-tension test is more damaging than the push-pull.

The variation of total and plastic strain with cycles to failure for a forged $\mathrm{Cr}-\mathrm{Mo}-\mathrm{V}(\mathrm{A} 1)$ with frequency $=20$ cycles/min was investigated by Cole and his co-workers. ${ }^{4}$ This type of test was simulated by strain cycling at constant amplitude, the plastic strain in the cycle usually being relatively large. They found good correlation for the following Manson-Coffin relationship:

$$
\epsilon_{\mathrm{p}} \mathrm{N}^{\beta}=\mathrm{C}_{1}
$$

where $\epsilon_{p}$ is the plastic strain increment per cycle, $N$ is the number of cycles, and $\beta$ and $C_{1}$ are constants. At room temperature, the exponent $\beta$ is approximately $1 / 2$, but at elevated temperature it increases to about unity for many materials, including stainless steel. 
A. REPRESENTATIVE STRESS-RANGE DIAGRAM

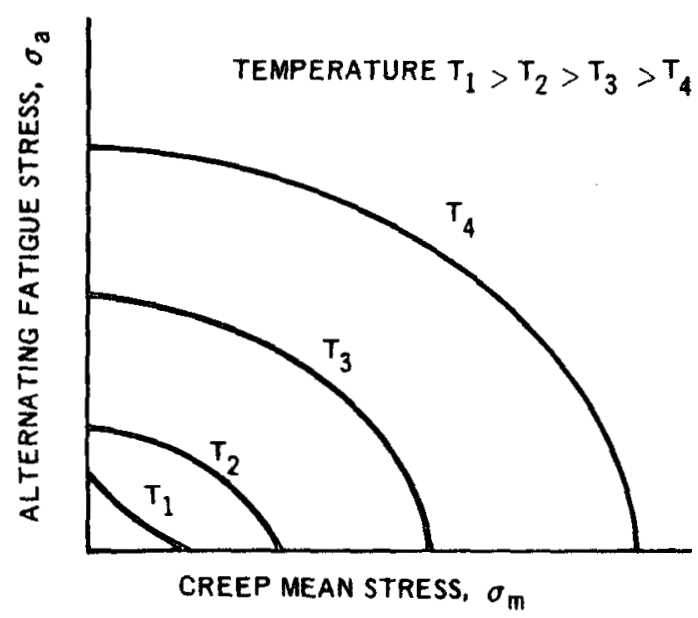

B. NORMALIZED STRESS-RANGE DIAGRAM

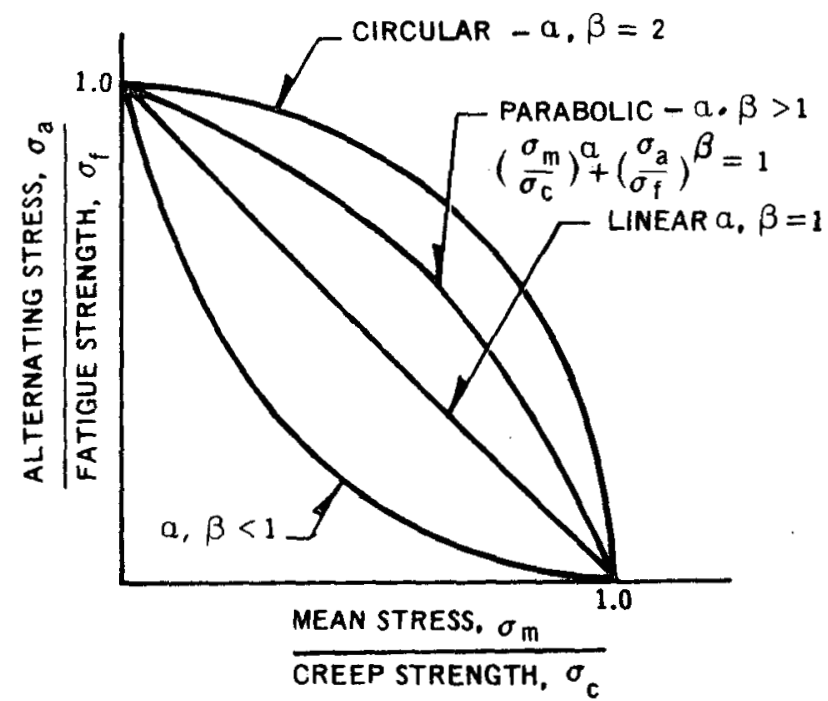

Figure F-1. Creep and Fatigue Interaction

A comparison of results for two types of thermal cycling was conducted by Taira and his co-workers. ${ }^{5}$ They found that failure life for pulsating tensile thermal stress cycling is much smaller than that for completely reversed thermal stress cycling.

\section{F.2.3 Hold Times}

Dawson and his associates" conducted uniaxial and reverse-bending cyclic tests on different austenitic steels. They observed that hold time reduced the life considerably. According to their test data, Type-316 steel with hold time from 30 to 480 minutes results in a life reduction of $5 / 1$.

A forged $1 \mathrm{Cr}-\mathrm{Mo}-\mathrm{V}$ steel at $565^{\circ} \mathrm{C}$ under a total strain amplitude of $\pm 1 \%$ for various cyclic frequencies and hold times was studied by Coles, et al. ${ }^{4}$ They found that the cycles to failure decrease with hold time and that the effect of frequencies variation diminishes with increase in hold time.

\section{F.2.4 Loading Frequency}

Generally, the effect of loading frequency on the number of cycles of failure is insignificant at low temperature. ${ }^{7}$ However, there is a frequency effect at elevated temperatures when failure becomes time dependent; i.e., the lower the frequency, the lower is the number of cycles to failure.

Some investigators ${ }^{4}$ have verified the relationship:

$$
\nu^{\mathrm{k}} \mathrm{t}=\mathrm{C}_{2} \text {. }
$$

where $\nu$ is the frequency, $t$ is the time, and $k$ and $C_{2}$ are constants. As the value of $k$ tends to unity, mechanical fatigue failure is predominant, while for $k$ approaching zero, creep rupture is to be expected.

\section{F.2.5 Strain Rate}

Berling and $\mathrm{Slot}^{8}$ observed that decreasing the strain rate leads to decrease in the time to fracture for stainless steels at elevated temperatures. Figure F-2 shows the test results for Type-304 stainless steel in air at $650^{\circ} \mathrm{C}$. 


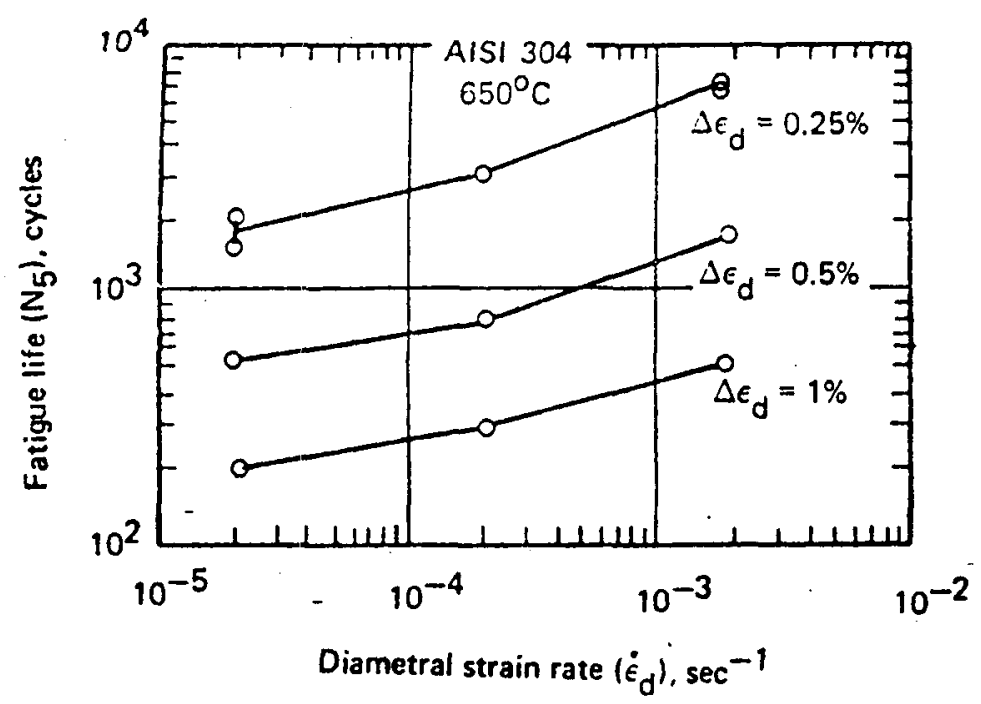

Figure F-2. Effect of Strain Rate on Low-Cycle Fatigue Life of AlS/ 304 Stainless Steel at $650^{\circ} \mathrm{C}$

\section{F.2.6 Temperature}

Temperature plays an important role in the problem of thermal fatigue. Theoretically, it would be ideal to simulate in the laboratory the actual variation of temperatures during operating conditions of the structures, but such a task is rather difficult and expensive. Consequently, tests are usually conducted at constant temperatures. According to the test results on $\mathrm{Ni}-\mathrm{Cr}$ base alloys, ${ }^{9}$ it was reported that shorter lives may be had in experiments if the temperature is cycled rather than in constant temperature tests at the peak value. However, for materials such as $1 \mathrm{Cr}-\mathrm{Mo}-\mathrm{V}$ steel, the isothermal tests at the maximum temperature gave a reasonable prediction of life. ${ }^{4}$

\section{F.2.7 Notches}

Usually, notches caused substantial reductions in cycles to failure. Figure F-3 shows the effect of notches on cycles to failure for $1-\mathrm{cpm}$ continuous cycling tests on forged $1 \mathrm{Cr} \cdot \mathrm{Mo}-\mathrm{V} \mathrm{Al}$ steel at $565^{\circ} \mathrm{C} .{ }^{4}$

\section{F.2.8 Radiation}

The effect of radiation on the materials usually shows the reduction of ductility as well as fatigue and creep life. ${ }^{10,11}$ Figure F-4 shows the effect of radiation on Type- 316 stainless steel at $1200^{\circ} \mathrm{F}$.

\section{F.2.9 Multiaxial Stress Systems}

Conventional fatigue data on ductile materials tested under uniaxial and biaxial conditions could be correlated quite well by the following von Mises stress invariant:

$$
\sigma_{\mathrm{e}}=\left(\sigma_{1}^{2}+\sigma_{2}^{2}-\sigma_{1} \sigma_{2}\right)^{1 / 2} \text {. }
$$

for the elastic conditions. ${ }^{12}$ In the case of plastic conditions, the corresponding strain variant becomes

$$
\epsilon_{\mathrm{e}}=\frac{2}{\sqrt{3}}\left(\epsilon_{1}^{2}+\epsilon_{2}^{2}+\epsilon_{1} \epsilon_{2}\right)^{1 / 2}
$$




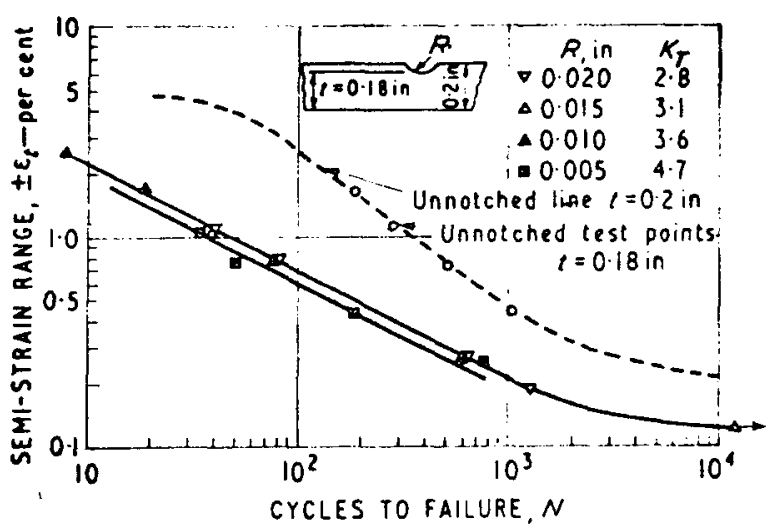

Figure F-3. Effect of Notches on Cycles to Failure for 1-cpm Continuous Cycling Tests on Forged $1 \mathrm{Cr}-\mathrm{Mo}-\mathrm{V}$ Al Steel at $565^{\circ} \mathrm{C}$

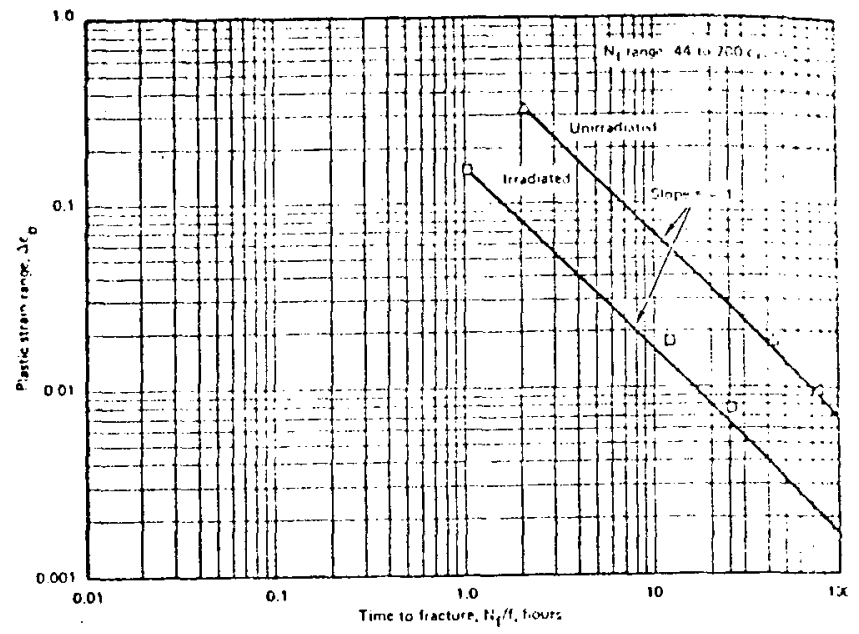

Figure F-4. Plastic Strain Range Versus $N_{f} / f$ for /rradiated and Unirradiated Type-316 Stainless Steel Tested at $1200^{\circ} \mathrm{F}$ and a Strain Rate of $4 \times 10^{-5} \mathrm{sec}$

\section{F.2.10 Ductility}

From the tests on tubular specimens of the nickel-base alloy Inconel, ${ }^{13}$ it was indicated that the ductilities were very different for creep and fatigue, as shown in Figure F.5.

\section{F.2.11 Mode of Failure}

Generally speaking, intergranular cracking is associated with static creep rupture, and transgranular with cyclic stressing, although both types of cracking are often observed in the creep-fatigue regime.

\section{F.2.12 Other Effects}

In addition to the foregoing factors, there are other parameters which also affect the behavior of metals at elevated temperatures; namely, prior creep on fatigue and vice versa, environments, random cyclic loads such as seismic motions, etc.

\section{F.3 PREDICTION OF FATIGUE AND CREEP INTERACTION}

\section{F.3.1 Method of Equivalent Stress: Lazan-Taira ${ }^{14,15}$}

Using the definition of stresses given in Figure F-6, the instantaneous stress at any instant of time during a cyclic stress test may be written as

$$
S=S_{m}(1+A \sin \omega t)
$$

If the Norton type law for the second stage of creep is assumed to be valid, then

$$
\dot{\epsilon}=k s^{n},
$$

where $\dot{\epsilon}=$ creep rate, in./in. $h$,

$\mathrm{k}=\mathrm{a}$ proportionality constant,

$\mathrm{S}=$ stress magnitude, $\mathrm{lb} / \mathrm{in}^{2}{ }^{2}$, and

$\mathrm{n}=$ the power or exponent determined from the slope of the log-log plots of minimum creep rate versus stress magnitude. 

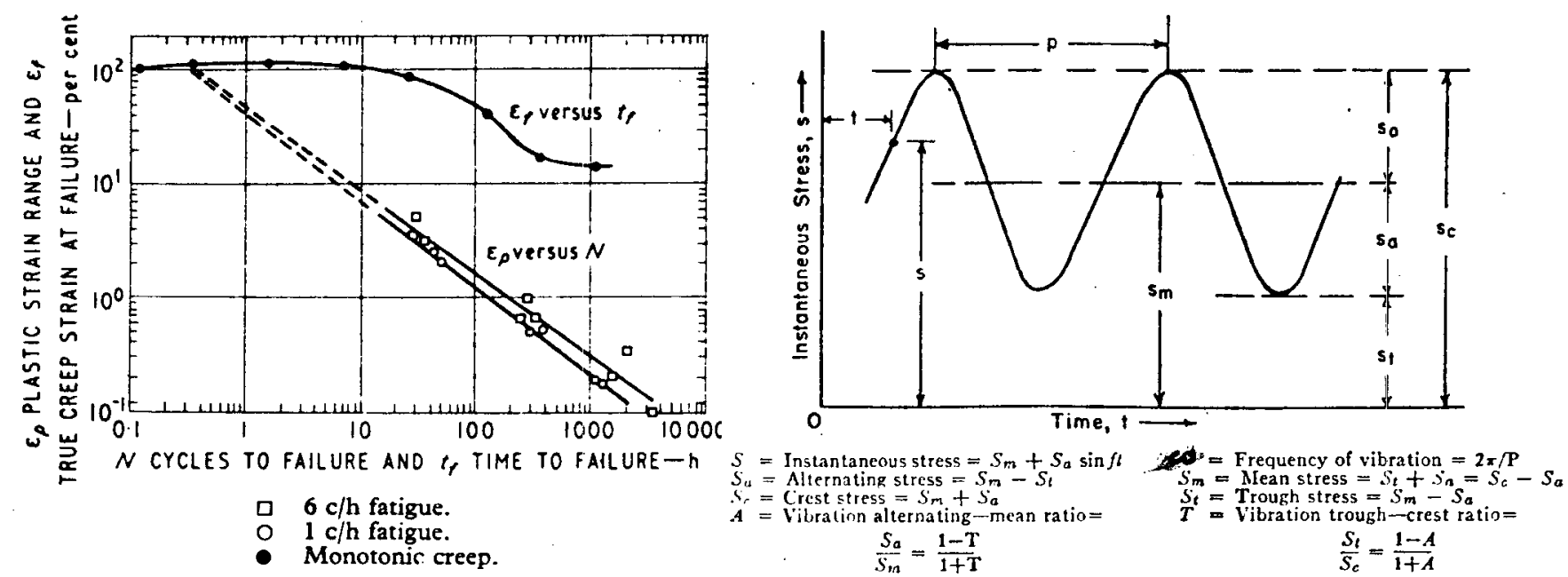

Figure F-5. Plastic Strain Fatigue Curve and Variation of Creep Ductility with Time for Inconel at $1500^{\circ} \mathrm{F}$

Figure F-6. Cyclic Stress Definitions

Substituting Equation ( $F-5)$ into Equation ( $F-6$ ) and integrating between limits $t_{1}$ and $t_{2}$ yield the total creep strain as follows:

$$
\epsilon=k S_{m}^{n} \int_{t_{1}}^{t_{2}}(1+A \sin \omega t) d t
$$

The total creep strain due to the equivalent static stress $S_{e}$, which will cause the same total secondary stage creep in a given interval of time as the dynamic stress $\left(S_{m} \pm S_{a} \sin \omega t\right)$, can be evaluated by

$$
\epsilon=k S_{e}^{n}\left(t_{2}-t_{1}\right)=k S_{m}^{n}\left(t_{2}-t_{1}\right) / E^{n} .
$$

The solution of Equations (F-7) and (F-8) gives

$$
E=\left[\frac{t_{2}-t_{1}}{\int_{t_{1}}^{t_{2}}(1+A \sin \omega t)^{n} d t}\right]^{\frac{1}{n}}=\frac{S_{m}}{S_{e}} .
$$

Table $F-1$ shows the numerical values of Equation $(F-9)$ for $n=7$, and 9 , and various values of $A$.

\begin{tabular}{|c|c|c|c|c|}
\hline \multirow[b]{2}{*}{ Vibration } & \multicolumn{2}{|c|}{ Values of $E$} & \multirow{3}{*}{$\frac{s_{e}}{s_{m}}$} & \multirow{3}{*}{$\frac{s_{c}}{S_{e}}$} \\
\hline & $n=7$ & $n=11$ & & \\
\hline Ratio A & & & & \\
\hline 0 & 1.000 & 1.000 & 1.00 & 1.00 \\
\hline 0.25 & 0.938 & 0.908 & $1.08-1.10$ & $1.16-1.12$ \\
\hline 0.67 & 0.736 & 0.698 & $1.23-1.16$ & \\
\hline 1.00 & 0.624 & 0.586 & $1.60-1.70$ & $1.25-1.17$ \\
\hline 2.00 & 0.426 & 0.399 & $2.34-2.52$ & $1.27-1.19$ \\
\hline 4.00 & 0.260 & 0.241 & $3.85-4.15$ & $1.30-1.20$ \\
\hline 9.00 & 0.135 & 0.122 & $7.42-8.22$ & $1.35-1.21$ \\
\hline
\end{tabular}

Table F-1

NUMERICAL VALUES OF EQUATION (F-9) 
Instead of using the second-stage creep law, the following strain-stress-time relation for the first-stage creep behavior for constant temperature has been employed by Taira to study the dynamic creep: ${ }^{16}$

$$
\epsilon=a \sigma^{\alpha} t^{n},
$$

where $a, \alpha$, and $n$ are constants.

Following similar procedure as that given by Lazan, the general expression for the stress ratio was obtained as

$$
E=\frac{\sigma_{m}}{\sigma_{e}}=\left[\frac{1}{2 \pi} \int_{0}^{2 \pi}(1+A \sin \omega t)^{\frac{\alpha}{n}} d(\omega t)\right]^{-\frac{n}{\alpha}}
$$

To improve the solutions for larger values of $\mathrm{A}$ and also eliminate the singularity at the limiting condition, Taira and Koterazawa ${ }^{17}$ extended the above approach to include the fatigue stresses. ${ }^{16}$ In the meantime, they modified the stress ratio $E$ given by Equation ( $F-11)$ to the form:

$$
E=\left[\frac{1}{2 \pi} \int_{0}^{2 \pi}(1+A \sin \omega t)^{\alpha} d(\omega t)\right]^{\frac{-1}{\alpha_{s}}} .
$$

which is based on the following hypotheses:

- The rate of increase in damage of material under dynamic stress can be expressed as a function of stress in the following way:

$$
d \phi_{s} / d t=a_{s}(|a|)^{\alpha} \text {. }
$$

where $a_{s}$ and $\alpha_{s}$ are constants independent of stress and time, and $\phi_{s}$ is a scalar function for creep damage.

- Fracture of material is initiated when the magnitude of accumulated creep damage reaches a critical value.

The corresponding hypotheses for the fatigue damage are:

- Tho rate of fatigue damage with respect to time is given by

$$
\left\{t=a_{f}\left(\mid \sigma-\sigma_{m}\right)^{\alpha_{f}}=a_{f}\left(\left|\sigma_{a} \sin \omega t\right|\right)^{\alpha_{f}}\right.
$$

W... is a function for fatigue damage.

- The criterion of fracture consists of the following two cases:

a. Material fractures when the sum of the creep and the fatigue damage reaches a critical value; i.e.,

$$
\phi_{\mathrm{c}}=\phi_{\mathrm{s}}+\phi_{\mathrm{f}}
$$

b. Material fractures when either the creep or the fatigue damage reaches its own critical value:

$$
\phi_{c}=\phi_{s} \text { or } \phi_{c}=\phi_{f}
$$


For Case a -the equivalent static stress takes the value

$$
\sigma_{e}^{1}=\sigma_{a} A\left\{1+A^{\alpha_{f}}\left(a_{f}^{t} / a_{s}\right) \sigma_{a} \alpha_{f}-\alpha_{s}\right\}^{\frac{1}{\alpha_{s}}} .
$$

where

$$
I=\frac{1}{2 \pi} \int_{0}^{2 \pi}(|1+A \sin \omega t|)^{\alpha_{s}} d(\omega t)
$$

and

$$
a_{f}^{1}=\frac{a_{f}}{2 \pi} \int_{0}^{2 \pi}(|\sin \omega t|)^{\alpha_{f}} d(\omega t)
$$

For Case $b$-the equivalent static stress is the larger one of the following two values for $\sigma_{e}^{1}$ :

$$
\begin{aligned}
& \left.\sigma_{\mathrm{e}}^{1}=\sigma_{\mathrm{m}}\left[\frac{1}{2 \pi} \int_{0}^{2 \pi}(\mid 1+A \sin \omega t)\right)^{\alpha_{s}} \mathrm{~d}(\omega t)\right]^{\frac{1}{\alpha_{s}}}, \\
& \sigma_{\mathrm{e}}^{1}=\sigma_{\mathrm{a}}\left(\sigma_{\mathrm{e}}^{1} / \sigma_{\mathrm{a}}\right)_{\mathrm{A}=\infty} .
\end{aligned}
$$

in which $\left(\sigma_{e}^{1} / \sigma_{a}\right)_{A=\infty}$ represents the value of $\sigma_{e}^{1} / \sigma_{a}$ for the case of reversed stress.

Figures F-7 and F-8 show the correlations between the analytical and experimental results for two different steels. $^{17}$

Using an exponential law for second-stage creep rate, Zamrik and Shewchuk ${ }^{18}$ obtained an analytical solution for the stress ratio $E$. In this approach, equal consideration has been given to the creep and the fatigue phenomena by introducing "isochronous stress-rupture lines" and "isochronous fatigue lines" by the investigators.

Partially based on the fracture criteria set forth by Robinson and Taira, techniques for the calculations of the elevated-temperature cyclic life and thermal-fatigue life were introduced by Spera. ${ }^{19,20,21}$ Although no specific expression for the interaction of creep and fatigue was attempted, the use of the linear interaction between creep and fatigue was favorably indicated.

\section{F.3.2 Method of Modified Universal Slopes: Manson-Halford 22,23}

A method is provided for the estimate of lower-bound, average, and upper-bound low-cycle fatigue behavior in the creep range, using the short-time static tensile and creep rupture properties. This approach is based on the so-called Method of Universal Silopes, the empirical expression of which is given by the following formula for the total strain range:

$$
\Delta \epsilon_{t}=\frac{3.5 \sigma_{u}}{E} N_{f}^{-0.12}+D^{0.6} N_{f}^{-0.6}
$$

where $\sigma_{u}, E, D$, and $N_{f}$ are the ultimate tensile strength, modulus of elasticity, true ductility, and fatigue life, respectively. The first term of the above equation represents the elastic strain range, while the second term gives the plastic strain range, the exponent of $N_{f}$ for each term indicates the universal slopes $(-0.12$ and -0.6$)$ of the log-log plots of the elastic strain range, and plastic strain range versus the fatigue life, respectively. 


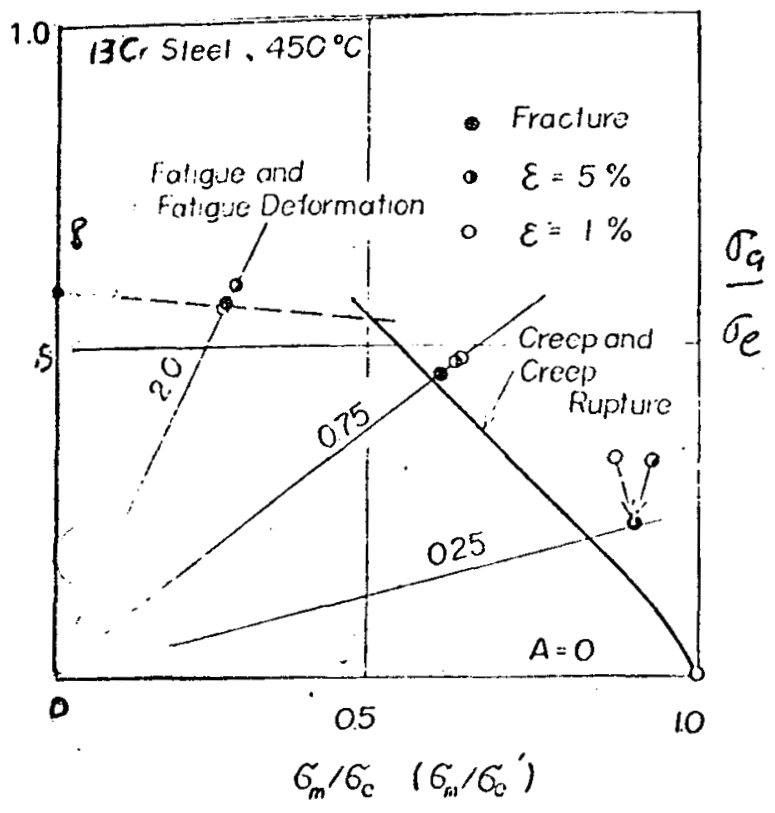

Figure F.7. Stress Range Diagram for Dynamic Creep and Fatigue-Chromium Steel in Nondimensional Expression

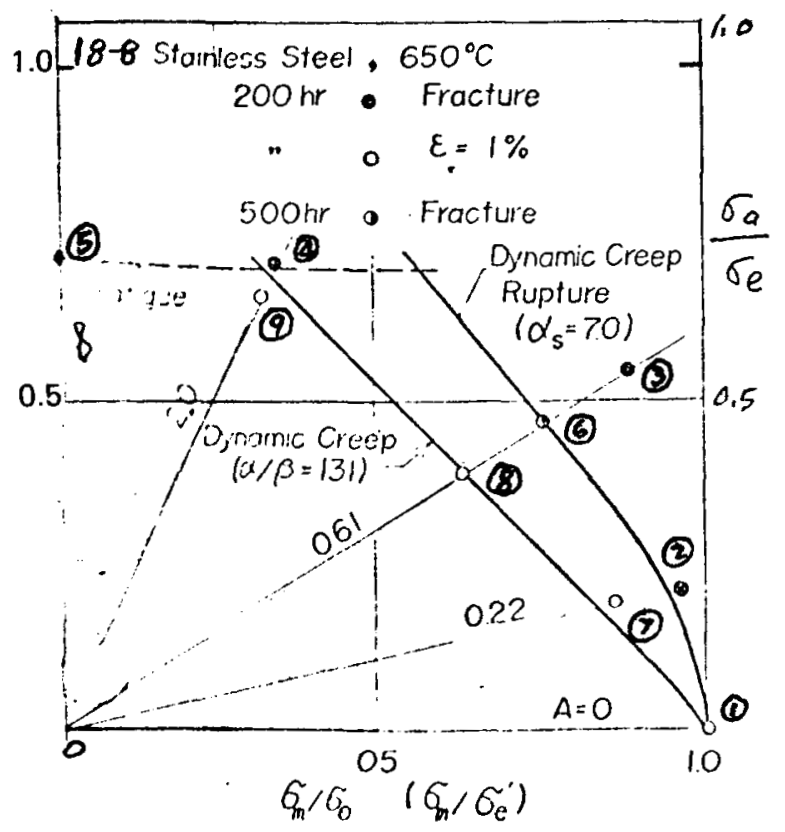

Figure F:8. Stress Range Diagram for Dynamic Creep and Fatigue-Stainless Steel in Nondimensional Expression

However, for very low frequencies or high temperatures, the failure may be primarily time dependent. An additional estimation of life $N_{f}^{1}$ is then necessary. Assuming a linear or cumulative damage law, the combination of creep and fatigue may be allowed for

$$
N_{f}^{1}=N_{f} /\left[1+\frac{0.3}{A F}\left(N_{f}\right)^{(m+0.12) / m}\right] \text {. }
$$

where

$$
\begin{aligned}
F= & \text { frequency of stress application (cycles/min), } \\
A= & \text { coefficient characterizing a time intercept of the creep rupture of the material at test temperature } \\
& \text { (the curve } \sigma_{r} \text { is linearized on log coordinates and is represented by the equation } \sigma_{r}=1.75 \sigma_{u} \text { ), } \\
m= & \text { slope of creep rupture line, } \\
N_{f}= & \text { life calculated from Equation }(F-19) .
\end{aligned}
$$

Equation (F-20) is only applicable if $\mathrm{N}_{f}^{1}<10 \% \mathrm{~N}_{f}$ and if $\mathrm{N}_{f}^{1}<10^{5}$ cycles.

From Equations (F-19) and (F-20), estimates of elevated temperature low cycle behavior can be made as follows:

- For the lower bound of life, use either $10 \% N_{f}$ or $N_{f}^{1}$, whichever is the lower.

- For the average life, use twice the lower bound life.

- For the upper bound of life, use 10 times the lower bound life.

\section{F.3.3 Method of Characteristic Slopes: Berling and Conway ${ }^{24,25}$}

From a study of low-cycle fatigue data for Types-304, -316 and -348 stainless steel to $815^{\circ} \mathrm{C}$ and at strain rates ranging from $4 \times 10^{-5}$ to $4 \times 10^{-3} \mathrm{sec}^{-1}$, Berling and Conway found that a log-log plot of the plastic strain versus time to fracture yields a linear relation and has a slope of minus one (see Figure $F-4$ ) and consequently, the following relation was established from the assumption that $\Delta \epsilon_{\mathrm{p}}=\epsilon_{\mathrm{f}}$ at $\mathrm{N}_{\mathrm{f}} / \nu=\epsilon_{\mathrm{f}} / \dot{\epsilon}_{\mathrm{t}}$, as follows:

$$
\Delta \epsilon_{p}=\frac{\epsilon_{f}^{2}}{\dot{\epsilon}_{t}}\left(\frac{N_{f}}{v}\right)^{-1}
$$


where $\dot{\epsilon}_{t}$ is the strain rate, $\nu$ is the cycling frequency, and $N_{f}$ is the cycles to fracture. Berling and Conway further observed that for the materials under consideration, the value of the elastic strain range at $N_{f}=10$ cycles was equal to twice the true elastic strain at fracture $\left(\epsilon_{\mathrm{ef}}\right)$ in a short-term tensile test at the same conditions of temperature and strain rate, and the slope $\left(-m^{\prime}\right)$ of the log-log plot of the elastic strain range versus $N_{f}$ was essentially identical to onehalf of the strain-hardening exponent $(\mathrm{m})$ obtained at the same test conditions. Based on the foregoing correlation features, it follows that

$$
\Delta \epsilon_{\mathrm{e}}=2 \epsilon_{\mathrm{ef}}\left(\frac{N_{\mathrm{f}}}{10}\right)^{-\frac{\mathrm{m}}{2}}
$$

The method of Characteristic Slopes or Berling-Conway Equation is obtained by the combination of Equations $(\mathrm{F}-21)$ and $(\mathrm{F}-22)$ and elimination of $\dot{\epsilon}_{\mathrm{t}}$ and $\nu$ from the relation $2 \Delta \epsilon_{\mathrm{t}} \nu=\dot{\epsilon}_{\mathrm{t}} ;$ namely,

$$
\Delta \epsilon_{\mathrm{t}}=\epsilon_{\mathrm{ef}}\left(\frac{N_{\mathrm{f}}}{10}\right)^{-\frac{\mathrm{m}}{2}}+\left[\epsilon_{\mathrm{ef}}^{2}\left(\frac{10}{N_{\mathrm{f}}}\right)^{m}+\frac{\epsilon_{\mathrm{f}}^{2}}{2 N_{\mathrm{f}}}\right]^{\frac{1}{2}} .
$$

F.3.4 Method of Generalized Equation: Coffin ${ }^{26,27}$

If Equations (F-1) and (F-2) are combined properly, the plastic strain range can be expressed in terms of fatigue life and frequency as follows:

$$
\Delta \epsilon_{p}=C_{2} N_{f}^{-\beta}(1-k) \beta
$$

where $C_{2}, \beta$, and $k$ are constants.

Using the modified nonlinear stress-strain relation established by Morrow, ${ }^{28}$ the elastic strain range can be approximated by the following formula:

$$
\Delta \epsilon_{\mathrm{e}}=\frac{A}{\mathrm{E}} \mathrm{C}_{2}{ }^{\mathrm{n}} \mathrm{N}_{\mathrm{f}}-\beta \mathrm{n} \nu^{\mathrm{k}_{1}+(1-\mathrm{k})} \beta \mathrm{n},
$$

where $E$ is the modulus of elasticity, and $A, n, k_{1}$, etc., are constants.

The combination of Equations (F-24) and (F-25) furnishes the following generalized equation:

$$
\Delta \epsilon=\Delta \epsilon_{\mathrm{e}}+\Delta \epsilon_{\mathrm{p}} .
$$

Figure F-9 shows the comparison of results obtained from Equations (F-19), (F-23), and (F-26) for Type-304 stainless steel at $1200^{\circ} \mathrm{F}$.

To take into account the effect of mean strain, Coffin established a nonlinear interaction relation between life ratio $N_{\mathrm{f}} / \mathrm{N}_{\mathrm{f}_{\mathrm{o}}}$ and $\epsilon_{\mathrm{f}} / \epsilon_{\mathrm{f}_{\mathrm{o}}}$, as follows: ${ }^{29}$

$$
\frac{\epsilon_{f}}{\epsilon_{f_{o}}}+\left(\frac{N_{f}}{N_{f_{o}}}\right)^{\beta}=1
$$

where $\epsilon_{f}$ is the mean strain at fracture, $\epsilon_{f_{o}}$ the tensile ductility, $N_{f}$ the fatigue life, and $N_{f_{o}}$ the fatigue life for zero mean strain. Experimental correlation of Equation $(F-10)$ for a specific material (Nickel A) with $\beta=0.563$ is shown in Figure F-10.

The value of $\beta$ is approximately directly proportional to the temperature. For low temperatures, $\beta=0.5$, and at high temperatures, the value of $\beta$ approaches 1.0 as a limit. ${ }^{8}$ Consequently, the approximate upper and lower bounds for the interaction predicted by Equation (F-27) can be expressed graphically as shown in Figure F-11. 


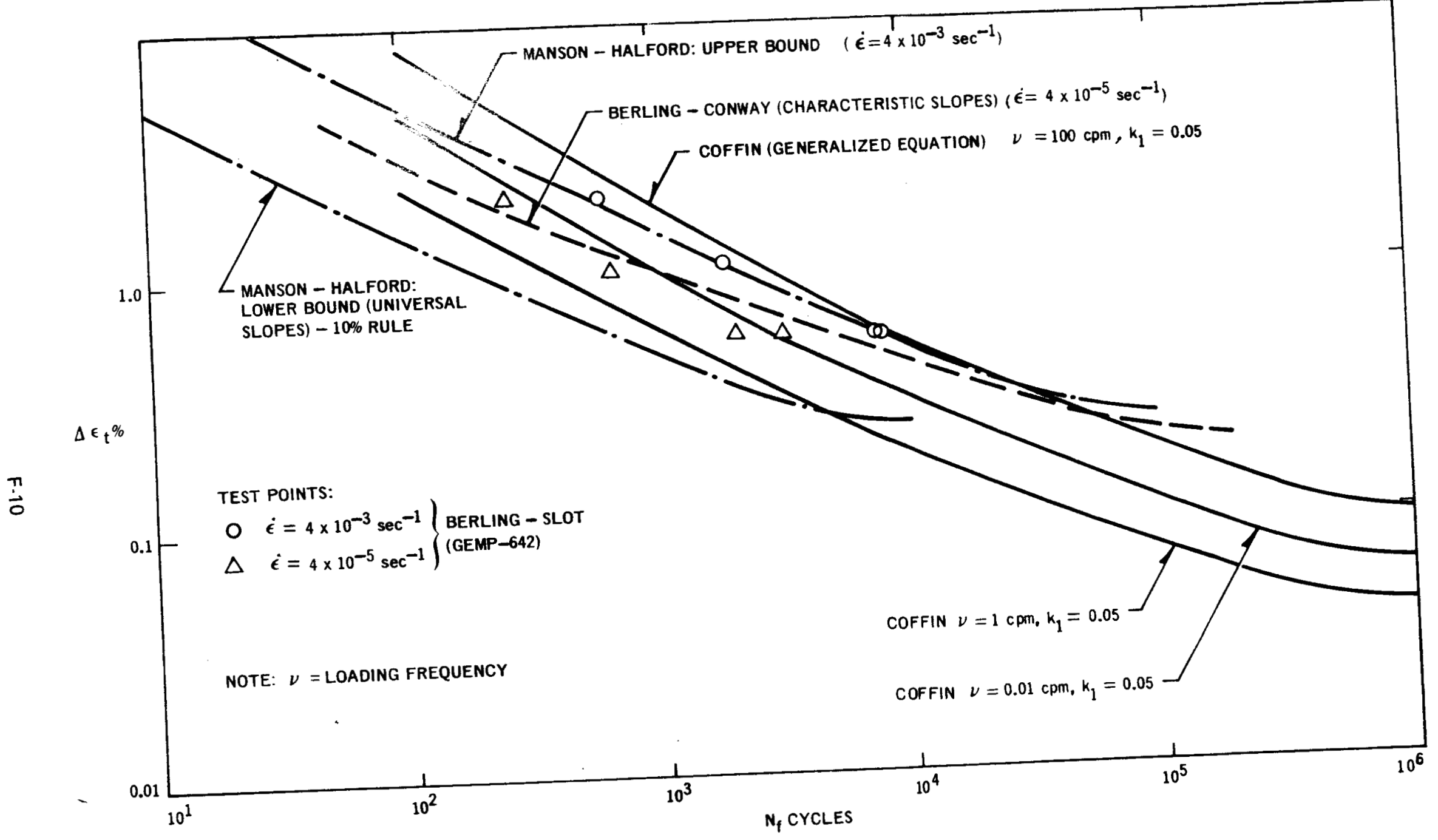

Figure F-9. Comparison of Results for Low-Cycle Fatigue Behavior of Type-304 Stainless Steel at $1200^{\circ} \mathrm{F}$ 


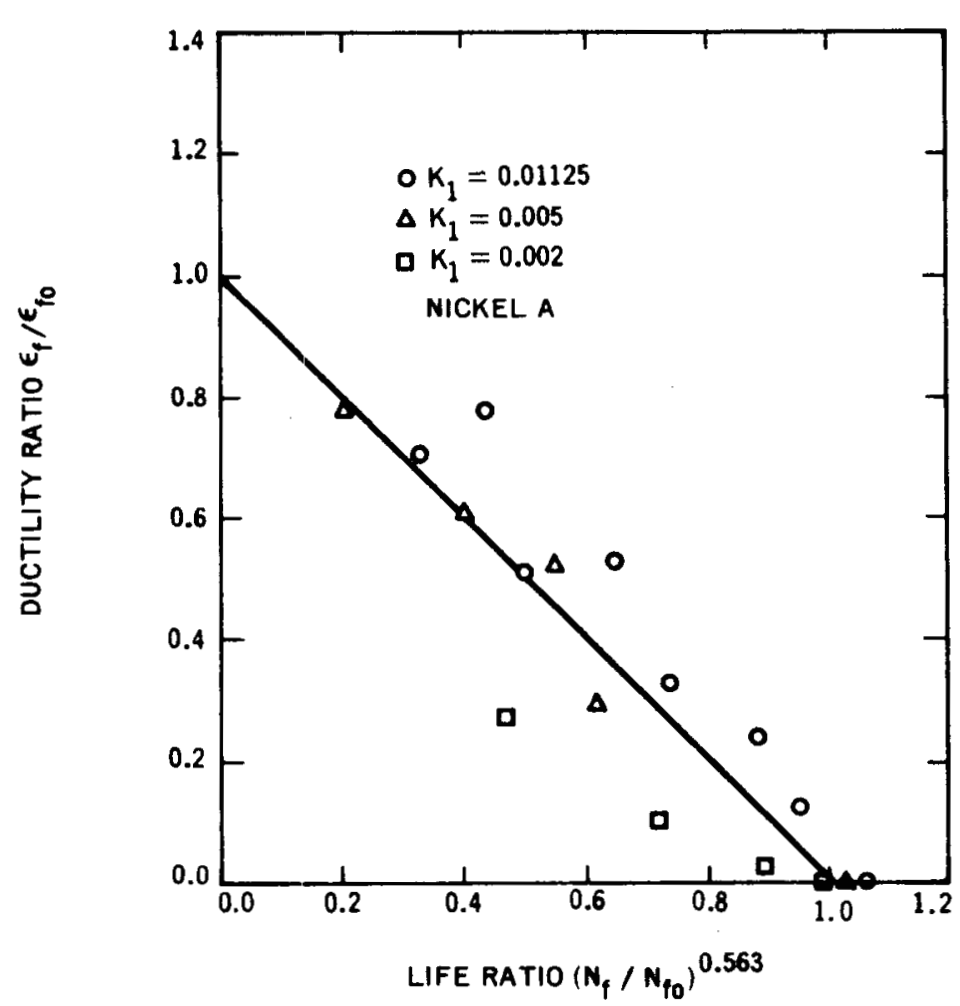

Figure F-10. Representation of Fracture for Mixed Cyclic and Monotonic Straining

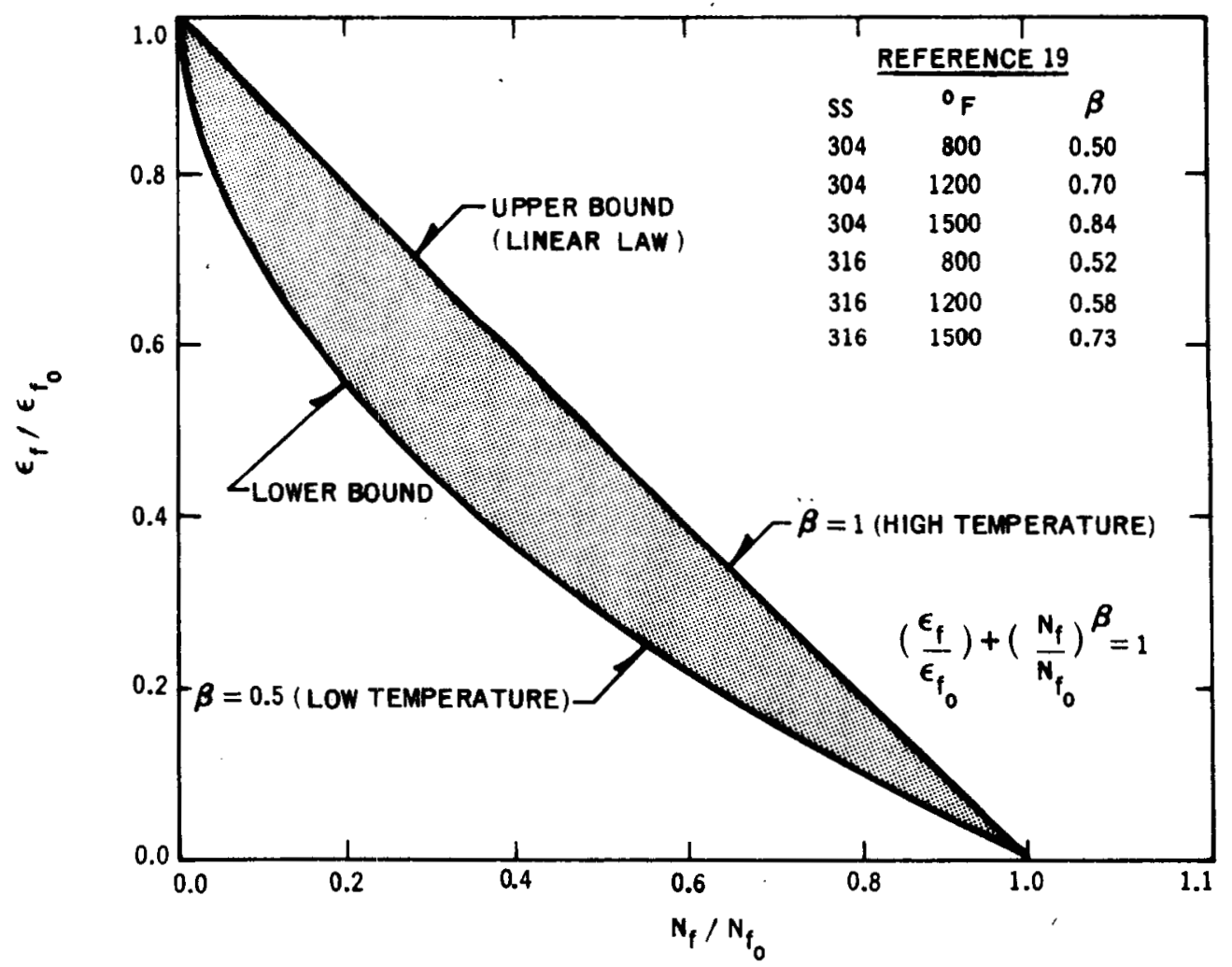

Figure F-11. Approximate Bounds for Equation (F-25) 


\section{F.3.5 Stress-Strain-Temperature-Time Considerations: Hill-Thornton-Quaass ${ }^{30,31,32}$}

This approach gives a general understanding of stress-strain relationships at elevated temperatures which provides a rational explanation of the differences in high-strain fatigue behavior. Such an understanding is based upon an examination of stress-strain-temperature-time curves. By differentiating the stress with respect to the parameter values of the stress-strain curves along each iso-total strain line. Hill, et al., observed that the high rate of stress relaxation occurs only over a small range of parameter values. This form of stress relaxation provides an indication of the rate of conversion of elastic to plastic strain that is considered to be particularly damaging.

F.3.6 Interaction Relations Determined Experimentally: DeMoney-Lazan-Kennedy-Wells-Sullivan-Swindeman ${ }^{33,34,35,36}$

DeMoney and Lazan obtained the interaction behavior of an aluminum alloy experimentally. They found that the interaction characteristics are very much influenced by the temperature; i.e., for temperature at $500^{\circ} \mathrm{F}$, the curves assume the shape of a circle, whereas for that of $300^{\circ} \mathrm{F}$, the curves for given fatigue strengths are approximate to the form of straight lines.

Kennedy obtained the test results for $\mathrm{S}-816$ alloy at different temperatures, as shown in Figure F-12. The general pattern of the curves is similar to that obtained by DeMoney and Lazan, namely, at high temperature, the behavior is quite nonlinear.

The interaction between creep and low-cycle fatigue in Udimet 700 at $1400^{\circ} \mathrm{F}$ was investigated experimentally by Wells and Sullivan. Results are shown in Figure F-13(a). If the abscissa of the test points in this plot are normalized, Figure $\mathrm{F}-13(\mathrm{~b})$ is obtained. In view of the latter plot, it is apparent that the interaction is quite linear.

The interrelation of cyclic and monotonic creep rupture for Inconel was studied experimentally by Swindeman. ${ }^{31}$ Figure F-14a shows some of his results. Apparently, the interaction varies as a function of the shapes of the stress waves. However, if only the nonconservative results are considered, and the coordinates of such test points are normalized as shown in Figure F-14b, it is seen that the interrelation is quite linear except at the upper end of the curve where failure is dominated by fatigue or cyclic loading.

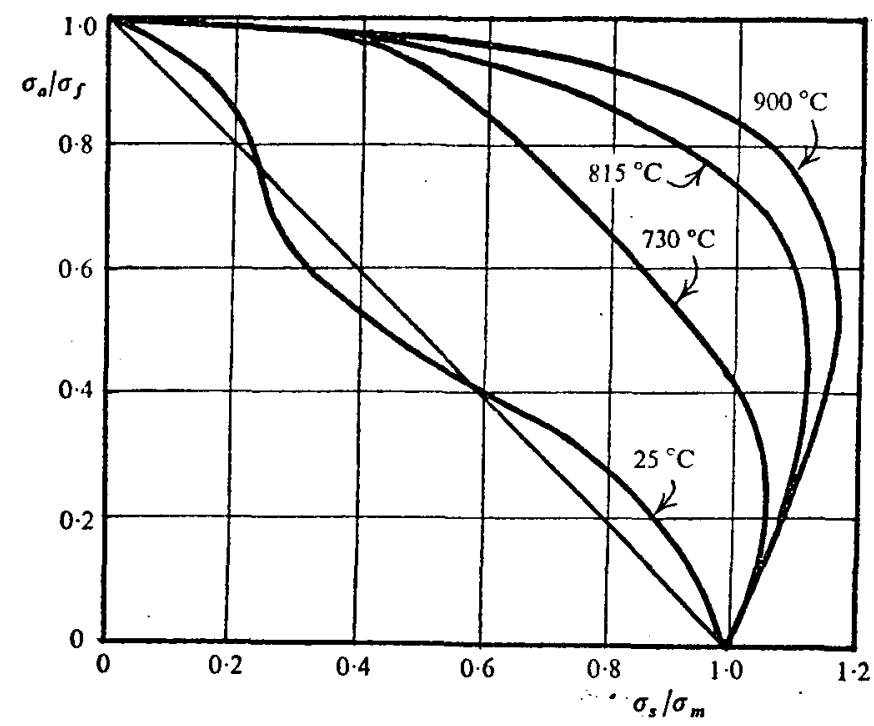

Figure F-12. Combinations of Alternating Stress and Static Stress for 100 hours Life at Different Temperatures for S-816 Alloy (Co-Cr-Ni). of $=$ endurance limit for 100 hours life; $\sigma_{m}=$ static stress for 100 hours life; $\sigma_{a}=$ amplitude of applied alternating stress; $\sigma_{s}=$ level of applied static stress. 

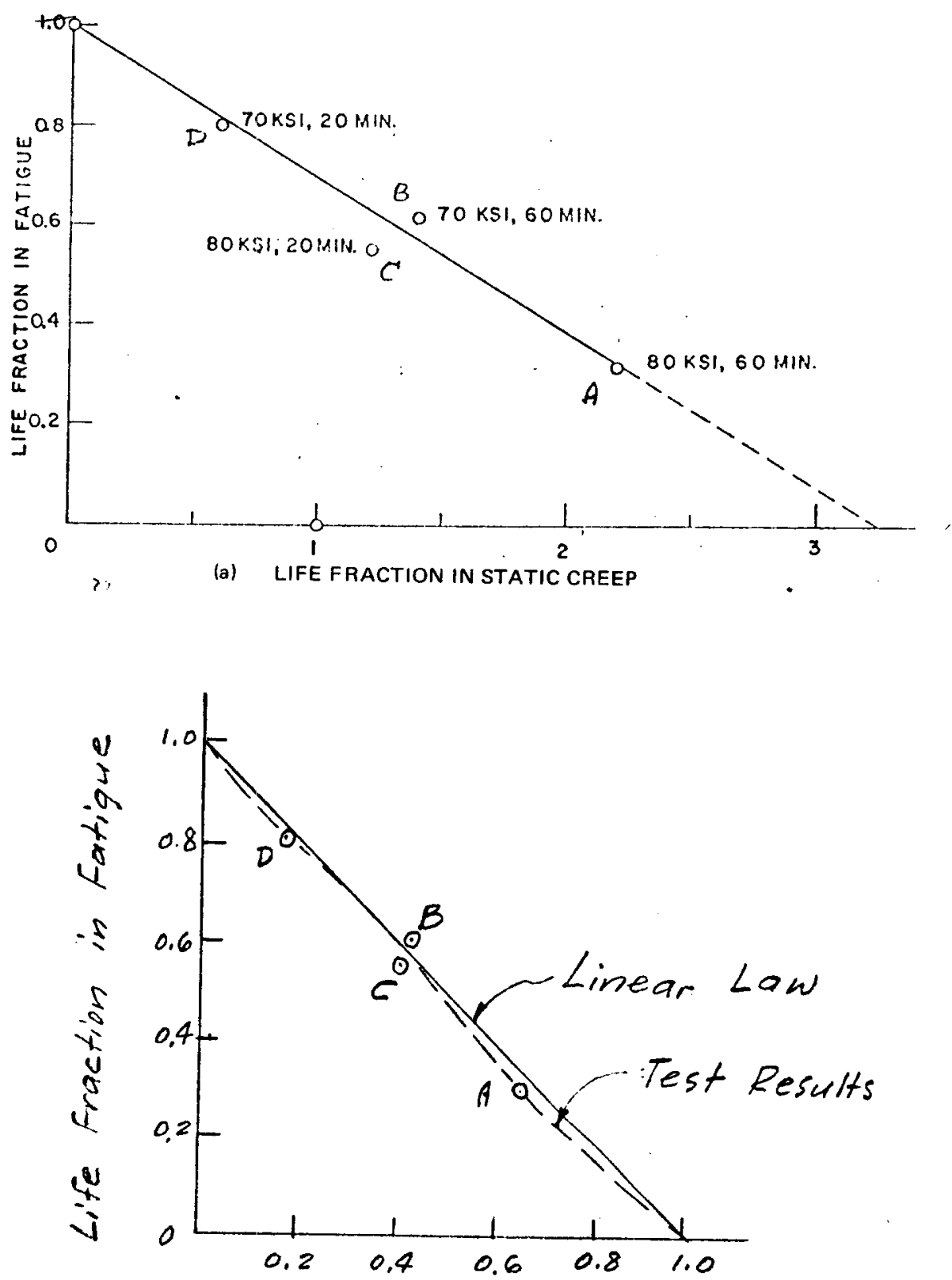

(b) NORMALIZED LIFE FRACTION IN STATIC CREEP

Figure F-13. Application of Linear Cumulative Damage Rule to Macrocrack Initiation in Creep 


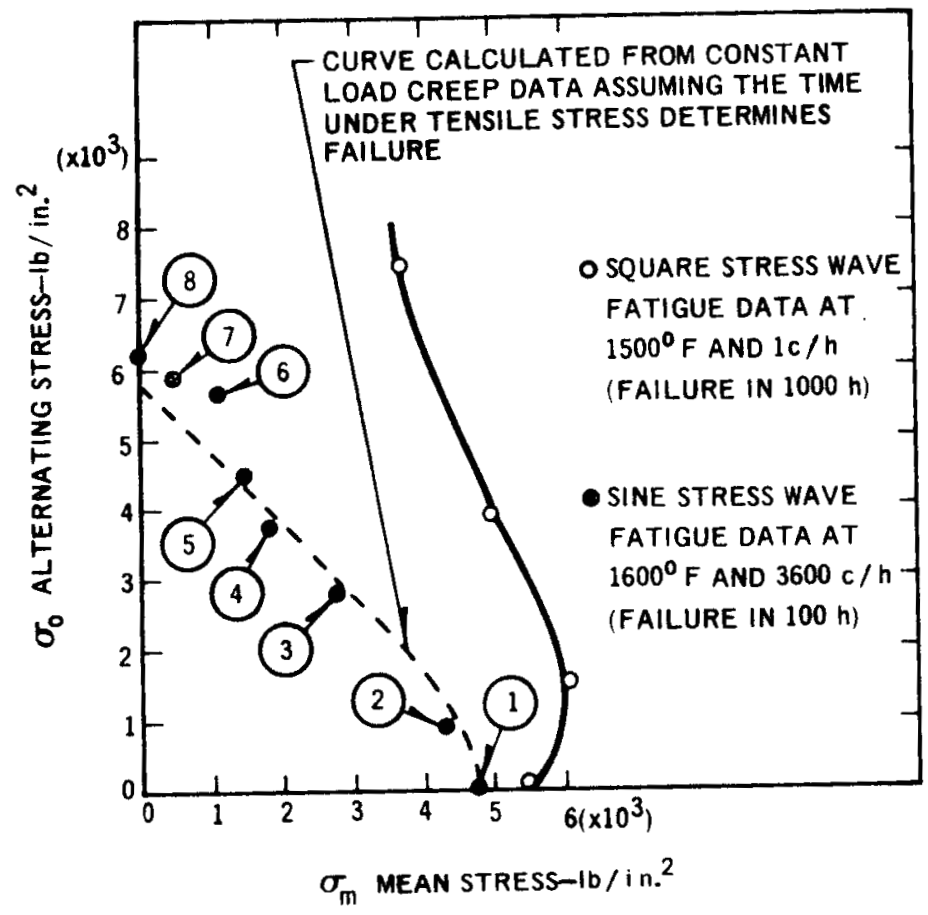

Figure F-14a. Goodman-Type Diagrams for Failure of Inconel under Square and Sine Wave Fatigue Stresses

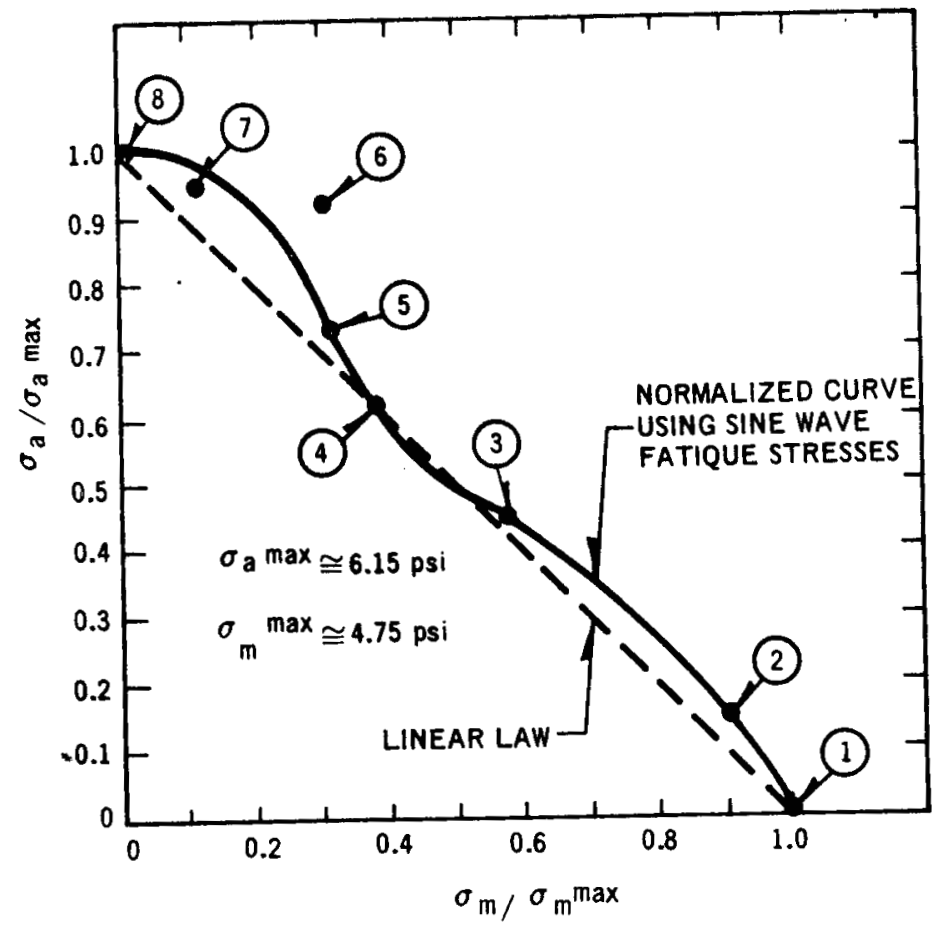

Figure F-14b. Normalized Swindeman Interaction Curve for Inconel 


\section{F.4 REFERENCES}

1. Kennedy, A. J., "Effect of Fatigue Stresses on Creep and Recovery," Proc. Int. Conf. Fatigue of Meta/s, Instn. Mech. Engrs., London, 1956.

2. Lazan, B. J., High Temperature Effects in Aircraft Structures, Pergamon Press, London, 1958.

3. Tilly. G. P., "Fracture Behavior of Two Creep-Resistant Materials Subjected to Cyclic Loading at Elevated Temperature," Proc. Instn. Mech. Engrs., Vol. 180, Pt. 1, No. 46, 1965-66.

4. Coles, A., Hill, G. J., Dawson, R. A. T., and Watson, S. J., "The High-Strain Fatigue Properties of Low-Alloy Creep-Resisting Materials," Proc. International Conference on Thermal and High-Strain Fatigue, Metals and Metallurgy Trust, London, 1967.

5. Taira, S. and Ohnami, M., Thermal Fatigue of Stainless Steels, the Fourth Japan Congress on Testing MaterialsMetallic Materials, 1961.

6. Dawson, R. A. T., Elder, W. J., Hill, G. J., and Price, A. T., "High-Strain Fatigue of Austenitic Steels," Proceedings, International Conference on Thermal and High-Strain Fatigue, Metals and Metallurgy Trust, London, 1967.

7. Ellison, E. G., "A Review of the Interaction of Creep and Fatigue," Journal of Mechanical Engineering Science, Vol. 11, No. 3, 1969.

8. Berling, J. T. and Slot, T., Effect of Temperature and Strain Rate on Low-Cycle Fatigue Resistance of A/SI 304, 316 and 348 Stainless Stee/s, GEMP-642, General Electric, 1966.

9. Forrest, P. G. and Armstrong, K. B., "Thermal Fatigue Resistance of Nickel-Chromium Alloys," Joint International Conference on Creep, Proc. Instn. Mech. Engrs., 1963.

10. Conway, J. B., Berling, J. T., and Steritz, R. H., "New Correlations Involving the Low-Cycle Fatigue and ShortTerm Tensile Behavior of Irradiated and Unirradiated 304 and 316 Stainless Steel," Nuclear Applications and Technologr, Vol. 9, 1970.

11. Berling, J. T. and Conway, J. B., "A Proposed Method for Predicting the Low-Cycle Fatigue Behavior of 304 and 316 Stainless Steel," Transactions, AIME, Vol. 245, 1969.

12. Forrest, P. G., Fatigue of Metals, Pergamon Press, Oxford, 1962.

13. Kennedy, A. J., "Interrelation of Cyclic and Monotonic Creep Rupture," Joint Int. Conf. on Creep, Proc. Instn. Mech. Engrs., 1963-64.

14. Lazan, B. J., "Dynamic Creep and Rupture Properties of Temperature Resistant Materials Under Tensile Fatigue Stress," Proceedings ASTM, Vol. 49, 1949

15. 'Taira, S., "Lifetime of Structures Subjected to Varying Load and Temperature," Creep in Structures, Academic Press, 1962.

16. Hoff, N. J., "A Survey of the Theories of Creep Buckling," Proc. Third U. S. Nat. Cong. Appl. Mech., 1958.

17. Taira, S. and Koterazawa, Dynamic Creep and Fatigue of Metallic Materials at Elevated Temperature, the Fourth Japan Congress on Testing Materials, Vol. 57, 1961.

18. Zamrik, S. Y. and Shewchuk, J., "Fatigue Damage Under Creep Effect," First International Conference on Pressure Vessel Technology, Part II, Materials and Fabrication, 1969.

19. Spera, D. A., The Calculation of Elevated-Temperature Cyclic Life Considering Low-Cycle Fatigue and Creep, NASA TN D 5317, 1969.

20. Spera, D. A., Calculation of Thermal-Fatigue Life Based on Accumulated Creep Damage, NASA TN D 5489, 1969.

21. Manson, S. S., Halford, G. R., and Spera, D. A., The Role of Creep in High-Temperature Low-Cycle Fatigue, A. E. Johnson Memorial Volume, Nat. Eng. Lab., Glasgow, Scotland, 1971.

22. Manson, S. S. and Halford, G., "A Method of Estimating High-Temperature Low-Cycle Fatigue Behavior of Materials," Proc. Inter. Conf. Thermal and High-Strain Fatigue, Inst. Metals and Iron \& Steel Inst., 1967.

23. Manson, S. S., "Interfaces Between Fatigue, Creep, and Fracture," Int. J. Fracture Mech., Vol. 2, No. 1, 1966.

24. Berling, J. T. and Conway, J. B., "A Proposed Method for Predicting the Low-Cycle Fatigue Behavior of 304 and 316 Stainless Steel," Transactions of AIME, Vol. 245, 1969.

25. Berling, J. T. and Conway, J. B., "A New Approach to the Prediction of Low-Cycle Fatigue Data," Metallurgical Transactions, Vol. 1, 1970.

26. Coffin, L. F., Jr., "Predictive Parameters and Their Application to High Temperature, Low-Cycle Fatigue," Proceedings of the Second International Conference on Fracture, 1969.

27. Coffin, L. F., Jr., A Generalized Equation for Predicting High-Temperature, Low-Cycle Fatigue, Inc/uding Hold Times, Report No. 69-C.401, General Electric, 1969.

28. Morrow, J., Cyclic Plastic Strain Energy and Fatigue of Metals, ASTM-STP No. 378, 1965. 
29. Coffin, L. F., Jr., The Deformation and Fracture of a Ductile Metal under Superimposed Cyclic and Monotonic Strains, Report No. 69.C-191, General Electric, 1969.

30. Hill, G. J., Thornton, D. V., and Quaass, S. T., "Elevated-Temperature High-Strain Fatigue of Metals," Institute of Metals, Vol. 93, 1964-65.

31. Quaass, S. T., "Correlation of Data from Elevated-Temperature Creep and High-Strain Fatigue of Metals," Institute of Metals, Vol. 95, 1967.

32. Quaass, S. T., "A Simple Graphical Analysis of Creep and Relaxation in Nimouic Alloys," Institute of Metals, Vol. 96, 1968.

33. DeMoney and Lazan, B. J., Dynamic Creep and Rupture Properties of an Aluminum Alloy under Axial Static and Fatigue Stress, WADC Tech. Report, 53-510, 1954.

34. Kennedy, A. J., Processes of Creep and Fatigue in Meta/s, John Wiley \& Sons, 1963.

35. Wells, C. H. and Sullivan, C.P., "Interactions Between Creep and Low-Cycle Fatigue in Udimet 700 at $1400^{\circ} \mathrm{F}$ ", ASTM STP 459, 1969.

36. Swindeman, R. W., The Interrelation of Cyclic and Monotonic Creep Rupture, Joint International Conference on Creep, 1963. 


\section{APPENDIX G. A BRIEF NOTE ON CREEP BUCKLING OF COLUMNS AND CIRCULAR CYLINDRICAL SHELLS}

\section{G.1 BUCKLING OF COLUMNS}

A graphical method, using an elementary two-flange model, to estimate the life of a column with creep was first suggested by Shanley. ${ }^{1}$ This method requires a set of isochronous stress-strain curves for the materials at given temperature(s). If the slope of the isochronous curve is considered as the time-dependent tangent modulus $E_{t}$, then a perfect column with simply supported ends would begin to deflect laterally after a slight disturbance, when the load becomes the Engesser critical buckling load $P_{t}=\pi E_{t} I / L^{2}$, in which $E_{t}$ has the value of Young's modulus at the instant of load application and thereafter decreases with time. The time at which the column is rendered useless may be approximately calculated by an iterative method devised by Higgens. ${ }^{2}$ Later on, Lin utilized the actual cross section of the column and introduced a numerical procedure for the computation of time-dependent deflections of the column through which the lifetime of creep buckling could be approximated. ${ }^{3}$

Using the following stress-strain-time relationship for the creep law at constant temperature.

$$
\epsilon=\sigma / E+A e^{B} \sigma_{t} K
$$

an analysis has been made of a slightly curved solid rectangular-section pin-ended column carrying a constant load by Libove $^{4}$ and his co-workers. ${ }^{5}$ The analysis led to a differential equation for the plastic strains at the middle of the column as a function of time, and the lifetime of column can be predicted by solving the differential equation numerically.

The creep buckling of both linearly and nonlinearly viscoelastic columns were studied by Kemper and his associates. ${ }^{6,7,8}$ They found that infinite deflection of a linearly viscoelastic column occurs only at infinite time after loading, while for nonlinearly viscoelastic columns the critical time is finite.

Analytic expressions for the lifetime of simply supported columns were obtained by Rabotnov. ${ }^{9}$ The solutions ase based on the assumption that the column is of ideal I-section and the elastic and plastic instantaneous cleformations are neglected:

a. For Power Law $\dot{\epsilon}=B \sigma^{n}$ : if $\mathrm{n}=3$ and $\mathrm{c}_{\mathrm{o}}=$ initial dimensionless deflection, then

$$
B \sigma^{3} t_{c r}=\frac{1}{6}\left(\frac{\pi h}{L}\right)^{2} \operatorname{Ln} \frac{3+c_{o}^{2}}{c_{o}^{2}}
$$

where $B, h$, and $L$ are the material constant, $1 / 2$ the depth, and length of the column, respectively.

b. For Hyperbolic Sine Law $\dot{\epsilon}=2 \epsilon_{\mathrm{e}} \sinh \sigma / \sigma_{\mathrm{e}}$ :

$$
\epsilon_{\mathrm{e}} \cosh \left(\frac{\sigma}{\sigma_{\mathrm{e}}}\right) \mathrm{t}_{\mathrm{cr}}=\left(\frac{\pi \mathrm{h}}{\mathrm{L}}\right)^{2} \frac{\sigma_{\mathrm{e}}}{\sigma} \operatorname{Ln}\left(1 / \tanh \left[\frac{\sigma \mathrm{c}_{\mathrm{o}}}{2 \sigma_{\mathrm{e}}}\right]\right),
$$

where $\epsilon_{\mathrm{e}}$ and $\sigma_{\mathrm{e}}$ are constants.

Numerical comparisons for the lifetime computed by Shanley's method and those obtained by the foregoing equations have been made by Hoff. ${ }^{10}$

\section{G.2 BUCKLING OF CYLINDRICAL SHELLS}

The sandwich-type cylindrical shell with a slight initial deviation from a circular shape subject to uniform lateral pressure was studied by Hoff, Jahsman, and Nachbar. ${ }^{11}$ The initial deformation is assumed to be of the following form:

$$
R(\phi, t)=\underline{R}[1+\alpha(t) \cos 2 \phi],
$$


where $\underline{R}$ and $\alpha$ are the mean radius of the shell and mode amplitude, respectively. The flow law is expressed as

$$
\dot{\epsilon}_{\phi}=\left(\frac{3}{4}\right)^{(n+1) / 2} \times\left(\frac{\sigma_{\phi}}{\lambda}\right)^{n} .
$$

For $n=3$, the critical time can be written as

$$
\frac{t}{\tau}=\frac{1}{2} \operatorname{Ln}\left(1+\frac{g}{2 x_{o}^{2}}\right)
$$

where $X_{o}$ denotes the value of $X=\alpha \underline{R} / \rho$ at time $t=0$, and $\tau$ is a time constant, depending on the material properties and involving the shell cross-sectional area (A). Figure $G-1$ shows the time-deformation relation for the specific values of the parameters $n=3$ and $X=173$.

The time-dependent variations of deformation and stress in an axially compressed cylindrical shell when the constitutive equation is a secondary creep law were investigated by Pittner and Hoff. ${ }^{12}$ Numerical results for a power law with $\mathbf{n}=3$ were obtained in graphical form. A computer program RMONIC has been developed, which is also applicable for a stepwise-changing load history.

Creep buckling of imperfect circular cylindrical shells under nonuniform external loads, including thermal gradients, was analyzed by Samuelson. ${ }^{13,14}$ From the results obtained for both elastic buckling and creep buck ling, it was found that the collapse load of a shell under external pressure depends strongly on the shape and amplitude of the imperfection. For a decreasing imperfection amplitude, the collapse load was found to approach the classical value asymptotically, regardless of the shape (Figure G-2). The creep behavior of the shell was shown to be similar to that of the elastic shell under increasing load. A digital computer program, COACS, has also been developed for the prediction of the lifetime of imperfect cylinders under various loading conditions. This program has recently been converted to GE 635 computer for the pre- and post-buckling analysis of cylindrical components.

\section{G.3 REFERENCES}

1. Shanley, F. R., "Principles of Creep Buckling," Weight-Strength Analysis of Aircraft Structures, McGraw-Hill, 1952.

2. Higgins, T.P., Jr., "Effect of Creep on Column Deflection," Weight-Strength Analysis of Aircraft Structures, McGraw-Hill, 1952.

3. Lin, T. H., Theory of Inelastic Structures, John Wiley \& Sons, 1968.

4. Libove, C., Creep-Buckling Analysis of Rectangular-Section Columns, NACA TN 2956.

5. Mathauser, E. E. and Libove, C., Preliminary Investigations of Strength Characteristics of Structural Elements at Elevated Temperatures, NACA RM L53E040, 1953.

6. Kempner, J. and Batel, S. A., Creep Buckling of Columns, NACA TN 3138, 1954.

7. Kempner, J., Creep Bending and Buckling of Linearly Viscoelastic Columns, NACA TN 3136, 1954.

8. Kempner, J., Creep Bending and Buckling of Nonlinearly Viscoelastic Columns, NACA TN 3137, 1954.

9. Rabotnov, Yu. N., Creep Problems in Structural Members, North Holland, 1969.

10. Hoff, N. J., A Survey of the Theory of Creep Buckling, Proceedings of the Third U. S. National Congress of Applied Mechanics, 1958.

11. Hoff, N. J., Jahsman, W. E., and Nachbar, W., "A Study of Creep Collapse of a Long Circular Cylindrical Shell Under Uniform External Pressure," J. of Aerospace Science, Vol. 26, 1959.

12. Pittner, E. V. and Hoff, N. J., Axisymmetric Creep Deformations of Circular Cylindrical Shells in Axial Compression, LMSC-B-71-67-1, Lockheed Missiles \& Space Company, Sunnyvale, Ca., 1967.

13. Samuelson, L. A., Nonlinear Analysis of a Circular Cylindrical Shell under Nonuniform Ex ternal Loads and Subjected to Secondary Creep, LMSC-B-70-68-1, Lockheed Missiles \& Space Company, Sunnyvale, Ca., 1968.

14. Samuelson, L. A., Creep Buckling of Imperfect Circular Cylindrical Shells under Nonuniform External Loads, Paper presented at an I.U.T.A.M. Conference in Sweden, August 1970.

15. Corum, J. M. and Greenstreet, W. L., An Experimental Investigation of Instantaneous Collapse and Creep Buckling Characteristics of Cylindrical Shee/s, ORNL-3555, 1964. 


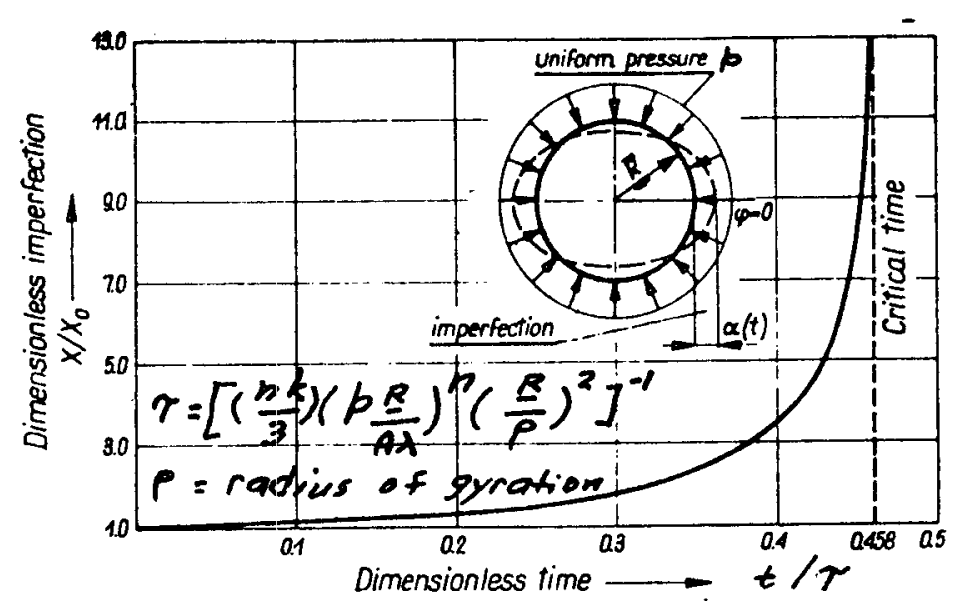

Figure G-1. Creep Buck ling of Long Cylinders under Uniform Pressure

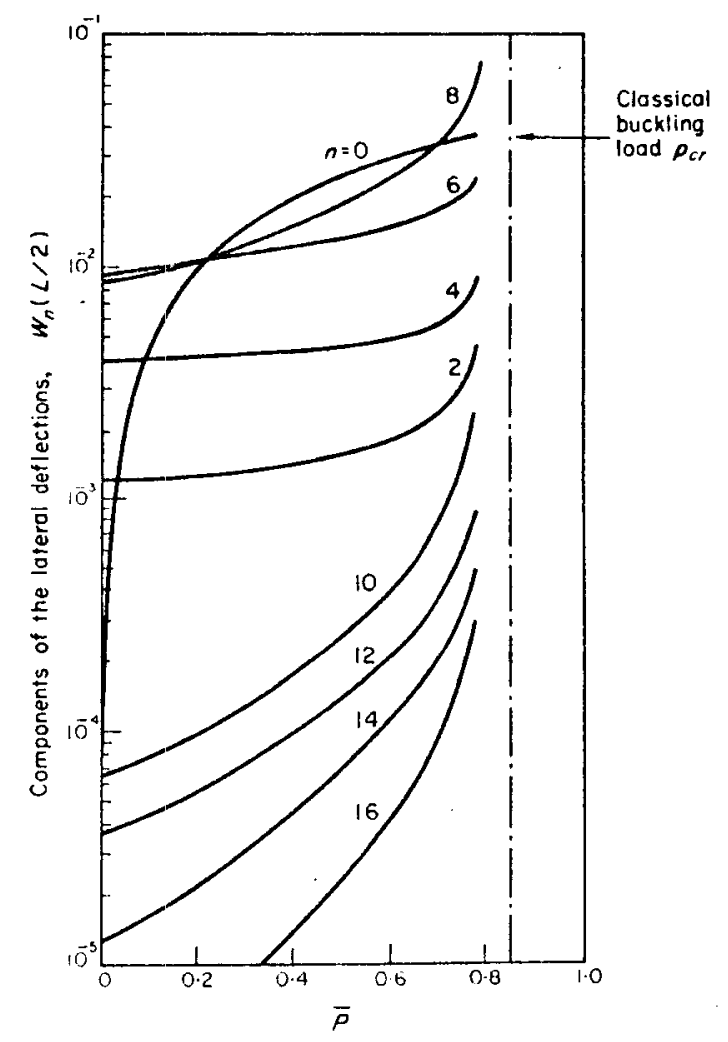

Figure G-2. Load Deflection Curves for a Cylinder with $R / h=100, L / R=1$ and $E=5000$, Subjected to Radial Pressure 
$\ominus$

$\bullet$ 


\section{APPENDIX H. MATERIAL DATA}

Shown in Figure $\mathrm{H}-1$ is the scatterband of the stress-rupture strength of $\mathrm{Gr}$. 347 austenitic steel for failure at 100,000 hours. These curves were extrapolated to 100,000 hours from the short-time uniaxial test data using LarsonMiller parameters, the constant being $\mathrm{C}=20$.

Figure $\mathrm{H}-2$ shows the biaxial stress rupture strengths of two types of annealed stainless steel in high-purity static liquid sodium at a temperature range between 1000 and $1400^{\circ} \mathrm{F}$. It is noted that the liquid sodium appears to have no significant effect on the rupture strengths of these metals.

Figure $\mathrm{H}-3$ shows some typical creep curves for the AISI-316 stainless steel at $1300^{\circ} \mathrm{F}$ under different stress levels. It is seen that at high stresses the secondary stage is rather short, while at low stresses the third stage almost disappears. The latter phenomenon is, of course, partially attributed to the fact that results are expressed in terms of true strains. The curves shown may be approximated by the following empirical formula:

$$
\epsilon=a+b\left(1-e^{c t}\right)+d t
$$

where $\quad a=$ instantaneous strain,

b = limiting transient creep strain,

$c=$ ratio of transient creep rate to the transient creep strain, and

d = secondary creep rate.

Values of these constants for the curves shown are given in Table H-1.

Table H-1

VALUES OF CONSTANTS

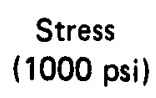

23.20

21.38

18.63

13.19

11.23

9.55

$$
\left(10^{-3}\right. \text { in./in.) }
$$

27.4

15.0

7.5

4.8

3.5

0.9 $b$ $\left(10^{-2}\right.$ in./in. $)$

9.94

8.47

6.90

4.39

3.29

0.67 $\left(10^{-2} h^{-1}\right)$

7.77

3.87

1.67

0.49

0.35

0.35

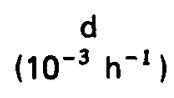

3.20

1.20

0.49

0.085

0.055

0.025

In view of Figure $\mathrm{H}-3$, it is apparent that the time derivative of the creep strain or creep rate is stress dependent. For the material under consideration, the strain rate-stress relationship can be approximated by the following expression:

$$
\dot{\epsilon}=K(\sinh A \sigma)^{\eta}
$$

where $\mathrm{K}, \mathrm{A}$, and $\eta$ are constant at constant temperature. For $T=1300^{\circ} \mathrm{F}$,

$$
\begin{aligned}
& K=5.30 \times 10^{-5} \mathrm{hr}^{-1} \\
& A=7.80 \times 10^{-5} \mathrm{in}^{2} / \mathrm{lb} \\
& \eta=3.64
\end{aligned}
$$




\section{BIBLIOGRAPHY FOR APPENDIX H}

1. Archinal, E. C., Parameter Rupture Strength Scatterband on Some Turbine Department Alloys, Technical Information Series No. DF-61-LS-82, General Electric Company, 1961.

2. Lee, W. T., Bi-axial Stress-Rupture Properties of Austenitic Stainless Stee/s in Static Sodium, Al-AEC-12694, Atomics International, 1968.

3. Conway, J. B., et al., Creep-Rupture Data for the Refractory Metals to High Temperatures, GEMP-685, Nuclear Systems Programs, General Electric Company, 1969.

4. Garofalo, F., Fundamentals of Creep and Creep-Rupture in Metals, MacMillan Company, 1965. 
GEAP-13719

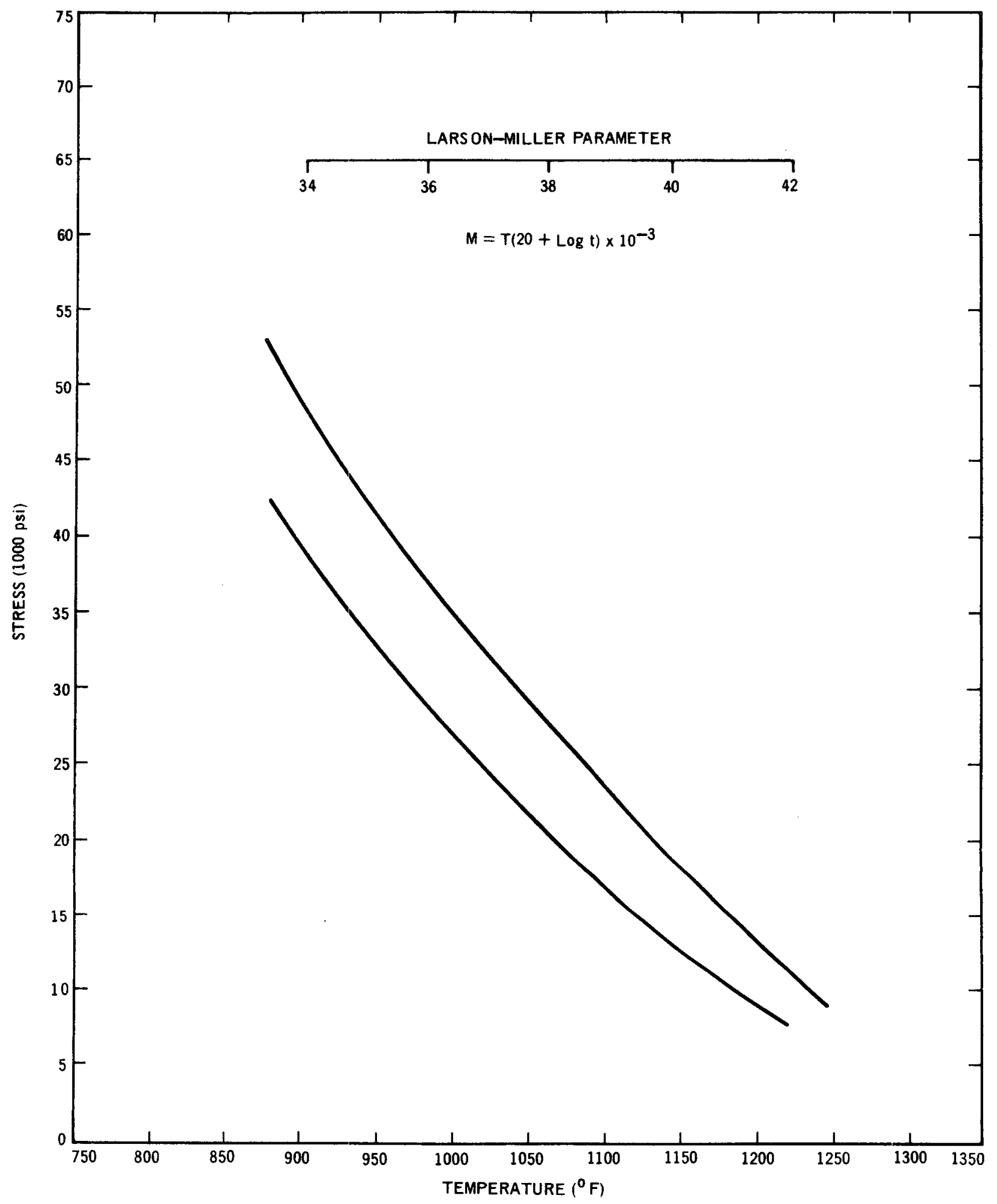

Figure H-1. Stress-Rupture Scatterband for Grade TP347H Austenitic Seamless Pipe 


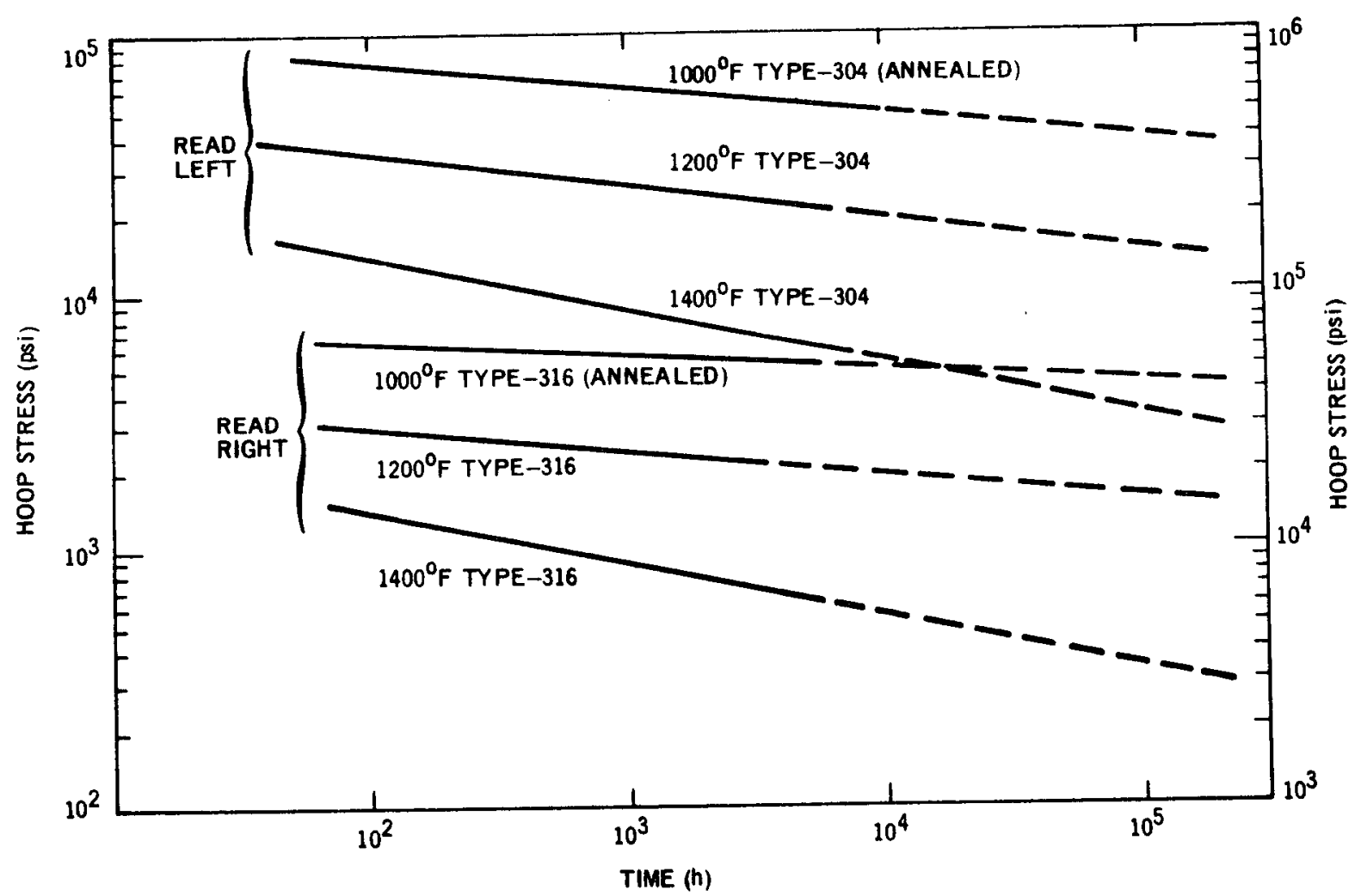

F. ire H-2. Biaxial Stress-Rupture Properties of Stainless Steel in High-Purity Sodium 

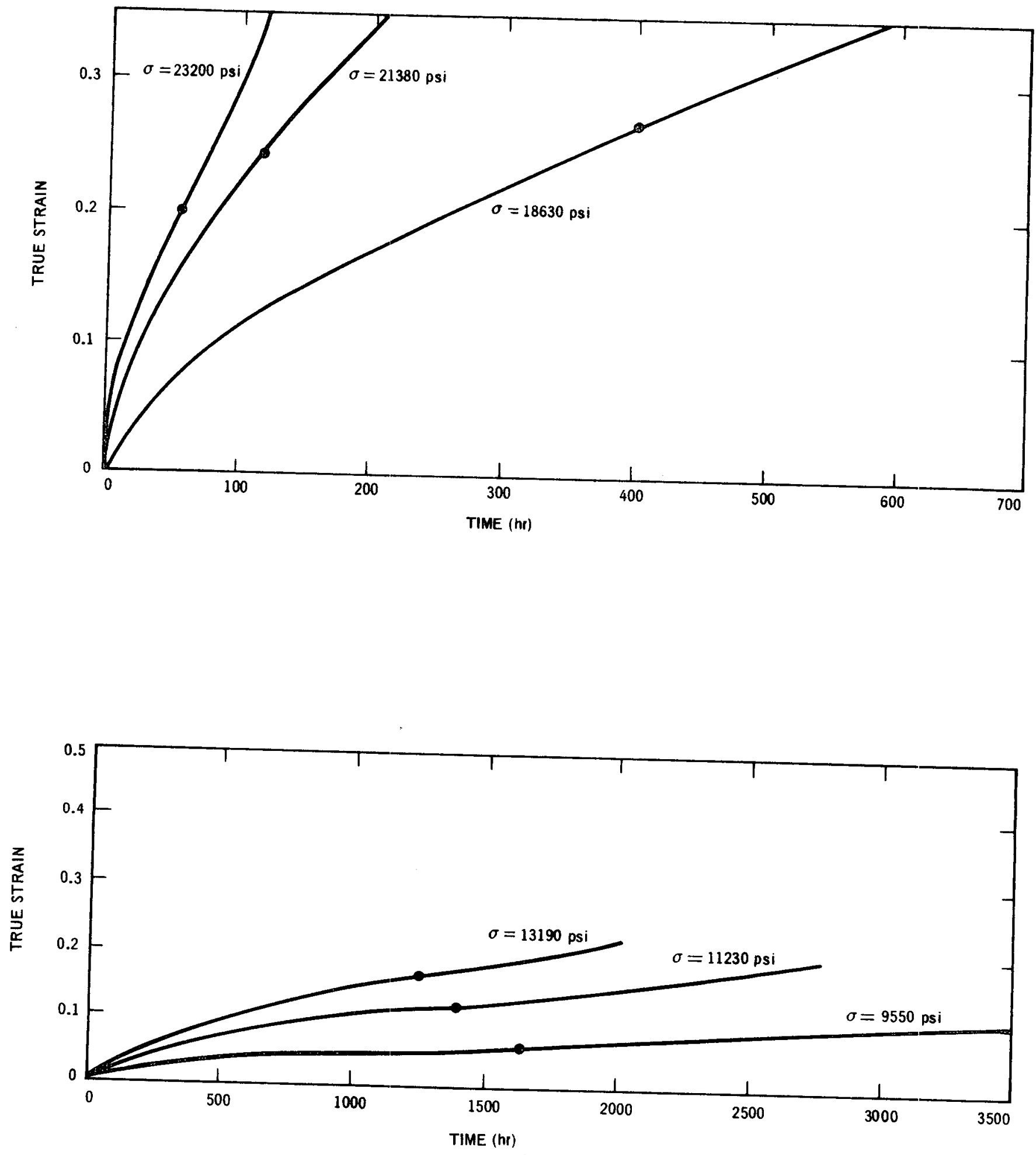

Figure H-3. Creep Curves for A/SI-316 Stainless Steel at $1300^{\circ} \mathrm{F}\left(704^{\circ} \mathrm{C}\right)$ under Constant Stresses 
$\bullet$

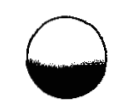
1 


\section{APPENDIX I. BASIS FOR ESTABLISHMENT AND USE OF A STRAIN CRITERIA FOR LMFBR CORE COMPONENTS}

\section{I.1 INTRODUCTION}

Fuel assembly components (i.e., fuel rods, flow channels, and grid spacers) for the LMFBR will be exposed to a core environment that will produce a severe reduction in the ductility of the austenitic stainless steels from which these components are constructed. The initial purpose of this report is to define and/or predict this embrittlement in terms of neutron exposure, irradiation temperature, and loading conditions, and to convey an understanding of the problems and uncertainties encountered in making such a prediction. Using this prediction in combination with observations from related though not directly applicable data, design insight, and engineering judgment, the secondary purpose of this report will be to recommend a method to account for this reduced strain capability in the various fuel assembly design considerations. This method is intended for use with whatever design criteria are determined by the fuel assembly designer to be appropriate. It is not intended to be those design criteria.

The fundamental reason for performing these analyses is to develop a self-consistent method for considering core-environment-produced embrittlement in the design of LMFBR fuel assembly components. As discussed later in this appendix, many problems exist that tend to discourage making this attempt; however, the fact remains that these components will be severely embrittled by exposures to the core environment. For example, Types-316 and -304 stainless steels, which exhibit tensile elongations of 40 to $50 \%$ prior to irradiation, have failed in tensile tests after total neutron exposures of $3 \times 10^{22} \mathrm{n} / \mathrm{cm}^{2}$ in DFR and $5 \times 10^{22}$ in EBR-II at elongations of as low as $0.9 \%$ and $0.5 \%$, respectively. This type of behavior has been shown to definitely affect the performance of fuel rods that have failed during irradiation in EBR-II. It seems logical that similar embrittlement will also affect the performance of the other fuel assembly components (i.e., channels and fuel rod spacers) and that a method for considering these effects in the design of all fuel assembly components is very necessary.

The basis for developing such a method lies in being able to predict the degree of embrittlement of the fuel assembly components as a function of the parameters affecting this embrittlement. This prediction, including a discussion of the methods used to make it and the limitations of its use, make up the first portion of this appendix. The second portion of this appendix uses this prediction to develop a method based on design criteria for considering core-environment-produced embrittlement of LMFBR fuel assembly components.

\section{I.2 PREDICTION OF CORE-ENVIRONMENT-PRODUCED EMBRITTLEMENT OF FUEL ASSEMBLY COMPONENT STRUCTURAL MATERIALS}

\subsubsection{Method of Analysis and Data Selection}

The ideal method for predicting the ductility of LMFBR fuel assembly components requires having a statistically significant set of data points that represent the range of all critical core parameters such as fluence, temperature, and type of loading. Since making such a prediction has been a prime objective of a nationwide materials development program at national and industrial laboratories for at least the past 5 years, a first assumption of the designer without an intimate knowledge of these programs would be that such a set of data points is readily available. Unfortunately, this is far from being the case, primarily because of the lack of adequate test facilities to simulate LMFBR conditions and the long times required to obtain appreciable neutron exposures.

Little, if any, applicable data are available that can be directly used in defining and predicting core environment effects on the ductility of austenitic stainless steels, and essentially all of the data must be applied indirectly. Peak neutron exposures for the available data are approximately one-third to two-thirds of those which will be seen in LMFBR fuel assembly components. Almost all of the data have been obtained from post-irradiation tensile tests which may not be representative of the ductility of core components during irradiation. Test temperatures for these post-irradiation tests are quite often considerably different, usually higher than those temperatures at which the samples were irradiated, thereby introducing an additional variable into the data interpretation. This variable usually eliminates the direct applicability of the particular data. Finally, the effects of parameters such as strain rate and mode of loading on ductility values are generally undefined. 
In light of these limitations on the data which are directly applicable to making ductility predictions, this analysis attempted to screen all of the related data and use only those data points which were most nearly applicable. The data which were determined to be most applicable, and which form the basis for the subject ductility predictions, were selected from post-irradiation tensile test results obtained from EBR-II irradiated specimens that were examined by General Electric-BRDO, Pacific Northwest Laboratory, Oak Ridge National Laboratory. Argonne National Laboratory, and WADCO. Because of various reasons, including differences between irradiation and test temperatures, differences in the core energy spectrum from EBR-II, and general uncertainties regarding the data, no data from UKAEA-Culchetch, Harwell, Dounreay, and the Centre d'Entudes Nucleaires deSaclay, France, were considered directly in the analysis.

To eliminate the very significant effects of test temperature on the ductilities measured in these post-irradiation tests, only data which were obtained from specimens that were tested at approximately the same temperatures as those at which they were irradiated were used. Most of the data points selected had test temperatures that differed from their irradiation temperatures by no more than $30^{\circ} \mathrm{C}\left(54^{\circ} \mathrm{F}\right)$. Only trends and tendencies from rejected data were considered.

Variations due to differences in the reporting of fluence values were reduced by considering all data on the basis of fluence $>0.1 \mathrm{MeV}$. In the cases where this value was not reported, conversions from total fluences to fluences $>0.1 \mathrm{MeV}$ were made by multiplying total fluence by 0.85 . This method also enables these predictions to be directly related to LMFBR fluences that are $>0.1 \mathrm{MeV}$ by eliminating differences between the relative flux spectrums.

Consistency was maintained throughout the data as to the type of ductility used in the correlation by always reporting ductility in terms of the uniform elongation of the test specimen. This value represents the amount of strain received by the specimen prior to the onset of necking, and it eliminates differences that would result due to using test specimens of varying gage lengths. It also introduces a note of conservatism into the analysis, since uniform strain does not reflect strain at failure but represents a strain "near" the failure point, the "nearness" being a function of the type of failure mode experienced by the specimen. In cases where only total elongation values were quoted in the literature, uniform strains were obtained by multiplying total strains by a factor of 0.80 .

Tables 1-1 through 1-6 list the data points that were used as the basis for the subject ductility prediction. By grouping the data according to irradiation temperatures (i.e., 371 to $400^{\circ} \mathrm{C}, 400$ to $450^{\circ} \mathrm{C}, 450$ to $500^{\circ} \mathrm{C}$, 500 to $550^{\circ} \mathrm{C}, 550$ to $600^{\circ} \mathrm{C}$ ) and all data points at greater than $600^{\circ} \mathrm{C}$, it is approximately possible to separate the effect of irradiation temperature from the uniform elongation versus fluence ( $\mathrm{E}>0.1 \mathrm{MeV}$ ) relationship. These data groups allow observations to be made on the effect of neutron exposure on the embrittlement of austenitic stainiess steels, in this case Types-304 and -316 in the annealed condition, at approximately constant conditions of irradiation-test temperature.

\section{I.2.2 Results of Analysis}

Figures 1-1 through 1-6 exhibit the data described in Tables I-1 through 1-6 by plotting uniform elongation as a function of fluence ( $\mathrm{E}>0.1 \mathrm{MeV}$ ). The symbol key in Figure 1-1 relates each data point to the reference from which it was obtained. These symbols apply to Figures 1-2 through 1-5 as well. Also included in each of these figures are lines representing the estimated value of the mean expectance of uniform elongation in the post-irradiation test and the estimated limit below which uniform elongations will not fall. Values that are indicated at a fluence of $10^{23}$ (E $>0.1$ $\mathrm{MeV}$ ) are assumed to remain unchanged at higher fluences. Because of the large amounts of scatter in the data at each temperature range, meaningful statistical determinations of these values was not attempted. Instead, these lines were estimated by the author primarily through consideration of the following factors: (1) the directly applicable data which are plotted on the figures; (2) data that were not directly applicable, such as post-irradiation tensile test results tested at test temperatures considerably different from the irradiation temperatures, foreign data, cyclotron bombardmenthelium embrittlement simulations, and fuel pin irradiations in EBR-II; (3) theoretical analyses; and (4) knowledge of the changes in microstructure experienced under the test environments.

The basic trend observable in these estimates is that the ductility reductions as a function of fluence tend to become flat in all temperature ranges above fluences of approximately $2 \times 10^{22}(\mathrm{E}>0.1 \mathrm{MeV})$. This trend, which is shown by the estimates but which is not so easily seen from the data, was introduced into the estimates by several key 
observations: (1) examinations of highly irradiated EBR-Il structural components which showed that uniform strain reductions appeared to saturate above $2 \times 10^{22} \mathrm{n} / \mathrm{cm}^{2}$ total fluence at temperatures of approximately $450^{\circ} \mathrm{C}\left(842^{\circ} \mathrm{F}\right)$, and (2) observations of sample microstructures which indicate that little change is experienced in the microstructure after irradiations in excess of $2 \times 10^{22} \mathrm{n} / \mathrm{cm}^{2}$ total fluence at high temperatures $\left(760^{\circ} \mathrm{C}\left(1112^{\circ} \mathrm{F}\right]\right)$ where large defect type swelling damage is minimal.

Figures $1-7 \mathrm{a}$ and $1-7 \mathrm{~b}$ show the effect of irradiation test temperature on the post-irradiation uniform strain for three different fluences as determined from the estimates in Figures 1-1 through I-6. Values for the mean and estimated lower limits are shown in Figures $1-7 \mathrm{a}$ and $1-7 \mathrm{~b}$, respectively. The most striking observation on these figures is the approximately twofold increase in the values of the predicted post-irradiation uniform strain in the irradiation test temperature range of 450 to $500^{\circ} \mathrm{C}\left(842\right.$ to $\left.932^{\circ} \mathrm{F}\right)$. This behavior reflects the tendency of the small irradiation-produced defect clusters in the metal to decrease in concentration as irradiation temperatures increase above approximately $370^{\circ} \mathrm{C}\left(698^{\circ} \mathrm{F}\right)$. Since it appears that these small defects, in contrast to the fairly large defects that produce volume changes, are primarily responsible for stainless steel embrittlement below about $500^{\circ} \mathrm{C}$, a decrease in their concentration should yield an increased value of the post-irradiation uniform ductility. Above about 500 to $550^{\circ} \mathrm{C}$ $\left(932\right.$ to $1022^{\circ} \mathrm{F}$ ), where very few of these small defect clusters remain, the dominant factor leading to low ductilities is believed to be helium produced by transmutation reactions. The higher values of uniform strain that are estimated at these temperatures, as compared with temperatures below $500^{\circ} \mathrm{C}\left(932^{\circ} \mathrm{F}\right)$ are more readily seen directly in the data in Figures I-1 through 1-6. These higher strains also closely agree with strains at failure which were measured on helium-injected samples at similar temperatures, and with more recent observations of EBR-II irradiated specimens after high fluences $\left(\sim 7 \times 10^{22}\right)$ where strains at failure of $5 \%$ have been seen.

Table 1-1

\section{UNIFORM STRAINS IN AUSTENITIC STAINLESS STEELS AFTER IRRADIATION IN EBR-II AT 371 TO $400^{\circ} \mathrm{C}\left(700 \mathrm{TO}^{\circ} 752^{\circ} \mathrm{F}\right)$}

\section{Fluence $\times 10^{-22}$ $\mathrm{E}>0.1 \mathrm{MeV}$}

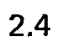

2.4

2.6

2.6

3.3

3.3

2.8

1.7

4.1

7.7

2.25

2.7

2.9 rradiation

Temperature

( $\left.{ }^{\circ} \mathrm{C}\right)$

371

371

387

387

399

399

400

371

371

388

399

399

393

\section{( $\left.{ }^{\circ} \mathrm{F}\right)$}

700

700

728

728

750

750

752

700

700

730

750

750

740
Test

Temperature
( $\left.{ }^{\circ} \mathrm{C}\right) \quad\left({ }^{\circ} \mathrm{F}\right)$

371

700

371

700

728

387

728

750

750

698

842

842

842

700

800

427

427

Uniform
Strain
0.7
1.2
0.8
1.2
0.6
0.8
0.7
2.5
2.7
1.5
5.0
1.4
1.1

Location
in EBR-II

XG05

XG05

XG05

XG05

XG05

XG05

XG05

XG05

XG05

Safety Rod

$\times 021$

X019

X019
Material

304

304

304

304

304

304

304

304

304

304

316

316

316 
Table $1-2$

STRAINS IN AUSTENITIC STAINLESS STEELS AFTER IRRADIATION IN EBR-II AT 400 TO $450^{\circ} \mathrm{C}$ (752 TO $842^{\circ} \mathrm{F}$ )

\begin{tabular}{|c|c|c|c|c|c|c|c|}
\hline \multirow{2}{*}{$\begin{array}{l}\text { Fluence } \times 10^{-22} \\
E>0.1 \mathrm{MeV}\end{array}$} & \multicolumn{2}{|c|}{$\begin{array}{l}\text { Irradiation } \\
\text { Temperature }\end{array}$} & \multicolumn{2}{|c|}{$\begin{array}{c}\text { Test } \\
\text { Temperature }\end{array}$} & \multirow{2}{*}{$\begin{array}{c}\text { Uniform } \\
\text { Strain }\end{array}$} & \multirow{2}{*}{$\begin{array}{l}\text { Location } \\
\text { in EBR-II }\end{array}$} & \multirow[b]{2}{*}{ Material } \\
\hline & $\left({ }^{\circ} \mathrm{C}\right)$ & $\left({ }^{\circ} \mathrm{F}\right)$ & $\left({ }^{\circ} \mathrm{C}\right)$ & $\left({ }^{\circ} \mathrm{F}\right)$ & & & \\
\hline 0.2 & 421 & 790 & 421 & 790 & 17.0 & XG05 & 304 \\
\hline 0.2 & 421 & 790 & 421 & 790 & 18.0 & XG05 & 304 \\
\hline 0.7 & 421 & 790 & 421 & 790 & 6.1 & XG05 & 304 \\
\hline 0.7 & 421 & 790 & 421 & 790 & 7.9 & XG05 & 304 \\
\hline 2.0 & 421 & 790 & 421 & 790 & 2.7 & XG05 & 304 \\
\hline 2.3 & 421 & 790 & 421 & 790 & 0.9 & XG05 & 304 \\
\hline 2.6 & 413 & 775 & 413 & 775 & 1.1 & XG05 & 304 \\
\hline 2.6 & 413 & 775 & 413 & 775 & 1.3 & XG05 & 304 \\
\hline 3.1 & 407 & 765 & 407 & 765 & 0.7 & XG05 & 304 \\
\hline 3.1 & 407 & 765 & 407 & 765 & 0.8 & XG05 & 304 \\
\hline 2.3 & 421 & 790 & 421 & 790 & 0.9 & XG05 & 304 \\
\hline 2.6 & 421 & 790 & 421 & 790 & 1.1 & XG05 & 304 \\
\hline 2.6 & 421 & 790 & 421 & 790 & 1.3 & XG05 & 304 \\
\hline 3.2 & 404 & 760 & 404 & 760 & 1.0 & XG05 & 304 \\
\hline 3.2 & 404 & 760 & 404 & 760 & 1.4 & XG05 & 304 \\
\hline 0.09 & 427 & 800 & 427 & 800 & 18.1 & Row II & 316 \\
\hline 0.4 & 427 & 800 & 427 & 800 & 21.8 & Row II & 304 \\
\hline 1.5 & 450 & 842 & 450 & 842 & 6.5 & $\times 034$ & 304 \\
\hline 1.8 & 450 & 842 & 450 & 842 & 2.0 & XG05 & 304 \\
\hline 3.2 & 450 & 842 & 450 & 842 & 1,8 & Safety Rod & 304 \\
\hline 1.25 & 438 & 820 & 427 & 800 & 13.2 & $\times 021 C$ & 316 \\
\hline 2.25 & 449 & 840 & 427 & 800 & 10.5 & $\mathrm{X021C}$ & 316 \\
\hline $0.5 f$ & 427 & 800 & 427 & 800 & 23.9 & $\times 019$ & 316 \\
\hline 0.80 & 427 & 800 & 427 & 800 & 13.4 & $\times 019$ & 316 \\
\hline 1.3 & 421 & 790 & 427 & 800 & 9.8 & $\times 019$ & 316 \\
\hline 2.5 & 404 & 760 & 427 & 800 & 1.7 & $\times 019$ & 316 \\
\hline
\end{tabular}


Table I-3

UNIFORM STRAINS IN AUSTENITIC STAINLESS STEELS AFTER IRRADIATION IN EBR-II AT 450 TO $500^{\circ} \mathrm{C}\left(842 \mathrm{TO}^{\circ} 932^{\circ} \mathrm{F}\right)$

Fluence $X 10^{-22}$ $\mathrm{E}>0.1 \mathrm{MeV}$

0.38

2.3

0.4

2.0

2.0

0.60

0.67

2.7

1.5

4.0-5.0

4.0-5.0

4.0-5.0

4.0-5.0

4.0-5.0

4.0-5.0

4.0-5.0

0.8
Fluence $\times 10^{-22}$

E $>0.1 \mathrm{MeV}$

1.4

2.1

1.6

1.6

1.5

0.8

1.1

2.6

2.6

1.4

2.1
Irradiation

Temperature

${ }^{\circ} \mathrm{Cl}$

460

450

460

480

480

460

500

450

450

400-525

400-525

400-525

400-525

400-525

400-525

400-525

489
( $\mathrm{F}$ )

$$
860
$$

842

860

896

896

860

932

842

842

752-977

752.977

752-977

752-977

$752-97$

752.977

752-977

900
Test

Temperature

( ${ }^{\circ} \mathrm{Cl}$

( $\mathrm{F})$

480

450

896

842

842

842

450

450

842

450

842

932

842

842

842

842

842

842

842

842

842

900

482

\section{Uniform \\ Strain}

22.9

2.6

18.4

5.7

7.5

6.7

14.4

1.8

6.0

17.6

16.0

14.4

15.2

14.1

15.2

18.6

28.9

Table 1-4

UNIFORM STRAINS IN AUSTENITIC STAINLESS STEELS AFTER IRRADIATION IN EBR-II AT 500 TO $550^{\circ} \mathrm{C}\left(932\right.$ TO $\left.1022^{\circ} \mathrm{F}\right)$

Irradiation

Temperature

$\left({ }^{\circ} \mathrm{C}\right)$

538

549

516

543

500-545

500

540

540

540

516

549

\begin{tabular}{rcr}
$\left.{ }^{\circ} \mathrm{F}\right)$ & \multicolumn{2}{c}{ Temperature } \\
10000 & $\left.{ }^{\circ} \mathrm{C}\right)$ & \multicolumn{1}{c}{$\left.{ }^{\circ} \mathrm{F}\right)$} \\
1020 & 538 & 1000 \\
960 & 538 & 986 \\
1010 & 538 & 1000 \\
$932-1013$ & 550 & 1022 \\
932 & 500 & 932 \\
1004 & 550 & 1022 \\
1004 & 550 & 1022 \\
1004 & 550 & 1022 \\
960 & 538 & 1000 \\
1020 & 538 & 1000
\end{tabular}

Test

Temperature

000

986

1000

932

022

022

022

1000

Uniform
Strain
12.3
6.3
7.9
2.6
13.6
14.4
11.6
8.0
12.5
11.0
6.5

Location
in EBR-II
Row II
Row II
Row II
Row II
X034
X016
X016
X016
X016
$?$
$?$

Material

304

316

316

304

304

304

304

304

304

316

316 
Table 1-5

UNIFORM STRAINS IN AUSTENITIC STAINLESS STEELS

AFTER IRRADIATION IN EBR-II AT 550 TO $600^{\circ} \mathrm{C}\left(1022\right.$ TO $\left.1112^{\circ} \mathrm{F}\right)$

\begin{tabular}{|c|c|c|c|c|c|c|c|}
\hline \multirow{2}{*}{$\begin{array}{l}\text { Fluence } \times 10^{-22} \\
E>0.1 \mathrm{MeV}\end{array}$} & \multicolumn{2}{|c|}{$\begin{array}{l}\text { Irradiation } \\
\text { Temperature }\end{array}$} & \multicolumn{2}{|c|}{ Test } & \multirow{2}{*}{$\begin{array}{l}\text { Uniform } \\
\text { Strain }\end{array}$} & \multirow{2}{*}{$\begin{array}{l}\text { Location } \\
\text { in EBR-II }\end{array}$} & \multirow[b]{2}{*}{ Material } \\
\hline & $\left({ }^{\circ} \mathrm{C}\right)$ & ( $\mathrm{O} F)$ & ${ }^{\circ} \mathrm{Cl}$ & $\left({ }^{\circ} \mathrm{F}\right)$ & & & \\
\hline 1.3 & 590 & 1094 & 594 & 1100 & 20.0 & $?$ & 304 \\
\hline 3.0 & 599 & 1110 & 593 & 1100 & 3.6 & Row 2 & 316 \\
\hline 2.7 & 599 & 1110 & 593 & 1100 & 2.1 & Row 2 & 304 \\
\hline 2.1 & 576 & 1070 & 593 & 1100 & 1.1 & Row 2 & 304 \\
\hline 3.5 & $550-605$ & $1022-1121$ & 540 & 1022 & 9.4 & $x 034$ & 304 \\
\hline 2.5 & $550-605$ & $1022-1121$ & 650 & 1202 & 3.7 & X034 & 304 \\
\hline 1.4 & 570 & 1058 & 550 & 1022 & 14.4 & $\times 016$ & 304 \\
\hline 1.5 & 575 & 1067 & 550 & 1022 & 13.3 & $\times 016$ & 304 \\
\hline 5.6 & 590 & 1094 & 550 & 1022 & 16.0 & XA08 & 304 \\
\hline 5.6 & 570 & 1058 & 650 & 1202 & 9.0 & XA08 & 304 \\
\hline 3.4-4.4 & $550-650$ & $1022-1202$ & 550 & 1022 & 5.2 & $\times 016$ & 304 \\
\hline 3.4-4.4 & $550-650$ & $1022-1202$ & 550 & 1022 & 9.0 & $\times 016$ & 304 \\
\hline 3.0 & 599 & 1110 & 593 & 1100 & 3.5 & ? & 316 \\
\hline 1.3 & 590 & 1094 & 594 & 1100 & 20.0 & $?$ & 304 \\
\hline 3.0 & 599 & 1110 & 593 & 1100 & 3.6 & Row 2 & 316 \\
\hline 2.7 & 599 & 1110 & 593 & 1100 & 2.1 & Row 2 & 304 \\
\hline 2.1 & 576 & 1070 & 593 & 1100 & 1.1 & Row 2 & 304 \\
\hline 3.5 & $550-605$ & $1022-1121$ & 540 & 1022 & 9.4 & X034 & 304 \\
\hline 2.5 & $550-605$ & $1022-1121$ & 650 & 1202 & 3.7 & $\times 034$ & 304 \\
\hline 1.4 & 570 & 1058 & 550 & 1022 & 14.4 & X016 & 304 \\
\hline 1.5 & 575 & 1067 & 550 & 1022 & 13.3 & X016 & 304 \\
\hline 5.6 & 590 & 1094 & 550 & 1022 & 16.0 & XA08 & 304 \\
\hline 5.6 & 570 & 1058 & 650 & 1202 & 9.0 & XA08 & 304 \\
\hline $3.4-4.4$ & $550-650$ & $1022-1202$ & 550 & 1022 & 5.2 & X016 & 304 \\
\hline $3.4-4.4$ & $550-650$ & $1022 \cdot 1202$ & 550 & 1022 & 9.0 & X016 & 304 \\
\hline 3.0 & 599 & 1110 & 593 & 1100 & 3.5 & $?$ & 316 \\
\hline
\end{tabular}


Table 1-6

\section{UNIFORM STRAINS IN AUSTENITIC STAINLESS STEELS AFTER IRRADIATION IN EBR-II AT GREATER THAN $600^{\circ} \mathrm{C}\left(1112^{\circ} \mathrm{F}\right)$}

\begin{tabular}{|c|c|c|c|c|c|c|c|}
\hline \multirow{2}{*}{$\begin{array}{l}\text { Fluence } \times 10^{-22} \\
E>0.1 \mathrm{MeV}\end{array}$} & \multicolumn{2}{|c|}{$\begin{array}{l}\text { Irradiation } \\
\text { Temperature }\end{array}$} & \multicolumn{2}{|c|}{$\begin{array}{c}\text { Test } \\
\text { Temperature }\end{array}$} & \multirow{2}{*}{$\begin{array}{l}\text { Uniform } \\
\text { Strain }\end{array}$} & \multirow{2}{*}{$\begin{array}{l}\text { Location } \\
\text { in EBR-II }\end{array}$} & \multirow[b]{2}{*}{ Materia } \\
\hline & $\left({ }^{\circ} \mathrm{C}\right)$ & ( $\left.{ }^{\circ} \mathrm{F}\right)$ & $\left({ }^{\circ} \mathrm{C}\right)$ & $\left({ }^{\circ} \mathrm{F}\right)$ & & & \\
\hline 3.2 & 615 & 1140 & 649 & 1200 & 4.9 & Row 11 & 304 \\
\hline $3.4-4.4$ & $550-650$ & $1022 \cdot 1202$ & 650 & 1202 & 6.5 & $\times 018$ & 304 \\
\hline $3.4-4.4$ & $550-650$ & $1022 \cdot 1202$ & 650 & 1202 & 6.6 & $\times 018$ & 304 \\
\hline 4.4 & 621 & 1150 & 593 & 1100 & 7.3 & $\mathrm{x} 021 \mathrm{C}$ & 316 \\
\hline 7.0 & 621 & 1150 & 593 & 1100 & 6.5 & $\mathrm{x} 021 \mathrm{C}$ & 316 \\
\hline 5.65 & 621 & 1150 & 649 & 1200 & 3.8 & $\mathrm{x} 021 \mathrm{C}$ & 316 \\
\hline 1.5 & $750-845$ & $1382-1553$ & 750 & 1382 & 9.8 & $x 034$ & 304 \\
\hline 3.5 & $750-820$ & $1382-1508$ & 750 & 1382 & 4.7 & $\times 034$ & 304 \\
\hline
\end{tabular}

\subsubsection{Correlation of Post-Irradiation Tensile Uniform Strain Estimates to In-Reactor Conditions with Various Types of Loading}

The estimates of how post-irradiation tensile uniform strains will vary as a function of fluence $(E>0.1 \mathrm{MeV})$ for annealed Types-304 and -316 stainless steel at various irradiation test temperatures (Figures $\mid-1$ through $(-6)$, and the resultant estimates as a function of irradiation test temperature at different fluences (Figures $1-7 \mathrm{a}$ and $1-7 \mathrm{~b}$ ), in reality do not directly predict the ductility of austenitic stainless steels while they are exposed to the core environment since the tests that supplied the data were not performed in-reactor. However, because these curves are based on the most nearly applicable set of data available, it should be assumed that they do represent a best estimate of the ability of an austenitic stainless steel to undergo straining before necking under uniaxial loading conditions in a core environment; thus, they form the basis for the balance of this appendix. It should also be assumed that these relationships are applicable to annealed Type-321 stainless steel, the reference structural material for the 350-MW fuel assembly components.

To estimate the amount of strain before necking that can be accommodated in the 350-MW core environment in Type-321 stainless steel fuel assembly components under various biaxial loading conditions as a function of fast neutron exposure and irradiation temperature, it is necessary to modify the uniaxial strain at necking values given in Figures 1-1 through 1-7b by use of Figure 1-8. This figure exhibits the factors by which the uniaxial strain values must be multiplied in order to obtain similar allowable strains under any biaxiality ratio. These values were obtained by compromising between the theoretical value determined by the use of the Von Mises (distortion energy) theory for effective strain and the data-based relationship now being used by WARD in the FFTF fuel assembly design. Both of these relationships are represented by dotted lines in Figure 1-8. The most probable explanation for the difference between the theoretical line (which is on top) and the data-based line (which is on the bottom) is that the tube specimens from which the actual data were obtained exhibited an appreciable degree of anisotropy, as compared to the theoretical prediction which assumes a perfectly isotropic material. Thus, they predict much worse properties in the circumferential direction $(0: 1$ biaxiality ratio) than in the longitudinal direction $(1: 0$ biaxiality ratio).

This type of anisotropic behavior has been seen to some extent in some DFR results which showed considerably lower strains at failure in biaxial tests-3\% after neutron exposures to $0.4 \times 10^{22} \mathrm{n} / \mathrm{cm}^{2}$ and 1 to $2 \%$ after $2 \times 10^{22}$-as compared with similar specimens that were tested in tension, which failed after strains of $11 \%$ and $6 \%$, respectively. Because of the following reasons: 
- There is considerable uncertainty concerning the composition and condition of the specimens that were used to obtain the data in the FFTF correlation;

- The British data do not exhibit as large biaxial strain at failure reductions as the FFTF correlations predicts but do indicate some anisotropy in the tubing, and

- There is reason to believe that improved material fabrication procedures used today and in the future should produce material with less anisotropy than either the British tubing or the tubing from which the FFTF data were obtained,

it was felt that the compromise between the two predictions, which is shown in Figure 1-8, would be most realistic and should be used in conjunction with the relationships shown in Figures $1-1$ through $1-7 \mathrm{~b}$ to predict strain at necking for any biaxiality loading condition.

\subsubsection{Discussion of Results}

The relationships exhibited in Figures $1-1$ through 1.8 have been recommended for use in estimating the amount of uniform strain that could occur in a fuel assembly component under given conditions of loading, fast fluence, and in-reactor temperature prior to the initiation of necking. These relationships tell the designer the amount of plastic deformation which he should not permit to be exceeded in order to prevent necking from occurring in the fuel assembly component which he is considering. The majority of the data used to construct these relationships, however, were obtained from tensile tests which were performed at strain rates of approximately 0.02 min $^{-1}$, which may be considerably different from the much slower strain rates, such as those seen in fuel pins under the build-up of fission gas pressure, and the much faster strain rates, such as will occur under transient conditions, that will have to be considered in design analyses. Thus for many cases, strain rate effects, if possible, must also be taken into account. A realistic determination of a quantitative relationship that considers the effects of this additional parameter, strain rate, is difficult at present due to the paucity of data available.

A comprehensive review of strain rate effects on all austenitic stainless steels under reactor conditions indicates that increases in the strain rate above $0.01 \mathrm{~min}^{-1}$ (approximately the tensile test strain rate from which Figures $1-1$ through 1.8 were obtained) should result in increases in the post-irradiation ductility of the specimen being tested. This review, however, did not give any quantitative results and indicated that little meaningful information is available on high strain rate effects on austenitic stainless steels, especially at high neutron exposures. Earlier work on irradiated Incoloy-800 does, however, give quantitative results which agree with these more general conclusions. A post-irradiation ductility minimum was found at strain rates of approximately $0.001 \mathrm{~min}^{-1}$ to $0.01 \mathrm{~min}^{-1}$, and ductility values were found to increase as the strain rates were increased. Fracture elongations over twice as large as those seen at strain rates of $0.01 \mathrm{~min}^{-1}$ were seen at strain rates in excess of $1 \mathrm{~min}^{-1}$. Additionally, decreases in strain rate below $0.01^{-1}$ were found to increase the fracture elongation of the incoloy -800 test specimens by over a factor of three times for strain rate decreases from $0.01 \mathrm{~min}^{-1}$ to $0.000001 \mathrm{~min}^{-1}$.

Based on these results, it appears that the use of the relationships shown in Figures 1.1 through $1-8$, which were obtained mainly from tests performed at strain rates of approximately $0.01 \mathrm{~min}^{-1}$, will result in conservative strain predictions, sinc: both higher and lower strain rates than $\sim 0.01 \mathrm{~min}^{-1}$ might result in an increased ability of the austenitic stainiess steels to undergo plastic strain. However, until more data are available, credit for this type of behavior should not be taken.

To use the estimates shown in Figures $1-1$ through $1-8$ to predict the amount of uniform plastic strain which an austenitic stainless steel can undergo in the core environment prior to necking as a function of temperature, fast neutron exposure, and loading condition, it is essential to know which of the different kinds of strain that occur in Type-321 stainless steel in-reactor must be considered. While in the core environment, a fuel assembly component can undergo significant strains of the following types:

a. Elastic strains

b. Irradiation-induced volume change strains (metal swelling)

c. Irradiation-induced creep strains

d. Short-term plastic strains

e. Long-term plastic strains (thermal creep). 
In predicting the amount of strain that should not be exceeded in order to prevent necking, only strain types a. and b., short-term plastic strains produced by exceeding the yield stress of the stainless steel and long-term strains due to thermally activated creep, need to be considered. Elastic strains, metal swelling strains, and irradiation-incluced creep strains are not considered to be significant in leading to the onset of necking or failure. Elastic strains and metal swelling strains are thought to be nondamaging in the sense that they do not "use up" the plastic strain capability of the metal and therefore do not aid in initiating necking or failure. The role that irradiation-induced creep strains play in initiating necking and failure is not as well understood since there is essentially no fast flux data in this area. The decision not to include irradiation-induced creep strains in necking considerations is based on the following observations:

a. Approximately five-sixths of the irradiation-induced creep deformation is expected to be volume-increasetype strains due to the hydrostatic stress component of the applied stress. These strains should be similar to the non-damaging types of strains associated with metal swelling.

b. Non-swelling-type, irradiation-induced creep strains are believed to be similar to superplastic types of strains, which have been seen to exceed $300 \%$ in unirradiated metals prior to failure.

c. Observations in thermally irradiated zirconium specimens have shown strains at failure in excess of $14 \%$ in-reactor, where irradiation-induced creep is operable, while similar specimens tested out-of-reactor failed at strains of less than $1 \%$.

An additional factor to consider in using the relationships shown in Figures $1-1$ through $1-8$ in accounting for the reduced strain capabilities of LMFBR fuel assembly components is that these relationships are intended to predict the onset of necking and that they do not predict the point of failure; that is, they consider uniform strain instead of total elongation or reduction of area at the point of failure. Partly because the use of uniform strain in the data correlation allowed post-irradiation test results to be evaluated on a consistent strain basis, and partly because most highly irradiated tensile specimens that are irradiated and tested at temperatures above approximately $500^{\circ} \mathrm{C}\left(932^{\circ} \mathrm{F}\right)$ fail very quickly after the onset of necking, uniform strains at necking do give a reasonable estimate of the strain which should not be exceeded in order to prevent failure under conditions of uniaxial loading and in-reactor temperatures in excess of $500^{\circ} \mathrm{C}\left(932^{\circ} \mathrm{F}\right)$. However, uniaxial specimens that were irradiated and tested at temperatures below $500^{\circ} \mathrm{C}\left(932^{\circ} \mathrm{F}\right)$ usually exhibit strains at failure (total elongations) that are a factor of two to three times larger than the uniform strains at the onset of necking. For the last-mentioned conditions of loading and temperature, the use of Figures $1-1$ through 1-8 to predict failure should be very conservative. Since the lowest ductilities at a given fluence, as shown in Figures 1-7a and 1-7b, are seen to occur in this temperature range, it should be an objective of materials research to establish how much of the two to three times higher value for the strain at failure than the values predicted for the uniform strain at necking the designer can take credit for (noting that for in-reactor temperatures in excess of $500^{\circ} \mathrm{C}$ $\left[932^{\circ} \mathrm{F}\right]$ uniform strains do predict the strain at failure fairly well).

The use of uniform strain predictions in the consideration of components loaded under other than uniaxial conditions may be conservative over the entire temperature range of interest $\left(371\right.$ to $\left.\sim 650^{\circ} \mathrm{C}\right)$, since these types of biaxial loading may tend to delay or prevent the plastic instability that is associated with the necking in a uniaxial tension test. However, there is so little data in this area that a recommendation for handling the reduction in the strain capabilities of biaxially loaded fuel assembly components beyond those shown in Figures $1-1$ through $1-8$ is beyond the scope of this study.

This dilemma-having reason to believe that more strain can occur before failure than is predicted in Figures $1-1$ through 1-8-also applies to the consideration of point-contact-type load conditions, such as might occur at grid-spacer or wire-wrap contact points with fuel rods. Tensile tests that indicate relatively small values of uniform elongation can still exhibit large amounts of strain that are concentrated in the neck region of the specimen. In these regions, such as might be adjacent to a point contact load, it may be possible for the fuel assembly component being considered to undergo considerably larger localized strains than predicted in Figures $1-1$ through I-8 (even after consideration is given to the possible increased necking ability of Type 321 at temperatures below $500^{\circ} \mathrm{C}\left(942^{\circ} \mathrm{F}\right)$. Again, since there are so little directly or even indirectly applicable data on which to base such a consideration, the use of the uniform strain values of Figures 1-1 through $1-8$ is recommended. 


\section{I.3 METHOD FOR USING RECOMMENDED RELATIONSHIPS TO ACCOUNT FOR THE REDUCTION IN THE STRAIN CAPABILITY OF TYPE-321 STAINLESS STEEL FUEL ASSEMBLY COMPONENTS}

The designer should use the relationships shown in Figures $1-1$ through 1-8 in determining allowable strain limits for fuel assembly structural materials (Type 321, annealed) according to the following steps:

a. Determine the irradiation temperature at which the section of interest in the fuel assembly is operating and select the figure that applies to this temperature.

b. Determine the fluence ( $E>0.1 \mathrm{MeV}$ ) at which it is desired to determine the strain capability of the section of interest.

c. Review the design considerations in order to decide on the degree of conservatism required for the particular section of interest. This decision should include consideration of such factors as the rate at which the section will be strained, and the consequences of necking (if it occurs) or failure. This decision should also reflect the design criteria for the section of interest.

d. Determine the amount of strain from the figure that can be accommodated at the selected degree of conservatism; i.e., the estimated mean or estimated lower limit, or some factor times these values.

e. Calculate the mode of loading that will be producing the strain in the section of interest. Using this biaxiality ratio, consult Figure 1-8 to determine the fraction by which the value obtained in Step d. should be multiplied to correct it for type of loading.

The value obtained after correcting for the type of loading in Step e. is the estimated amount of strain that should not be exceeded at the selected in-reactor irradiation temperature after exposure to the fast fluence value of interest in order to ensure that the consequence of interest (necking or failure) will not occur to the desired estimated confidence level. This value is not applicable to strains that accumulate over the lifetime of the section of interest, possibly at various temperatures throughout this lifetime, since the amount of strain that can be accommodated is continually decreasing with neutron exposure until it flattens out at high fluences, and since it also varies with the temperature at which the section of interest is irradiated and strained. Because of this, a given amount of strain in the section of interest at its beginning of life (before it has received a high fast neutron exposure) will not "use up" as much of its strain capability as the same amount of strain will near the end of the life of the section of interest.

The recommended method for considering strains at various times in the life of the section of interest involves a damage-index type of analysis. Each strain limit calculated for the section of interest at each fluence value should be used as a normalizing value for the amount of strain that is calculated to occur during the time period associated with the fluence value. Rejection due to the occurrence of either necking or failure (depending on whichever occurrence is being considered by the designer) will be assumed to occur when the sum of these fractions totals 1 or greater. For example, consider an imaginary component that receives step increment strains of $1 \%$ at fluences of $10^{21}, 10^{22}$ and $10^{23}(\mathrm{E}>0.1 \mathrm{MeV})$, and that the allowable strains determined for the component using the methods described in Steps a. through e. are $10 \%, 5 \%$, and $1.5 \%$. The fraction of available strain used at each fluence value, and the total life fraction used as determined by this damage index, are as follows:

$$
\begin{aligned}
& 10^{21} \mathrm{n} / \mathrm{cm}^{2} \quad 10^{22} \mathrm{n} / \mathrm{cm}^{2} \quad 10^{23} \mathrm{n} / \mathrm{cm}^{2} \quad \text { Total } \\
& \frac{1 \%}{10 \%}+\frac{1 \%}{5 \%}+\frac{1 \%}{1.5 \%}=0.9667
\end{aligned}
$$

Thus, according to this method of considering strain, design considerations for a section of interest in an LMFBR component could predict a total of $3 \%$ strain without predicting necking or failure, even though a strain of $1.5 \%$ at $10^{23} \mathrm{n} / \mathrm{cm}^{2}$ is defined as the point at which this will occur. 


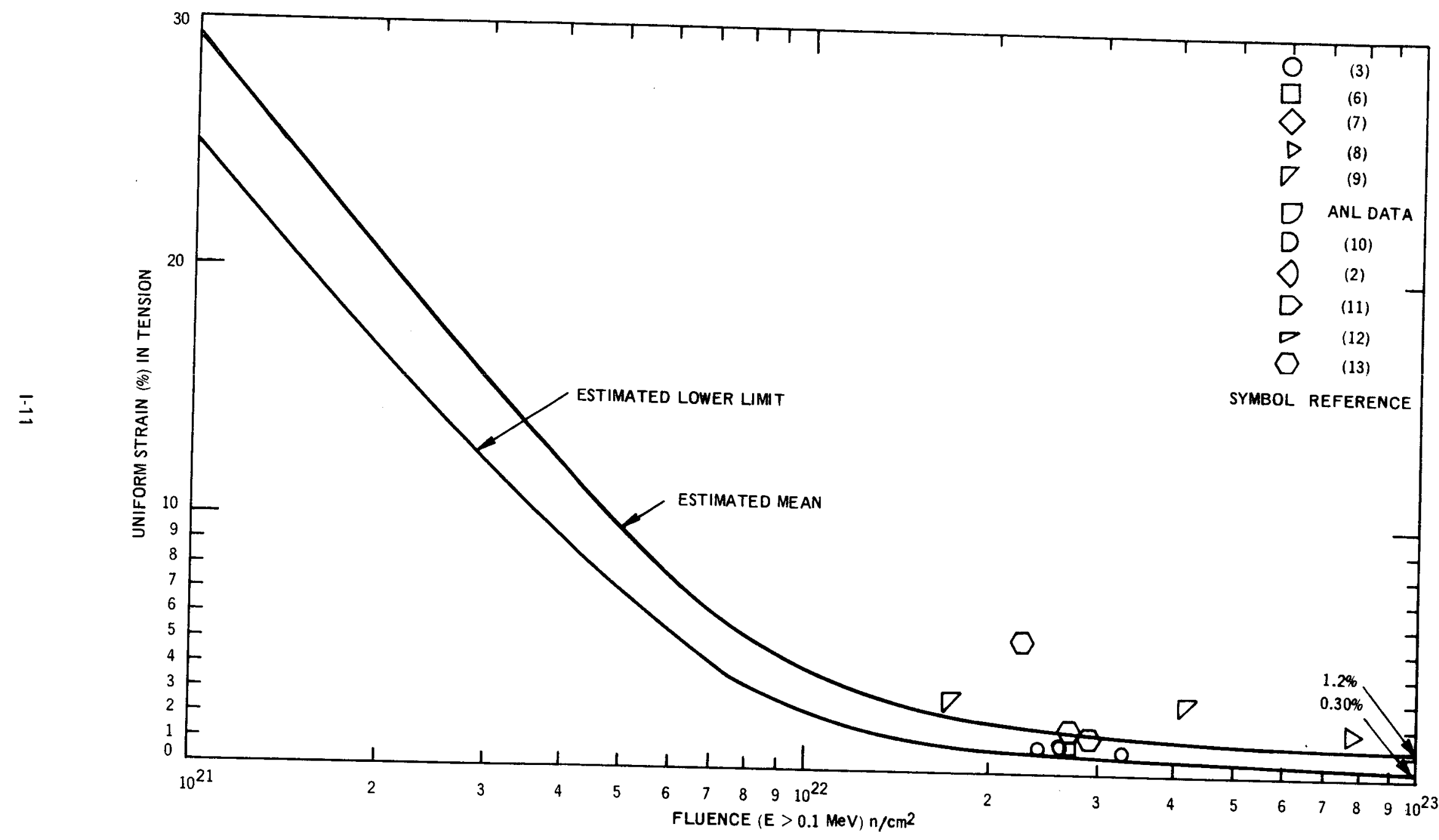

Figure 1-1. Tensile Uniform Elongation for Types-304 and -316 Stainless Stee/s versus Fluence at Irradiation Temperatures of 371 to $400^{\circ} \mathrm{C}\left(700\right.$ to $\left.752^{\circ} \mathrm{F}\right)$ 


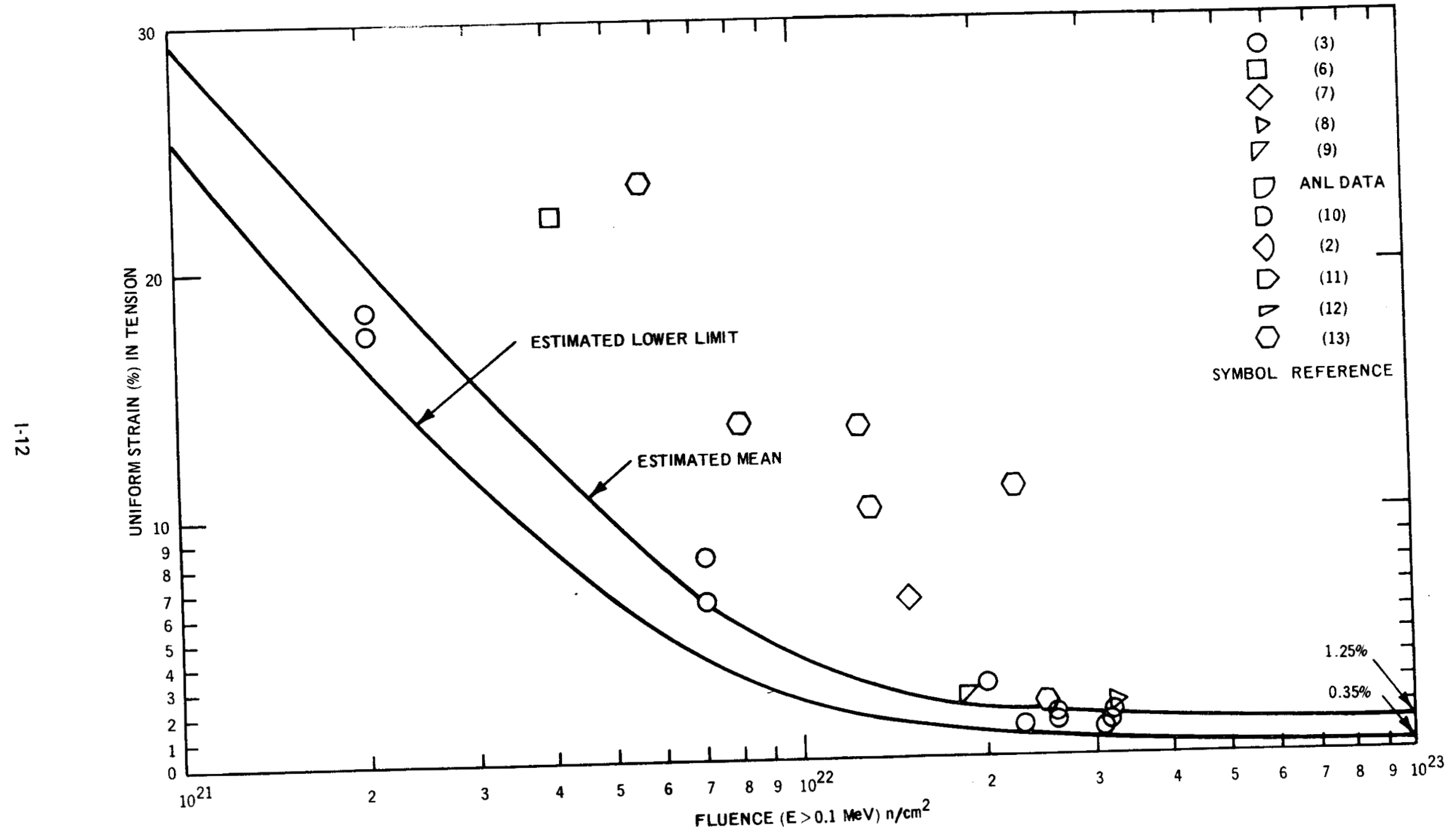

Figure 1-2. Tensile Uniform Elongation for Types-304 and -316 Stainless Stee/s versus of 400 to $450^{\circ} \mathrm{C}\left(752\right.$ to $\left.842^{\circ} \mathrm{F}\right)$ 


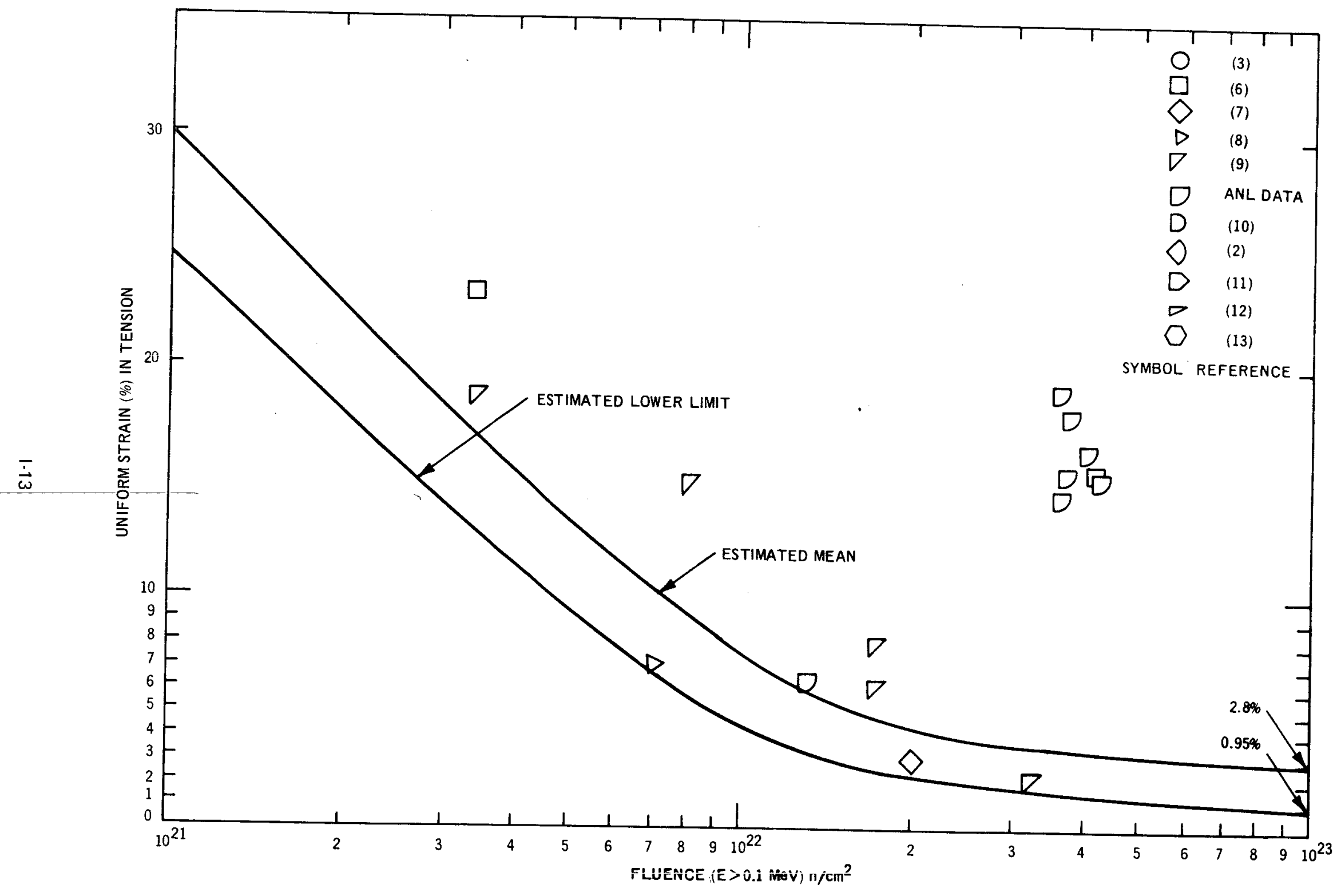

Figure 1-3. Tensile Uniform Elongation for Types-304 and -316 Stainless Stee/s versus Fluence at Irradiation Temperatures of 450 to $500^{\circ} \mathrm{C}\left(842\right.$ to $\left.932^{\circ} \mathrm{F}\right)$ 


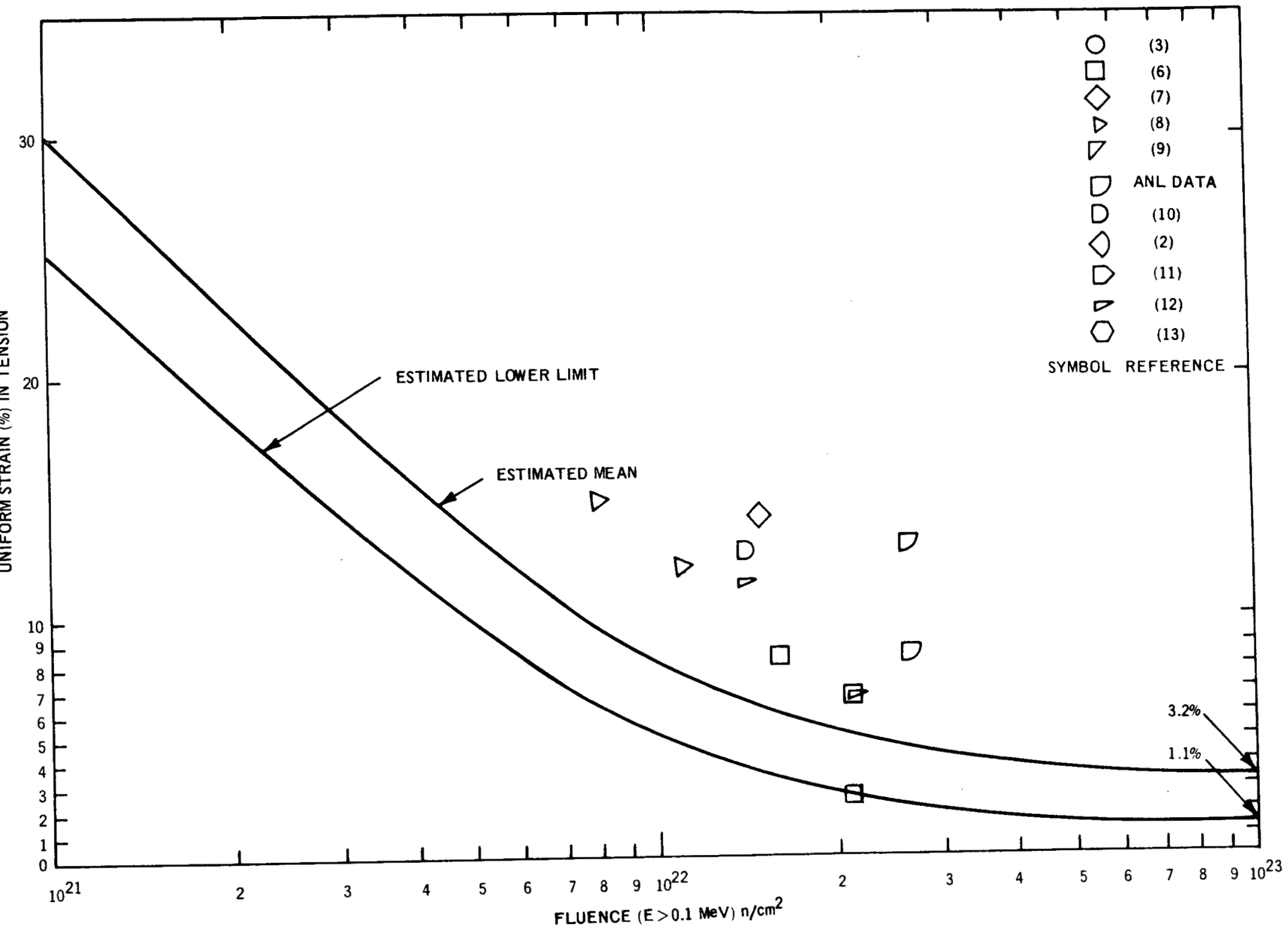

Figure 1-4. Tensile Uniform Elongation for Types-304 and -316 Stainless Stee/s versus Fluence at /rradiation Temperatures of 500 to $550^{\circ} \mathrm{C} 1932$ to $1022^{\circ} \mathrm{F}$ 


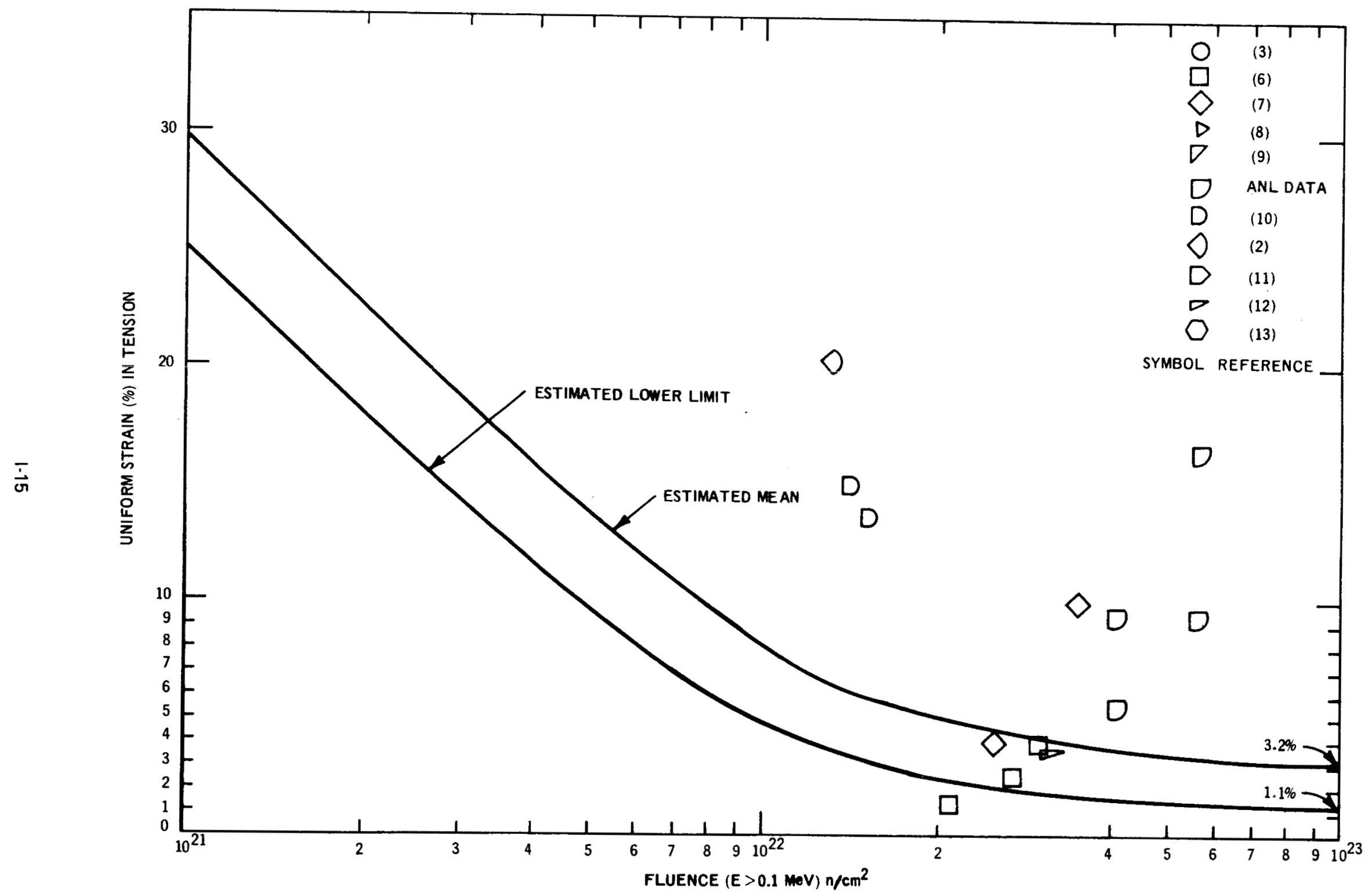

Figure 1-5. Tensile Uniform Elongation for Types-304 and -316 Stainless Stee/s versus Fluence at Irradiation Temperatures of 550 to $600^{\circ} \mathrm{C}\left(1022\right.$ to $\left.1112^{\circ} \mathrm{F}\right)$ 


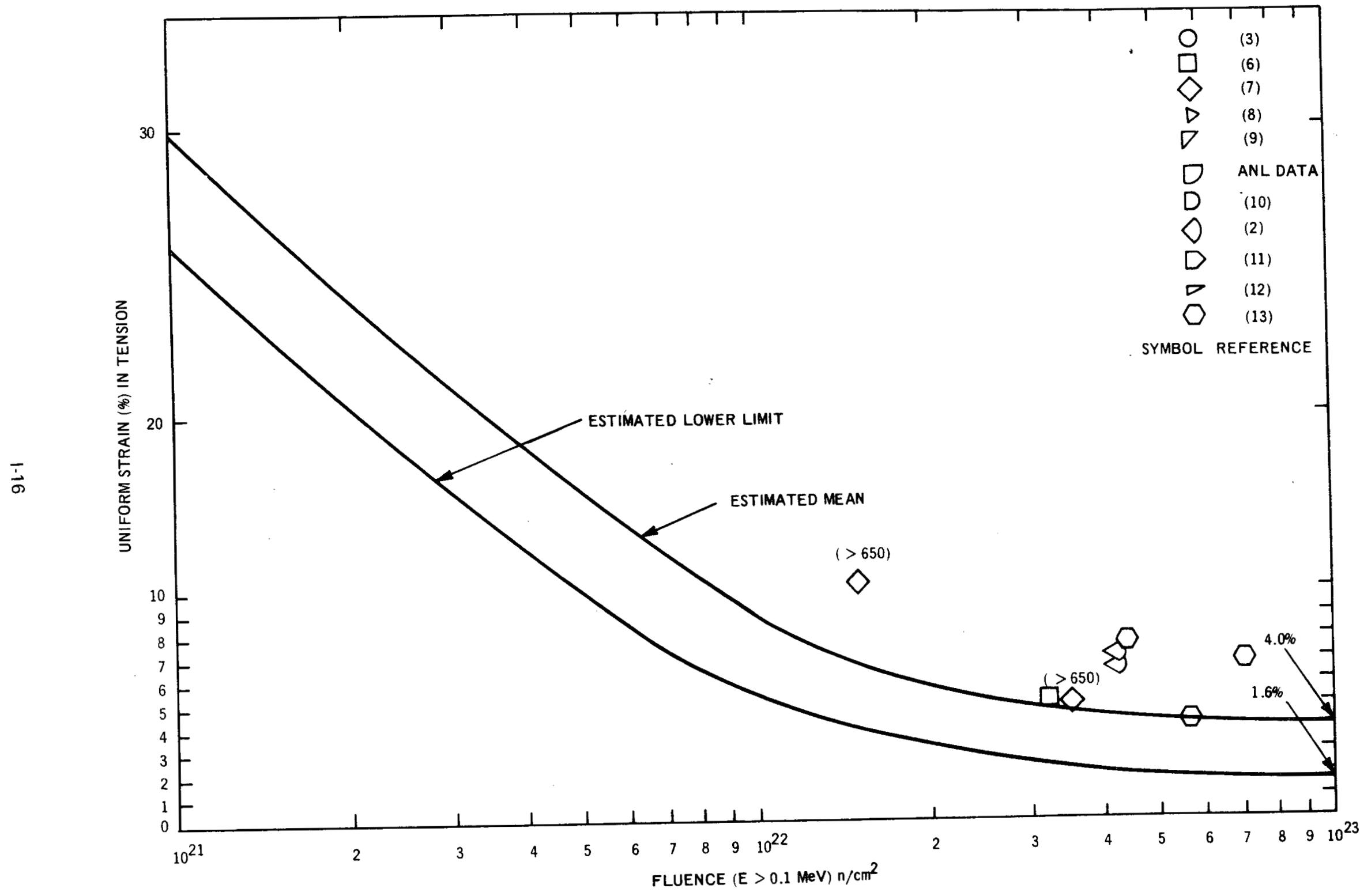

Figure 1-6. Tensile Uniform Elongation for Types-304 and -316 Stainless Stee/s versus Fluence at Irradiation Temperatures of 600 to $750^{\circ} \mathrm{C}\left(1112\right.$ to $1382^{\circ} \mathrm{F}$ ) 


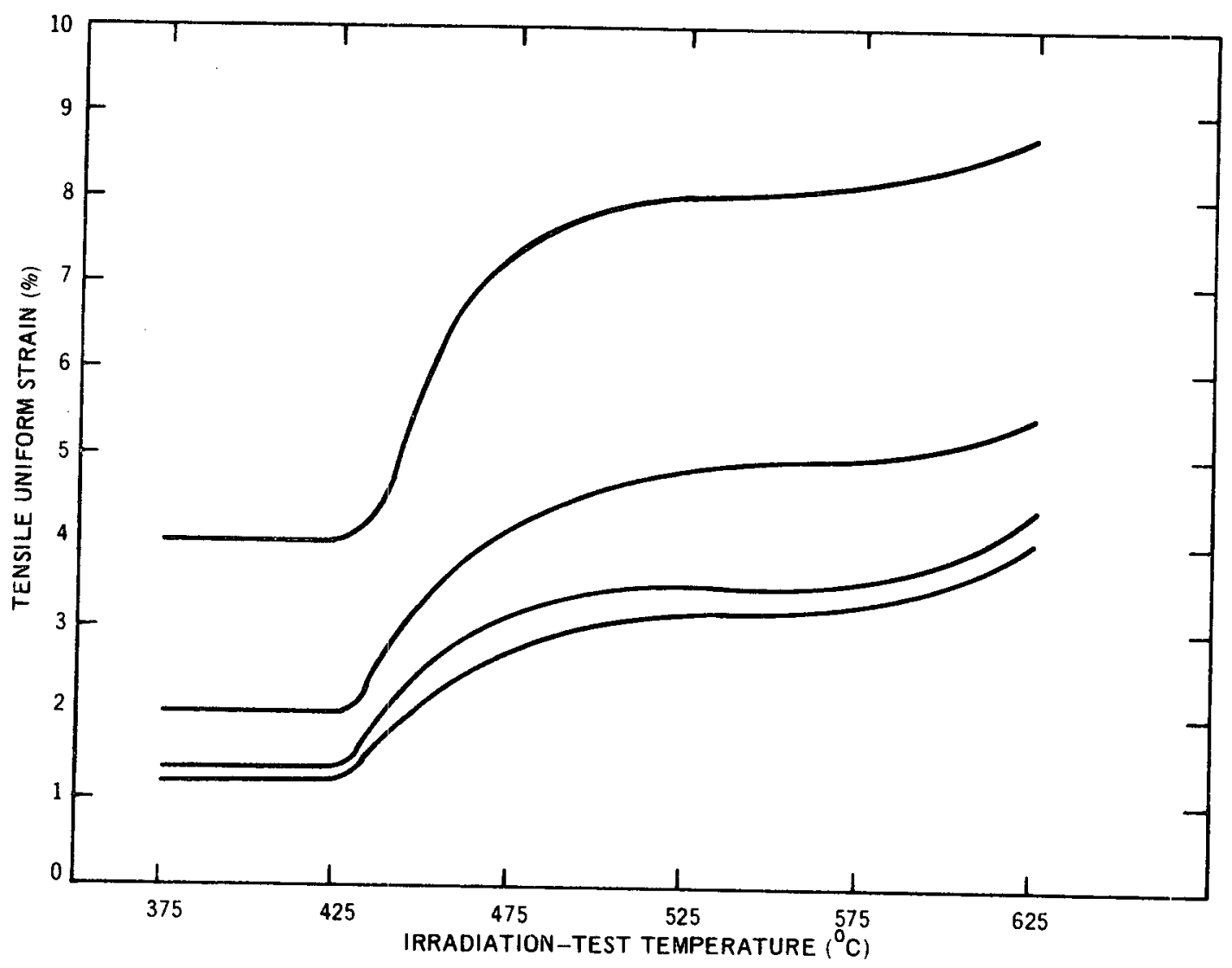

Figure 1-7A. Estimated Mean Uniform Strain versus Temperature

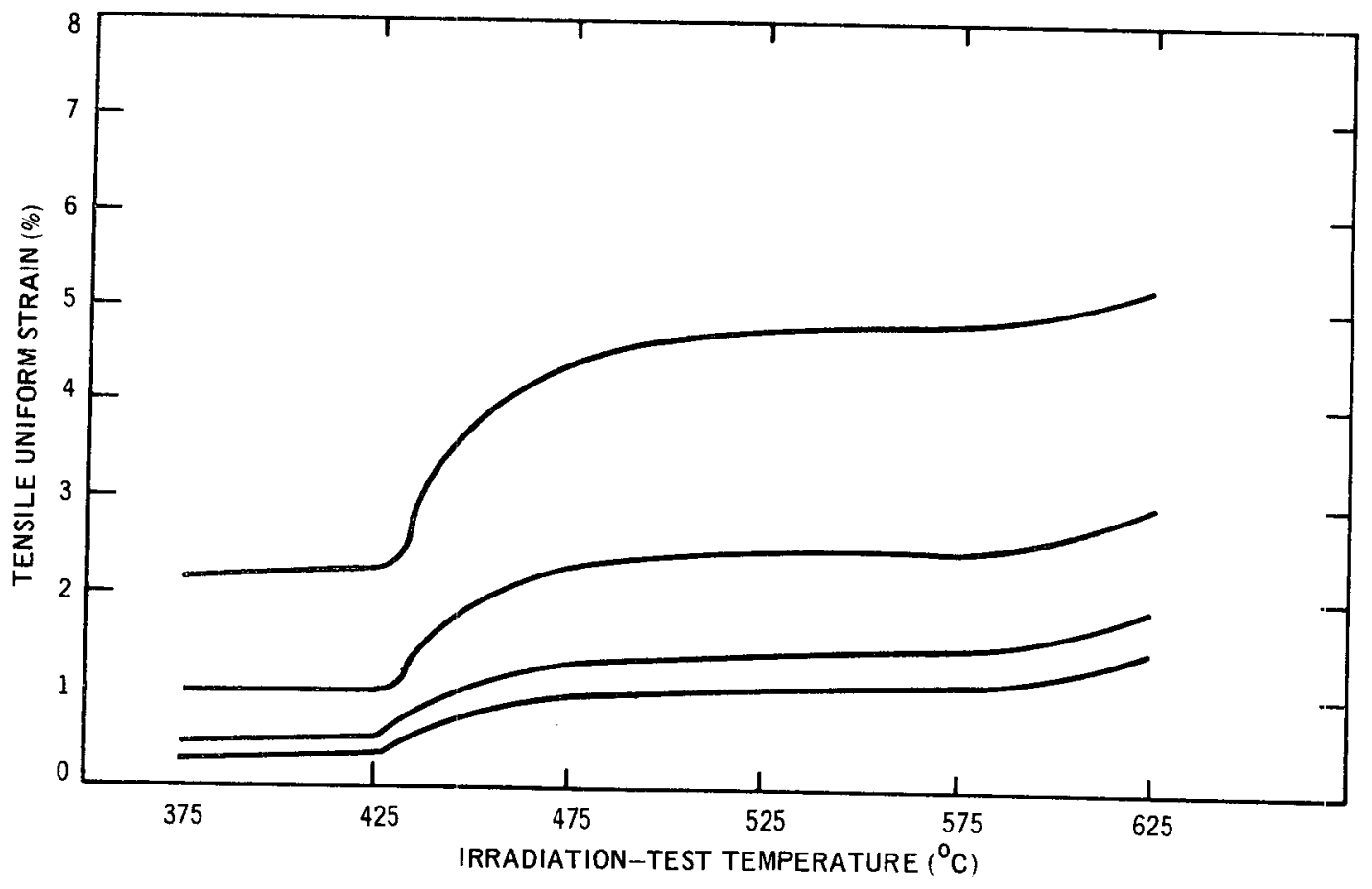

Figure 1-7B. Estimated Lower Limit versus Temperature 


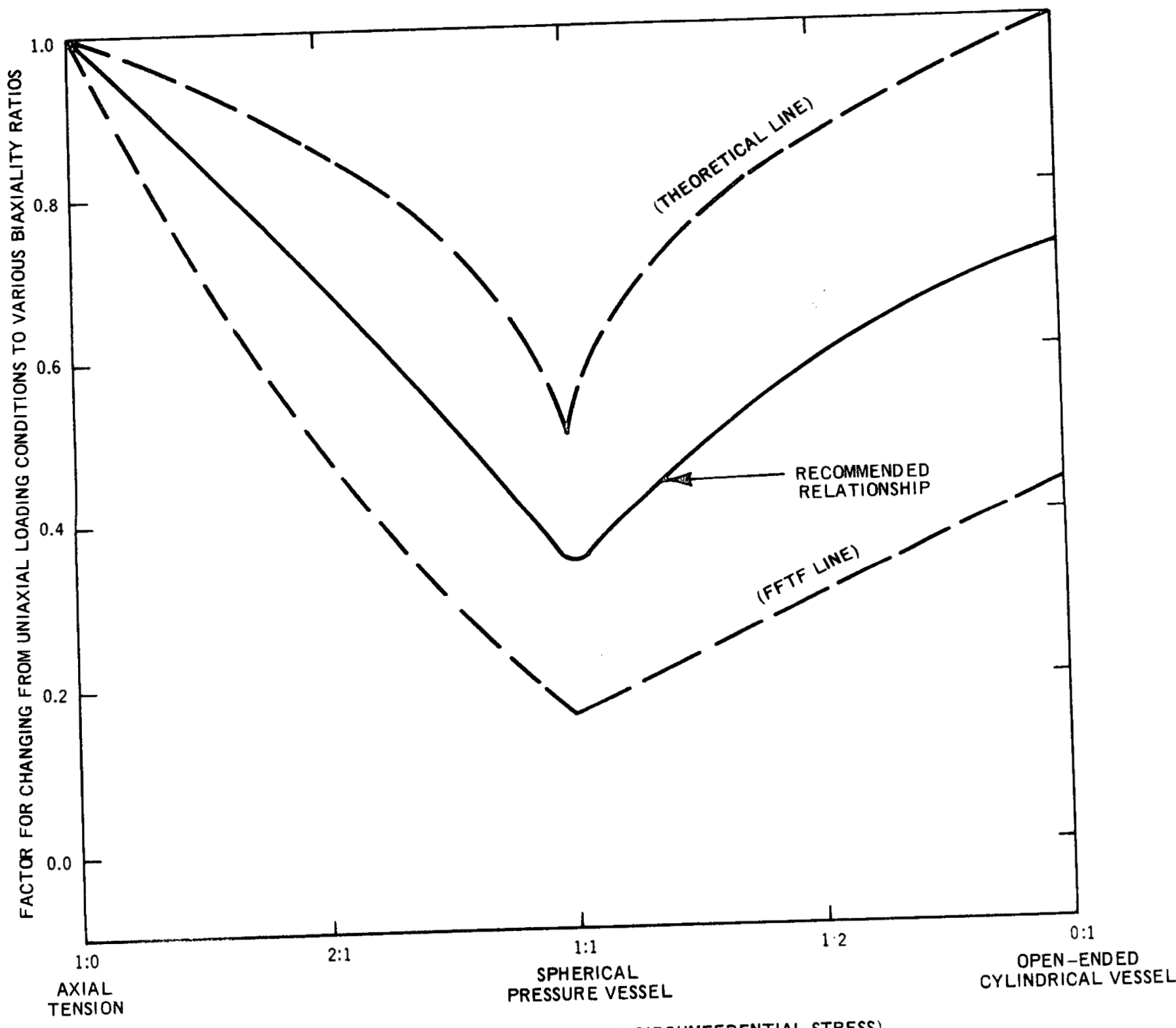

BIAXIALITY (LONGITUDINAL STRESS: CIRCUMFERENTIAL STRESS)

Figure 1-8. Correction Factors for Various Biaxiality Ratios 


\section{I.4 BIBLIOGRAPHY FOR APPENDIX I}

1. FFTF Materials Design Data, BNWL-891, October 1968.

2. Comprelli, F., et al., Mechanical Properties of Irradiated Type-304 and Type-316 Stainless Steel in Fast Reactors, (GEAP-10062), June 1969, p. 16.

3. Busboom, H. J. and Asamoto, R. R., Evaluation of Physical and Mechanical Properties of Type-304 Stainless Steel After Irradiation to $3.9 \times 10^{22} \mathrm{n} / \mathrm{cm}^{2}$ Total Fluence, (GEAP-13571), February 1970, p. 18.

4. Sodium-Cooled Reactors Fast Ceramic Reactor Development Program, Twenty-Sixth Quarterly Report, February-April, 1968, (GEAP-5631).

5. Sodium-Cooled Reactors Fast Ceramic Reactor Development Program, Thirty-Sixth Quarterly Report, AugustOctober, 1970, (GEAP-10028-36).

6. Ward, Blackburn, and Hollerich, Pacific Northwest Laboratory Presentation at 1970 Libby Cockroft Meeting, June 22-25, 1970.

7. Fuels and Materials Development Programs Quarterly for September 30, 1970, (ORNL-4630), March 1971, p. 84.

8. Reactor Development Program Progress Report for August 1969, (ANL-7606), p. 84.

9. Reactor Development Program Progress Report for July 1968, (ANL-7478), p. 56.

10. Holmes, J. J., Robbins, R. E., and Lovell, A. J., "Postirradiation Tensile Behavior of 300 Series Stainless Steels," p. 375 in Irradiation Effects on Structural Alloys for Thermal and Fast Reactors, Spec. Tech Pub. 457, American Society for Testing and Materials, San Francisco, CA, 1968.

11. Quarterly Progress Report, July, August, September, 1968, Reactor Fuels and Materials Development F'rogram, (BNWL-919), November 1968, pp. 12, 41.

12. Quarterly Progress Report, Irradiation Effects on Reactor Structural Materials, May, June, July, 1969, (BNWL-1318-3), September 1969, p. 10.14.

13. Quarterly Progress Report, Irradiation Effects on Reactor Structural Materials, November, December, January, 1971, (HEDL-TME-71-43), March 1971.

14. Bagley, K. Q., et al., The Effects of Irradiation in DFR and DMTR on Austenitic Stainless Stee/s Proposed as PFR Cladding Materials, UKAEA Report TR 61076 (D), August 1966.

15. Bagley, K. Q. and Fraser, A. S., Irradiation Effects on PFR Cladding Materials Irradiated in the DFR and the DMTR, UKAEA Report TRG 791 (D), August 1964.

16. Standering, J., et al., "Effects of Neutron Irradiation on Creep-Rupture Properties of Type 316 Stainless Steel Tubes," p. 414 in Spec. Tech. Publ. 457. American Society for Testing and Materials, San Francisco, CA, 1968.

17. Kramer, O., et al., Helium Embrittlement of Type 316 Stainless Steel, (AI - AEC-12670), April $30,1968$.

18. Bloom, E., An Investigation of Fast Neutron Radiation Damage in an Austenitic Stainless Steel, (ORNL-4580), August 1970.

19. Monthly Technical Progress Report, (HEDL-TME 71-1), December 1970.

20. Snow, A. L., Sim, R., and Starr, J., FFTF Initial Core Driver Fuel Assembly Design Criteria, (FRA-136), Preliminary, March 31, 1970.

21. Comprelli, F. A., et al., "Comparison of Radiation Damage Studies and Fuel Cladding Performance for Incoloy-800," p. 407 in Spec. Tech. Publ. 457, American Society for Testing and Materials, San Francisco, CA, 1968.

22. Hoagland, R. G., Effect of Strain Rate on Mechanical Properties of Austenitic Stainless Steels, (BNWL-1105-UC-80), September 1969.

23. Gilbert, E. R. and Blackburn, L. O., Irradiation-Induced Creep in Austenitic Stainless Steel, (WHAN-FR-30), October 1970, p. 4.

24. Nichols, F. A., Evidences for Superplasticity During Irradiation Creep, (WAPD-T-2252), Bettis Atomic: Power Laboratory, Westinghouse Electric Corp., West Mifflin, Pa., October 1969. Presented at the October 1969 AIME Meeting, Philadelphia, Pa. 



\section{GEAP-13719}

\section{EXTERNAL DISTRIBUTION}

\section{Copies}

Oak Ridge National Laboratory

50

P. O. Box X

Oak Ridge, Tenn. 37830

Attn: B. L. Greenstreet 